\title{
REGENERATION AND LONG-TERM STABILITY OF SURFACTANT-MODIFIED ZEOLITE FOR REMOVAL OF VOLATILE ORGANIC COMPOUNDS FROM PRODUCED WATER
}

by

Craig Richard Altare

\begin{abstract}
Submitted in Partial Fulfillment of
the Requirements for the Degree of

Master of Science in Hydrology
\end{abstract}

New Mexico Institute of Mining and Technology

Socorro, New Mexico

August 2006 


\section{DEDICATION}

This is dedicated in loving memory of my grandfather, Arthur Joecks. 


\begin{abstract}
This work provides the results of laboratory-scale experiments of a producedwater treatment system. This treatment system used surfactant-modified zeolite (SMZ) to remove volatile organic compounds, including benzene, toluene, ethylbenzene, $p$-, $m$-and o-xylene (BTEX) from produced waters generated as a result of oil and gas recovery. Previous studies showed that SMZ was an effective sorptive medium for BTEX and that SMZ was easily and cost-effectively regenerable by air sparging. Furthermore, BTEX sorption and regeneration was reproducible for 10 cycles in the laboratory. Fieldmeasurements from a pilot-scale treatment system showed good agreement with the laboratory results.
\end{abstract}

The focus of the current study was to use laboratory-scale column studies to (1) investigate how different airflow rates impact regeneration and (2) perform long-term tests to infer the chemical and physical stability of SMZ in a produced-water treatment system.

The results of the regeneration airflow rate studies showed that kinetic effects of varying airflow rates (from 1.3 to 10 pore volumes of air per minute) did not significantly affect removal of BTEX. Rather, the volume of air pumped through the column during air sparging was the predictor of removal rates. The implication of these results is that simple predictions can be made about BTEX removal rates from SMZ by knowing the airflow rate and number of pore volumes that have passed through the column. This is important for coupling of the SMZ treatment system with a process designed to treat the 
off-gas, such as a vapor phase bioreactor (VPB). End-users of such a system must be able to predict the rate of regeneration and tune it to an optimal level for the VPB.

Long-term laboratory-scale results of the SMZ produced-water treatment system were promising. Fifty sorption/regeneration cycles were carried out, each consisting of sorption from 100 PV of produced water followed by regeneration with approximately 2000 PV of air. A weakly decreasing trend was observed for the BTEX distribution coefficients $\left(K_{d}\right)$, indicating only a small loss in sorption capacity after 50 cycles of sorption and regeneration. Hydraulic conductivity of the SMZ decreased by roughly $30 \%$ after the 50 cycles. Most of this hydraulic conductivity loss was likely caused by particle attrition. 


\section{ACKNOWLEDGEMENTS}

I would like to thank the United States Department of Energy for funding this work under a grant (contract \#: DE-FC26-04NTI5546) to the University of Texas at Austin. I would also like to thank B.C. Technologies and Burlington Resources for providing the produced water used in the laboratory experiments.

I would also like to thank the members of my committee, Dr. Rob Bowman, Dr. Fred Phillips, and Dr. Jeri Sullivan. In addition I would like to thank all of those who have helped me along the way - Mike Ranck for helping me get started in the lab, Josh Simpson for helping with the long-term lab tests, Tyler Munson for setting up the hydrometer tests, Lily Chen and Soondong Kwon from UT Austin for their collaboration, and all of my fellow graduate students for the support they provided.

Finally, I would like to thank Heather Shannon and my family, without whom none of this would have been possible. 


\section{TABLE OF CONTENTS}

ACKNOWLEDGEMENTS

TABLE OF CONTENTS iii

LIST OF FIGURES $\quad$ V

LIST OF TABLES vii

LIST OF APPENDIX FIGURES viii

LIST OF APPENDIX TABLES X Xiv

INTRODUCTION 1

MANUSCRIPT: $\quad 2$

$\begin{array}{ll}\text { ABSTRACT } & 2\end{array}$

$\begin{array}{ll}\text { INTRODUCTION } & 4\end{array}$

$\begin{array}{ll}\text { MATERIALS AND METHODS } & 9\end{array}$

RESULTS AND DISCUSSION 15

$\begin{array}{ll}\text { CONCLUSIONS } & 23\end{array}$

$\begin{array}{ll}\text { ACKNOWLEDGEMENTS } & 25\end{array}$

$\begin{array}{ll}\text { REFERENCES } & 26\end{array}$

FIGURE CAPTIONS

APPENDIX A. REGENERATION AIRFLOW RATE SORPTION AND

REGENERATION DATA 44

APPENDIX B. TRITIUM TRACER TEST RESULTS FOR THE LONG-TERM

STABILITY TESTS $\quad 62$

APPENDIX C. LONG-TERM STABILITY TEST SORPTION AND REGENERATION

RESULTS 66 
APPENDIX D. HYDRAULIC CONDUCTIVITY AND GRAIN SIZE

MEASUREMENTS FOR THE LONG-TERM STABILITY EXPERIMENTS

132

APPENDIX E. SEM IMAGES, CHEMICAL ANALYSIS, AND CHEMICAL

DISTRIBUTION MAPS OF SMZ FROM LONG-TERM STABILITY EXPERIMENTS

137 


\section{LIST OF FIGURES}

Figure 1. BTCs for each BTEX compound from column RRT1.

Figure 2. BTCs for toluene and $p$ - and $m$-xylene on four different virgin-SMZ columns. The columns were saturated with BTEX under identical conditions but regenerated at airflow rates of 1.3 PV/min, 2.7 PV/min, $5 \mathrm{PV} / \mathrm{min}$, and $10 \mathrm{PV} / \mathrm{min}$, respectively.

Figure 3. $p$ - and $m$-xylene regeneration curves as a function of (a) time and (b) pore volumes of air. Columns RRT1, RRT2, RRT3, and RRT4 used airflow rates of 1.3 PV/min, 2.7 PV/min, $5 \mathrm{PV} / \mathrm{min}$, and $10 \mathrm{PV} / \mathrm{min}$, respectively.

Figure 4. BTCs of tritiated water in column LST2 for (a) virgin SMZ and (b) after the $25^{\text {th }}$ regeneration cycle and (c) after the $50^{\text {th }}$ regeneration cycle. Solid lines represent fitted values using an equilibrium advection-dispersion equation

Figure 5. BTCs for every fifth sorption cycle on column LST1 for (a) benzene and (b) $p$ - and $m$-xylene

Figure 6. Observed and fitted BTCs of $p$ - and $m$-xylene for the first sorption cycle on column LST1. The solid line shows the fit using an equilibrium advection-dispersion equation while the dashed line shows the fit using a two-site chemical nonequilibrium advection-dispersion equation.

Figure 7. $K_{d}$ 's and lines fit to the $K_{d}$ values for (a) benzene and (b) $p$ - \& $m$-xylene from column LST1. Error bars represent the 95\% confidence interval from the curve-fit process using CXTFIT. 
Figure 8. Vapor-phase concentrations of toluene and $p$ - and $m$-xylene over 50 regeneration cycles on column LST1.

Figure 9. Backscattered electron image of virgin SMZ.

Figure 10. Backscattered electron image of SMZ from column LST1 used for 50 sorption cycles.

Figure 11. Backscattered electron image of SMZ from column LST2 used for 50 sorption cycles. 


\section{LIST OF TABLES}

Table 1. Compositions of the produced water used for regeneration, long-term laboratory experiments, and field tests.

Table 2. Octanol water coefficients $\left(K_{\text {ow }}\right)$ and solubility at $25^{\circ} \mathrm{C}$ for the BTEX compounds. Additionally, the calculated distribution coefficients $\left(K_{d}\right)$ and their standard deviations from the LST columns, the slopes of linear regressions fit to $K_{d}$ values as a function of the number of cycles, and the calculated p-values.

Table 3. Fitted D and R values for tritium tracer tests conducted on columns LST1 and LST2 for the unused column, after the $25^{\text {th }}$ regeneration cycle, and after the $50^{\text {th }}$ regeneration cycle. 


\section{LIST OF APPENDIX FIGURES}

Figure A- 1. Benzene sorption on virgin SMZ for four replicate columns. 52

Figure A- 2. Toluene sorption on virgin SMZ for four replicate columns. 53

Figure A- 3. Ethylbenzene sorption on virgin SMZ for four replicate columns. 54

Figure A- 4. $p$ - and m-xylene sorption on virgin SMZ for four replicate columns. $\quad 55$

Figure A- 5. o-xylene sorption on virgin SMZ for four replicate columns. 56

Figure A- 6. Benzene regeneration at four different airflow rates as a function of (a) time and (b) PV of air. Columns RRT1, RRT2, RRT3, and RRT4 used flow rates of 1.3 PV/min, 2.7 PV/min, 5 PV/min, and $10 \mathrm{PV} / \mathrm{min}$, respectively.

Figure A- 7. Toluene regeneration at four different airflow rates as a function of (a) time and (b) PV of air. Columns RRT1, RRT2, RRT3, and RRT4 used flow rates of 1.3 PV/min, 2.7 PV/min, 5 PV/min, and $10 \mathrm{PV} / \mathrm{min}$, respectively.

Figure A- 8. Ethylbenzene regeneration at four different airflow rates as a function of (a) time and (b) PV of air. Columns RRT1, RRT2, RRT3, and RRT4 used flow rates of 1.3 PV/min, 2.7 PV/min, 5 PV/min, and $10 \mathrm{PV} / \mathrm{min}$, respectively.

Figure A- 9. $p$ - and $m$-xylene regeneration at four different airflow rates as a function of (a) time and (b) PV of air. Columns RRT1, RRT2, RRT3, and RRT4 used flow rates of 1.3 PV/min, 2.7 PV/min, 5 PV/min, and $10 \mathrm{PV} / \mathrm{min}$, respectively. 
Figure A-10. o-xylene regeneration at four different airflow rates as a function of (a) time and (b) PV of air. Columns RRT1, RRT2, RRT3, and RRT4 used flow rates of $1.3 \mathrm{PV} / \mathrm{min}, 2.7 \mathrm{PV} / \mathrm{min}, 5 \mathrm{PV} / \mathrm{min}$, and $10 \mathrm{PV} / \mathrm{min}$, respectively.

Figure B- 1. BTCs of tritiated water in column LST1 for (a) virgin SMZ and (b) after the $25^{\text {th }}$ regeneration cycle and (c) after the $50^{\text {th }}$ regeneration cycle. Solid lines represent fitted values using an equilibrium advection-dispersion equation.

Figure C- 1. BTCs of toluene for every fifth sorption cycle on column LST1.

Figure C- 2. BTCs of ethylbenzene for every fifth sorption cycle on column

LST1.

Figure C- 3. BTCs of o-xylene for every fifth sorption cycle on column LST1.

Figure C- 4. Benzene removal for every fifth regeneration cycle on column LST1.

Figure C- 5. Toluene removal for every fifth regeneration cycle on column LST1.

Figure C- 6. Ethylbenzene removal for every fifth regeneration cycle on column LST1.

Figure C- 7. p- \& m-xylene removal for every fifth regeneration cycle on column LST1.

Figure C- 8. o-xylene removal for every fifth regeneration cycle on column LST1. 
Figure C- 10. BTCs of toluene for every fifth sorption cycle on column LST2.

Figure C- 11. BTCs of ethylbenzene for every fifth sorption cycle on column LST2.

Figure C- 12. BTCs of p- \& m-xylene for every fifth sorption cycle on column LST2.

Figure C- 13. BTCs o-xylene for every fifth sorption cycle on column LST2.

Figure C- 14. Benzene removal for every fifth regeneration cycle on column LST2

Figure C- 15. Toluene removal for every fifth regeneration cycle on column LST2 118

Figure C- 16. Ethylbenzene removal for every fifth regeneration cycle on column LST2

Figure C- 17. p- \& m-xylene removal for every fifth regeneration cycle on column LST2

Figure C- 18. o-xylene removal for every fifth regeneration cycle on column LST2

Figure C- $19 . K_{d}$ 's and linear regression fit to the $K_{d}$ values for benzene from column LST1. Error bars represent the 95\% confidence interval from the curve-fit process using CXTFIT.

Figure C- 20. $K_{d}$ 's and linear regression fit to the $K_{d}$ values for toluene from column LST1. Error bars represent the 95\% confidence interval from the curve-fit process using CXTFIT. 
Figure C- 21. $K_{d}$ 's and linear regression fit to the $K_{d}$ values for ethylbenzene from column LST1. Error bars represent the 95\% confidence interval from the curve-fit process using CXTFIT.

Figure C- 22. $K_{d}$ 's and linear regression fit to the $K_{d}$ values for $p$ - \& $m$-xylene from column LST1. Error bars represent the 95\% confidence interval from the curve-fit process using CXTFIT.

Figure C- 23. $K_{d}$ 's and linear regression fit to the $K_{d}$ values for $o$-xylene from column LST1. Error bars represent the 95\% confidence interval from the curve-fit process using CXTFIT.

Figure C- 24. $K_{d}$ 's and linear regression fit to the $K_{d}$ values for benzene from column LST2. Error bars represent the 95\% confidence interval from the curve-fit process using CXTFIT.

Figure C- $25 . K_{d}$ 's and linear regression fit to the $K_{d}$ values for toluene from column LST2. Error bars represent the 95\% confidence interval from the curve-fit process using CXTFIT.

Figure C- 26. $K_{d}$ 's and linear regression fit to the $K_{d}$ values for ethylbenzene from column LST2. Error bars represent the 95\% confidence interval from the curve-fit process using CXTFIT.

Figure C- 27. $K_{d}$ 's and linear regression fit to the $K_{d}$ values for $p$ - \& $m$-xylene from column LST2. Error bars represent the 95\% confidence interval from the curve-fit process using CXTFIT. 
Figure C- 28. $K_{d}$ 's and linear regression fit to the $K_{d}$ values for $o$-xylene from column LST2. Error bars represent the 95\% confidence interval from the curve-fit process using CXTFIT.

Figure D- 1. Grain size distribution for used $14-40$ mesh SMZ from column LST1

Figure D- 2. Grain size distribution for used 14 - 40 mesh SMZ from column LST2

Figure D- 3. Grain size distribution for virgin $14-40$ mesh SMZ

Figure E- 1. Backscattered SEM image of a virgin SMZ grain.

Figure E- 2. Backscattered SEM image of a used SMZ grain from column LST1.

Figure E- 3. Backscattered SEM image of a used SMZ grain from column LST2.

Figure E- 4. (a) Backscattered electron image and (b) iron distribution map of a virgin SMZ grain.

Figure E- 5. (a) Backscattered electron image and (b) iron distribution map of a virgin SMZ grain

Figure E- 6. (a) Backscattered electron image and (b) iron distribution map of a used SMZ grain from column LST1

Figure E- 7. (a) Backscattered electron image and (b) iron distribution map of a used SMZ grain from column LST1

Figure E- 8. (a) Backscattered electron image and (b) iron distribution map of a used SMZ grain from column LST2 
Figure E- 9. (a) Backscattered electron image and (b) iron distribution map of a used SMZ grain from column LST2 


\section{LIST OF APPENDIX TABLES}

Table A- 1. Data for BTEX BTCs from column RRT1 45

Table A- 2. Data for BTEX BTCs for column RRT2 45

Table A- 3. Data for BTEX BTCs for column RRT3 46

Table A- 4. Data for BTEX BTCs for column RRT4 46

Table B- 1. Observed and fitted values for $\mathrm{C} / \mathrm{C}_{0}$ for tritium tracer tests conducted on column LST1

Table B- 2. Observed and fitted values for $\mathrm{C} / \mathrm{C}_{0}$ for tritium tracer tests conducted on column LT2

Table C- 1 . Data for BTEX BTCs from the $1^{\text {st }}$ sorption cycle on column LST1

Table C- 2. Data for BTEX BTCs from the $5^{\text {th }}$ sorption cycle on column LST1

Table C- 3. Data for BTEX BTCs from the $10^{\text {th }}$ sorption cycle on column LST1

Table C- 4. Data for BTEX BTCs from the $15^{\text {th }}$ sorption cycle on column LST1

Table C- 5. Data for BTEX BTCs from the $20^{\text {th }}$ sorption cycle on column LST1

Table C- 6. Data for BTEX BTCs from the $25^{\text {th }}$ sorption cycle on column LST1

Table C- 7. Data for BTEX BTCs from the $30^{\text {th }}$ sorption cycle on column LST1 70

Table C- 8. Data for BTEX BTCs from the $35^{\text {th }}$ sorption cycle on column LST1 70

Table C- 9. Data for BTEX BTCs from the $40^{\text {th }}$ sorption cycle on column LST1 71

Table C- 10. Data for BTEX BTCs from the $45^{\text {th }}$ sorption cycle on column LST1 71

Table C- 11. Data for BTEX BTCs from the $50^{\text {th }}$ sorption cycle on column LST1 72 
Table C- 12. Data for BTEX removal from the $1^{\text {st }}$ regeneration cycle on column LST1

Table C- 13. Data for BTEX removal from the $5^{\text {th }}$ regeneration cycle on column LST1

Table C- 14. Data for BTEX removal from the $10^{\text {th }}$ regeneration cycle on column LST1

Table C- 15. Data for BTEX removal from the $15^{\text {th }}$ regeneration cycle on column LST1

Table C- 16 . Data for BTEX removal from the $20^{\text {th }}$ regeneration cycle on column LST1

Table C- 17 . Data for BTEX removal from the $25^{\text {th }}$ regeneration cycle on column LST1

Table C- 18. Data for BTEX removal from the $30^{\text {th }}$ regeneration cycle on column LST1

Table C- 19. Data for BTEX removal from the $35^{\text {th }}$ regeneration cycle on column LST1

Table C- 20. Data for BTEX removal from the $40^{\text {th }}$ regeneration cycle on column LST1

Table C- 21. Data for BTEX removal from the $45^{\text {th }}$ regeneration cycle on column LST1

Table C- 22. Data for BTEX removal from the $50^{\mathrm{h}}$ regeneration cycle on column LST1

Table C- 23. Data for BTEX BTCs from the $1^{\text {st }}$ sorption cycle on column LST2 
Table C- 24. Data for BTEX BTCs from the $5^{\text {th }}$ sorption cycle on column LST2

Table C- 25. Data for BTEX BTCs from the $10^{\text {th }}$ sorption cycle on column LST2 85

Table C- 26. Data for BTEX BTCs from the $15^{\text {th }}$ sorption cycle on column LST2 85

Table C- 27. Data for BTEX BTCs from the $20^{\text {th }}$ sorption cycle on column LST2 86

Table C- 28. Data for BTEX BTCs from the $25^{\text {th }}$ sorption cycle on column LST2 86

Table C- 29. Data for BTEX BTCs from the $30^{\text {th }}$ sorption cycle on column LST2 87

Table C- 30. Data for BTEX BTCs from the $35^{\text {th }}$ sorption cycle on column LST2 87

Table C- 31. Data for BTEX BTCs from the $40^{\text {th }}$ sorption cycle on column LST2 88

Table C- 32. Data for BTEX BTCs from the $45^{\text {th }}$ sorption cycle on column LST2 88

Table C- 33. Data for BTEX BTCs from the $50^{\text {th }}$ sorption cycle on column LST2 89

Table C- 34. Data for BTEX removal from the $1^{\text {st }}$ regeneration cycle on column LST2

Table C- 35. Data for BTEX removal from the $5^{\text {th }}$ regeneration cycle on column LST2

Table C- 36. Data for BTEX removal from the $10^{\text {th }}$ regeneration cycle on column LST2

Table C- 37. Data for BTEX removal from the $15^{\text {th }}$ regeneration cycle on column LST2

Table C- 38. Data for BTEX removal from the $20^{\text {th }}$ regeneration cycle on column LST2

Table C- 39. Data for BTEX removal from the $25^{\text {th }}$ regeneration cycle on column LST2 
Table C- 40. Data for BTEX removal from the $30^{\text {th }}$ regeneration cycle on column LST2

Table C- 41. Data for BTEX removal from the $35^{\text {th }}$ regeneration cycle on column LST2

Table C- 42. Data for BTEX removal from the $40^{\text {th }}$ regeneration cycle on column LST2

Table C- 43. Data for BTEX removal from the $45^{\text {th }}$ regeneration cycle on column LST2

Table C- 44. Data for BTEX removal from the $50^{\mathrm{h}}$ regeneration cycle on column LS

Table C- 45. Cumulative BTEX mass sorbed and removed from column LST1.

Table C- 46. Cumulative BTEX mass sorbed and removed from column LST2.

Table C- 47. Calculated $K_{d}$ values for BTEX from columns LST1 and LST2

Table D- 1. Hydraulic conductivity measurements made after every fifth cycle on columns LST1 and LT2

Table E- 1. Total iron and manganese for used SMZ from columns LST1 and LST2 and for virgin SMZ. Units are mg of analyte per kg of SMZ 


\section{INTRODUCTION}

This document is the result of a thesis project and contains a manuscript to be submitted to a scientific journal as well as supporting appendices. The study examines the use of surfactant-modified zeolite (SMZ) to remove dissolved organic compounds, particularly BTEX (benzene, toluene, ethylbenzene, and the xylenes), from produced waters. Two main objectives were investigated. The first was to examine the regeneration of BTEX-saturated SMZ. This process must be understood for interfacing with other treatment methods that can degrade the stripped-off BTEX. The second objective was to perform long-term laboratory column experiments with the SMZ treatment system. These results will be useful for designing and predicting the effectiveness of field-scale treatment systems.

The following manuscript, entitled "Regeneration and long-term stability of surfactant-modified zeolite for removal of volatile organic compounds from produced water” was prepared for submission to a scientific journal. The article presents results of laboratory-scale column experiments described above.

The appendices contain the complete data sets from the laboratory work

performed as well as further discussion on some key points. 


\title{
MANUSCRIPT:
}

\section{REGENERATION AND LONG-TERM STABILITY OF SURFACTANT- MODIFIED ZEOLITE FOR REMOVAL OF VOLATILE ORGANIC COMPOUNDS FROM PRODUCED WATER}

\author{
Craig R. Altare ${ }^{1}$, Robert S. Bowman ${ }^{1}$, Lynn E. Katz ${ }^{2}$, and Enid J. Sullivan ${ }^{3}$
}

\begin{abstract}
This work provides the results of laboratory-scale experiments of a producedwater treatment system. This treatment system used surfactant-modified zeolite (SMZ) to remove volatile organic compounds, including benzene, toluene, ethylbenzene, $p$-, $m$-and o-xylene (BTEX) from produced waters generated as a result of oil and gas recovery. Previous studies showed that SMZ was an effective sorptive medium for BTEX and that SMZ was easily and cost-effectively regenerable by air sparging. Furthermore, BTEX sorption and regeneration was reproducible for 10 cycles in the laboratory. Fieldmeasurements from a pilot-scale treatment system showed good agreement with the laboratory results.
\end{abstract}

The focus of the current study was to use laboratory-scale column studies to (1) investigate how different airflow rates impact regeneration and (2) perform long-term tests to infer the chemical and physical stability of SMZ in a produced-water treatment system.

\footnotetext{
${ }^{1}$ Department of Earth and Environmental Science, New Mexico Tech, Socorro, NM 87801.

${ }^{2}$ Department of Civil Engineering, University of Texas-Austin, Austin, TX 78712.

${ }^{3}$ Los Alamos National Laboratory, Chemistry Division, Los Alamos, NM 87545.
} 
The results of the regeneration airflow rate studies showed that kinetic effects of varying airflow rates (from 1.3 to 10 pore volumes of air per minute) did not significantly affect removal of BTEX. Rather, the volume of air pumped through the column during air sparging was the predictor of removal rates. The implication of these results is that simple predictions can be made about BTEX removal rates from SMZ by knowing the airflow rate and number of pore volumes that have passed through the column. This is important for coupling of the SMZ treatment system with a process designed to treat the off-gas, such as a vapor phase bioreactor (VPB). End-users of such a system must be able to predict the rate of regeneration and tune it to an optimal level for the VPB.

Long-term laboratory-scale results of the SMZ produced-water treatment system were promising. Fifty sorption/regeneration cycles were carried out, each consisting of sorption from $100 \mathrm{PV}$ of produced water followed by regeneration with approximately 2000 PV of air. A weakly decreasing trend was observed for the BTEX distribution coefficients $\left(K_{d}\right)$, indicating only a small loss in sorption capacity after 50 cycles of sorption and regeneration. Hydraulic conductivity of the SMZ decreased by roughly $30 \%$ after the 50 cycles. Most of this hydraulic conductivity loss was likely caused by particle attrition. 


\section{INTRODUCTION}

Oilfield produced water is an enormous waste stream in the United States.

Produced water is brought to the surface as a result of oil and gas recovery and includes both formation water and water injected to enhance the recovery process. The ratio of produced water to recovered oil and gas generally increases during the lifetime of a well and cumulative produced water generation can be 10 times that of oil and gas (Stephenson 1992). The Rocky Mountain region of the U.S. (Colorado, Montana, New Mexico, Utah, and Wyoming) generated more than 3 billion bbl (1 bbl = 42 gal) of produced water in 2000 (Boysen et al. 2002).

Produced waters are highly variable in composition but often contain high total dissolved solids (TDS), dissolved organic compounds, heavy metals, radionuclides, and chemical additives associated with the recovery process (Stephenson 1992). Among the dissolved organic compounds are the volatile organic compounds benzene, toluene, ethylbenzene, and para-, ortho- and meta-xylenes, known collectively as BTEX. Additionally, produced water often contains high amounts of organic acids (API 2002).

The majority of produced water, including up to $92 \%$ of that produced onshore, is disposed via injection into the subsurface (API 2000). This includes produced water injected to further enhance oil recovery. Remaining onshore produced water is disposed and/or used at the surface in evaporation pits, irrigation, or for application to roads (U.S. EPA 2000). Onshore surface discharge is regulated at the Federal level by the National Pollutant Discharge Elimination System (NPDES). Permits are only issued for smallvolume wells, defined as less than 10 bbls oil per day, and west of the $98^{\text {th }}$ meridian in instances where the water can be put to a beneficial use (40 CFR Part 465). 
Boysen et al. (2002) surveyed oil and gas producers in the Rocky Mountain region and found per-barrel disposal costs for produced water ranging from $\$ 0.01$ to $\$ 10$. This cost was heavily dependant on whether the producer was able to dispose of the water on site or had to transport the water to an off-site disposal facility. Trucking costs were quoted to be as much as $\$ 80 / \mathrm{hr}$, and can only be expected to rise with increasing fuel costs. Boysen et al (2002) concluded that costs for disposal were increasing due to more stringent state regulations. This led producers to look for on-site treatment and recycling methods to lower their costs.

Several methods are available for removal of dissolved organic contaminants from produced water. One of the most widely used methods uses granular activated carbon (GAC) to remove aromatic organic compounds from solution. However, as Hansen and Davies (1994) explained, GAC must be regenerated by wet-air oxidation (WAO) once it is saturated with organic compounds. WAO oxidizes organic and inorganic contaminants in the aqueous phase at elevated temperature and pressure. Furthermore, Hansen and Davies (1994) noted that, for typical gas-field produced-water volumes (1000 bbl per day), WAO could be used to remove organic contaminants without the use of GAC. Where organic concentrations exceed $10-40 \mathrm{mg} / \mathrm{L}$, costs associated with GAC became prohibitive for oil and gas producers (Hayes and Arthur, 2004).

Miller et al. (1997) performed a pilot test using a granular activated-carbon fluidized-bed biological reactor (GAC-FBR) to remove dissolved organic material from produced water. In this process GAC was coated with a fixed microbial film that degraded the sorbed organic compounds. The GAC-FBR could be run under either 
aerobic conditions, which gave higher removal efficiency, or anoxic conditions, which were capable of handling higher organic concentrations. The field test described by Miller et al. used an anoxic GAC-FBR in series with an aerobic GAC-FBR. BTEX removal efficiencies for this apparatus ranged from 95 to $99.8 \%$. The GAC-FBR's did not need to be regenerated because the organic compounds were constantly being degraded. Costs for the system were not reported.

Another method for removing dissolved organics from produced water is air stripping. Fang and Lin (1988) described three types of air-stripping methods common in industrial applications - (1) a fixed tank with air spargers; (2) air and water in countercurrent flow through a packed column; (3) a tray column where air passes through flowing produced water. The authors provided laboratory results from a scaled-down type (1) apparatus. Their findings showed greater than $99 \%$ benzene removal from an aqueous solution after less than 1 hour of air stripping. Disadvantages of air stripping are that it does not remove non-volatile compounds (Fang and Lin, 1988) and scale deposition may prove problematic (Hansen and Davies, 1994).

Additionally, modified zeolites have been proposed as a treatment option for removing BTEX compounds from contaminated water. Zeolites are a group of naturally occurring aluminosilcate minerals with a cage-like crystal structure. They are characterized by high internal and external surface areas and high cation exchange capacities (CECs). Zeolites are mined as aggregates and as such can be ground to any desired mesh size, making them ideal for flow-through and column applications that are sensitive to hydraulic properties of the medium. 
Positively charged surfactant molecules such as hexadecyltrimethylammonium (HDTMA) can replace positively charged counterions on the surface of the zeolite. A surfactant bilayer forms on the zeolite surface with addition of sufficient surfactant. Organic compounds such as BTEX can then partition into this hydrophobic, nonpolar layer.

Batch tests have been performed using zeolites modified with several different amines to remove BTEX from produced water. Janks and Cadena (1991) reported removal efficiencies ranging from 9.4 to $85.2 \%$ depending on the amine used. Highest removal efficiencies were achieved with lower-molecular-weight amines. Bowman et al. (1995) reported the results of batch experiments using HDTMA-modified zeolite to remove benzene, toluene, $p$-xylene, and ethylbenzene. Linear sorption isotherms, noncompetitive sorption, and increasing sorption with decreasing solubility for each compound led Bowman et al. (1995) to conclude that BTEX sorption on SMZ could be explained by a simple partitioning mechanism.

Unlike the energy- and cost- intensive WAO required to regenerate activated carbon, SMZ can be regenerated simply by blowing room-temperature air through the column. Li and Bowman (2001) reported full regeneration of perchloroethylene-(PCE) saturated SMZ with air sparging. The vapor-phase stream of organic compounds can then be treated in various ways, including use of a vapor-phase bioreactor (VPB) (Kwon et al., 2005), which degrades the compounds into respiration products such as carbon dioxide and water. At roughly $\$ 460$ per ton (Bowman et al., 2001), SMZ offers a low cost, regenerable option for removing volatile organics from produced water. When coupled with additional processes, such as reverse-osmosis filtration to reduce salinity, SMZ can 
potentially treat water so that it is clean enough to be put towards an improved use such as irrigation, road watering, or make-up water for industrial processes.

Ranck et al. (2005) further investigated using SMZ for treating produced water by perfoming laboratory- and field-scale column experiments. The laboratory-scale studies described in Ranck et al. (2005) demonstrate that BTEX sorption and regeneration on SMZ is repeatable for 10 cycles. Pilot-scale field tests were performed at a producedwater treatment facility in Wyoming and agreement was good between laboratory and field observations. Ranck et al. (2005) concluded that SMZ has the potential to be a successful, cost effective treatment option for produced water.

The purpose of the current study was to address two critical issues for deployment of full-scale produced-water treatment systems. The first component of the study, termed the regeneration rate tests (RRT), examined airflow rate during regeneration. When interfacing SMZ treatment with a VPB or other off-gas treatment system, it is necessary to know the rate at which BTEX will be removed based on the flow rate of air through the column. VPB's and other gas treatment systems are sensitive to concentrations of BTEX that are either too high or too low. The regeneration portion of this study utilized laboratory-scale column tests to investigate air stripping of SMZ at several flow rates.

Additionally, concerns have been raised regarding the long-term stability of SMZ for a produced-water treatment system. Ranck et al. (2005) found that high backpressure and significant particle deterioration occurred in laboratory columns after 10 sorption and regeneration cycles. Approximately 500 pore volumes (PV) of produced water were treated during each cycle in that study. Mean SMZ particle diameter for the Ranck et al. (2005) study was $0.164 \mathrm{~mm}$. The second component of the current study, termed the 
long-term stability tests (LST), utilized laboratory-scale columns packed using SMZ with a mean particle diameter of $0.90 \mathrm{~mm}$. This grain size was chosen because it is typical of the size that would be used in a full-scale treatment system, it replicates the grain size used in the previously discussed pilot-scale tests (Ranck et al., 2005), and the larger grain size may be more resistant to particle attrition.

\section{MATERIALS AND METHODS}

\section{Produced Water}

The produced water for the RRT experiments was obtained from the Crystal Solutions, LLC, produced-water treatment facility in Wamsutter, Wyoming in December 2002. This was the site of the Ranck et al. (2005) pilot-scale field tests. Water at this site was placed in separation tanks before being sent to a series of lined evaporation ponds. The water was collected from the separation tanks and stored in sealed 208-L metal drums at room temperature. The composition of this water is listed in Table 1.

The produced water for the LST experiments was obtained from a produced-water reinjection facility owned by Burlington Resources located near Farmington, NM, in the San Juan basin. This facility was also the site of pilot-scale SMZ and VPB field tests conducted in August 2005 (Altare et al., 2005). Water was trucked in to the site and stored in tanks. The water was then put through a separation tank, sand filters, and 1- $\mu \mathrm{m}$ filters before being reinjected. The water for the laboratory experiments was collected in July 2005 downstream of the sand filters and sealed in 208-L metal drums. Composition of the water from the treatment facility collected for laboratory experiments was analyzed in June 2006 and the results are shown in Table 1. Produced water used in the LST 
laboratory experiments described below was spiked with toluene so that concentrations were similar to that of the influent produced water from the August 2005 pilot tests (toluene $=3.3 \mathrm{mg} / \mathrm{L})^{1}$.

\section{$\underline{\text { Surfactant-Modified Zeolite }}$}

The zeolite used in this study was obtained from the St. Cloud mine in Winston, NM. Mineralogical analysis of this zeolite showed that it had a composition of $74 \%$ clinoptilolite, 5\% smectite, 10\% quartz/cristobalite, and 1\% illite. The internal and external CEC’s were 800 meq/kg and 90-100 meq/kg, respectively (Bowman et al. 2000).

The RRT experiments used zeolite crushed to $0.18-0.15 \mathrm{~mm}$ grains $(80-100$ mesh). This zeolite was then treated with 0.10 M HDTMA-Cl (Aldrich, Milwaukee, WI) as described by Ranck et al (2005). HDTMA loading was $157 \mathrm{mmol} / \mathrm{kg}$ of zeolite. SMZ used for the LST experiments was crushed to a grain size of 1.4 - $0.4 \mathrm{~mm}$ (14-40 mesh) and bulk produced by the St. Cloud mine (Bowman et al. 2001). HDTMA loading on this zeolite was $180 \mathrm{mmol} / \mathrm{kg}$ zeolite. Discrepancies in HDTMA loading rates likely resulted from differences in the zeolite content of the material mined at different times.

\section{$\underline{\text { Regeneration Airflow-Rate Column Studies }}$}

Columns for the RRT experiments were scaled down from the Wyoming field columns using the rapid small-scale column method developed for GAC (Crittenden et al. 1991), as discussed in Ranck et al. (2005). Columns were prepared by packing 80-110 mesh SMZ into four glass columns (ID $=0.4 \mathrm{~cm}, \mathrm{~L}=10 \mathrm{~cm}$ ) (Ace Glass, Vineland, NJ) capped with polytetrafluoroethylene (PTFE) end fittings. Four-way valves (Cole-Parmer,

\footnotetext{
${ }^{1}$ Unpublished data from Lily Chen, University of Texas at Austin
} 
Vernon Hills, Ill.) were attached to the end fittings with Luer connections and served as sampling ports for influent and effluent waters.

A separate column was packed for each RRT experiment. Each column was saturated from the bottom with a synthetic brine that matched the inorganic composition of the Wyoming produced water (Table 1). The brine was injected using a Waters model 501 HPLC pump.

A 10-L Tedlar® gas sampling bag (Alltech Associates, Inc., Deerfield, Ill.) filled with Wyoming produced water was attached to the pump with Teflon tubing. A $0.45-\mu \mathrm{m}$ nylon syringe-tip filter (Supelco, Bellefonte, Pa.) was plumbed in between the pump and column to remove particulates. Produced water was pumped through each column individually until effluent BTEX concentrations equaled influent concentrations ( $\sim 40$ PV). Influent and effluent water samples were collected approximately every 10 PV for the first $100 \mathrm{PV}$ and every 50 PV for the duration of the experiment. Three-milliliter water samples were withdrawn using a 10-mL gastight syringe, injected into $10-\mathrm{mL}$ glass headspace vials, and capped with Teflon-faced butyl septa (Supelco) for subsequent analysis.

The BTEX-saturated SMZ was then regenerated by air sparging. A compressed air tank was attached to the effluent end of the column and a 65-mm single-float flow controller (Cole-Parmer) was placed between the tank and column to regulate airflow. The flow rate was measured downstream of the column with a soap-film flow meter. The four RRT columns were regenerated at 4.0, 7.5, 15 and $30 \mathrm{~mL} / \mathrm{min}(1.3,2.7,5.0$, and 10 $\mathrm{PV} / \mathrm{min}$ ), respectively. The effluent gas was sampled by withdrawing $0.2-\mathrm{mL}$ samples with a 1.0-mL gastight syringe. These samples were analyzed immediately using gas 
chromatography. Regeneration was continued for at least $3000 \mathrm{PV}$ to ensure effluent gas BTEX concentrations were less than $2 \%$ of initial values. The RRT columns were not replicated.

\section{Long-Term Stability Column Studies}

Columns for the LST experiments were prepared by adding 14-40 mesh SMZ to two replicate glass columns with a length of $11 \mathrm{~cm}$ and radius of $2.5 \mathrm{~cm}$ (Omnifit, Boonton, NJ). These columns were outfitted with replaceable 100- $\mu \mathrm{m}$ PTFE frits and one fixed and one adjustable end fitting. The adjustable end fitting allowed any headspace that developed due to particle loss to be eliminated. The LST columns were saturated with $\mathrm{NaCl}$ brine with electrical conductivity similar to the New Mexico produced water (21.5 mmho/cm). A constant-head tank was attached to the column inlet and the volumetric flowrate was measured at the effluent end in order to determine the hydraulic conductivity. This measurement was repeated after every fifth regeneration cycle.

A 2-PV slug of tritiated water was then injected into each column at a specific discharge of $2.5 \mathrm{~cm} / \mathrm{min}$ in order to determine the hydraulic properties of the SMZ bed. This discharge was chosen to be similar to that of the New Mexico field experiments ( $2.4 \mathrm{~cm} / \mathrm{min}$ ) (Altare et al., 2005). Effluent samples were collected in 7-mL glass vials in 0.5-min intervals using a Retriever II fraction collector (ISCO Inc., Lincoln, NE). One milliliter of each effluent sample was combined with $5 \mathrm{~mL}$ of scintillation cocktail solution (ICN Biomedicals, Inc., Irvine, CA) and analyzed with a LS6500 liquid scintillation counter (Beckman Coulter, Inc., Fullerton, CA). The tritium tracer tests were repeated after the $25^{\text {th }}$ and $50^{\text {th }}$ cycles to monitor changes in hydraulic properties. 
Fifty sorption and regeneration cycles were performed on the LST columns, with water and off gas analyzed every fifth cycle. Each BTEX saturation step was carried out for $100 \mathrm{PV}$ in order to better simulate operating conditions of the New Mexico field-scale experiments. The produced-water specific discharge during sorption cycles was 2.5 $\mathrm{cm} / \mathrm{min}$. The columns were regenerated using $160 \mathrm{~mL} / \mathrm{min}$ (5.5 PV/min) of air.

After the LST experiments were complete, the end fittings were removed, the used frits were replaced with new ones, and the columns were reassembled. The conductivity was measured once again to determine how much of the conductivity loss, if any, could be explained by clogging of the frits. The columns were then disassembled. Two 0.5-g SMZ samples were taken from the inlet end of each LST column, one for biological analysis and one for electron microprobe analysis. The biological analysis consisted of DNA extractions using the methods described by Sambrook et al. (1989) and a protein analysis using SDS-PAGE gel (Laemmli, 1970). Microprobe images were obtained from a Cameca (Trumbull, CT) model SX 100 electron probe using an accelerating voltage of $15 \mathrm{kV}$ and a beam current of $20 \mathrm{nA}$. X-ray chemical distribution maps were collected at a resolution of 512 by 512 pixels with a 7 millisecond per pixel collection time.

The remainder of the used SMZ from each column was removed and homogenized. An additional 0.5-g sample was taken from the homogenized SMZ from each column for a total chemical analysis. The chemical analysis was performed by digesting the samples with a four-acid method after Briggs (1996) and analyzing the digestion products by inductively coupled plasma (ICP) - atomic emission spectroscopy. The rest of the used SMZ from each column was used for a hydrometer particle size 
analysis (ASTM, 1995) to determine changes in particle size and the amount of particle attrition.

\section{$\underline{\text { Analytical Methods }}$}

The influent and effluent produced-water sample vials were loaded into a HewlettPackard (HP) model 7694 headspace autosampler. The autosampler operating conditions were: oven temperature $70^{\circ} \mathrm{C}$, loop temperature $75^{\circ} \mathrm{C}$, transfer line temperature $75^{\circ} \mathrm{C}$, equilibrium time 1.0 min, pressurization time $1.0 \mathrm{~min}$, loop fill time $1.0 \mathrm{~min}$, loop equilibration time $0.5 \mathrm{~min}$, and injection time $0.09 \mathrm{~min}$.

The autosampler was attached to a HP model 5890A gas chromatograph (GC) with a 10-m long, 0.53-mm I.D. HP-5 capillary column and a flame ionization detector (FID). Operating conditions of the GC were: carrier gas (He) flow rate $35 \mathrm{~mL} / \mathrm{min}$, split gas (He) flow rate $28 \mathrm{~mL} / \mathrm{min}$, oven temperature (isothermal) $55^{\circ} \mathrm{C}$, injector temperature $210^{\circ} \mathrm{C}$, and detector temperature $240^{\circ} \mathrm{C}$. The GC was calibrated before each cycle was analyzed using five BTEX standards over a range from 0.5 to $40 \mathrm{mg} / \mathrm{L} . p$-xylene and $m$ xylene were not resolved by this method and as such were treated as a single compound.

Gas-phase BTEX concentrations from the regeneration cycles of the RRT columns were measured by direct injection into the HP 5890A GC. Operating conditions of the GC were the same as for the sorption analysis with the exception of the split flow rate, which was increased to $63 \mathrm{~mL} / \mathrm{min}$. Calibration for these analyses was conducted by preparing BTEX standard solutions in 10-ml glass vials capped with Teflon-faced septa. BTEX concentrations in the headspace of the standards were calculated based on the Henry’s Law constant for each compound. 
Gas-phase BTEX concentrations for the LST regeneration experiments were measured using a Varian Inc. (Walnut Creek, CA) model 5890 GC equipped with an automated gas-sampling valve, FID, and a 15-m long, 0.25-mm I.D Varian Factor Four VF-1ms column. The valve, which used a $0.25 \mathrm{~mL}$ sampling loop, automatically collected a sample every 20 minutes and injected it into the column. Off-gas from the LST columns was plumbed into the sampling valve with Teflon tubing. Operating conditions of this GC were: carrier gas (He) flow $25 \mathrm{~mL} / \mathrm{min}$, split ratio 50, oven temperature (isothermal) $55^{\circ} \mathrm{C}$, column flow $2.0 \mathrm{~mL} / \mathrm{min}$, injector temperature $140^{\circ} \mathrm{C}$, and detector temperature $200^{\circ} \mathrm{C}$. Calibration was carried out by manual injection of BTEX standards in a similar fashion as the manual-injection calibration for the HP 5890 GC.

\section{RESULTS AND DISCUSSION}

\section{$\underline{\text { Regeneration-Rate-Test Experimental Results }}$}

All four columns in the RRT experiments were fully and reproducibly saturated with BTEX. Figure 1 shows BTEX breakthrough on column RRT1. Benzene, which has the highest aqueous solubility and the lowest octanol-water partition coefficient $\left(K_{o w}\right)$ of the BTEX compounds (Table 2), is the first compound to elute from the columns. The other compounds elute in order of decreasing solubility and increasing $K_{o w}$, with ethylbenzene and the xylenes eluting at nearly the same time, as their similar $K_{\text {ow }}$ values would predict. Figure 2 shows the reproducibility of sorption for toluene and $p$ - and $m$ xylene. 
The four RRT columns were then regenerated at airflow rates of 1.3 PV/min, 2.7 $\mathrm{PV} / \mathrm{min}$, 5.0 PV/min, and 10 PV/min, respectively. Off-gas $p$ - and $m$-xylene concentrations are shown in Figure 3a as a function of time and in Figure 3b as a function of PV of air. As Figure 3a shows, for an airflow rate of $10 \mathrm{PV} / \mathrm{min}$, nearly all of the $p$ and $m$-xylene has been removed before $500 \mathrm{~min}$. However, for an airflow rate of 1.3 $\mathrm{PV} / \mathrm{min}$, similar removal takes at least $1500 \mathrm{~min}$. When these data are viewed as a function of PV of air (Figure 3b), rather than time, we see that for early-time regeneration, xylene concentration for the two highest flow rates $(10 \mathrm{PV} / \mathrm{min}$ and 5 $\mathrm{PV} / \mathrm{min})$ is lower than the concentration for the two lowest flow rates $(1.3 \mathrm{PV} / \mathrm{min}$ and 2.7 PV/min). This is consistent with a kinetically-limited desorption mechanism for BTEX compounds during air sparging. However, nearly all of the p- and m-xylene was removed after $2000 \mathrm{PV}$ of air, regardless of airflow rate. This means that while removal of BTEX from SMZ during air sparging was somewhat kinetically limited, kinetic effects did not play a large role in regeneration. The number of pore volumes of air required for regeneration can be predicted simply by knowing the volume of air that was pumped through the columns. Additionally, deviations in early-time removal may have been due to variations in the rate at which the column dried. No water was removed by gravity drainage prior to regeneration, resulting in saturated conditions as the cycle was begun. As the column dried an increasing percentage of the BTEX-saturated SMZ surface was available for air stripping.

\section{Long-Term Stability Experimental Results}


Tritium breakthrough curves (BTCs) from column LST1 for the virgin SMZ, after the $25^{\text {th }}$ regeneration cycle, and after the $50^{\text {th }}$ regeneration cycle are shown in Figures 4 a, 4b, and 4c, respectively. These BTCs were well described by the 1-dimensional advection-dispersion equation:

$$
R \frac{\partial C^{*}}{\partial T}=\frac{1}{P} \frac{\partial^{2} C^{*}}{\partial X^{2}}-\frac{\partial C^{*}}{\partial X}
$$

where:

$$
\begin{gathered}
C^{*}=\frac{c}{C_{0}} \\
P=\frac{v L}{D} \\
R=1+\left(\frac{\rho}{\theta}\right) K_{d} \\
T=\frac{v t}{L} \\
X=\frac{x}{L}
\end{gathered}
$$

and $R$ is the retardation factor, $\mathrm{C}^{*}$ is the dimensionless solute concentration, $T$ is dimensionless time (pore volumes), $P$ is the Peclet number, $X$ is the dimensionless length, $c$ is the effluent solute concentration $\left(\mathrm{ML}^{-3}\right), c_{0}$ is the influent solute concentration $\left(\mathrm{ML}^{-3}\right)$ , $v$ is the pore-water velocity $\left(\mathrm{LT}^{-1}\right), L$ is the column length $(\mathrm{L}), D$ is the dispersion coefficient $\left(\mathrm{L}^{2} \mathrm{~T}^{-1}\right)$, $\rho$ is bulk density $\left(\mathrm{ML}^{-3}\right), \theta$ is volumetric water content, $K_{d}$ is the linear equilibrium sorption constant $\left(\mathrm{L}^{3} \mathrm{M}^{-1}\right), t$ is the time $(\mathrm{T})$, and $x$ is the distance (L). 
Equation 1 was fit to the observed tritium data using the nonlinear, least-squares optimization program CXTFIT 2.1 (Torride et al. 1999). A flux-type upper boundary and semi-infinite lower boundary condition were used, $v$ was treated as a known value, and $R$ and $D$ were fitted. As seen in Figure 4, a good fit was achieved with the equilibrium model. The fitted $D$ and $R$ values are shown in Table 3. No distinct trends were observed that would have indicated a change in the column hydraulic properties over time. The fact that the tritium tracer is well described by Equation 1 suggests that physical nonequilibrium (immobile water zones) was not a major factor for these column tests.

BTCs for benzene and $p$ - and $m$-xylene for every $5^{\text {th }}$ cycle on column LST1 are shown in Figures 5a and 5b. Figure 6 shows observed $p$ - and $m$-xylene breakthrough from the first sorption cycle on column LST1, as well as the fitted BTC using Equation 1. Clearly, the simple equilibrium advection-dispersion equation did not adequately describe the sorption of $p$ - and $m$-xylene on SMZ, indicating nonequilibrium processes were present. Similar trends were found during 50 cycles of sorption and regeneration for each of the other BTEX compounds. The presence of immobile water domains was ruled out by the tritium experiments. Chemical nonequilibrium may have occurred due to slow kinetics during the partitioning of BTEX compounds from the aqueous phase into the hydrophobic regions of the SMZ (Pignatello and Xing, 1996). Thus, a two-site chemical nonequilibium advection-dispersion model was chosen based on Toride et al. (1999):

$$
\begin{gathered}
\beta R \frac{\partial C_{1}}{\partial T}=\frac{1}{P} \frac{\partial^{2} C_{1}}{\partial X^{2}}-\frac{\partial C_{1}}{\partial X}-\omega\left(C_{1}-C_{2}\right) \\
(1-\beta) R \frac{\partial C_{2}}{\partial p}=\omega\left(C_{1}-C_{2}\right)
\end{gathered}
$$


where:

$$
\begin{gathered}
\beta=\frac{\theta+f \rho K_{d}}{\theta+\rho K_{d}} \\
C_{1}=\frac{c}{c_{0}} \\
C_{2}=\frac{s_{k}}{(1-f) K_{d} C_{o}} \\
\omega=\frac{\alpha(1-\beta) R L}{v}
\end{gathered}
$$

and subscripts 1,2 , and $k$ refer to equilibrium sites, nonequilibrium sites, and kinetic adsorption sites, respectively; $f$ is the fraction of sorption sites that are always at equilibrium, $s$ is the concentration of the adsorbed phase, and $\alpha$ is a first-order kinetic rate coefficient $\left(\mathrm{T}^{-1}\right)$.

Equations 7 and 8 were fit to the observed BTEX data using CXTFIT (Toride et al., 1999). A flux-type upper boundary and semi-infinite lower boundary condition were imposed, $v$ was treated as a fixed value, and $D, \beta$, and $\omega$ were fitted with the program.

$K_{d}$ for each BTEX compound was calculated for every analyzed sorption cycle using Equation 4 and the fitted value of $R$. Figure 7 shows the values of $K_{d}$ plotted for benzene and $p$ - and $m$-xylene, respectively, from column LST1 along with error bars representing the $95 \%$ confidence interval of the fitted $K_{d}$ and a line that was fit to the data using a linear regression. The slopes for these best-fit lines, in addition to the best-fit lines for the other BTEX compounds, are shown in Table 2. A loss in sorptive capacity over time would be indicated by a decreasing trend in $K_{d}$ values as the number of sorption cycles increased. As Table 2 shows, all of the slope values are negative. However, as 
demonstrated by the large error associated with each fitted value of $K_{d}$, the trend is weak. Additionally, attempts were made to fit the data using a non-linear curve. These attempts also failed to yield a good fit to the observed data. Although these attempts were not successful, changes in sorption capacity may not be a linear process. Several factors influence sorption capacity. Among these are surfactant wash-off and sorption of other organic compounds that are not removed by air sparging but which can increase the sorption of volatile organics.

Off-gas concentrations of toluene and $p$ - and $m$-xylene are shown in Figure 8 for each of the measured regeneration cycles on column LST1. Reproducibility of the regeneration experiments was excellent. Early-time variability in off-gas concentration was once again observed. This may be indicative that the degree of water saturation of the column dictates early-time off-gas concentrations during regeneration.

The hydraulic conductivity of the columns was measured after every fifth regeneration cycle. After the $25^{\text {th }}$ cycle, the conductivity of column LST1 had dropped to approximately 3\% of the virgin-SMZ column. After 50 cycles both columns appeared to have lost $98 \%$ of their original conductivity. However, conductivity measured after the inlet and outlet frits were replaced showed that the columns had retained roughly $70 \%$ of their original conductivity, indicating the majority of the conductivity loss can be accounted for by clogging of the frits.

Several factors could account for the remaining $30 \%$ loss in hydraulic conductivity, among them particle attrition, formation of coatings on the SMZ grains, and biofouling of the column. However, biological testing for the presence of DNA and/or 
proteins on the used SMZ was negative for both replicate columns. This rules out biofouling as a mechanism for hydraulic conductivity loss.

As the LST column experiments proceeded, a distinct brown coloring of the zeolite particles was noted. Total digestion and compositional analysis of the used SMZ was conducted to determine whether the discoloration was due to precipitation of iron or manganese surface coatings on the SMZ. These analyses did not reveal any measureable increase in iron or manganese relative to virgin SMZ.

Images of the used SMZ were prepared using an electron microprobe in order to determine whether a surface coating was in fact accumulating on the SMZ in the column. Backscattered electron images of used- and virgin-SMZ grains are shown in Figures 911. Figure 9 is an image of a virgin SMZ particle, showing that the particle is largely made up of smaller zeolite mineral grains (the plate-like grains on the right hand side of the image) with uniform, clean surfaces. Figures 10 and 11 show images of used-SMZ from the influent ends of column LST1 and LST2, respectively. These figures show that a change in surface texture has occurred for certain regions of the used-SMZ grains. This change in surface texture was interpreted to be a surface coating. The coatings were not continuous over the used SMZ grains and appeared, due to the fact that surface features could still be interpreted below the coatings, to be thin. Coatings were likely caused by accumulation of non-volatile organics that were not removed during air sparging, or mineral precipitation that occurred when the column was being regenerated. At that time, water was evaporating within the column, leading to precipitation of mineral phases on the SMZ surfaces. Those phases that were water-soluble would be washed off during subsequent sorption cycles, while non-water-soluble mineral phases would accumulate on 
the SMZ grains. Chemical distribution maps were non-indicative and inconclusive for determining the composition of the proposed surface coatings. The maps were made using an SMZ particle that was mounted in epoxy and ground to a flat surface. This grinding step eliminated the ability to look at the external surface of the SMZ particle. Due to the discontinuous, thin nature of the coatings it is unlikely they played a large role in the loss of hydraulic conductivity.

Particle-size analysis conducted by the hydrometer method revealed a high amount of particle attrition. Virgin SMZ contained only $1.83 \%$ fines (smaller than 0.075 $\mathrm{mm}$ ) while the used SMZ from columns LST1 and LST2 contained 13.9\% and 17.9\% fines, respectively. Particle attrition appears to be the most likely cause of the observed hydraulic conductivity loss.

Attempts were made to quantify the amount of surfactant lost from SMZ during the 50 cycles of the LST experiments. HDTMA concentration in the effluent water was measured using an HPLC method described by Li and Bowman (1997). The results of these attempts were confounded by a compound present in the influent produced water that had a similar elution time as HDTMA. Even though direct measurements of HDTMA loss were inconclusive, indirect evidence exists to infer the limits of surfactant wash-off. If HDTMA washed off such that the coverage on the zeolite surface was below monolayer coverage (below $90 \mathrm{mmol} / \mathrm{kg}$ ), pronounced decrease in sorption capacity would be have been observed. This was shown by Li and Bowman (1998), who observed that sorption of PCE on SMZ increased linearly as a function of surfactant loading rate up to the equivalent of monolayer loading capacity. Additional surfactant loading led to minimal increases in sorptive capacity for PCE (Li and Bowman, 1998). Since little to no 
loss in sorptive capacity was observed for the current study, it was presumed that surfactant loading remained, at a minimum, at the equivalent monolayer loading capacity throughout the LST experiments. It is expected, however, that some surfactant wash-off occurred. Li et al. (2003) presented the results of column experiments designed to determine surfactant wash-off from modified clinoptilolite. Li et al. (2003) determined that, after $100 \mathrm{PV}$ of a $0.5 \mathrm{mM} \mathrm{NaHCO}$ solution had passed through the column, $17 \%$ of the total surfactant was washed off from 14-40 mesh SMZ that originally had been loaded to almost twice the external CEC. Furthermore, Li et al. (2003) found that wash-off of the outer surfactant layer occurred at a faster rate than wash-off of the surfactant molecules that were held to the zeolite surface by cation exchange. The fact that the monolayer coverage is more stable than bilayer coverage is expected considering the forces holding surfactant molecules to the zeolite surface (electrostatic interactions) are stronger than the forces holding the upper layer of surfactant to the lower layer (hydrophobic interactions) (Li et al., 1998).

\section{CONCLUSIONS}

Surfactant-modified zeolite (SMZ) is an effective sorptive medium for removing dissolved organics from produced water. It offers a low-cost, easily regenerable option for producers who want or need to treat their produced water.

Regeneration-curve predictions can be made simply by knowing the volume of air pumped through the column. Kinetic effects due to various airflow rates do not have a large impact on the removal rate of BTEX during air sparging. Thus, when interfacing the 
SMZ regeneration process with a VPB or other off-gas treatment system, the end user can tailor the delivery of BTEX to the VPB by changing the airflow rate.

Long-term laboratory-scale column tests (50 sorption and regeneration cycles; 5000 PV total water treated) show that SMZ retains its ability to remove BTEX compounds over many cycles. Observation of $K_{d}$ over the 50 cycles reveals a weakly decreasing trend. Even if the $K_{d}$ in a field column dropped too low, additional HDTMA could be pumped through the column to restore surfactant loading on the SMZ. Hydraulic conductivity of the SMZ decreased by approximately $30 \%$ during the tests. This decrease was attributed to particle breakdown in the column and cannot be explained by biofouling or the accumulation of surface coatings on the SMZ particles. Future work should focus on the issue of particle attrition. Knowledge of conditions that inhibit or promote attrition of SMZ particles should be determined. Methods to stabilize the SMZ particles should also be investigated. Particle breakdown will lead to high backpressure in columns and decreased treatment capacity.

Further work needs to be done in order to quantify the amount of HDTMA washed off during the long-term tests. Although quantification of HDTMA wash-off was not successful for this study, indirect evidence suggests that surfactant loading did not drop below equivalent monolayer coverage. Additionally, work must be done at the laboratory and field scales to couple SMZ treatment with other treatment methods. These systems should aim to remove organic acids and reduce the TDS of the effluent waters. Successful implementation of these practices can yield water that meets state-imposed discharge requirements. 


\section{ACKNOWLEDGEMENTS}

This work was funded by the U.S. Department of Energy under contract number DEFC26-04NTI5546. We thank Mr. John Boysen of B.C. Technologies (Laramie, WY) and Burlington Resources (now ConocoPhillips) for providing the produced water used in the column studies. SMZ for the RRT experiments was prepared by Guifang Tan at the University of Texas at Austin. Dr. Snezna Rogelj of the New Mexico Tech tested the SMZ from LST experiments for biological activity. Dr. Nelia Dunbar of the New Mexico Bureau of Geology prepared the electron microprobe images and chemical distribution

maps. Tyler Munson of New Mexico Tech assisted in the hydrometer tests. Josh Simpson and Aaron Jenkins of New Mexico Tech assisted with laboratory experiments. 


\section{REFERENCES}

Altare, C.R., Bowman, R.S., Sullivan, E.J., Katz, L.E., Kinney, K.A. Abstracts, Geological Society of America Annual Meeting, Salt Lake City, UT; Geological Society of America: Boulder, 2005; Abstract 94295.

American Petroleum Institute (API). (2000). "Overview of exploration and production waste volumes and waste management practices in the United States.” API, Washington, D.C.

American Petroleum Institute (API). (2002). "Predictors of water-soluble organics in produced water - a literature review.” API, Washington, D.C.

ASTM, (1995) ASTM test method for particle size analyis of soils (D 422 - 63) Annual Book of ASTM Standard, Soil and Rock (I), 04.08. American Society for Testing Materials.

Bowman, R.S., Haggerty, G.M., Huddleston, R.G., Neel, D., and Flynn, M.M. (1995). "Sorption of nonpolar organic compounds, inorganic cations, and inorganic oxyanions by surfactant-modified zeolites." Surfactant-enhanced subsurface remediation, D.A. Sabatini, R.C. Knox, and J.H. Harwell, eds., American Chemical Society, Washington DC, 54-64.

Bowman, R.S., Li, Z., Roy, S.J., Burt, T., Johnson, T.L., and Johnson, R.L. (2001). “Pilot test of a surfactant-modified zeolite permeable barrier for groundwater remediation.” Physicochemical groundwater remediation, S.A. Burns, ed., Kluwer Academic/Plenum Publishers, New York, 161-185.

Bowman, R.S., Sullivan, E.J., and Li, Z. (2000). "Uptake of cations, anions, and nonpolar organic molecules by surfactant-modified clinoptilolite-rich tuff.” Natural zeolites for the third millennium, C. Colella and F.A. Mumpton, eds., De Frede Editore, Napoli, Italy, 287-297.

Boysen, D.B., Boysen, J.E., and Boysen, J.A. (2002) "Creative strategies for produced water disposal in the Rocky Mountain region." Proc., $9^{\text {th }}$ Annual International Petroleum Environmental Conference, Integrated Petroleum Environmental Consortium, Tulsa, OK. (CD-ROM).

Briggs, P.H. (1996) "Forty elements by inductively coupled-plasma atomic emission spectrometry." Analytical methods manual for the Mineral Resources Program Arbogast, B.F. ed., U.S. Geological Survey: U.S. Geological Survey Open-File Report 96-525, 77-94.

Code of Federal Regulations (CFR). (2002). Title 40, United States Government Printing Office, Washington, D.C. 
Crittenden, J.C., Reddy, P.S., Arora, H., Trynoski, J., Hand, D.W., Perram, D.L., and Summers, R.S. (1991) "Predicting GAC performance with rapid small-scale column tests.” Journal AWWA, 83(1) 77-87.

Fang, C.S., and Lin, J.H. (1988). “Air stripping for treatment of produced water.” J. Pet. Technol., 40(5), 619-624.

Hansen, B.R., and Davies, S.R.H. (1994). "Review of potential technologies for the removal of dissolved components from produced water.” Chem. Eng. Res. Des., 72(A2), 176-188.

Hayes, T., and Arthur, D. (2004). "Overview of emerging produced water treatment technologies.” Proc., $11^{\text {th }}$ Annual International Petroleum Environmental Conference, Integrated Petroleum Environmental Consortium, Albuquerque, NM.

Janks, J.S., and Cadena, F. (1991). "Identification and properties of modified zeolites for the removal of benzene, toluene, and xylene from aqueous solutions.” Proc., SPE Annual Technical Conference and Exhibition, Society of Petroleum Engineers, Dallas, TX, 153-167.

Kwon, S., Kinney, K.A., Katz, L.E., and Bowman, R.S. Abstracts, Geological Society of America Annual Meeting, Salt Lake City, UT; Geological Society of America: Boulder, 2005; Abstract 95375.

Laemmli, U.K. (1970) "Cleavage of structural proteins during the assembly of the head of bacteriophage T4.” Nature, 227, 680-685.

Li, Z., and Bowman, R.S. (1997). "Counterion effects on the sorption of cationic surfactant and chromate on natural clinoptilolite.” Env. Sci. Technol., 31(8), 24072412.

Li, Z., and Bowman, R.S. (1998). "Sorption of perchloroethylene by surfactant-modified zeolite as controlled by surfactant loading.” Env. Sci. Technol., 32(15), 22782282.

Li, Z., and Bowman, R.S. (2001). "Regeneration of surfactant-modified zeolite after saturation with chromate and perchloroethylene.” Water Research., 35(1), 322326.

Li, Z., Roy, S.J., Yiqiao, Z., and Bowman, R.S. (1998). "Long-term chemical and biological stability of surfactant-modifed zeolite.” Env. Sci. Techno., 32(17), 2628-2632. 
Li, Z., Willms, C., Roy, S., and Bowman, R.S. (2003). "Desorption of hexadecyltrimethylamonium from charged mineral surfaces.” Env. Geosciences, 10(1), 37-45.

Mackay, D., Shiu, W.Y., and Ma, K.C. (1992) Illustrated handbook of physical-chemical properties and environmental fate for organic chemicals, Lewis, Chelsea, MI.

Miller, J.A., Lawrence, A.W., Hickey, R.F., and Hayes, T.D. (1997) "Pilot plant treatment of natural gas produced waters to meet beneficial use discharge requirements." Proc. SPE/EPA Exploration and Production Environmental Conf., Society of Petroleum Engineers, Dallas, TX, 155-161.

Neel, D., and Bowman, R.S. (1992). "Sorption of organics to surface-altered zeolites". Proc. 36th Annual New Mexico Water Conf., November 1991, Las Cruces, NM. 57-61.

Pignatello, J. J., and Xing, B. (1996). "Mechanisms of slow sorption of organic chemicals to natural particles." Environ. Sci. Technol., 30(1), 1-11.

Ranck, J.M., Bowman, R.S., Weeber, J.L., Katz, L.E., and Sullivan, E.J. (2005). “BTEX removal from produced water using surfactant-modified zeolite.” J. Envir. Engrg., 131(3) 434-442.

Sambrook, J., Fritsch, E.F. and Maniatis, T. (1989) Molecular Cloning: a Laboratory Manual, 2nd edn. Cold Spring Harbor Laboratory Press, Cold Spring Harbor, NY.

Stephenson, M.T. (1992). "Components of produced water: a compilation of industry studies” J. Petroleum Technol., 44(5), 548-603

Toride, N., Leij, F.J., and van Genuchten, M.T. (1999). "The CXTFIT code for estimating transport parameters from laboratory or field tracer experiments, version 2.1.” Research Report No. 137, U.S. Salinity Laboratory, USDA, ARS, Riverside, CA.

United States Environmental Protection Agency (USEPA). (2000). "Profile of the oil and gas extraction industry.” EPA/310-R-99-006, USEPA, Washington, DC. 
Table 1. Compositions of the produced water used for regeneration, long-term laboratory experiments, and field tests.

\begin{tabular}{cccc} 
Produced water sample & $\begin{array}{c}\text { Wyoming (used for RRT } \\
\text { experiments) }\end{array}$ & $\begin{array}{c}\text { San Juan Basin, NM (used } \\
\text { for LST experiments; } \\
\text { collected July 2005, analyzed } \\
\text { May 2006) }\end{array}$ & $\begin{array}{c}\text { San Juan Basin, NM } \\
\text { (collected May 2005) }\end{array}$ \\
\hline Constituent & 15.8 & Concentration (mg/L) $^{3}$ & \\
\hline Benzene & 36.7 & 1.37 & 2.23 \\
Toluene & 1.4 & $\mathrm{ND}^{4}$ & 7.07 \\
Ethylbenzene & 6.4 & 0.21 & 0.38 \\
$\mathrm{p}-$ \& m-xylene & 3.4 & 2.58 (total xylenes) & 3.89 \\
o-xylene & 4400 & 7000 & 1.08 \\
$\mathrm{Cl}^{-}$ & 3120 & 2150 & 5360 \\
$\mathrm{HCO}_{3}^{-}$ & 57 & $<10$ & 672 \\
$\mathrm{~F}^{-}$ & 22 & 19 & 12 \\
$\mathrm{Br}^{-}$ & 13 & $<100$ & 408 \\
$\mathrm{SO}^{-}$ & 4100 & 4870 & 3700 \\
$\mathrm{Na}^{+}$ & 44 & 150 & 74.7 \\
$\mathrm{~K}^{+}$ & 30 & 20 & 77.8 \\
$\mathrm{Ca}^{2+}$ & 6.4 & 46 & 25.4 \\
$\mathrm{Mg}^{2+}$ & 11792 & 13180 & 10076 \\
Total Dissolved Solids & 1000 & $\mathrm{NA}$ & 318 \\
Total Organic Carbon & & &
\end{tabular}

\footnotetext{
${ }^{1}$ from Ranck et al., 2005

${ }^{2}$ BTEX analysis performed by General Engineering Laboratories, Charleston, SC. Inorganic analysis performed by New Mexico Bureau of Geology

${ }^{3}$ Unpublished data from Lily Chen, University of Texas at Austin

${ }^{4} \mathrm{ND}=$ not detected above reporting limit

${ }^{5} \mathrm{NA}=$ not analyzed
} 
Table 2. Octanol water coefficients $\left(K_{\text {ow }}\right)$ and solubility at $25^{\circ} \mathrm{C}$ for the BTEX compounds. Additionally, the calculated distribution coefficients $\left(K_{d}\right)$ and their standard deviations from the LST columns, the slopes of linear regressions fit to $K_{d}$ values as a function of the number of cycles, and the calculated p-values.

\begin{tabular}{cccccc} 
& Benzene & Toluene & Ethylbenzene & $\mathrm{p}$ - \& m-xylene & o-xylene \\
\cline { 2 - 5 } $\log \mathrm{K}_{\mathrm{ow}}{ }^{1}$ & 2.13 & 2.69 & 3.15 & $3.15,3.20$ & 3.15 \\
Solubility $^{1}(\mathrm{mg} / \mathrm{L}) 25^{\circ} \mathrm{C}$ & 1850 & 470 & 140 & 200,173 & 204
\end{tabular}

\begin{tabular}{|c|c|c|c|c|c|c|}
\hline Column & & & & & & \\
\hline \multirow{3}{*}{ LST1 } & $\mathrm{K}_{\mathrm{d}}(\mathrm{L} / \mathrm{kg})$ & 13.1 & 31.8 & 67.6 & 67.7 & 64.6 \\
\hline & Std. Dev. & 2.3 & 3.9 & 7.8 & 5.2 & 9.3 \\
\hline & Slope $\left(K_{d} /\right.$ cycle) & -0.05 & -0.03 & -0.27 & -0.09 & -0.36 \\
\hline \multirow{3}{*}{ LST2 } & $\mathrm{K}_{\mathrm{d}}(\mathrm{L} / \mathrm{kg})$ & 14.6 & 29.4 & 62.7 & 62.8 & 62.9 \\
\hline & Std. Dev. & 1.8 & 3.3 & 4.6 & 5.2 & 5.1 \\
\hline & Slope $\left(K_{d} /\right.$ cycle $)$ & -0.04 & -0.15 & -0.12 & -0.22 & -0.16 \\
\hline
\end{tabular}

Table 3. Fitted D and R values for tritium tracer tests conducted on columns LST1 and LST2 for the unused column, after the $25^{\text {th }}$ regeneration cycle, and after the $50^{\text {th }}$ regeneration cycle.

\begin{tabular}{llcc} 
& Column & $\mathrm{D}\left(\mathrm{cm}^{2} / \mathrm{min}\right)$ & $\mathrm{R}$ \\
\hline \multirow{4}{*}{ LST1 } & Virgin SMZ & 0.46 & 1.02 \\
& after 25 cycles & 0.73 & 1.10 \\
& after 50 cycles & 0.45 & 1.09 \\
LST2 & Virgin SMZ & 0.38 & 1.03 \\
& after 25 cycles & 0.40 & 1.14 \\
& after 50 cycles & 0.26 & 1.14
\end{tabular}




\section{FIGURE CAPTIONS}

Figure 1. BTCs for each BTEX compound from column RRT1.

Figure 2. $\quad$ BTCs for toluene and $p$ - and $m$-xylene on four different virgin-SMZ columns. The columns were saturated with BTEX under identical conditions but regenerated at airflow rates of $1.3 \mathrm{PV} / \mathrm{min}, 2.7 \mathrm{PV} / \mathrm{min}, 5$ $\mathrm{PV} / \mathrm{min}$, and $10 \mathrm{PV} / \mathrm{min}$, respectively.

Figure 3. $\quad p$ - and $m$-xylene regeneration curves as a function of (a) time and (b) pore volumes of air. Columns RRT1, RRT2, RRT3, and RRT4 used airflow rates of 1.3 PV/min, 2.7 PV/min, $5 \mathrm{PV} / \mathrm{min}$, and $10 \mathrm{PV} / \mathrm{min}$, respectively.

Figure 4. BTCs of tritiated water in column LST1 for (a) virgin SMZ and (b) after the $25^{\text {th }}$ regeneration cycle and (c) after the $50^{\text {th }}$ regeneration cycle. Solid lines represent fitted values using an equilibrium advection-dispersion equation.

Figure 5. BTCs for every fifth cycle on column LST1 for (a) benzene and (b) p-and m-xylene.

Figure 6. Observed and fitted BTCs of $p$ - and $m$-xylene for the first sorption cycle on column LST1. The solid line shows the fit using an equilibrium advection-dispersion equation while the dashed line shows the fit using a two-site chemical nonequilibrium advection-dispersion equation.

Figure 7. $\quad K_{d}$ 's and lines fit to the $K_{d}$ values for columns LST1 and LST2 for (a) benzene and (b) $p$ - and $m$-xylene.

Figure 8. Vapor-phase concentrations of toluene and $p$ - and $m$-xylene over 50 regeneration cycles on column LST1. 
Figure 9. Backscattered electron image of virgin SMZ.

Figure 10. Backscattered electron image of SMZ from column LST1 used for 50 sorption cycles.

Figure 11. Backscattered electron image of SMZ from column LST2 used for 50 sorption cycles. 


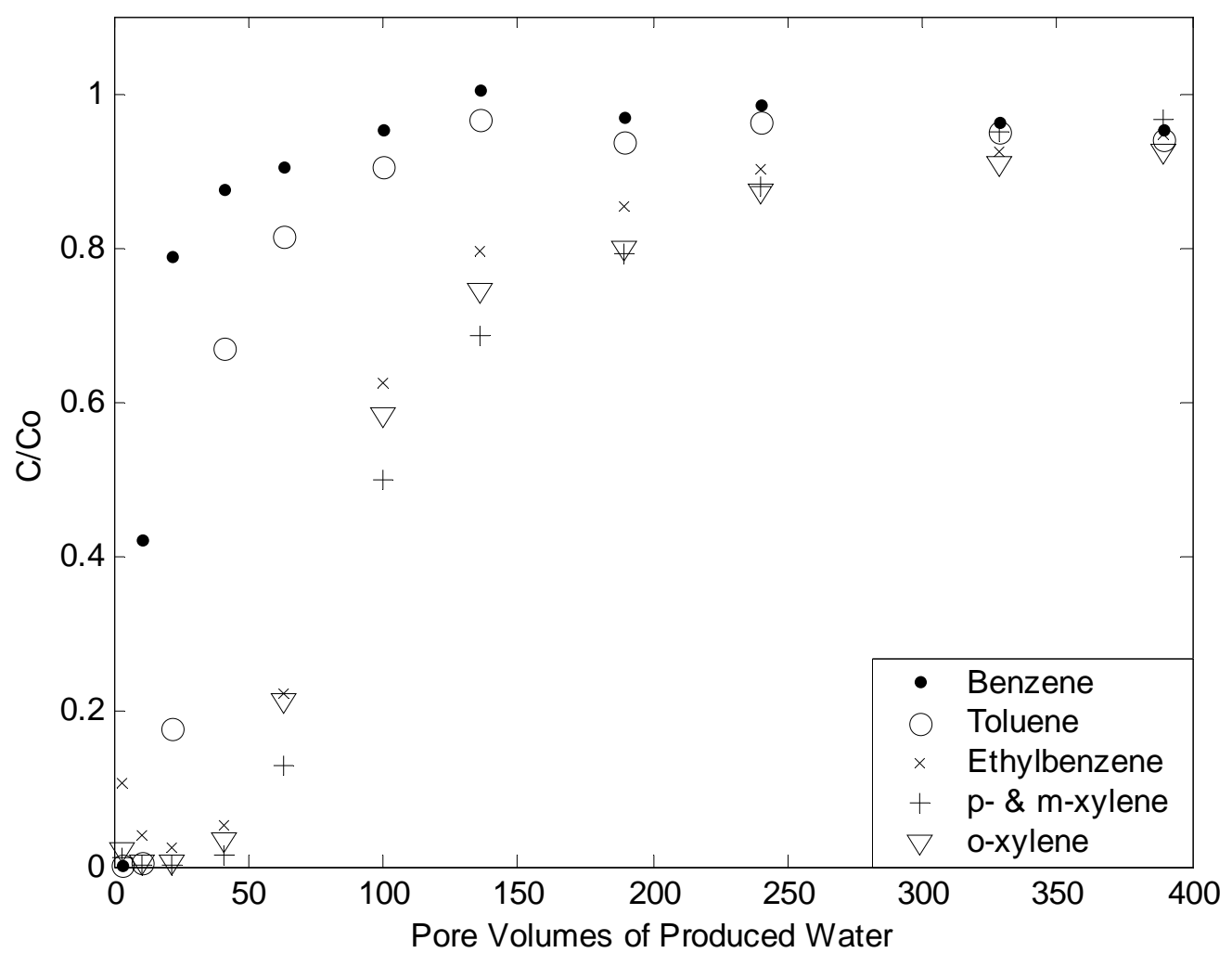

Figure 1. BTCs for each BTEX compound from column RRT1. 


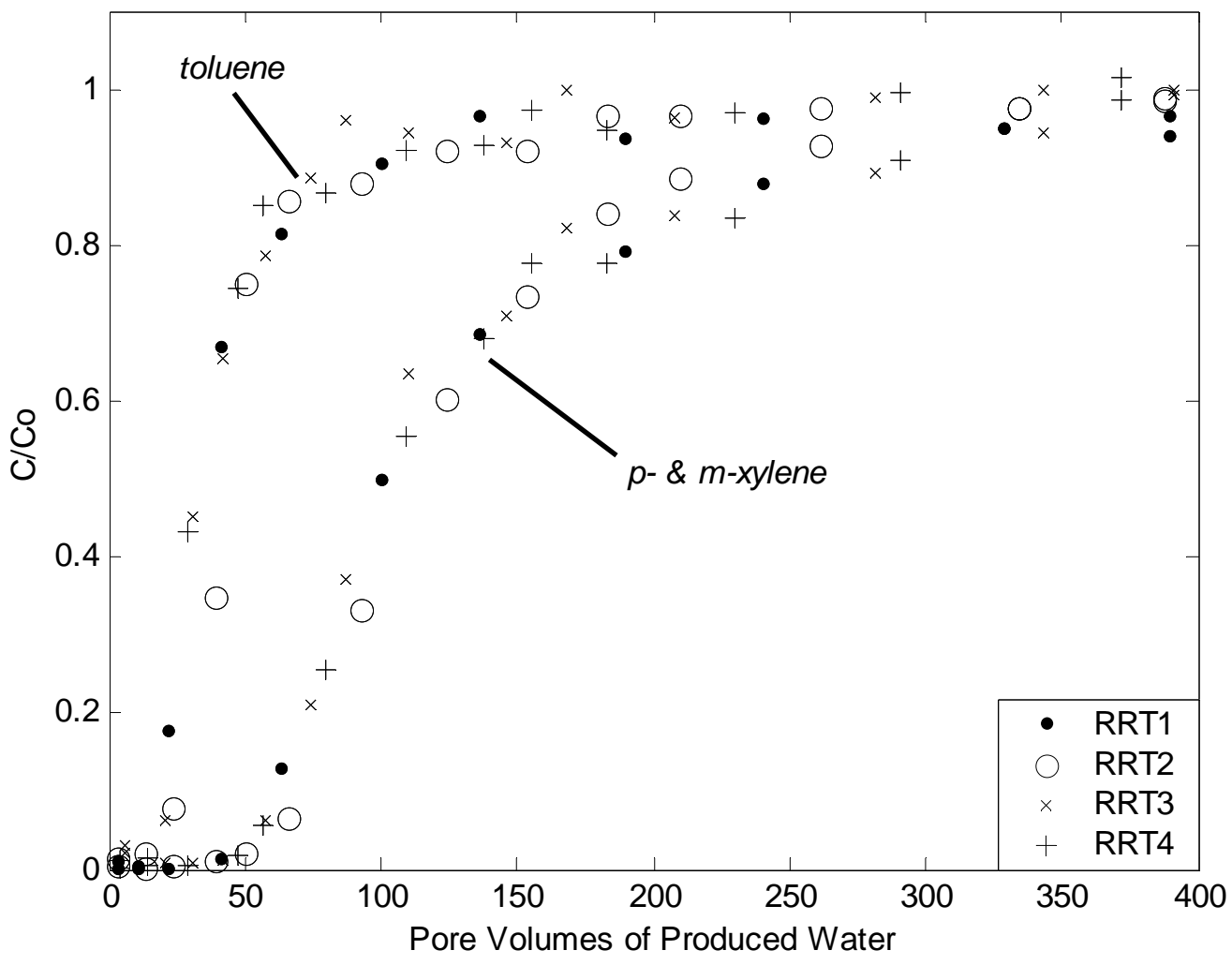

Figure 2. BTCs for toluene and $p$ - and $m$-xylene on four different virgin-SMZ columns. The columns were saturated with BTEX under identical conditions but regenerated at airflow rates of $1.3 \mathrm{PV} / \mathrm{min}$, 2.7 PV/min, $5 \mathrm{PV} / \mathrm{min}$, and $10 \mathrm{PV} / \mathrm{min}$, respectively. 

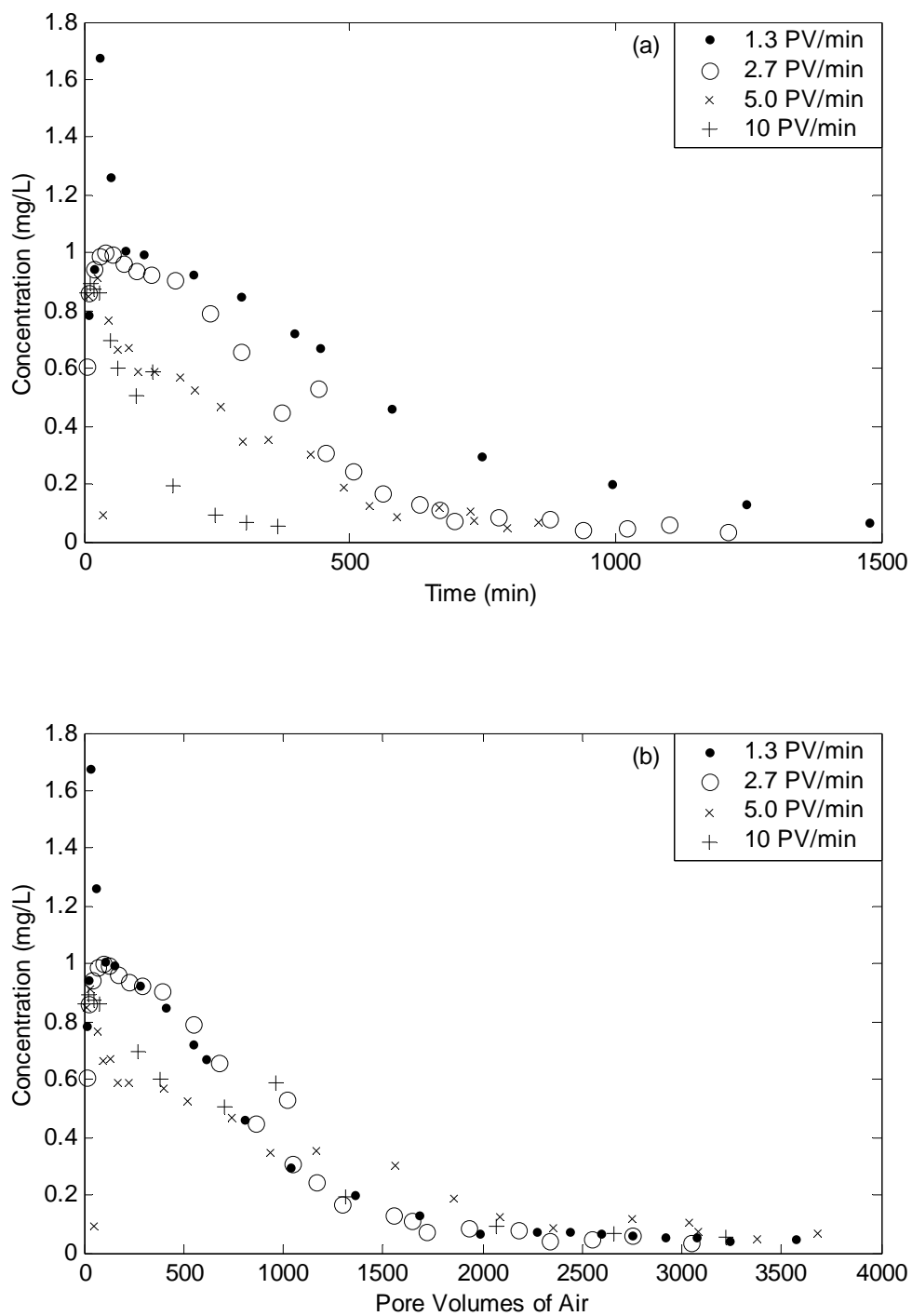

Figure 3. $p$ - and $m$-xylene regeneration curves as a function of (a) time and (b) pore volumes of air. Columns RRT1, RRT2, RRT3, and RRT4 used airflow rates of $1.3 \mathrm{PV} / \mathrm{min}, 2.7 \mathrm{PV} / \mathrm{min}, 5 \mathrm{PV} / \mathrm{min}$, and $10 \mathrm{PV} / \mathrm{min}$, respectively. 

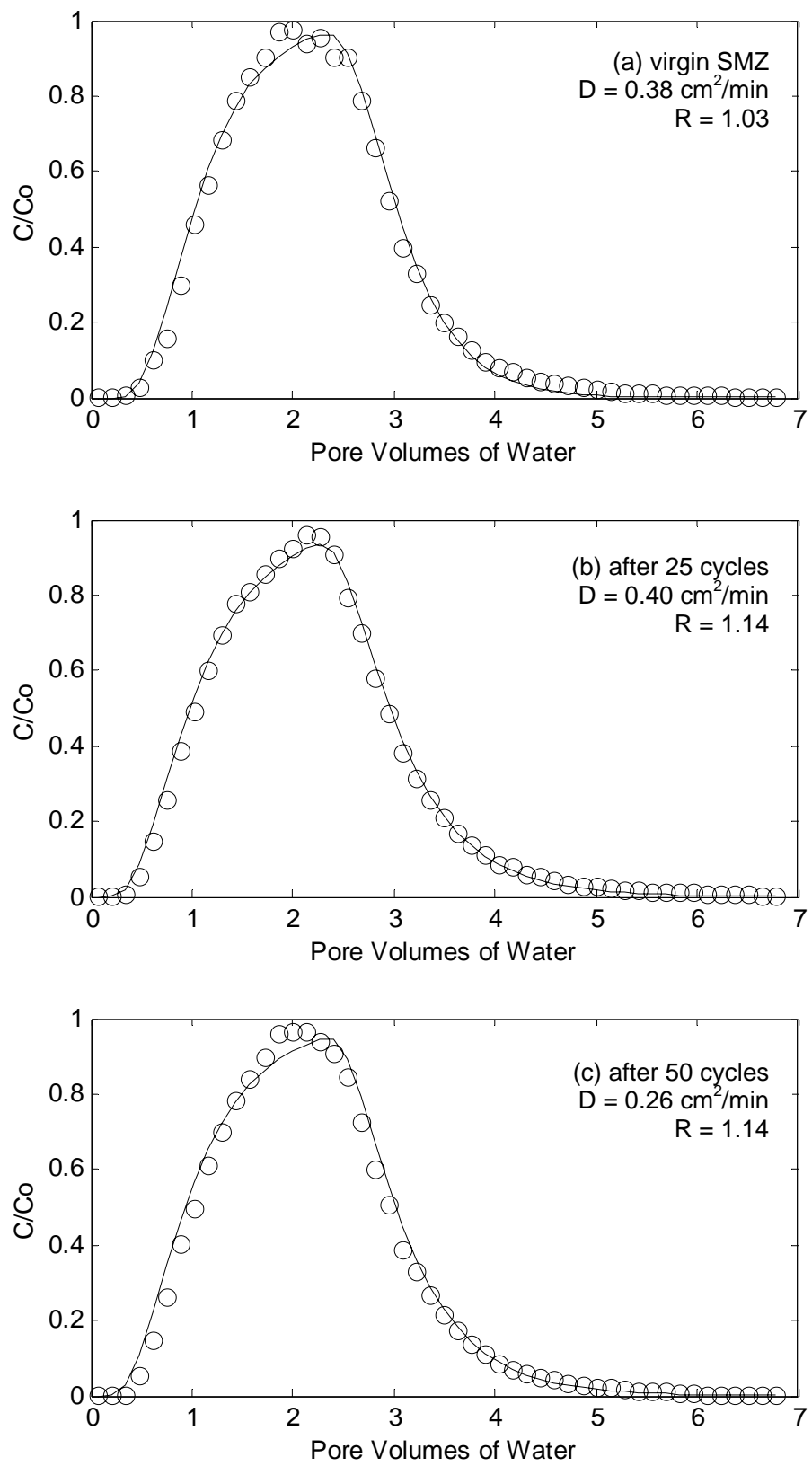

Figure 4. BTCs of tritiated water in column LST2 for (a) virgin SMZ and (b) after the $25^{\text {th }}$ regeneration cycle and (c) after the $50^{\text {th }}$ regeneration cycle. Solid lines represent fitted values using an equilibrium advection-dispersion equation 

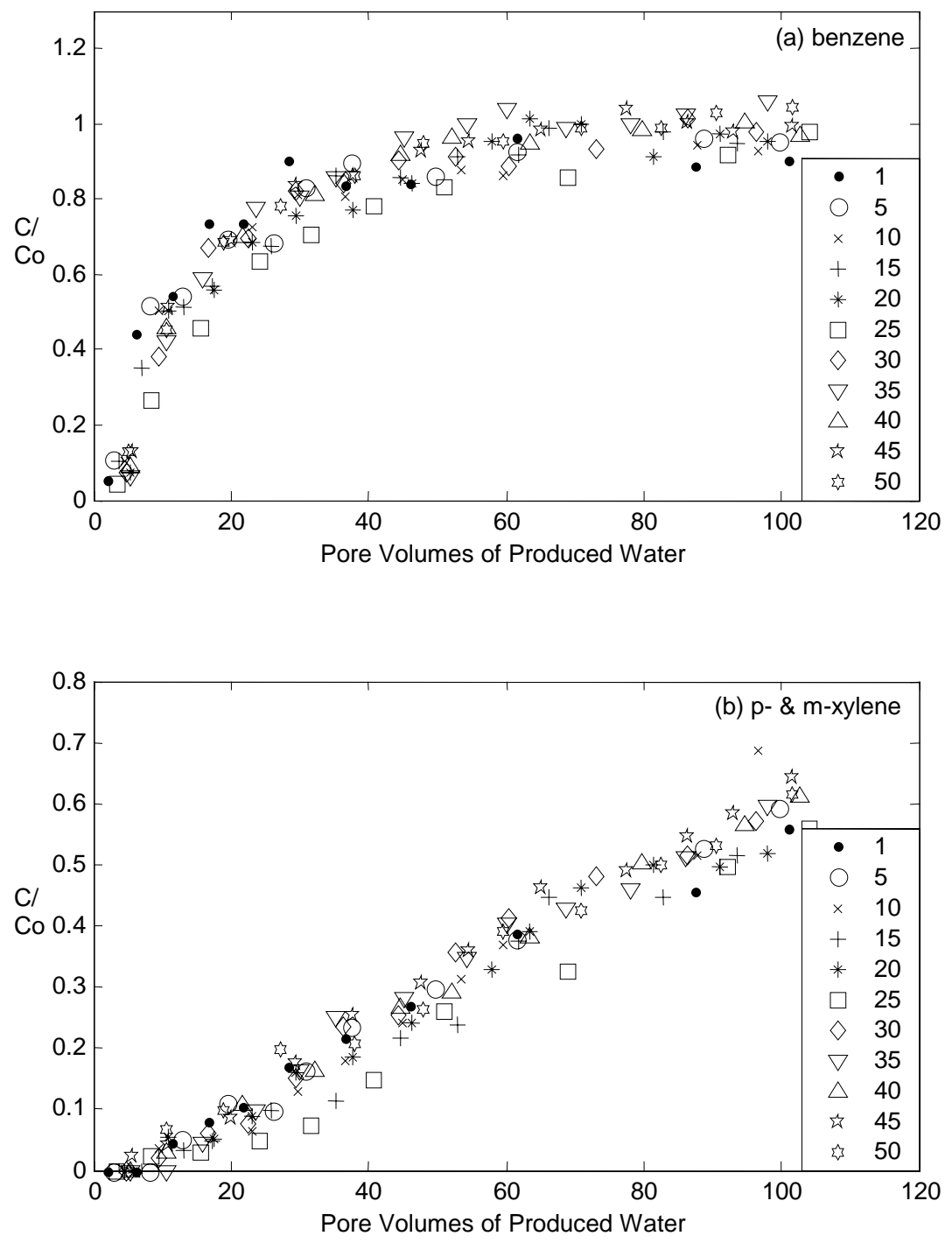

Figure 5. BTCs for every fifth sorption cycle on column LST1 for (a) benzene and (b) $p$ - and $m$ xylene 


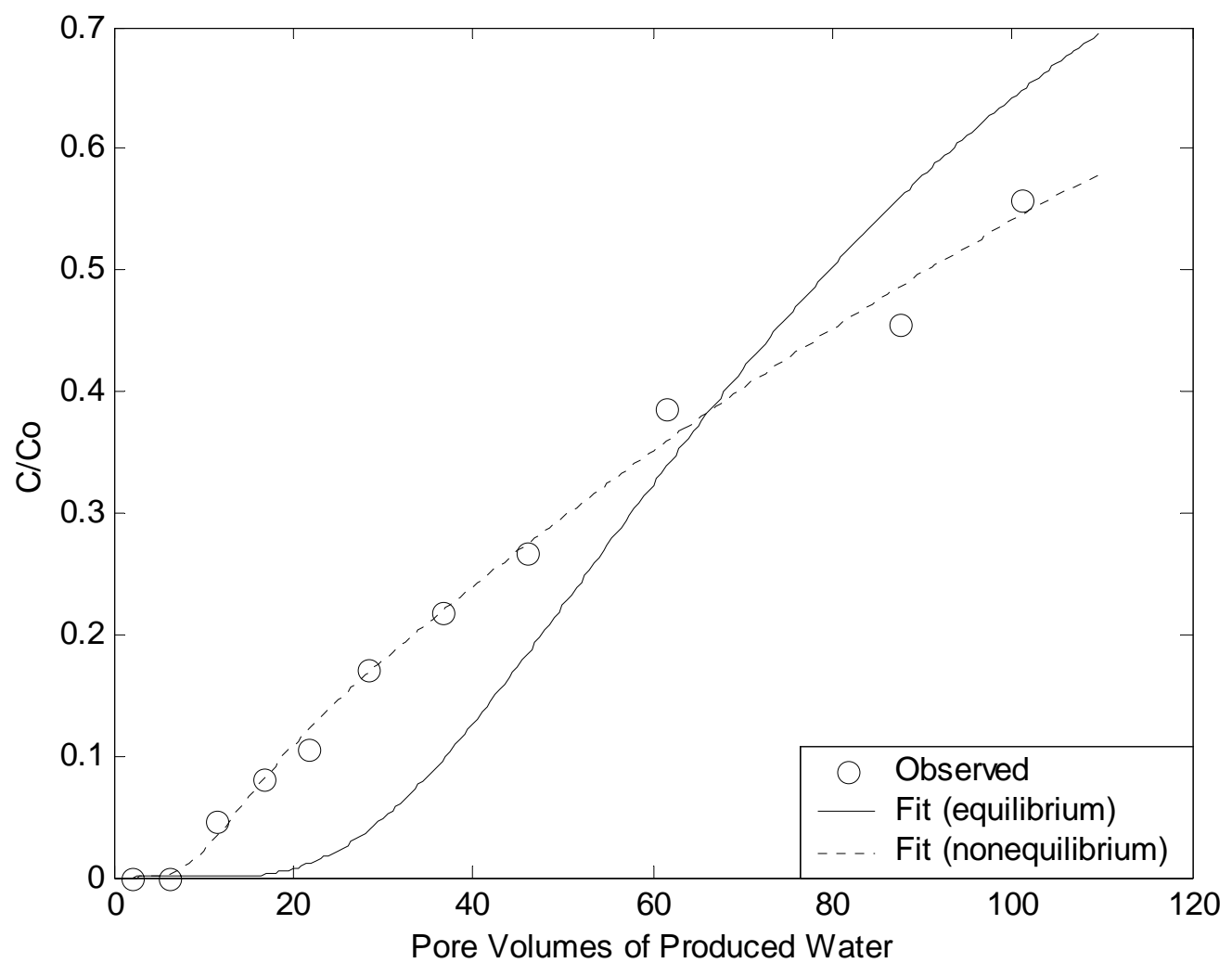

Figure 6. Observed and fitted BTCs of $p$ - and $m$-xylene for the first sorption cycle on column LST1. The solid line shows the fit using an equilibrium advection-dispersion equation while the dashed line shows the fit using a two-site chemical nonequilibrium advection-dispersion equation. 

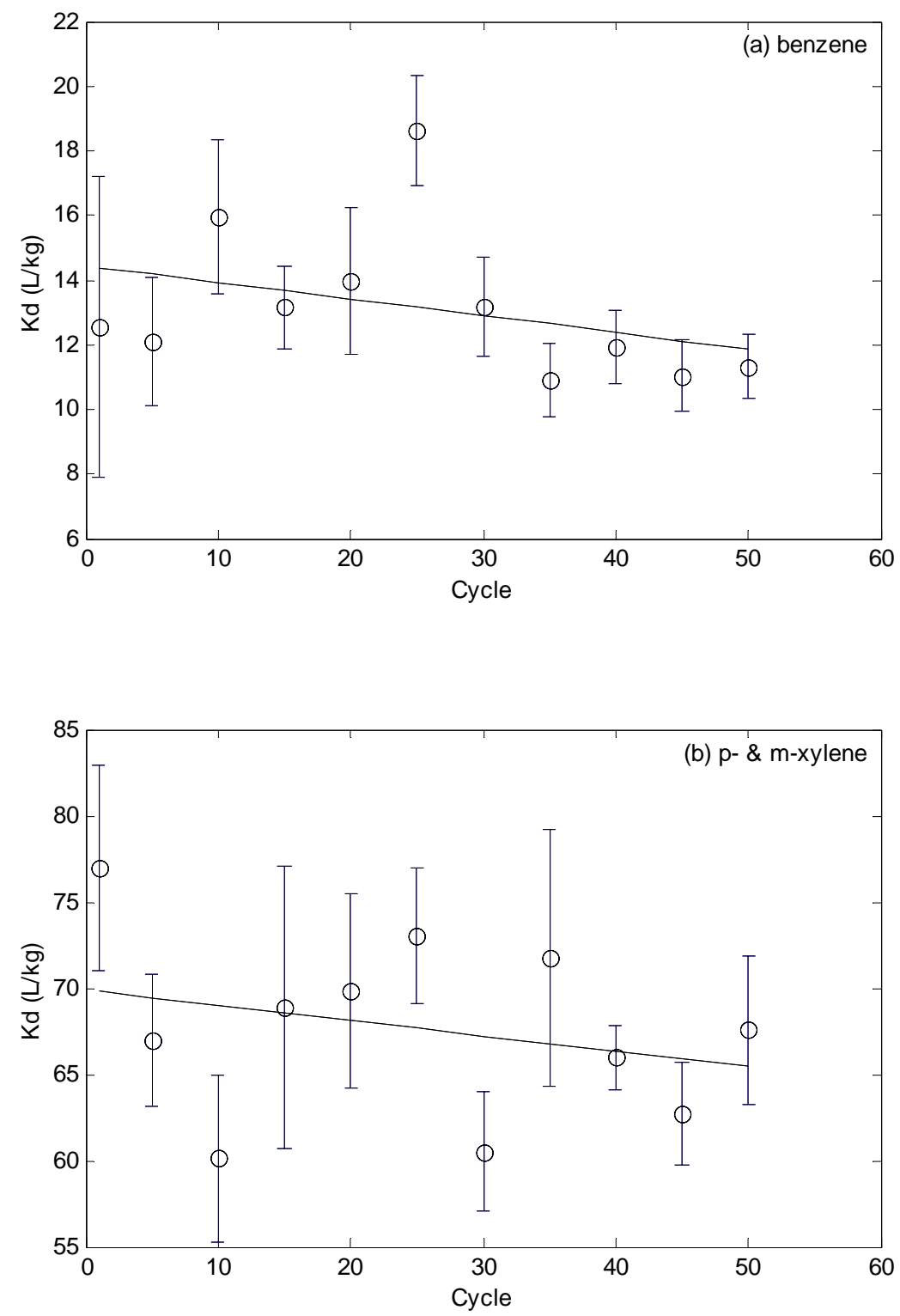

Figure 7. $K_{d}$ 's and lines fit to the $K_{d}$ values for (a) benzene and (b) $p$ - \& $m$-xylene from column LST1. Error bars represent the $\mathbf{9 5 \%}$ confidence interval from the curve-fit process using CXTFIT. 


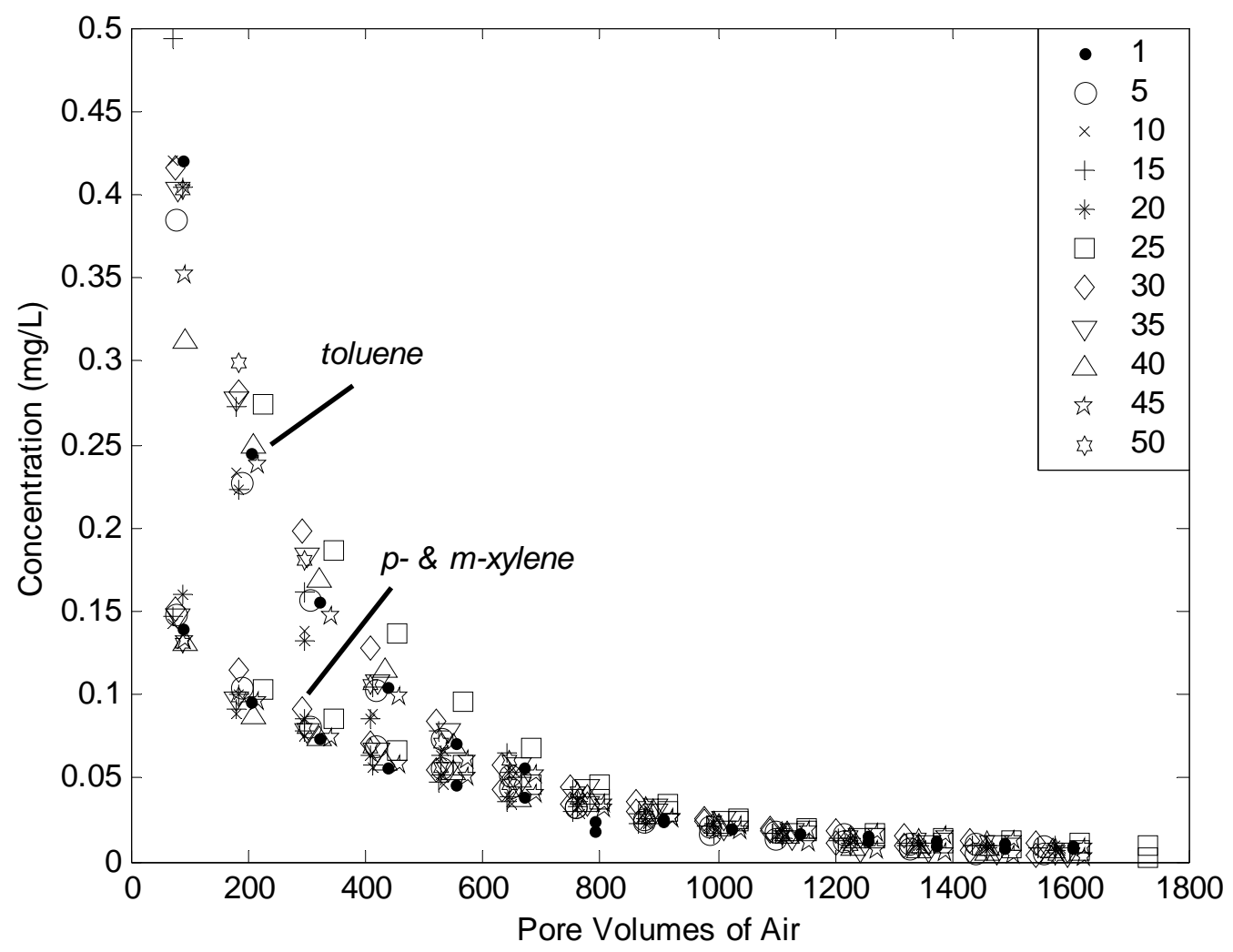

Figure 8. Vapor-phase concentrations of toluene and $p$ - and $\boldsymbol{m}$-xylene over 50 regeneration cycles on column LST1. 


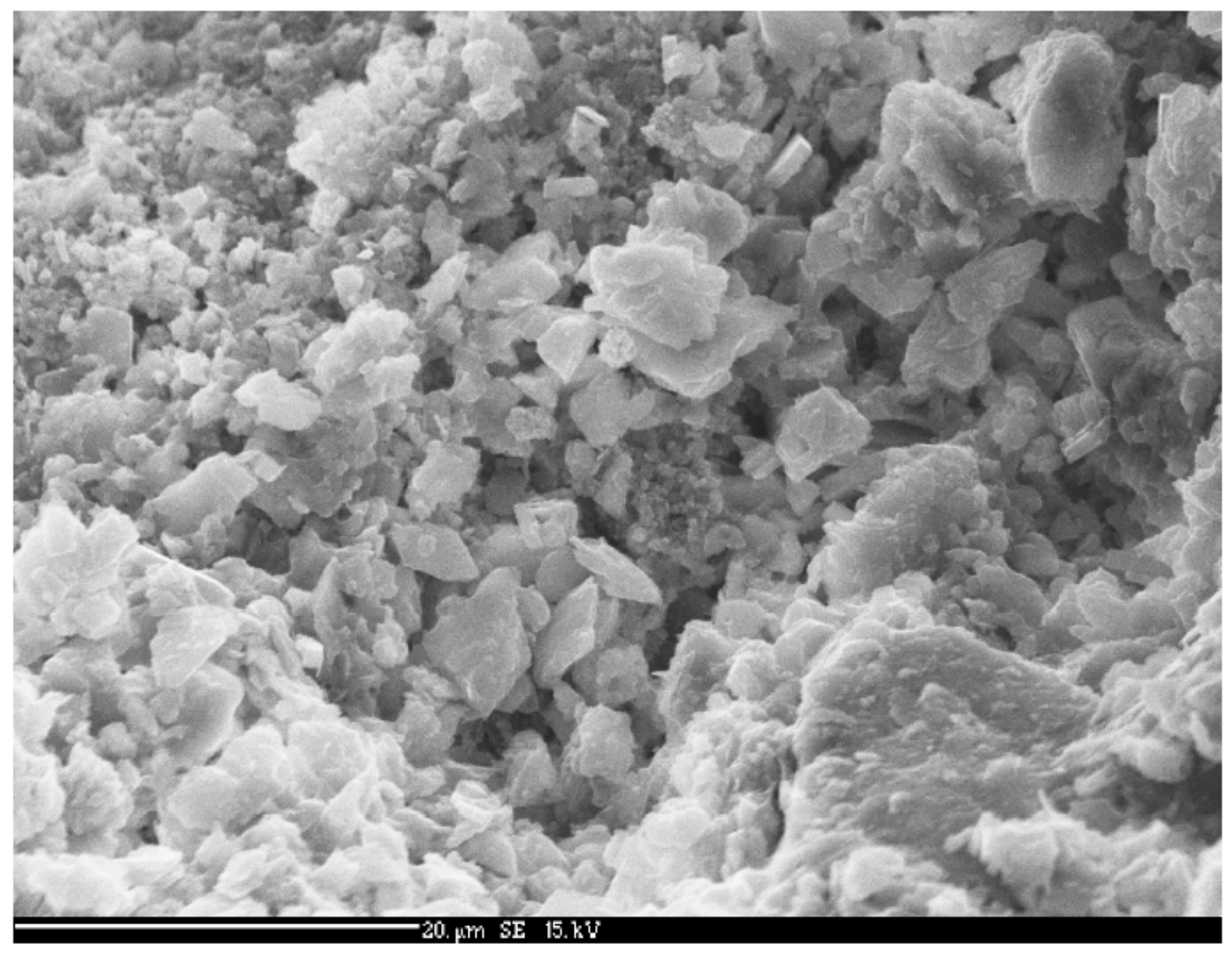

Figure 9. Backscattered electron image of virgin SMZ. 


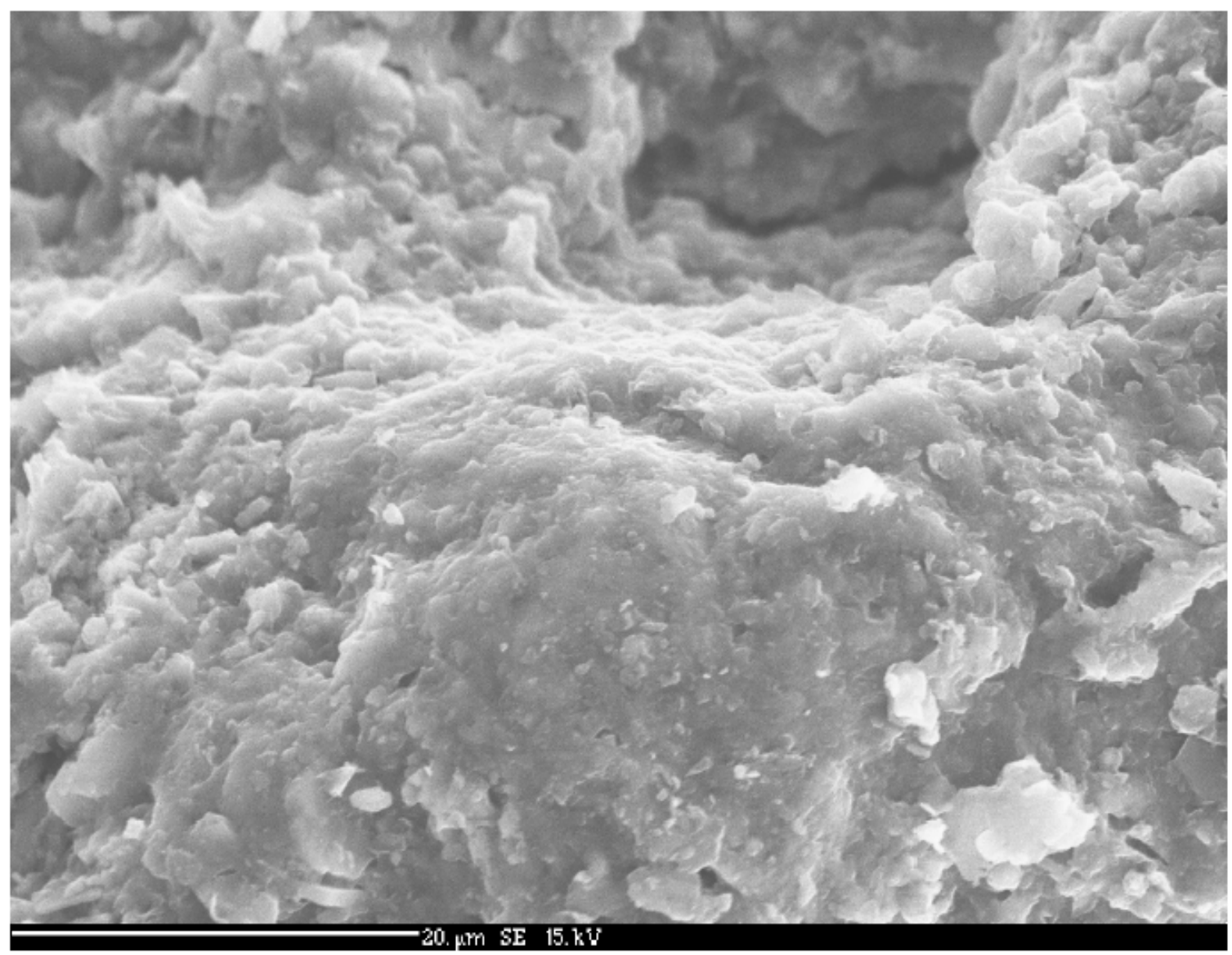

Figure 10. Backscattered electron image of SMZ from column LST1 used for 50 sorption cycles. 


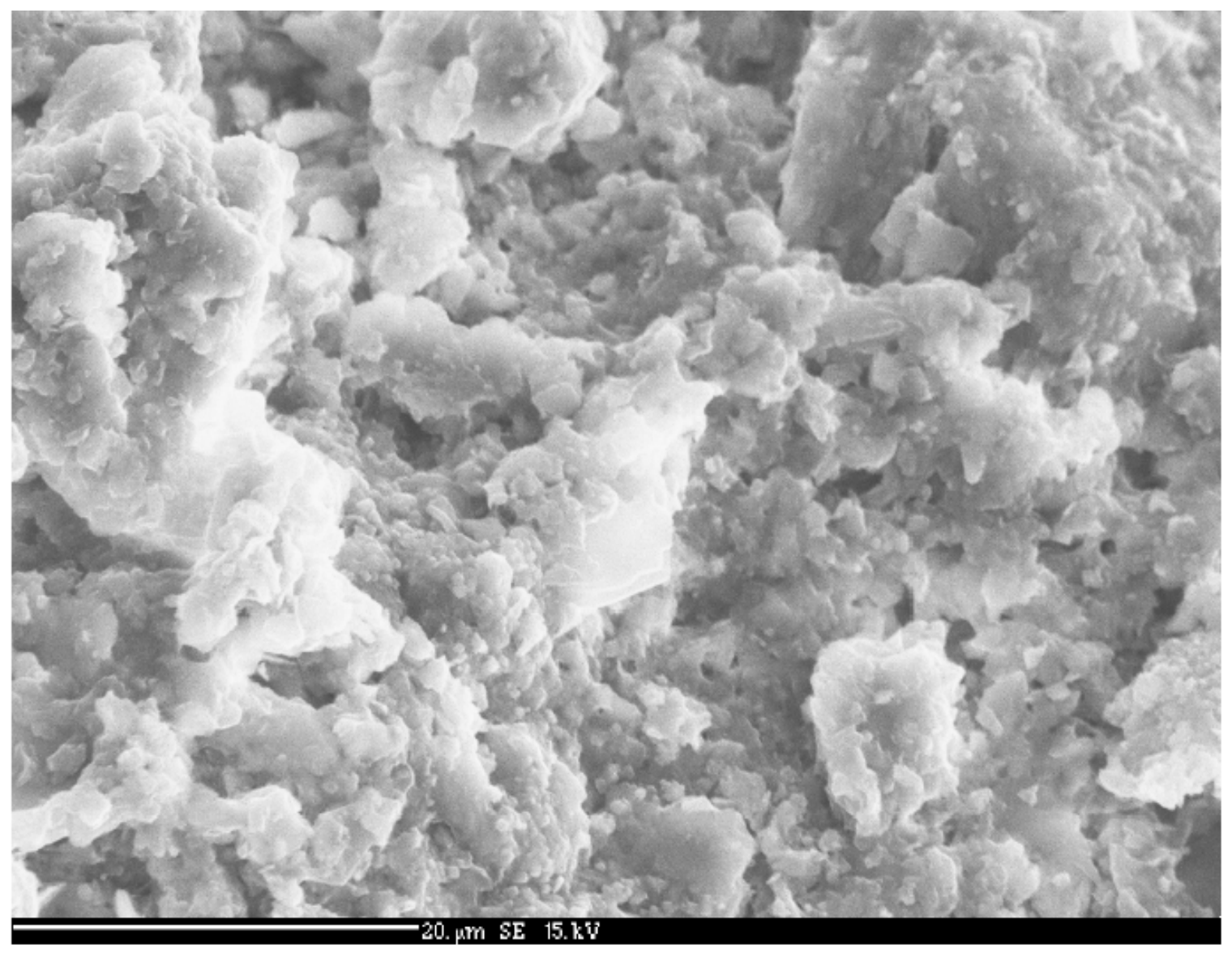

Figure 11. Backscattered electron image of SMZ from column LST2 used for 50 sorption cycles. 


\section{APPENDIX A. REGENERATION AIRFLOW RATE SORPTION AND REGENERATION DATA}

This appendix contains the breakthrough curves (BTCs) and data for the regeneration rate test (RRT) experiments. Columns RRT1, RRT2, RRT3, RRT4 were all sorbed and regenerated as described in the manuscript. The only difference in the column runs was the airflow rate used during regeneration. Tables A-1 through A-4 contain the BTC data for columns RRT1, RRT2, RRT3, and RRT4, respectively. Tables A-5 through A-8 contain the vapor phase BTEX concentrations and cumulative mass removed for the regeneration of columns RRT1, RRT2, RRT3, and RRT4, respectively. Table A-9 shows the cumulative mass of each BTEX compound sorbed and removed on the RRT columns. Figures A-1 through A-5 show BTEX sorption on virgin SMZ. Figures A-6 through A-10 show BTEX regeneration for each column as a function of both time and PV of air. 
Table A- 1. Data for BTEX BTCs from column RRT1

\begin{tabular}{ccccccc} 
& & \multicolumn{5}{c}{ C/Co } \\
\cline { 3 - 7 } Sample & Polumes & Benzene & Toluene & Ethylbenzene & p- \& m-xylene & o-xylene \\
\hline 1 & 3.1 & 0.001 & 0.002 & 0.109 & 0.010 & 0.021 \\
2 & 10.6 & 0.423 & 0.003 & 0.039 & 0.003 & 0.006 \\
3 & 21.7 & 0.788 & 0.178 & 0.023 & 0.002 & 0.004 \\
4 & 41.1 & 0.877 & 0.671 & 0.054 & 0.016 & 0.034 \\
5 & 62.8 & 0.905 & 0.814 & 0.223 & 0.131 & 0.213 \\
6 & 100.4 & 0.953 & 0.906 & 0.627 & 0.499 & 0.584 \\
7 & 135.9 & 1.005 & 0.967 & 0.795 & 0.688 & 0.746 \\
8 & 189.5 & 0.971 & 0.937 & 0.854 & 0.794 & 0.800 \\
9 & 240.3 & 0.987 & 0.964 & 0.902 & 0.879 & 0.873 \\
10 & 328.3 & 0.964 & 0.950 & 0.926 & 0.950 & 0.908 \\
11 & 389.6 & 0.952 & 0.942 & 0.947 & 0.967 & 0.926
\end{tabular}

Table A- 2. Data for BTEX BTCs for column RRT2

\begin{tabular}{ccccccc} 
& & \multicolumn{5}{c}{ C/Co } \\
\cline { 3 - 7 } Sample & $\begin{array}{c}\text { Pore } \\
\text { Volumes }\end{array}$ & Benzene & Toluene & Ethylbenzene & p- \& m-xylene & o-xylene \\
\hline 1 & 3.4 & 0.004 & 0.015 & 0.049 & 0.004 & 0.009 \\
2 & 13.1 & 0.709 & 0.019 & 0.028 & 0.003 & 0.006 \\
3 & 23.8 & 0.886 & 0.080 & 0.036 & 0.006 & 0.015 \\
4 & 38.7 & 0.895 & 0.350 & 0.041 & 0.011 & 0.025 \\
5 & 49.9 & 0.960 & 0.752 & 0.062 & 0.020 & 0.047 \\
6 & 65.6 & 0.931 & 0.856 & 0.130 & 0.066 & 0.098 \\
7 & 92.8 & 0.975 & 0.879 & 0.459 & 0.332 & 0.410 \\
8 & 123.6 & 0.966 & 0.922 & 0.719 & 0.602 & 0.692 \\
9 & 153.2 & 1.011 & 0.923 & 0.838 & 0.735 & 0.795 \\
10 & 182.9 & 0.987 & 0.966 & 0.892 & 0.841 & 0.856 \\
11 & 209.6 & 1.001 & 0.967 & 0.899 & 0.888 & 0.903 \\
12 & 261.2 & 1.017 & 0.977 & 0.934 & 0.928 & 0.924 \\
13 & 333.9 & 1.009 & 0.977 & 0.973 & 0.978 & 0.963 \\
14 & 387.2 & 0.987 & 0.991 & 0.976 & 0.987 & 0.988
\end{tabular}


Table A- 3. Data for BTEX BTCs for column RRT3

\begin{tabular}{ccccccc} 
& & \multicolumn{5}{c}{ C/Co } \\
\cline { 3 - 7 } Sample & $\begin{array}{c}\text { Pore } \\
\text { Volumes }\end{array}$ & Benzene & Toluene & Ethylbenzene & p- \& m-xylene & o-xylene \\
\hline 1 & 5.9 & 0.028 & 0.022 & 0.118 & 0.031 & 0.041 \\
2 & 20.6 & 0.751 & 0.064 & 0.043 & 0.010 & 0.013 \\
3 & 31.3 & 0.897 & 0.451 & 0.032 & 0.007 & 0.011 \\
4 & 41.7 & 0.891 & 0.654 & 0.038 & 0.010 & 0.022 \\
5 & 57.9 & 0.887 & 0.787 & 0.124 & 0.062 & 0.121 \\
6 & 74.1 & 0.946 & 0.885 & 0.319 & 0.212 & 0.316 \\
7 & 87.1 & 1.008 & 0.961 & 0.482 & 0.372 & 0.483 \\
8 & 110.4 & 0.994 & 0.943 & 0.706 & 0.634 & 0.693 \\
9 & 146.0 & 0.965 & 0.932 & 0.754 & 0.710 & 0.748 \\
10 & 168.0 & 1.058 & 1.000 & 0.852 & 0.823 & 0.852 \\
11 & 207.7 & 1.008 & 0.963 & 0.862 & 0.836 & 0.845 \\
12 & 281.1 & 1.005 & 0.989 & 0.902 & 0.892 & 0.901 \\
13 & 343.6 & 1.013 & 1.000 & 0.913 & 0.942 & 0.933 \\
14 & 391.4 & 1.004 & 0.994 & 0.972 & 0.998 & 0.947
\end{tabular}

Table A- 4. Data for BTEX BTCs for column RRT4

\begin{tabular}{ccccccc} 
& & \multicolumn{5}{c}{ C/Co } \\
\cline { 3 - 7 } Sample & $\begin{array}{c}\text { Pore } \\
\text { Volumes }\end{array}$ & Benzene & Toluene & Ethylbenzene & p- \& m-xylene & o-xylene \\
\hline 1 & 4.5 & 0.004 & 0.002 & 0.094 & 0.012 & 0.022 \\
2 & 14.7 & 0.709 & 0.013 & 0.036 & 0.005 & 0.009 \\
3 & 29.0 & 0.886 & 0.432 & 0.000 & 0.005 & 0.000 \\
4 & 47.4 & 0.895 & 0.745 & 0.065 & 0.018 & 0.045 \\
5 & 56.6 & 0.960 & 0.850 & 0.136 & 0.056 & 0.121 \\
6 & 80.0 & 0.931 & 0.866 & 0.389 & 0.257 & 0.375 \\
7 & 108.8 & 0.975 & 0.923 & 0.664 & 0.555 & 0.647 \\
8 & 137.7 & 0.966 & 0.928 & 0.775 & 0.679 & 0.736 \\
9 & 155.7 & 1.011 & 0.972 & 0.851 & 0.777 & 0.814 \\
10 & 182.7 & 0.987 & 0.946 & 0.844 & 0.777 & 0.816 \\
11 & 230.0 & 1.001 & 0.969 & 0.891 & 0.835 & 0.844 \\
12 & 290.4 & 1.017 & 0.995 & 0.926 & 0.909 & 0.932 \\
13 & 372.1 & 1.009 & 1.013 & 1.007 & 0.986 & 0.973
\end{tabular}


Appendix Table A-1. Regeneration data for column RRT1. Airflow rate equals 1.3 PV/min.

\begin{tabular}{|c|c|c|c|c|c|c|c|c|c|c|c|}
\hline \multirow[b]{2}{*}{ Sample } & \multirow[b]{2}{*}{ PV } & \multicolumn{5}{|c|}{ Concentration (mg/L) } & \multicolumn{5}{|c|}{ Mass Removed (mg) } \\
\hline & & Benzene & Toluene & Ethylbenzene & p- \& m-xylene & o-xylene & Benzene & Toluene & Ethylbenzene & p- \& m-xylene & o-xylene \\
\hline 1 & 9.3 & 2.102 & 3.863 & 0.071 & 0.784 & 0.250 & 0.057 & 0.105 & 0.002 & 0.021 & 0.007 \\
\hline 2 & 22.6 & 1.837 & 4.263 & 0.084 & 0.946 & 0.314 & 0.134 & 0.264 & 0.005 & 0.055 & 0.018 \\
\hline 3 & 36.3 & 2.636 & 6.634 & 0.087 & 1.676 & 0.605 & 0.224 & 0.482 & 0.008 & 0.108 & 0.036 \\
\hline 4 & 63.5 & 1.610 & 5.119 & 0.118 & 1.261 & 0.434 & 0.393 & 0.951 & 0.017 & 0.225 & 0.078 \\
\hline 5 & 102.5 & 0.978 & 3.993 & 0.090 & 1.010 & 0.342 & 0.541 & 1.471 & 0.028 & 0.354 & 0.122 \\
\hline 6 & 149.1 & 0.649 & 3.752 & 0.085 & 0.998 & 0.337 & 0.652 & 2.000 & 0.040 & 0.492 & 0.168 \\
\hline 8 & 406.7 & 0.116 & 1.478 & 0.071 & 0.849 & 0.305 & 0.880 & 3.981 & 0.100 & 1.190 & 0.410 \\
\hline 9 & 547.9 & 0.072 & 0.790 & 0.057 & 0.724 & 0.279 & 0.918 & 4.451 & 0.126 & 1.516 & 0.531 \\
\hline 10 & 614.8 & 0.053 & 0.608 & 0.049 & 0.672 & 0.273 & 0.931 & 4.588 & 0.137 & 1.653 & 0.585 \\
\hline 11 & 806.6 & 0.040 & 0.383 & 0.034 & 0.459 & 0.227 & 0.957 & 4.866 & 0.160 & 1.970 & 0.726 \\
\hline 12 & 1034.3 & 0.032 & 0.287 & 0.027 & 0.299 & 0.176 & 0.981 & 5.090 & 0.180 & 2.223 & 0.860 \\
\hline 13 & 1357.3 & 0.050 & 0.210 & 0.062 & 0.202 & 0.143 & 1.010 & 5.267 & 0.212 & 2.402 & 0.974 \\
\hline 14 & 1684.4 & 0.026 & 0.145 & 0.040 & 0.133 & 0.088 & 1.047 & 5.437 & 0.261 & 2.563 & 1.085 \\
\hline 16 & 2275.7 & 0.012 & 0.080 & 0.021 & 0.072 & 0.044 & 1.070 & 5.591 & 0.299 & 2.712 & 1.178 \\
\hline 17 & 2434.3 & 0.011 & 0.079 & 0.023 & 0.072 & 0.043 & 1.075 & 5.628 & 0.309 & 2.746 & 1.198 \\
\hline 18 & 2592.3 & 0.007 & 0.061 & 0.021 & 0.066 & 0.040 & 1.080 & 5.660 & 0.319 & 2.777 & 1.217 \\
\hline 19 & 2753.4 & 0.005 & 0.050 & 0.019 & 0.059 & 0.035 & 1.082 & 5.686 & 0.329 & 2.807 & 1.235 \\
\hline 20 & 2918.9 & 0.005 & 0.051 & 0.018 & 0.056 & 0.033 & 1.085 & 5.711 & 0.338 & 2.835 & 1.251 \\
\hline 21 & 3078.3 & 0.004 & 0.042 & 0.016 & 0.051 & 0.030 & 1.087 & 5.733 & 0.346 & 2.860 & 1.266 \\
\hline 22 & 3241.8 & 0.003 & 0.035 & 0.014 & 0.044 & 0.026 & 1.089 & 5.751 & 0.353 & 2.882 & 1.279 \\
\hline 23 & 3575.0 & 0.004 & 0.039 & 0.016 & 0.045 & 0.026 & 1.093 & 5.787 & 0.368 & 2.926 & 1.305 \\
\hline
\end{tabular}


Appendix Table A-2. Regeneration data for column RRT2. Airflow rate equals 2.6 PV/min.

\begin{tabular}{|c|c|c|c|c|c|c|c|c|c|c|c|}
\hline \multirow[b]{2}{*}{ Sample } & \multirow[b]{2}{*}{ PV } & \multicolumn{5}{|c|}{ Concentration (mg/L) } & \multicolumn{5}{|c|}{ Mass Removed (mg) } \\
\hline & & Benzene & Toluene & Ethylbenzene & p- \& m-xylene & o-xylene & Benzene & Toluene & Ethylbenzene & p- \& m-xylene & o-xylene \\
\hline 1 & 9.43 & 1.315 & 3.074 & 0.092 & 0.606 & 0.201 & 0.040 & 0.095 & 0.003 & 0.019 & 0.006 \\
\hline 2 & 22.36 & 1.652 & 4.450 & 0.113 & 0.862 & 0.275 & 0.103 & 0.253 & 0.007 & 0.050 & 0.016 \\
\hline 3 & 42.17 & 1.507 & 4.744 & 0.120 & 0.945 & 0.307 & 0.205 & 0.550 & 0.015 & 0.108 & 0.035 \\
\hline 4 & 69.80 & 1.268 & 4.837 & 0.125 & 0.991 & 0.323 & 0.330 & 0.981 & 0.026 & 0.195 & 0.063 \\
\hline 5 & 94.73 & 1.059 & 4.742 & 0.123 & 0.999 & 0.330 & 0.424 & 1.371 & 0.036 & 0.276 & 0.090 \\
\hline 6 & 127.65 & 0.785 & 4.518 & 0.124 & 0.992 & 0.326 & 0.523 & 1.868 & 0.049 & 0.383 & 0.125 \\
\hline 8 & 228.61 & 0.238 & 3.712 & 0.117 & 0.941 & 0.315 & 0.675 & 3.213 & 0.089 & 0.700 & 0.231 \\
\hline 9 & 293.77 & 0.125 & 3.074 & 0.113 & 0.925 & 0.314 & 0.714 & 3.934 & 0.113 & 0.899 & 0.298 \\
\hline 10 & 392.92 & 0.065 & 1.915 & 0.114 & 0.908 & 0.323 & 0.745 & 4.740 & 0.149 & 1.195 & 0.401 \\
\hline 11 & 544.98 & 0.037 & 0.729 & 0.099 & 0.795 & 0.301 & 0.770 & 5.396 & 0.202 & 1.617 & 0.555 \\
\hline 12 & 678.96 & 0.026 & 0.396 & 0.077 & 0.660 & 0.279 & 0.784 & 5.641 & 0.241 & 1.935 & 0.682 \\
\hline 13 & 858.88 & 0.020 & 0.025 & 0.053 & 0.451 & 0.242 & 0.797 & 5.765 & 0.279 & 2.260 & 0.835 \\
\hline 14 & 1015.14 & 0.033 & 0.392 & 0.061 & 0.529 & 0.227 & 0.810 & 5.871 & 0.308 & 2.510 & 0.954 \\
\hline 16 & 1169.21 & 0.030 & 0.187 & 0.076 & 0.244 & 0.183 & 0.826 & 6.001 & 0.343 & 2.664 & 1.056 \\
\hline 17 & 1298.99 & 0.021 & 0.131 & 0.059 & 0.171 & 0.134 & 0.837 & 6.068 & 0.372 & 2.752 & 1.123 \\
\hline 18 & 1554.45 & 0.019 & 0.105 & 0.053 & 0.128 & 0.097 & 0.848 & 6.133 & 0.403 & 2.835 & 1.186 \\
\hline 19 & 1649.34 & 0.014 & 0.087 & 0.046 & 0.108 & 0.080 & 0.853 & 6.161 & 0.417 & 2.869 & 1.212 \\
\hline 20 & 1718.39 & 0.008 & 0.055 & 0.027 & 0.074 & 0.056 & 0.855 & 6.177 & 0.425 & 2.889 & 1.227 \\
\hline 21 & 1928.46 & 0.013 & 0.081 & 0.045 & 0.085 & 0.062 & 0.862 & 6.220 & 0.448 & 2.940 & 1.265 \\
\hline 22 & 2177.45 & 0.012 & 0.073 & 0.039 & 0.076 & 0.050 & 0.871 & 6.279 & 0.480 & 3.002 & 1.308 \\
\hline 23 & 2332.60 & 0.008 & 0.036 & 0.018 & 0.041 & 0.026 & 0.876 & 6.305 & 0.494 & 3.030 & 1.326 \\
\hline 24 & 2545.54 & 0.007 & 0.041 & 0.022 & 0.045 & 0.027 & 0.881 & 6.331 & 0.508 & 3.058 & 1.344 \\
\hline 25 & 2754.17 & 0.011 & 0.059 & 0.032 & 0.058 & 0.034 & 0.886 & 6.363 & 0.525 & 3.091 & 1.363 \\
\hline 26 & 3044.00 & 0.006 & 0.030 & 0.016 & 0.032 & 0.018 & 0.894 & 6.403 & 0.547 & 3.131 & 1.386 \\
\hline
\end{tabular}


Appendix Table A-3. Regeneration data for column RRT3. Airflow rate equals 5.0 PV/min.

\begin{tabular}{|c|c|c|c|c|c|c|c|c|c|c|c|}
\hline \multirow[b]{2}{*}{ Sample } & \multirow[b]{2}{*}{ PV } & \multicolumn{5}{|c|}{ Concentration (mg/L) } & \multicolumn{5}{|c|}{ Mass Removed (mg) } \\
\hline & & Benzene & Toluene & Ethylbenzene & p- \& m-xylene & o-xylene & Benzene & Toluene & Ethylbenzene & p- \& m-xylene & o-xylene \\
\hline 1 & 12.04 & 1.340 & 2.890 & 0.082 & 0.848 & 0.271 & 0.053 & 0.113 & 0.003 & 0.033 & 0.011 \\
\hline 2 & 32.94 & 1.256 & 2.979 & 0.082 & 0.910 & 0.363 & 0.141 & 0.313 & 0.009 & 0.093 & 0.032 \\
\hline 4 & 68.19 & 0.811 & 2.383 & 0.076 & 0.765 & 0.253 & 0.261 & 0.635 & 0.018 & 0.146 & 0.066 \\
\hline 5 & 96.08 & 0.619 & 1.977 & 0.067 & 0.665 & 0.222 & 0.326 & 0.833 & 0.025 & 0.211 & 0.087 \\
\hline 6 & 137.30 & 0.541 & 1.976 & 0.084 & 0.668 & 0.258 & 0.404 & 1.098 & 0.035 & 0.301 & 0.120 \\
\hline 8 & 225.74 & 0.238 & 1.654 & 0.062 & 0.591 & 0.198 & 0.508 & 1.600 & 0.053 & 0.474 & 0.179 \\
\hline 9 & 403.47 & 0.214 & 1.623 & 0.061 & 0.566 & 0.188 & 0.638 & 2.550 & 0.089 & 0.810 & 0.291 \\
\hline 10 & 519.60 & 0.101 & 1.228 & 0.046 & 0.527 & 0.171 & 0.698 & 3.089 & 0.109 & 1.017 & 0.359 \\
\hline 11 & 745.97 & 0.053 & 0.553 & 0.050 & 0.468 & 0.164 & 0.755 & 3.746 & 0.144 & 1.384 & 0.483 \\
\hline 12 & 932.88 & 0.034 & 0.291 & 0.038 & 0.347 & 0.135 & 0.781 & 4.004 & 0.171 & 1.632 & 0.574 \\
\hline 13 & 1167.84 & 0.042 & 0.331 & 0.039 & 0.355 & 0.149 & 0.810 & 4.242 & 0.201 & 1.901 & 0.683 \\
\hline 14 & 1557.91 & 0.050 & 0.235 & 0.042 & 0.300 & 0.136 & 0.869 & 4.602 & 0.252 & 2.317 & 0.864 \\
\hline 16 & 2091.54 & 0.025 & 0.110 & 0.042 & 0.126 & 0.074 & 0.954 & 4.902 & 0.324 & 2.678 & 1.065 \\
\hline 17 & 2355.14 & 0.025 & 0.077 & 0.025 & 0.087 & 0.049 & 0.975 & 4.982 & 0.353 & 2.769 & 1.118 \\
\hline 18 & 2750.59 & 0.025 & 0.160 & 0.047 & 0.118 & 0.067 & 1.007 & 5.135 & 0.400 & 2.901 & 1.193 \\
\hline 19 & 3040.84 & 0.021 & 0.084 & 0.036 & 0.102 & 0.056 & 1.029 & 5.251 & 0.439 & 3.005 & 1.251 \\
\hline 20 & 3084.90 & 0.013 & 0.057 & 0.024 & 0.074 & 0.037 & 1.032 & 5.261 & 0.444 & 3.017 & 1.258 \\
\hline 21 & 3377.90 & 0.008 & 0.038 & 0.013 & 0.049 & 0.024 & 1.042 & 5.306 & 0.461 & 3.076 & 1.287 \\
\hline 22 & 3684.15 & 0.010 & 0.052 & 0.023 & 0.066 & 0.034 & 1.050 & 5.351 & 0.479 & 3.133 & 1.316 \\
\hline
\end{tabular}


Appendix Table A-4. Regeneration data for column RRT4. Airflow rate equals 10 PV/min.

\begin{tabular}{|c|c|c|c|c|c|c|c|c|c|c|c|}
\hline \multirow[b]{2}{*}{ Sample } & \multirow[b]{2}{*}{ PV } & \multicolumn{5}{|c|}{ Concentration (mg/L) } & \multicolumn{5}{|c|}{ Mass Removed (mg) } \\
\hline & & Benzene & Toluene & Ethylbenzene & p- \& m-xylene & o-xylene & Benzene & Toluene & Ethylbenzene & p- \& m-xylene & o-xylene \\
\hline 1 & 6.68 & 1.359 & 3.396 & 0.245 & 0.860 & 0.307 & 0.029 & 0.072 & 0.005 & 0.018 & 0.006 \\
\hline 2 & 25.25 & 1.051 & 3.434 & 0.139 & 0.892 & 0.269 & 0.100 & 0.273 & 0.016 & 0.070 & 0.023 \\
\hline 3 & 49.31 & 0.824 & 3.227 & 0.141 & 0.876 & 0.264 & 0.171 & 0.527 & 0.027 & 0.137 & 0.044 \\
\hline 4 & 78.25 & 0.626 & 2.974 & 0.126 & 0.864 & 0.259 & 0.238 & 0.811 & 0.039 & 0.217 & 0.068 \\
\hline 5 & 270.08 & 0.377 & 2.088 & 0.099 & 0.694 & 0.215 & 0.543 & 2.350 & 0.108 & 0.691 & 0.212 \\
\hline 6 & 378.01 & 0.132 & 1.799 & 0.090 & 0.601 & 0.224 & 0.630 & 3.015 & 0.140 & 0.912 & 0.287 \\
\hline 7 & 700.82 & 0.044 & 0.545 & 0.076 & 0.508 & 0.170 & 0.720 & 4.214 & 0.225 & 1.479 & 0.488 \\
\hline 8 & 961.84 & 0.038 & 0.393 & 0.050 & 0.587 & 0.271 & 0.754 & 4.603 & 0.277 & 1.932 & 0.671 \\
\hline 9 & 1310.62 & 0.014 & 0.125 & 0.025 & 0.193 & 0.111 & 0.783 & 4.889 & 0.319 & 2.363 & 0.882 \\
\hline 10 & 2073.48 & 0.014 & 0.093 & 0.028 & 0.094 & 0.047 & 0.816 & 5.153 & 0.382 & 2.710 & 1.073 \\
\hline 11 & 2660.01 & 0.007 & 0.066 & 0.023 & 0.068 & 0.033 & 0.835 & 5.301 & 0.429 & 2.861 & 1.147 \\
\hline 12 & 3225.73 & 0.007 & 0.051 & 0.019 & 0.053 & 0.025 & 0.848 & 5.406 & 0.467 & 2.970 & 1.198 \\
\hline
\end{tabular}


Appendix Table A-9. Total mass sorbed, removed, and the residual for columns RRT 1-4.

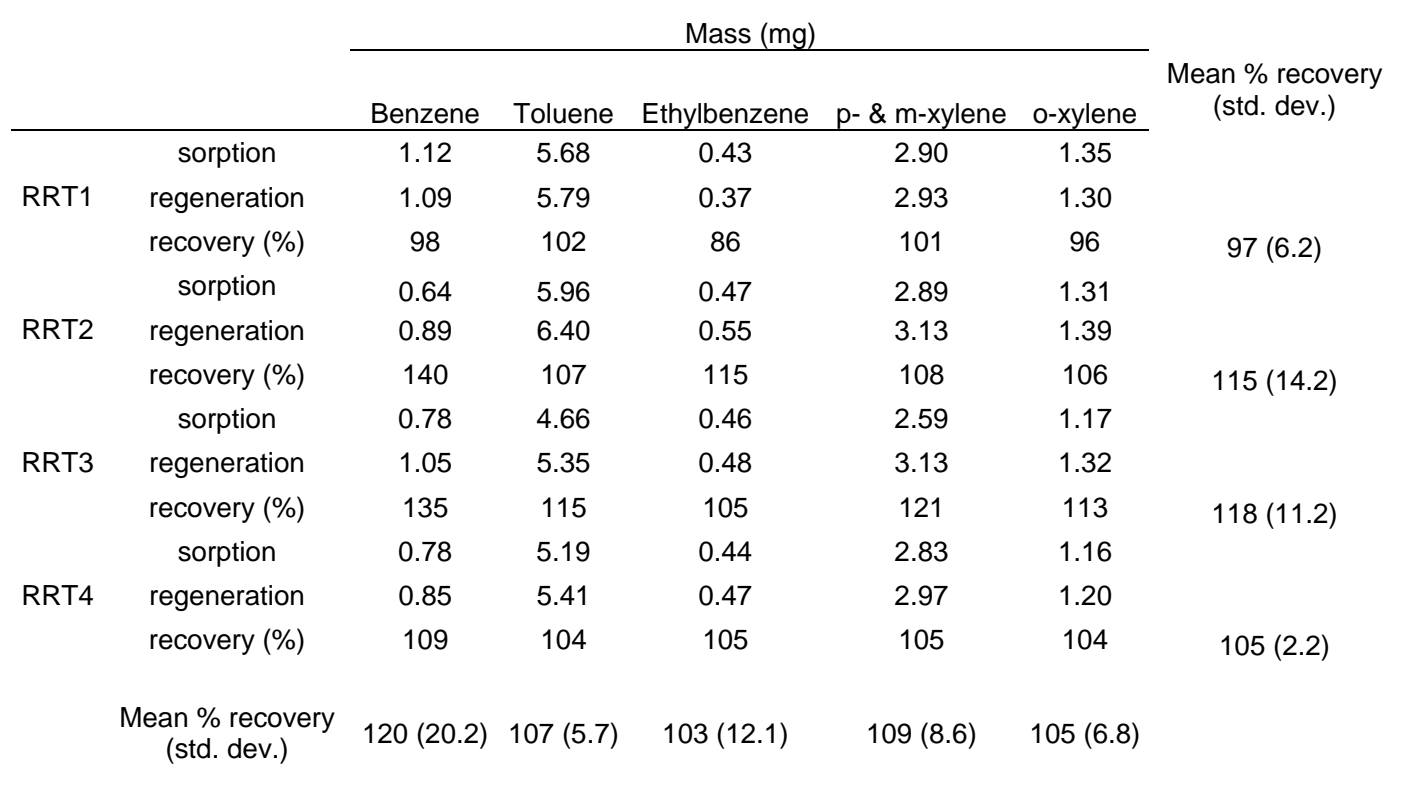




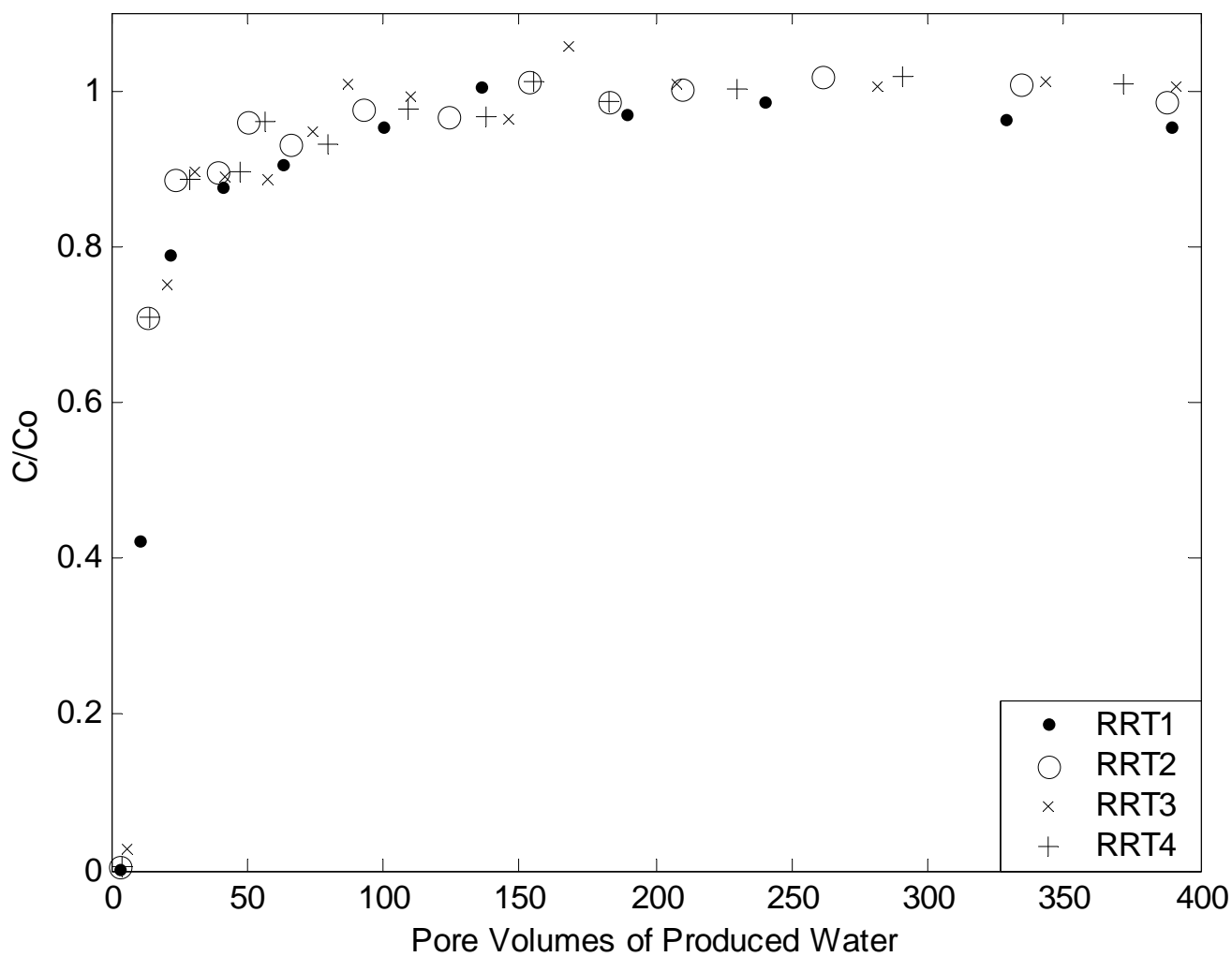

Figure A- 1. Benzene sorption on virgin SMZ for four replicate columns. 


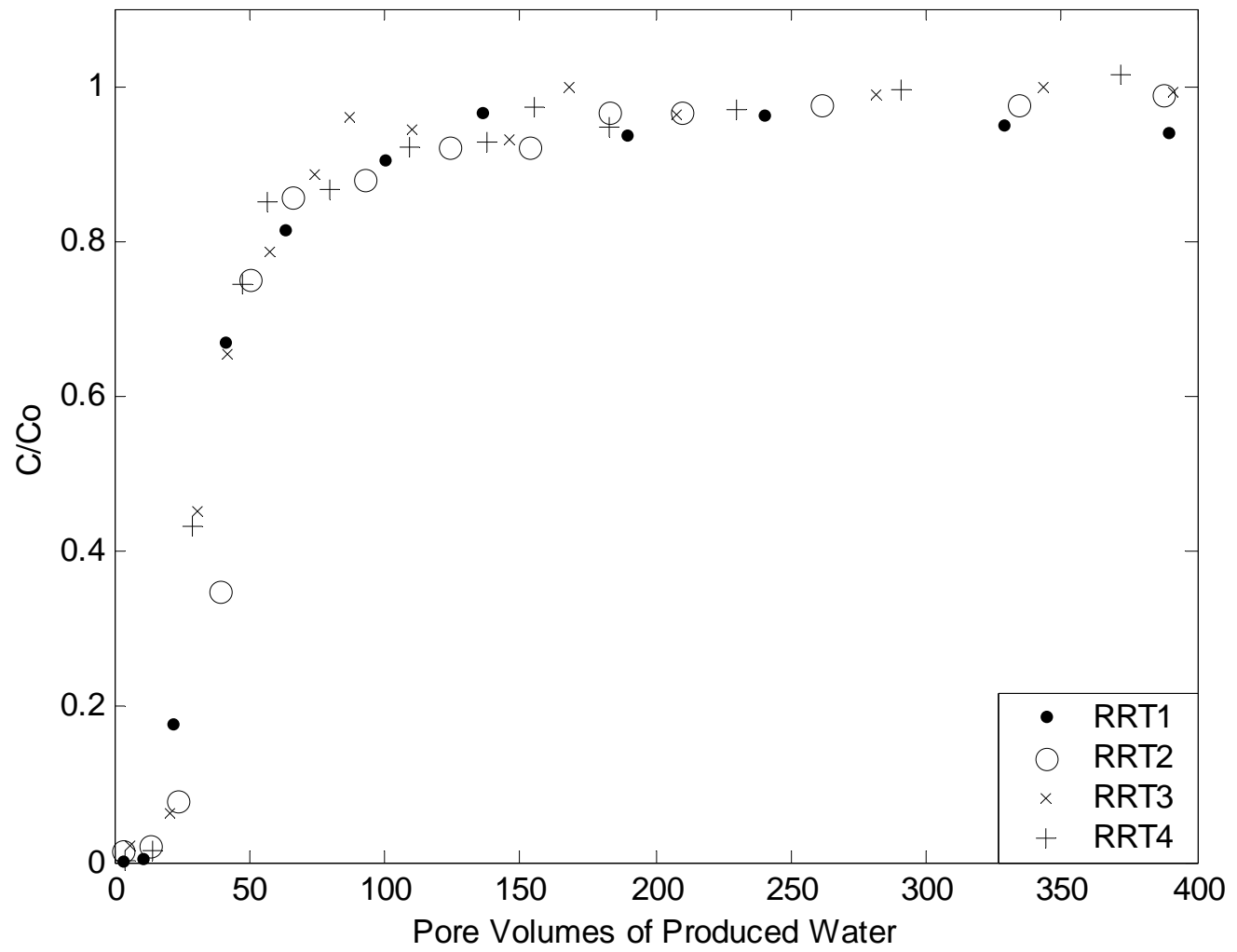

Figure A- 2. Toluene sorption on virgin SMZ for four replicate columns. 


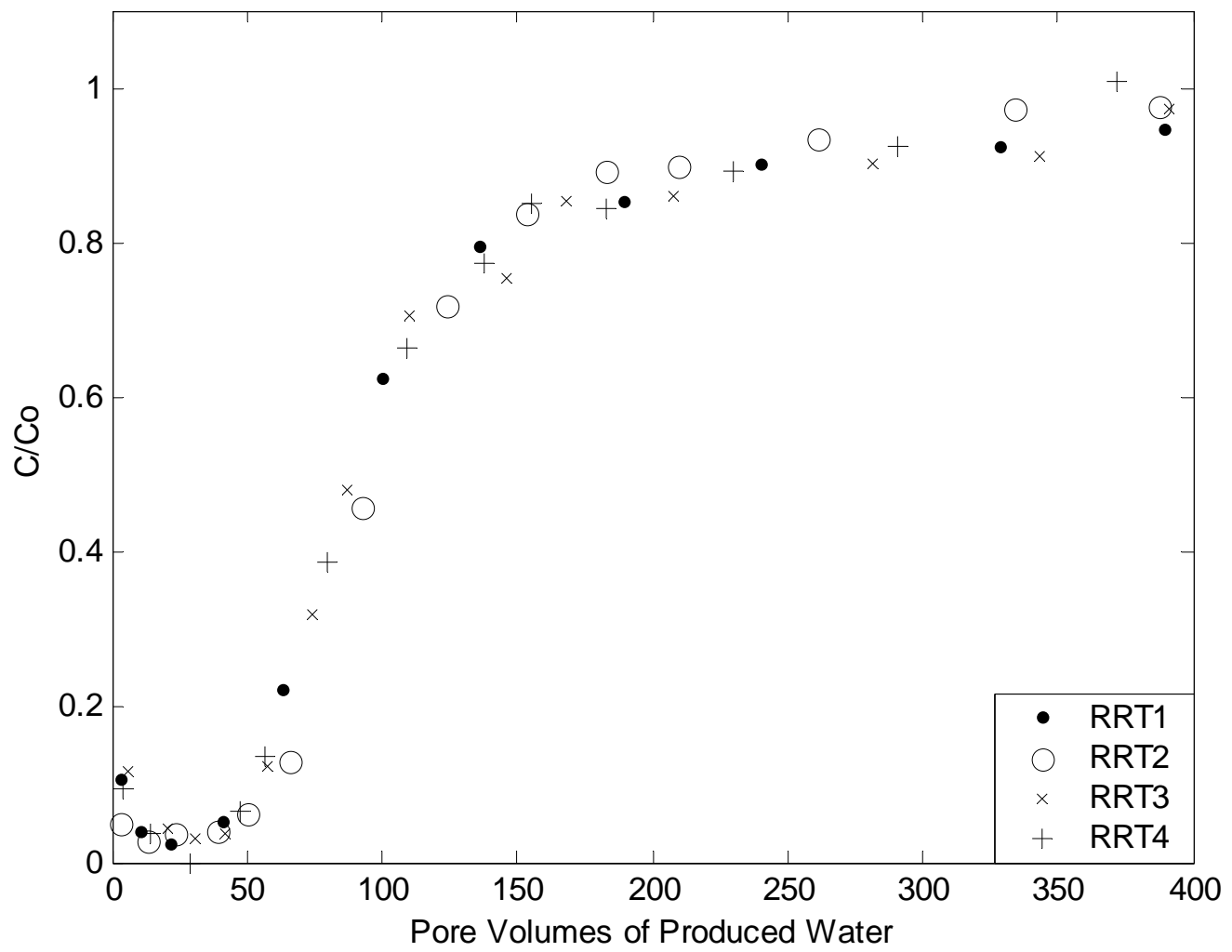

Figure A- 3. Ethylbenzene sorption on virgin SMZ for four replicate columns. 


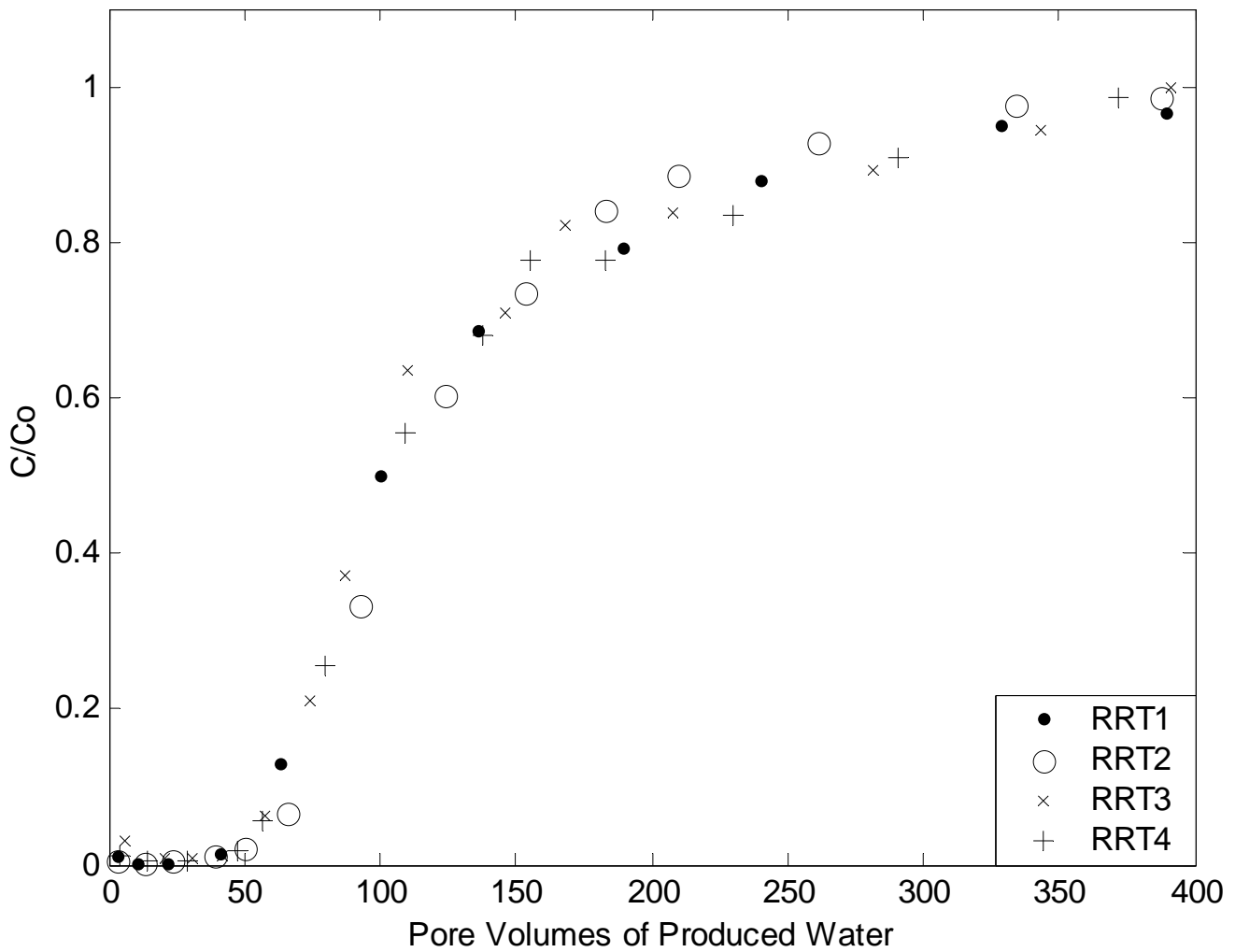

Figure A- 4. $p$ - and $m$-xylene sorption on virgin SMZ for four replicate columns. 


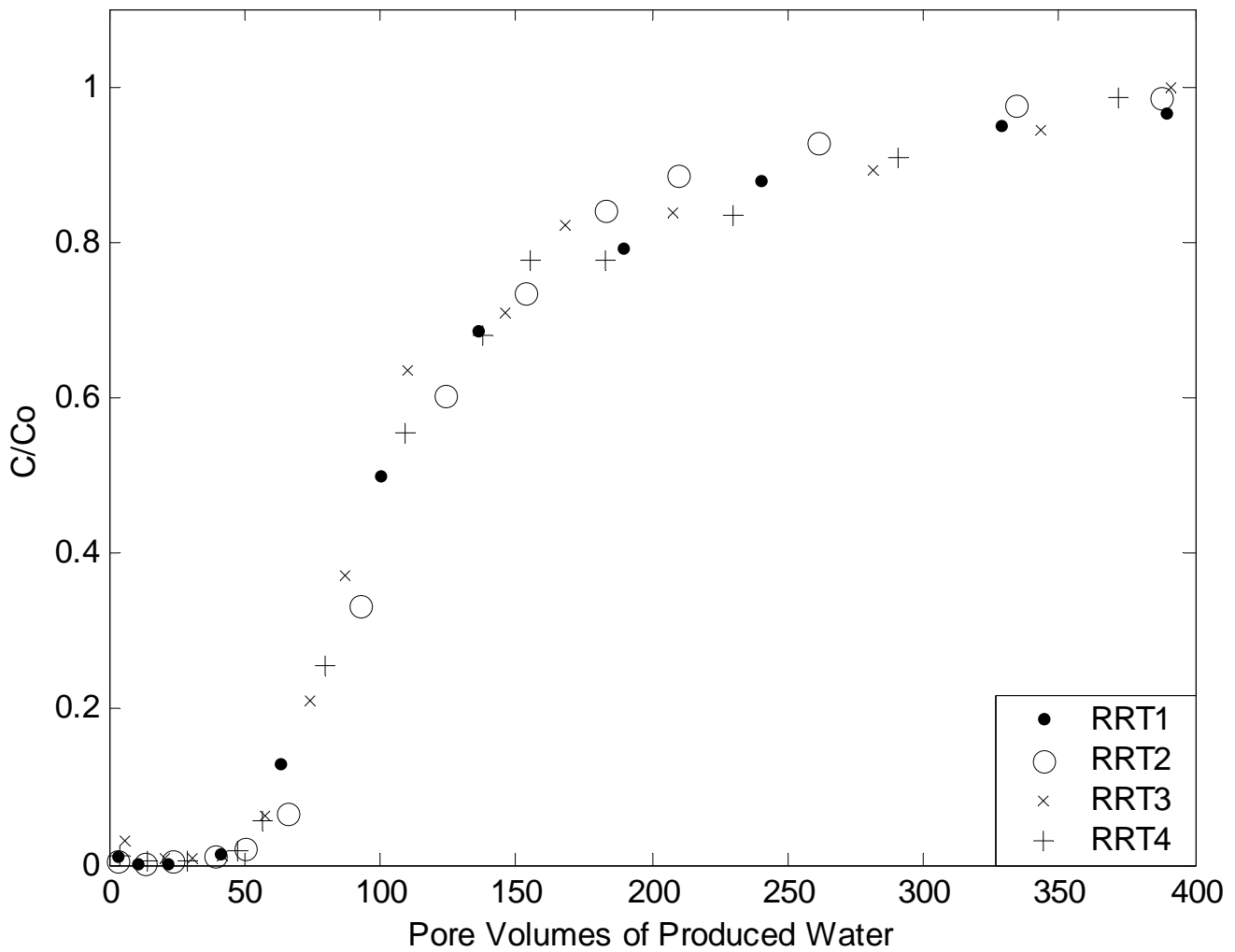

Figure A- 5. o-xylene sorption on virgin SMZ for four replicate columns. 

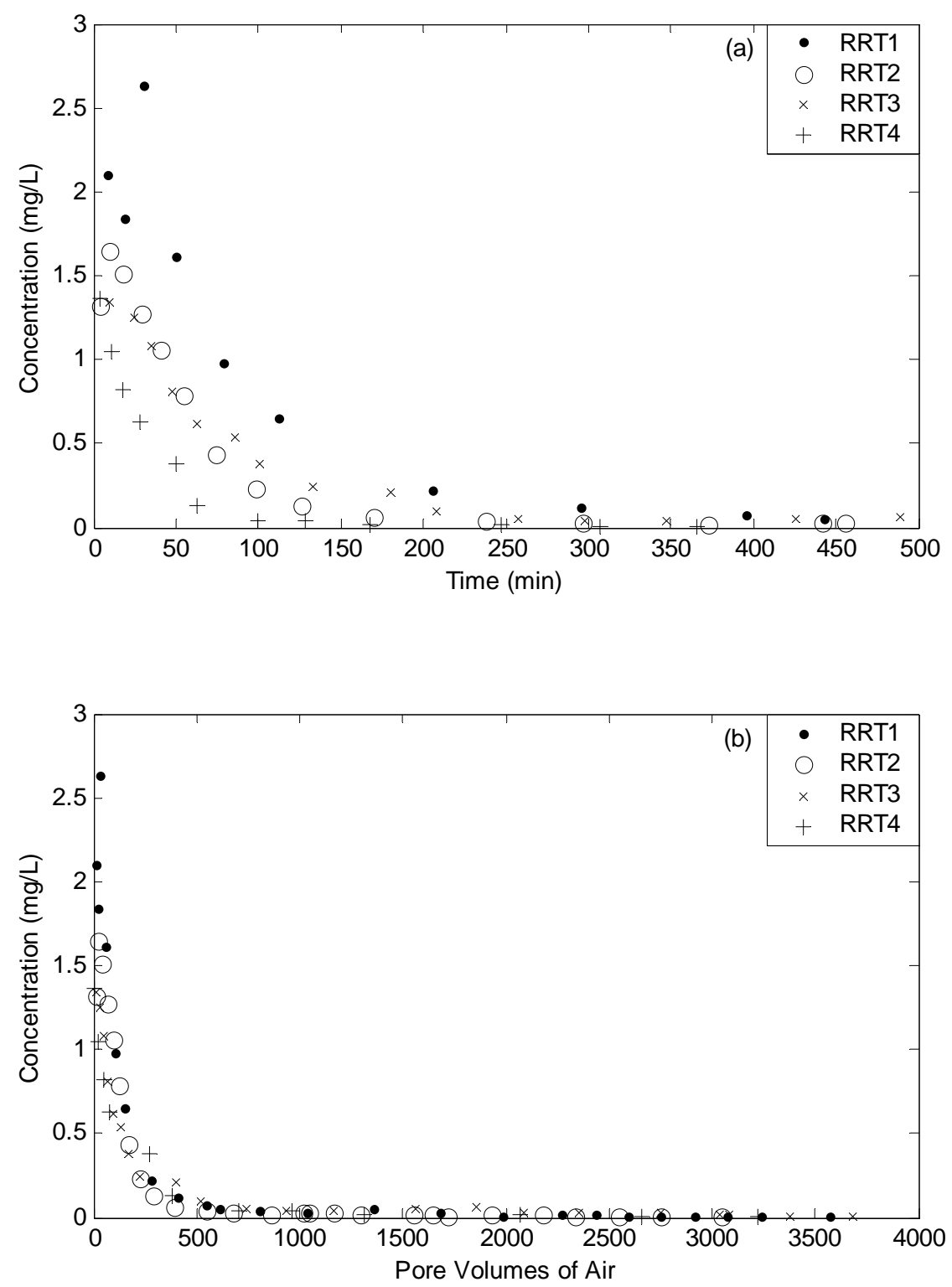

Figure A- 6. Benzene regeneration at four different airflow rates as a function of (a) time and (b) PV of air. Columns RRT1, RRT2, RRT3, and RRT4 used flow rates of $1.3 \mathrm{PV} / \mathrm{min}, 2.7 \mathrm{PV} / \mathrm{min}, 5$ $\mathrm{PV} / \mathrm{min}$, and $10 \mathrm{PV} / \mathrm{min}$, respectively. 

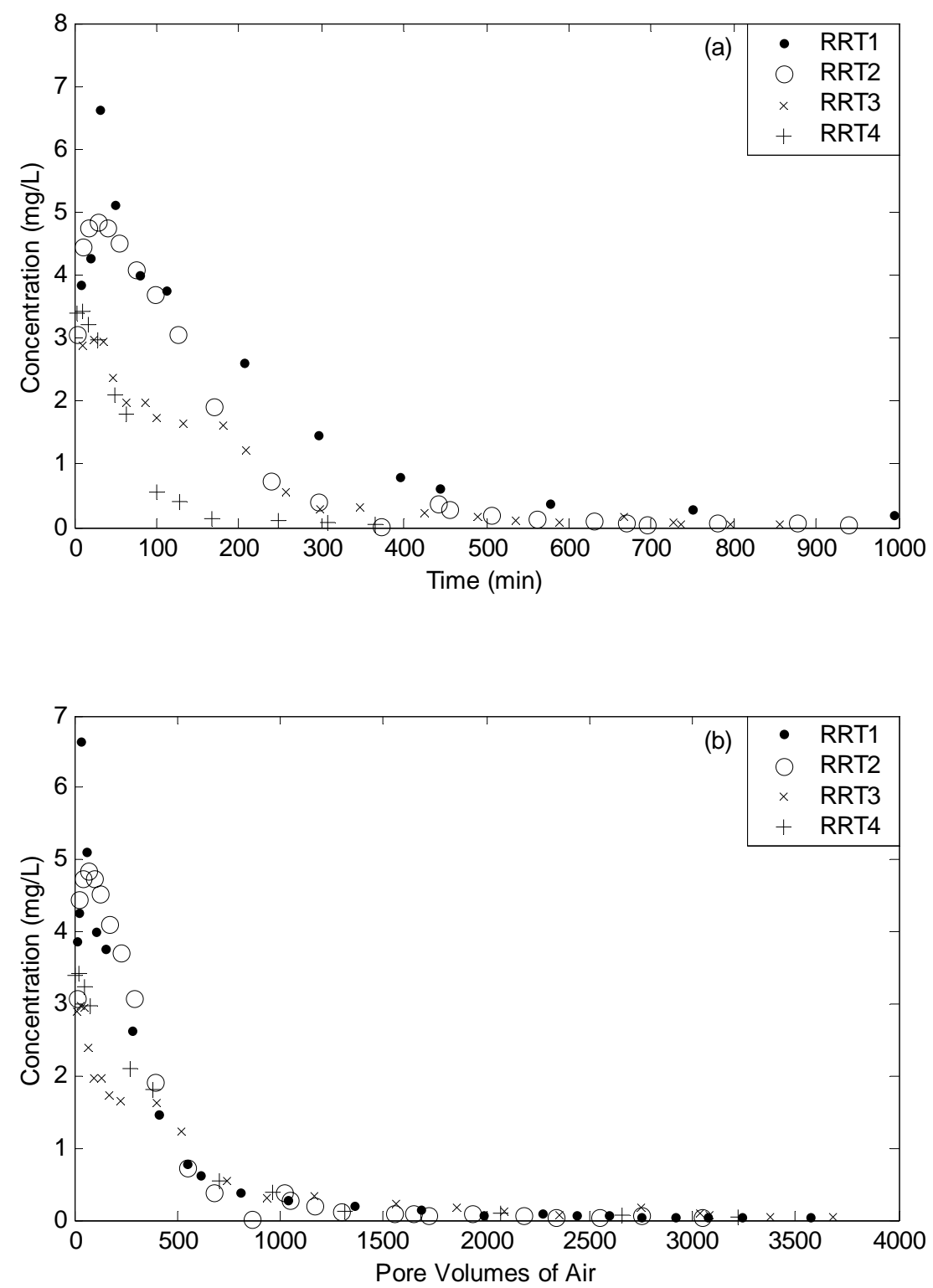

Figure A- 7. Toluene regeneration at four different airflow rates as a function of (a) time and (b) PV of air. Columns RRT1, RRT2, RRT3, and RRT4 used flow rates of $1.3 \mathrm{PV} / \mathrm{min}, 2.7 \mathrm{PV} / \mathrm{min}, 5$ $\mathrm{PV} / \mathrm{min}$, and $10 \mathrm{PV} / \mathrm{min}$, respectively. 

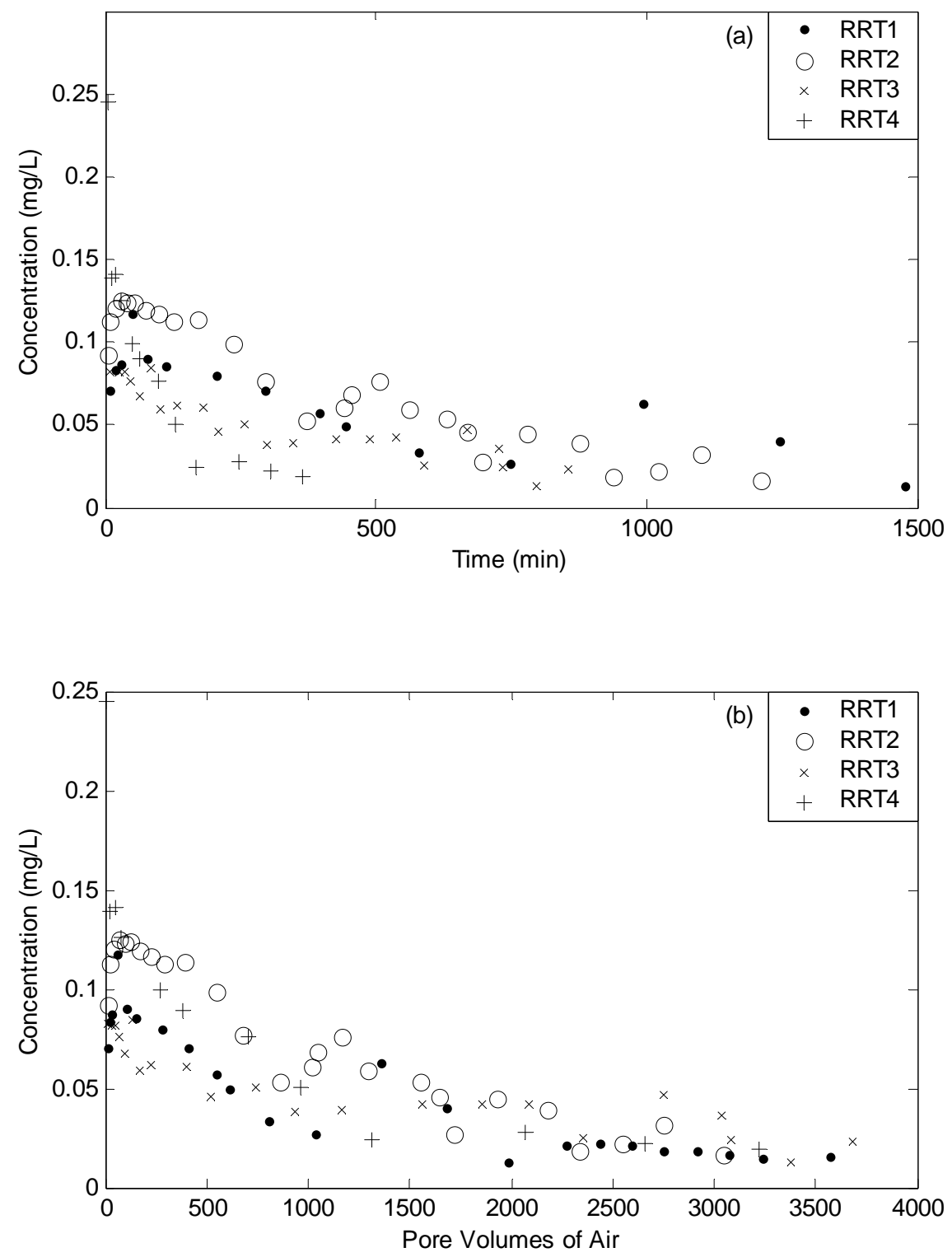

Figure A- 8. Ethylbenzene regeneration at four different airflow rates as a function of (a) time and (b) PV of air. Columns RRT1, RRT2, RRT3, and RRT4 used flow rates of $1.3 \mathrm{PV} / \mathrm{min}, 2.7 \mathrm{PV} / \mathrm{min}, 5$ $\mathrm{PV} / \mathrm{min}$, and $10 \mathrm{PV} / \mathrm{min}$, respectively. 

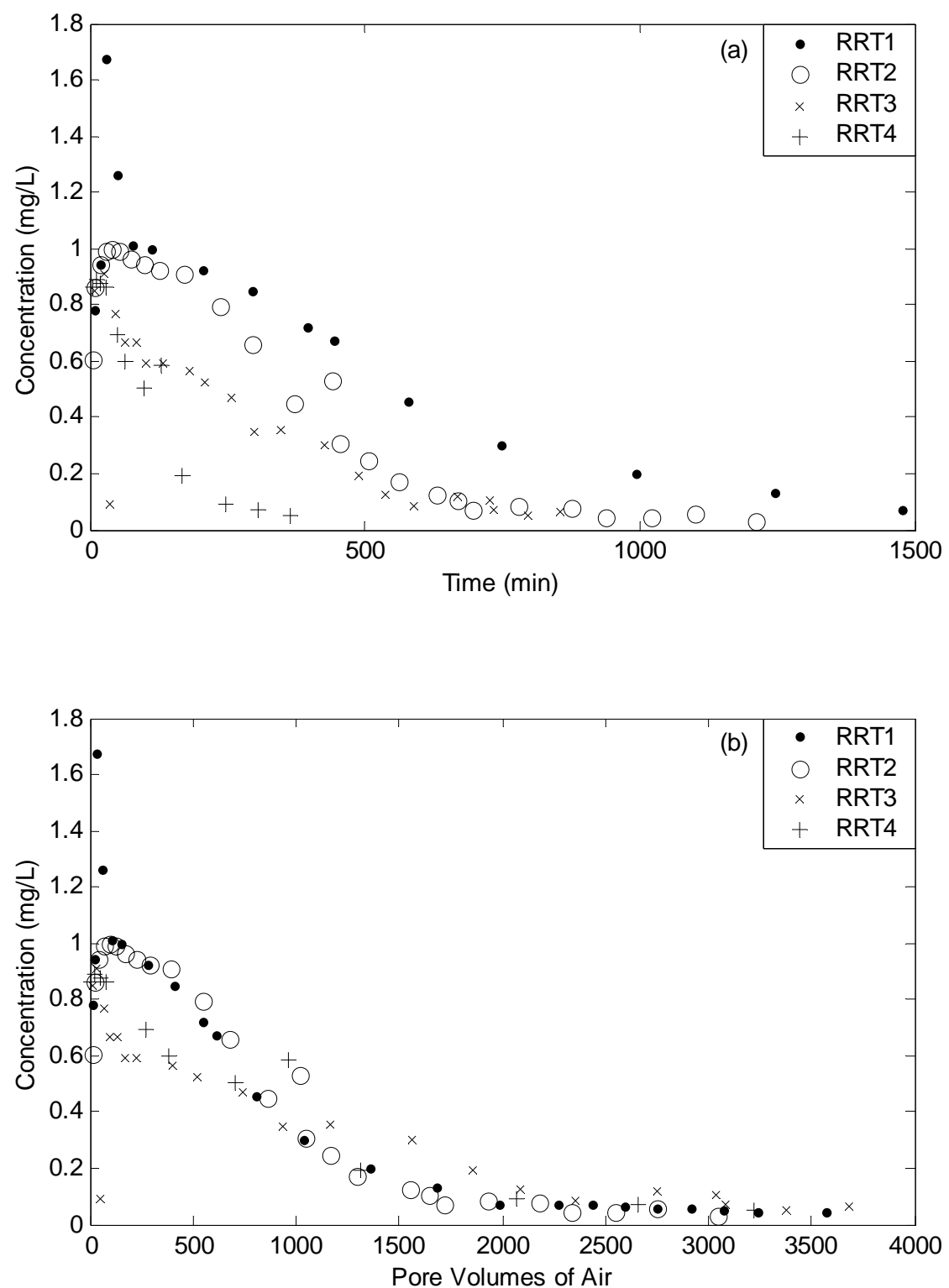

Figure A- 9. $p$ - and $m$-xylene regeneration at four different airflow rates as a function of (a) time and (b) PV of air. Columns RRT1, RRT2, RRT3, and RRT4 used flow rates of $1.3 \mathrm{PV} / \mathrm{min}, 2.7 \mathrm{PV} / \mathrm{min}, 5$ $\mathrm{PV} / \mathrm{min}$, and $10 \mathrm{PV} / \mathrm{min}$, respectively. 

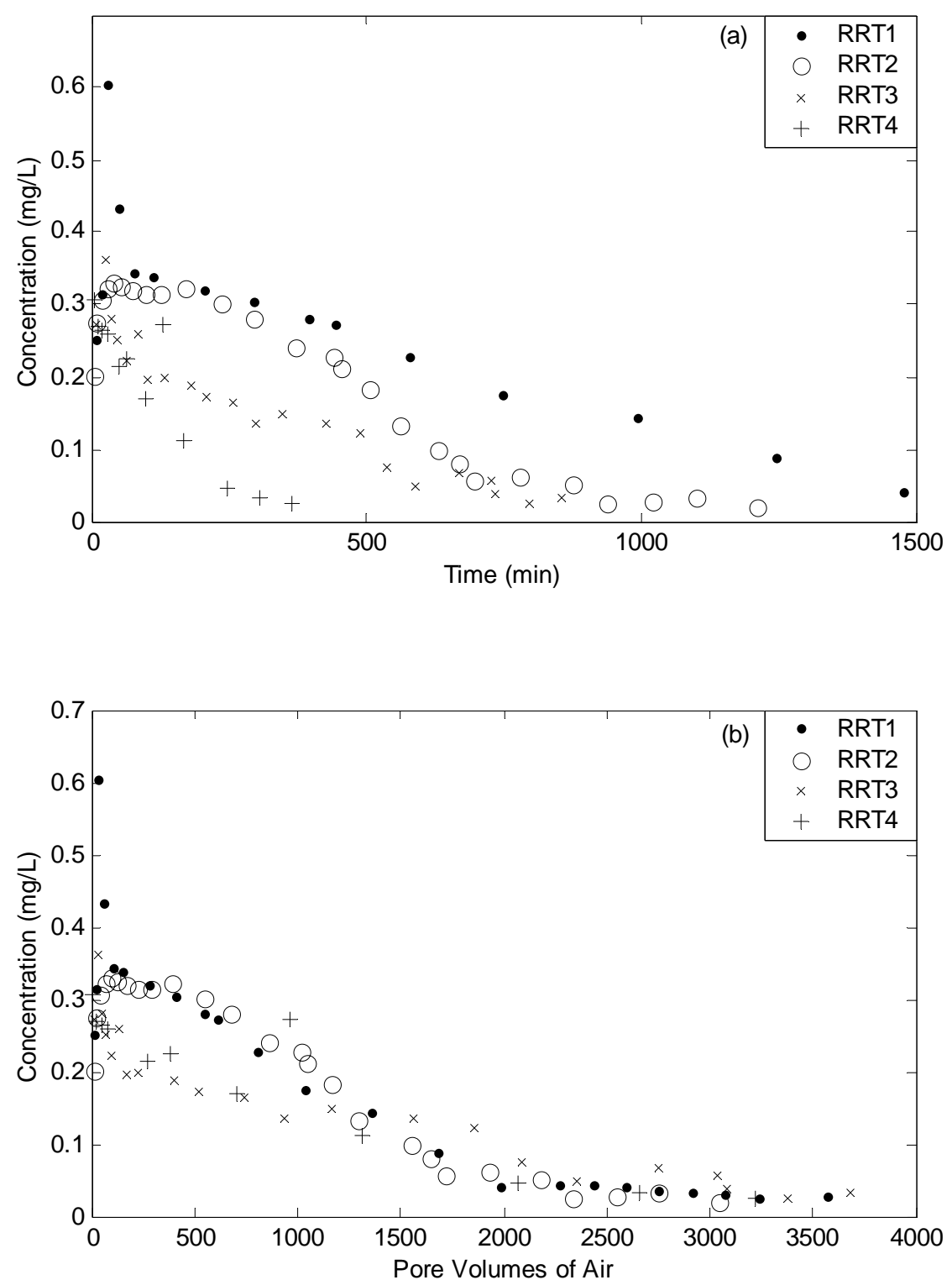

Figure A- 10. o-xylene regeneration at four different airflow rates as a function of (a) time and (b) PV of air. Columns RRT1, RRT2, RRT3, and RRT4 used flow rates of $1.3 \mathrm{PV} / \mathrm{min}, 2.7 \mathrm{PV} / \mathrm{min}, 5$ $\mathrm{PV} / \mathrm{min}$, and $10 \mathrm{PV} / \mathrm{min}$, respectively. 


\section{APPENDIX B. TRITIUM TRACER TEST RESULTS FOR THE LONG-TERM STABILITY TESTS}

This appendix contains information on the tritium tracer tests conducted on the LST columns. Appendix Tables B-1 and B-2 give the observed and fitted data for the tritium tests, presented as normalized concentration $\left(\mathrm{C} / \mathrm{C}_{0}\right)$ as a function of PV of tritiated water. The fitted data used the equilibrium model from CXTFIT2.1. Figures B-1a through B-1c show observed and fitted tritium BTCs on column LST2 for the virgin column, after the $25^{\text {th }}$ regeneration cycle, and after the $50^{\text {th }}$ regeneration cycle, respectively. Figure 4 in the manuscript shows similar data for column LST1. 
Table B- 1. Observed and fitted values for $C / C_{0}$ for tritium tracer tests conducted on column LST1

\begin{tabular}{|c|c|c|c|c|c|c|c|}
\hline \multirow[b]{2}{*}{ Sample } & \multirow[b]{2}{*}{ Pore Volumes } & \multicolumn{2}{|c|}{ Virgin SMZ } & \multicolumn{2}{|c|}{ After 25 th cycle } & \multicolumn{2}{|c|}{ After 50th cycle } \\
\hline & & Obs C/Co & Fit C/Co & Obs C/Co & Fit C/Co & Obs C/Co & Fit C/Co \\
\hline 1 & 0.069 & 0.001 & 0.000 & 0.001 & 0.000 & 0.001 & 0.000 \\
\hline 2 & 0.205 & 0.002 & 0.003 & 0.002 & 0.012 & 0.001 & 0.002 \\
\hline 3 & 0.342 & 0.007 & 0.045 & 0.021 & 0.085 & 0.013 & 0.032 \\
\hline 4 & 0.479 & 0.090 & 0.147 & 0.110 & 0.199 & 0.089 & 0.117 \\
\hline 5 & 0.616 & 0.230 & 0.276 & 0.220 & 0.318 & 0.204 & 0.234 \\
\hline 6 & 0.753 & 0.359 & 0.404 & 0.350 & 0.427 & 0.335 & 0.357 \\
\hline 7 & 0.890 & 0.475 & 0.519 & 0.474 & 0.520 & 0.460 & 0.471 \\
\hline 8 & 1.027 & 0.594 & 0.616 & 0.621 & 0.599 & 0.537 & 0.570 \\
\hline 9 & 1.164 & 0.684 & 0.695 & 0.724 & 0.664 & 0.621 & 0.653 \\
\hline 10 & 1.301 & 0.779 & 0.759 & 0.781 & 0.719 & 0.686 & 0.722 \\
\hline 11 & 1.438 & 0.850 & 0.809 & 0.860 & 0.764 & 0.739 & 0.777 \\
\hline 12 & 1.575 & 0.857 & 0.850 & 0.933 & 0.801 & 0.801 & 0.822 \\
\hline 13 & 1.712 & 0.924 & 0.881 & 0.942 & 0.832 & 0.851 & 0.857 \\
\hline 14 & 1.849 & 0.915 & 0.906 & 0.929 & 0.858 & 0.913 & 0.886 \\
\hline 15 & 1.986 & 0.963 & 0.926 & 0.934 & 0.880 & 0.969 & 0.909 \\
\hline 16 & 2.123 & 0.999 & 0.941 & 0.942 & 0.898 & 0.949 & 0.927 \\
\hline 17 & 2.260 & 0.994 & 0.953 & 0.961 & 0.913 & 0.999 & 0.941 \\
\hline 18 & 2.396 & 0.970 & 0.963 & 0.950 & 0.926 & 0.915 & 0.937 \\
\hline 19 & 2.533 & 0.992 & 0.964 & 0.913 & 0.937 & 0.869 & 0.879 \\
\hline 20 & 2.670 & 0.879 & 0.915 & 0.864 & 0.941 & 0.757 & 0.777 \\
\hline 21 & 2.807 & 0.743 & 0.810 & 0.766 & 0.893 & 0.653 & 0.660 \\
\hline 22 & 2.944 & 0.619 & 0.683 & 0.640 & 0.792 & 0.486 & 0.546 \\
\hline 23 & 3.081 & 0.535 & 0.559 & 0.599 & 0.678 & 0.397 & 0.446 \\
\hline 24 & 3.218 & 0.446 & 0.450 & 0.549 & 0.570 & 0.350 & 0.360 \\
\hline 25 & 3.355 & 0.351 & 0.359 & 0.495 & 0.477 & 0.293 & 0.290 \\
\hline 26 & 3.492 & 0.286 & 0.285 & 0.429 & 0.398 & 0.212 & 0.232 \\
\hline 27 & 3.629 & 0.215 & 0.225 & 0.386 & 0.332 & 0.167 & 0.186 \\
\hline 28 & 3.766 & 0.172 & 0.178 & 0.335 & 0.278 & 0.138 & 0.148 \\
\hline 29 & 3.903 & 0.115 & 0.140 & 0.301 & 0.233 & 0.108 & 0.119 \\
\hline 30 & 4.040 & 0.142 & 0.111 & 0.258 & 0.196 & 0.089 & 0.095 \\
\hline 31 & 4.177 & 0.107 & 0.088 & 0.189 & 0.165 & 0.075 & 0.076 \\
\hline 32 & 4.314 & 0.094 & 0.069 & 0.163 & 0.139 & 0.059 & 0.061 \\
\hline 33 & 4.451 & 0.077 & 0.055 & 0.150 & 0.118 & 0.052 & 0.049 \\
\hline 34 & 4.588 & 0.070 & 0.043 & 0.131 & 0.100 & 0.043 & 0.039 \\
\hline 35 & 4.724 & 0.061 & 0.034 & 0.120 & 0.085 & 0.034 & 0.031 \\
\hline 36 & 4.861 & 0.052 & 0.027 & 0.093 & 0.072 & 0.032 & 0.025 \\
\hline 37 & 4.998 & 0.045 & 0.022 & 0.087 & 0.061 & 0.028 & 0.020 \\
\hline 38 & 5.135 & 0.042 & 0.017 & 0.077 & 0.053 & 0.023 & 0.016 \\
\hline 39 & 5.272 & 0.035 & 0.014 & 0.061 & 0.045 & 0.019 & 0.013 \\
\hline 40 & 5.409 & 0.035 & 0.011 & 0.039 & 0.039 & 0.018 & 0.011 \\
\hline 41 & 5.546 & 0.032 & 0.009 & 0.033 & 0.033 & 0.014 & 0.009 \\
\hline 42 & 5.683 & 0.024 & 0.007 & 0.028 & 0.028 & 0.012 & 0.007 \\
\hline 43 & 5.820 & 0.020 & 0.006 & 0.017 & 0.024 & 0.012 & 0.006 \\
\hline 44 & 5.957 & 0.016 & 0.005 & 0.013 & 0.021 & 0.010 & 0.005 \\
\hline 45 & 6.094 & 0.015 & 0.004 & 0.010 & 0.018 & 0.008 & 0.004 \\
\hline 46 & 6.231 & 0.014 & 0.003 & 0.009 & 0.016 & 0.009 & 0.003 \\
\hline 47 & 6.368 & 0.016 & 0.002 & 0.008 & 0.014 & 0.007 & 0.002 \\
\hline 48 & 6.505 & 0.012 & 0.002 & 0.007 & 0.012 & 0.005 & 0.002 \\
\hline 49 & 6.642 & 0.013 & 0.002 & 0.007 & 0.010 & 0.004 & 0.002 \\
\hline 50 & 6.779 & 0.011 & 0.001 & 0.006 & 0.009 & 0.004 & 0.001 \\
\hline
\end{tabular}


Table B- 2. Observed and fitted values for $C_{/} C_{0}$ for tritium tracer tests conducted on column LT2

\begin{tabular}{|c|c|c|c|c|c|c|c|}
\hline \multirow[b]{2}{*}{ Sample } & \multirow[b]{2}{*}{ Pore Volumes } & \multicolumn{2}{|c|}{ Virgin SMZ } & \multicolumn{2}{|c|}{ After 25th cycle } & \multicolumn{2}{|c|}{ After 50th cycle } \\
\hline & & Obs C/Co & Fit C/Co & Obs C/Co & Fit C/Co & Obs C/Co & Fit C/Co \\
\hline 1 & 0.069 & 0.002 & 0.000 & 0.002 & 0.000 & 0.001 & 0.000 \\
\hline 2 & 0.205 & 0.002 & 0.000 & 0.002 & 0.001 & 0.001 & 0.002 \\
\hline 3 & 0.342 & 0.006 & 0.004 & 0.008 & 0.019 & 0.004 & 0.037 \\
\hline 4 & 0.479 & 0.030 & 0.037 & 0.053 & 0.085 & 0.056 & 0.131 \\
\hline 5 & 0.616 & 0.103 & 0.119 & 0.149 & 0.190 & 0.155 & 0.257 \\
\hline 6 & 0.753 & 0.158 & 0.237 & 0.259 & 0.309 & 0.272 & 0.387 \\
\hline 7 & 0.890 & 0.298 & 0.368 & 0.386 & 0.426 & 0.420 & 0.505 \\
\hline 8 & 1.027 & 0.461 & 0.494 & 0.494 & 0.531 & 0.518 & 0.606 \\
\hline 9 & 1.164 & 0.565 & 0.605 & 0.600 & 0.621 & 0.636 & 0.688 \\
\hline 10 & 1.301 & 0.686 & 0.697 & 0.694 & 0.696 & 0.727 & 0.754 \\
\hline 11 & 1.438 & 0.788 & 0.770 & 0.778 & 0.757 & 0.816 & 0.807 \\
\hline 12 & 1.575 & 0.850 & 0.828 & 0.811 & 0.806 & 0.876 & 0.849 \\
\hline 13 & 1.712 & 0.905 & 0.872 & 0.855 & 0.846 & 0.937 & 0.882 \\
\hline 14 & 1.849 & 0.969 & 0.905 & 0.898 & 0.878 & 0.997 & 0.907 \\
\hline 15 & 1.986 & 0.975 & 0.930 & 0.924 & 0.903 & 1.004 & 0.927 \\
\hline 16 & 2.123 & 0.941 & 0.948 & 0.961 & 0.923 & 1.007 & 0.943 \\
\hline 17 & 2.260 & 0.958 & 0.962 & 0.957 & 0.935 & 0.975 & 0.955 \\
\hline 18 & 2.396 & 0.902 & 0.960 & 0.910 & 0.912 & 0.944 & 0.963 \\
\hline 19 & 2.533 & 0.904 & 0.916 & 0.792 & 0.838 & 0.879 & 0.940 \\
\hline 20 & 2.670 & 0.789 & 0.823 & 0.700 & 0.733 & 0.753 & 0.855 \\
\hline 21 & 2.807 & 0.663 & 0.701 & 0.581 & 0.619 & 0.628 & 0.734 \\
\hline 22 & 2.944 & 0.526 & 0.573 & 0.486 & 0.511 & 0.528 & 0.607 \\
\hline 23 & 3.081 & 0.398 & 0.454 & 0.383 & 0.416 & 0.404 & 0.491 \\
\hline 24 & 3.218 & 0.329 & 0.352 & 0.317 & 0.335 & 0.342 & 0.392 \\
\hline 25 & 3.355 & 0.245 & 0.269 & 0.257 & 0.269 & 0.279 & 0.310 \\
\hline 26 & 3.492 & 0.203 & 0.203 & 0.209 & 0.214 & 0.226 & 0.244 \\
\hline 27 & 3.629 & 0.162 & 0.152 & 0.172 & 0.171 & 0.179 & 0.192 \\
\hline 28 & 3.766 & 0.128 & 0.113 & 0.138 & 0.136 & 0.146 & 0.150 \\
\hline 29 & 3.903 & 0.096 & 0.084 & 0.111 & 0.108 & 0.118 & 0.118 \\
\hline 30 & 4.040 & 0.083 & 0.062 & 0.088 & 0.086 & 0.089 & 0.092 \\
\hline 31 & 4.177 & 0.072 & 0.045 & 0.081 & 0.068 & 0.075 & 0.072 \\
\hline 32 & 4.314 & 0.056 & 0.033 & 0.061 & 0.054 & 0.064 & 0.057 \\
\hline 33 & 4.451 & 0.046 & 0.024 & 0.053 & 0.043 & 0.053 & 0.045 \\
\hline 34 & 4.588 & 0.038 & 0.018 & 0.047 & 0.034 & 0.048 & 0.035 \\
\hline 35 & 4.724 & 0.033 & 0.013 & 0.035 & 0.027 & 0.036 & 0.028 \\
\hline 36 & 4.861 & 0.028 & 0.010 & 0.031 & 0.022 & 0.028 & 0.022 \\
\hline 37 & 4.998 & 0.024 & 0.007 & 0.027 & 0.017 & 0.026 & 0.017 \\
\hline 38 & 5.135 & 0.019 & 0.005 & 0.024 & 0.014 & 0.023 & 0.014 \\
\hline 39 & 5.272 & 0.015 & 0.004 & 0.021 & 0.011 & 0.019 & 0.011 \\
\hline 40 & 5.409 & 0.013 & 0.003 & 0.020 & 0.009 & 0.015 & 0.008 \\
\hline 41 & 5.546 & 0.011 & 0.002 & 0.016 & 0.007 & 0.013 & 0.007 \\
\hline 42 & 5.683 & 0.010 & 0.001 & 0.015 & 0.006 & 0.011 & 0.005 \\
\hline 43 & 5.820 & 0.010 & 0.001 & 0.014 & 0.004 & 0.009 & 0.004 \\
\hline 44 & 5.957 & 0.007 & 0.001 & 0.011 & 0.004 & 0.009 & 0.003 \\
\hline 45 & 6.094 & 0.007 & 0.001 & 0.009 & 0.003 & 0.005 & 0.003 \\
\hline 46 & 6.231 & 0.006 & 0.000 & 0.009 & 0.002 & 0.005 & 0.002 \\
\hline 47 & 6.368 & 0.005 & 0.000 & 0.007 & 0.002 & 0.005 & 0.002 \\
\hline 48 & 6.505 & 0.004 & 0.000 & 0.007 & 0.002 & 0.004 & 0.001 \\
\hline 49 & 6.642 & 0.004 & 0.000 & 0.005 & 0.001 & 0.004 & 0.001 \\
\hline 50 & 6.779 & 0.004 & 0.000 & 0.005 & 0.001 & 0.005 & 0.001 \\
\hline
\end{tabular}



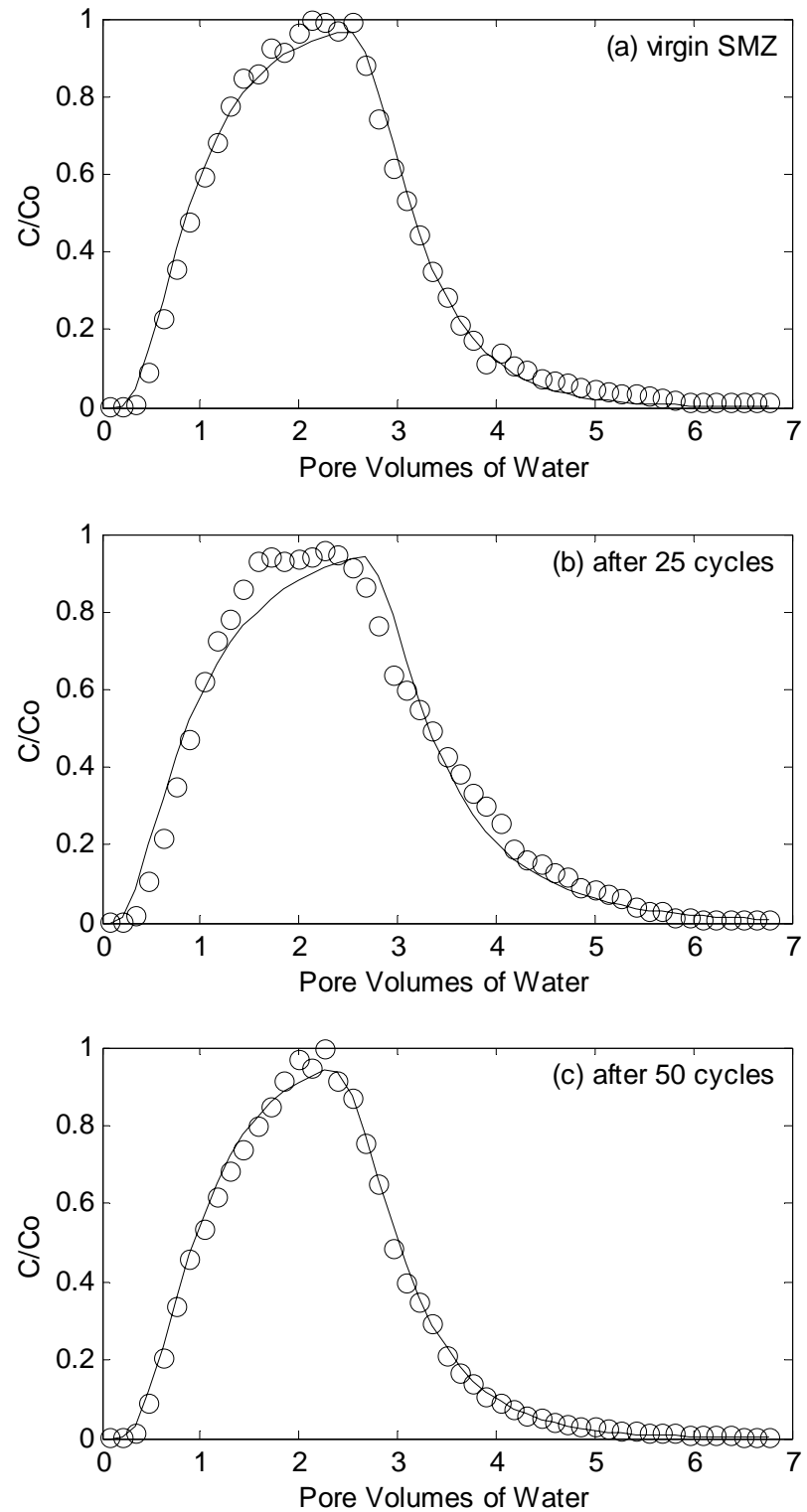

Figure B- 1. BTCs of tritiated water in column LST1 for (a) virgin SMZ and (b) after the $25^{\text {th }}$ regeneration cycle and (c) after the $50^{\text {th }}$ regeneration cycle. Solid lines represent fitted values using an equilibrium advection-dispersion equation. 


\section{APPENDIX C. LONG-TERM STABILITY TEST SORPTION AND REGENERATION RESULTS}

Appendix C presents laboratory data for the LTS experiments. Tables C-1 through C-11 contain relative BTEX concentrations $\left(\mathrm{C} / \mathrm{C}_{0}\right)$ as a function of $\mathrm{PV}$ of produced water for all of the analyzed sorption cycles on column LST1. Tables C-12 through C-22 contain off-gas BTEX concentrations and total mass removed for each of the analyzed regeneration cycles on column LST1. Likewise, Tables C-23 through C-33 contain BTEX sorption data for column LST2 and Tables C-34 through C-44 contain BTEX regeneration data for column LST2. Tables C-45 and C-46 show the total mass of BTEX sorbed and removed during each analyzed cycle on columns LST1 and LST2, respectively. Table C-47 gives $\mathrm{K}_{\mathrm{d}}$ values caluculated from fitted the $\mathrm{R}$ of each compound. Observed trends in $\mathrm{K}_{\mathrm{d}}$ 's are discussed within the manuscript.

Figures C-1 through C-3 show BTCs for toluene, ethylbenzene, and o-xylene for every analyzed cycle of the LST experiments. Figures C-4 through C-8 show regeneration curves for each BTEX compound for column LST1. Figures C-9 through C13 show BTEX BTCs for column LST2. Figures C-14 through C-18 show curves for each BTEX compound for column LST2. Figures C-19 through C-28 show the Kd values calculated for each compound from each measured cycles and linear regressions fit to these values. 
Table C- 1. Data for BTEX BTCs from the $1^{\text {st }}$ sorption cycle on column LST1

\begin{tabular}{ccccccc} 
& & \multicolumn{5}{c}{ C/Co } \\
\cline { 3 - 7 } Sample & Pore Volumes & Benzene & Toluene & Ethylbenzene & $\begin{array}{c}\mathrm{p} \text { - \& } \mathrm{m} \text { - } \\
\text { xylene }\end{array}$ & o-xylene \\
\hline 1 & 2.1 & 0.055 & 0.000 & 0.000 & 0.000 & 0.000 \\
2 & 6.2 & 0.441 & 0.101 & 0.000 & 0.000 & 0.000 \\
3 & 11.5 & 0.543 & 0.201 & 0.000 & 0.046 & 0.000 \\
4 & 16.7 & 0.737 & 0.314 & 0.119 & 0.081 & 0.160 \\
5 & 21.8 & 0.738 & 0.390 & 0.161 & 0.105 & 0.175 \\
6 & 28.3 & 0.901 & 0.508 & 0.249 & 0.170 & 0.228 \\
7 & 36.6 & 0.838 & 0.572 & 0.277 & 0.217 & 0.275 \\
8 & 46.0 & 0.842 & 0.641 & 0.353 & 0.268 & 0.321 \\
9 & 61.6 & 0.964 & 0.780 & 0.415 & 0.386 & 0.455 \\
10 & 87.5 & 0.887 & 0.774 & 0.561 & 0.455 & 0.527 \\
11 & 101.1 & 0.902 & 0.788 & 0.599 & 0.558 & 0.563
\end{tabular}

Table C- 2. Data for BTEX BTCs from the $5^{\text {th }}$ sorption cycle on column LST1

\begin{tabular}{ccccccc} 
& & \multicolumn{5}{c}{ C/Co } \\
\cline { 3 - 7 } Sample & Pore Volumes & Benzene & Toluene & Ethylbenzene & $\begin{array}{c}p-\& m-~ \\
\text { xylene }\end{array}$ & o-xylene \\
\hline 1 & 2.9 & 0.108 & 0.000 & 0.000 & 0.000 & 0.000 \\
2 & 8.0 & 0.519 & 0.089 & 0.000 & 0.000 & 0.000 \\
3 & 12.9 & 0.543 & 0.192 & 0.087 & 0.053 & 0.117 \\
4 & 19.4 & 0.696 & 0.314 & 0.159 & 0.110 & 0.192 \\
5 & 26.1 & 0.685 & 0.435 & 0.177 & 0.097 & 0.191 \\
6 & 30.9 & 0.831 & 0.535 & 0.287 & 0.164 & 0.216 \\
7 & 37.6 & 0.897 & 0.619 & 0.303 & 0.235 & 0.313 \\
8 & 49.5 & 0.862 & 0.677 & 0.377 & 0.298 & 0.382 \\
9 & 61.6 & 0.930 & 0.755 & 0.441 & 0.377 & 0.487 \\
10 & 88.5 & 0.966 & 0.807 & 0.520 & 0.527 & 0.561 \\
11 & 99.6 & 0.952 & 0.893 & 0.551 & 0.592 & 0.585
\end{tabular}


Table C- 3. Data for BTEX BTCs from the $10^{\text {th }}$ sorption cycle on column LST1

\begin{tabular}{ccccccc} 
& & \multicolumn{5}{c}{ C/Co } \\
\cline { 3 - 7 } Sample & Pore Volumes & Benzene & Toluene & Ethylbenzene & $\begin{array}{c}\mathrm{p} \text { - \& m- } \\
\text { xylene }\end{array}$ & o-xylene \\
\hline 1 & 4.6 & 0.106 & 0.025 & 0.000 & 0.000 & 0.000 \\
2 & 9.6 & 0.503 & 0.089 & 0.085 & 0.036 & 0.071 \\
3 & 23.1 & 0.728 & 0.346 & 0.188 & 0.064 & 0.154 \\
4 & 29.8 & 0.813 & 0.493 & 0.303 & 0.129 & 0.214 \\
5 & 36.7 & 0.807 & 0.592 & 0.240 & 0.180 & 0.269 \\
6 & 45.0 & 0.851 & 0.634 & 0.353 & 0.241 & 0.341 \\
7 & 53.4 & 0.878 & 0.728 & 0.414 & 0.312 & 0.377 \\
8 & 59.6 & 0.865 & 0.830 & 0.487 & 0.368 & 0.464 \\
9 & 87.8 & 0.941 & 0.828 & 0.541 & 0.515 & 0.543 \\
10 & 96.6 & 0.926 & 0.897 & 0.579 & 0.686 & 0.607
\end{tabular}

Table C- 4. Data for BTEX BTCs from the $15^{\text {th }}$ sorption cycle on column LST1

\begin{tabular}{ccccccc} 
& & \multicolumn{5}{c}{ C/Co } \\
\cline { 3 - 7 } Sample & Pore Volumes & Benzene & Toluene & Ethylbenzene & $\begin{array}{c}p-\& \text { m- } \\
\text { xylene }\end{array}$ & o-xylene \\
\hline 1 & 3.8 & 0.101 & 0.000 & 0.000 & 0.000 & 0.000 \\
2 & 7.2 & 0.354 & 0.063 & 0.000 & 0.000 & 0.000 \\
3 & 13.0 & 0.512 & 0.143 & 0.000 & 0.032 & 0.088 \\
4 & 17.2 & 0.568 & 0.258 & 0.126 & 0.048 & 0.154 \\
5 & 25.9 & 0.674 & 0.370 & 0.185 & 0.099 & 0.182 \\
6 & 35.3 & 0.863 & 0.481 & 0.221 & 0.115 & 0.302 \\
7 & 44.6 & 0.857 & 0.603 & 0.265 & 0.217 & 0.306 \\
8 & 52.9 & 0.911 & 0.670 & 0.380 & 0.238 & 0.378 \\
9 & 61.8 & 0.916 & 0.725 & 0.443 & 0.375 & 0.386 \\
10 & 66.1 & 0.989 & 0.747 & 0.464 & 0.447 & 0.501 \\
11 & 82.9 & 0.978 & 0.768 & 0.508 & 0.446 & 0.521 \\
12 & 93.5 & 0.951 & 0.811 & 0.555 & 0.515 & 0.546
\end{tabular}


Table C- 5. Data for BTEX BTCs from the $\mathbf{2 0}^{\text {th }}$ sorption cycle on column LST1

\begin{tabular}{ccccccc} 
& & \multicolumn{5}{c}{ C/Co } \\
\cline { 3 - 7 } Sample & Pore Volumes & Benzene & Toluene & Ethylbenzene & $\begin{array}{c}\text { p- \& m- } \\
\text { xylene }\end{array}$ & o-xylene \\
\hline 1 & 5.5 & 0.072 & 0.000 & 0.000 & 0.000 & 0.000 \\
2 & 10.9 & 0.505 & 0.072 & 0.000 & 0.053 & 0.100 \\
3 & 17.4 & 0.561 & 0.221 & 0.145 & 0.052 & 0.149 \\
4 & 23.0 & 0.686 & 0.339 & 0.189 & 0.089 & 0.188 \\
5 & 29.4 & 0.756 & 0.425 & 0.231 & 0.161 & 0.228 \\
6 & 37.7 & 0.772 & 0.556 & 0.276 & 0.185 & 0.267 \\
7 & 46.4 & 0.841 & 0.668 & 0.353 & 0.242 & 0.332 \\
8 & 57.9 & 0.952 & 0.736 & 0.389 & 0.329 & 0.398 \\
9 & 63.3 & 1.014 & 0.772 & 0.412 & 0.391 & 0.474 \\
10 & 70.9 & 0.998 & 0.854 & 0.480 & 0.462 & 0.519 \\
11 & 81.4 & 0.913 & 0.802 & 0.548 & 0.500 & 0.541 \\
12 & 91.1 & 0.972 & 0.856 & 0.584 & 0.496 & 0.540 \\
13 & 97.9 & 0.953 & 0.867 & 0.619 & 0.519 & 0.550
\end{tabular}

Table C- 6. Data for BTEX BTCs from the $25^{\text {th }}$ sorption cycle on column LST1

\begin{tabular}{ccccccc} 
& & \multicolumn{5}{c}{ C/Co } \\
\cline { 3 - 7 } Sample & Pore Volumes & Benzene & Toluene & Ethylbenzene & $\begin{array}{c}\mathrm{p} \text { - \& m- } \\
\text { xylene }\end{array}$ & o-xylene \\
\hline 1 & 3.4 & 0.044 & 0.012 & 0.000 & 0.000 & 0.000 \\
2 & 8.5 & 0.264 & 0.022 & 0.000 & 0.023 & 0.076 \\
3 & 15.5 & 0.458 & 0.139 & 0.119 & 0.030 & 0.090 \\
4 & 24.3 & 0.633 & 0.307 & 0.127 & 0.048 & 0.144 \\
5 & 31.6 & 0.706 & 0.398 & 0.164 & 0.073 & 0.170 \\
6 & 40.8 & 0.780 & 0.493 & 0.245 & 0.148 & 0.227 \\
7 & 51.0 & 0.833 & 0.594 & 0.319 & 0.260 & 0.292 \\
8 & 69.1 & 0.855 & 0.724 & 0.388 & 0.327 & 0.409 \\
9 & 92.2 & 0.918 & 0.816 & 0.480 & 0.498 & 0.468 \\
10 & 104.2 & 0.978 & 0.879 & 0.520 & 0.560 & 0.539
\end{tabular}


Table C- 7. Data for BTEX BTCs from the $30^{\text {th }}$ sorption cycle on column LST1

\begin{tabular}{ccccccc} 
& & \multicolumn{5}{c}{ C/Co } \\
\cline { 3 - 7 } Sample & Pore Volumes & Benzene & Toluene & Ethylbenzene & $\begin{array}{c}\mathrm{p} \text { - \& } \mathrm{m} \text { - } \\
\text { xylene }\end{array}$ & o-xylene \\
\hline 1 & 4.8 & 0.072 & 0.047 & 0.000 & 0.000 & 0.000 \\
2 & 9.6 & 0.384 & 0.065 & 0.099 & 0.021 & 0.000 \\
3 & 16.9 & 0.668 & 0.263 & 0.124 & 0.061 & 0.136 \\
4 & 22.7 & 0.697 & 0.305 & 0.206 & 0.076 & 0.176 \\
5 & 29.3 & 0.821 & 0.447 & 0.262 & 0.150 & 0.217 \\
6 & 36.5 & 0.840 & 0.555 & 0.274 & 0.236 & 0.289 \\
7 & 44.3 & 0.902 & 0.575 & 0.343 & 0.255 & 0.342 \\
8 & 52.7 & 0.912 & 0.659 & 0.392 & 0.356 & 0.388 \\
9 & 60.3 & 0.889 & 0.695 & 0.371 & 0.413 & 0.425 \\
10 & 73.1 & 0.932 & 0.755 & 0.448 & 0.481 & 0.513 \\
11 & 86.3 & 1.014 & 0.802 & 0.503 & 0.515 & 0.590 \\
12 & 96.5 & 0.978 & 0.866 & 0.544 & 0.572 & 0.613
\end{tabular}

Table C- 8. Data for BTEX BTCs from the $35^{\text {th }}$ sorption cycle on column LST1

\begin{tabular}{ccccccc} 
& & \multicolumn{5}{c}{ C/Co } \\
\cline { 3 - 7 } Sample & Pore Volumes & Benzene & Toluene & Ethylbenzene & $\begin{array}{c}\mathrm{p} \text { - \& m- } \\
\text { xylene }\end{array}$ & o-xylene \\
\hline 1 & 5.3 & 0.061 & 0.056 & 0.088 & 0.000 & 0.000 \\
2 & 10.5 & 0.423 & 0.173 & 0.104 & 0.000 & 0.082 \\
3 & 16.0 & 0.588 & 0.257 & 0.144 & 0.046 & 0.154 \\
4 & 23.5 & 0.774 & 0.408 & 0.196 & 0.099 & 0.222 \\
5 & 30.1 & 0.805 & 0.486 & 0.231 & 0.165 & 0.267 \\
6 & 35.1 & 0.858 & 0.560 & 0.254 & 0.251 & 0.291 \\
7 & 45.1 & 0.962 & 0.654 & 0.314 & 0.283 & 0.316 \\
8 & 54.3 & 0.997 & 0.735 & 0.415 & 0.347 & 0.399 \\
9 & 60.0 & 1.042 & 0.782 & 0.462 & 0.402 & 0.473 \\
10 & 68.6 & 0.989 & 0.858 & 0.469 & 0.429 & 0.535 \\
11 & 78.2 & 0.997 & 0.841 & 0.483 & 0.458 & 0.623 \\
12 & 86.2 & 1.023 & 0.879 & 0.568 & 0.512 & 0.630 \\
13 & 97.9 & 1.059 & 0.876 & 0.548 & 0.596 & 0.713
\end{tabular}


Table C- 9. Data for BTEX BTCs from the $40^{\text {th }}$ sorption cycle on column LST1

\begin{tabular}{ccccccc} 
& & \multicolumn{5}{c}{ C/Co } \\
\cline { 3 - 7 } Sample & Pore Volumes & Benzene & Toluene & Ethylbenzene & $\begin{array}{c}\mathrm{p} \text { - \& m- } \\
\text { xylene }\end{array}$ & o-xylene \\
\hline 1 & 5.3 & 0.086 & 0.080 & 0.000 & 0.000 & 0.000 \\
2 & 10.6 & 0.459 & 0.153 & 0.093 & 0.031 & 0.000 \\
3 & 21.8 & 0.702 & 0.327 & 0.123 & 0.109 & 0.134 \\
4 & 32.3 & 0.812 & 0.513 & 0.251 & 0.163 & 0.230 \\
5 & 44.6 & 0.917 & 0.623 & 0.302 & 0.265 & 0.277 \\
6 & 52.1 & 0.966 & 0.744 & 0.412 & 0.292 & 0.343 \\
7 & 63.4 & 0.949 & 0.757 & 0.483 & 0.380 & 0.449 \\
8 & 79.9 & 0.984 & 0.839 & 0.487 & 0.504 & 0.560 \\
9 & 94.8 & 1.006 & 0.917 & 0.540 & 0.564 & 0.596 \\
10 & 102.6 & 0.970 & 0.878 & 0.614 & 0.612 & 0.668
\end{tabular}

Table C- 10. Data for BTEX BTCs from the $45^{\text {th }}$ sorption cycle on column LST1

\begin{tabular}{ccccccc} 
& & \multicolumn{5}{c}{ C/Co } \\
\cline { 3 - 7 } Sample & Pore Volumes & Benzene & Toluene & Ethylbenzene & $\begin{array}{c}\mathrm{p} \text { - \& m- } \\
\text { xylene }\end{array}$ & o-xylene \\
\hline 1 & 5.6 & 0.130 & 0.000 & 0.000 & 0.024 & 0.000 \\
2 & 11.0 & 0.514 & 0.116 & 0.117 & 0.041 & 0.000 \\
3 & 20.1 & 0.691 & 0.275 & 0.137 & 0.085 & 0.193 \\
4 & 29.5 & 0.839 & 0.449 & 0.266 & 0.177 & 0.266 \\
5 & 37.7 & 0.865 & 0.629 & 0.320 & 0.253 & 0.294 \\
6 & 47.6 & 0.926 & 0.728 & 0.417 & 0.306 & 0.395 \\
7 & 54.6 & 0.953 & 0.756 & 0.426 & 0.359 & 0.456 \\
8 & 65.0 & 0.984 & 0.826 & 0.477 & 0.464 & 0.534 \\
9 & 77.6 & 1.041 & 0.840 & 0.531 & 0.491 & 0.555 \\
10 & 86.3 & 1.007 & 0.839 & 0.621 & 0.548 & 0.611 \\
11 & 92.9 & 0.977 & 0.881 & 0.609 & 0.583 & 0.665 \\
12 & 101.7 & 0.996 & 0.874 & 0.589 & 0.643 & 0.771
\end{tabular}


Table C- 11. Data for BTEX BTCs from the $50^{\text {th }}$ sorption cycle on column LST1

\begin{tabular}{ccccccc} 
& & \multicolumn{5}{c}{ C/Co } \\
\cline { 3 - 7 } Sample & Pore Volumes & Benzene & Toluene & Ethylbenzene & $\begin{array}{c}\text { p- \& } \mathrm{m} \text { - } \\
\text { xylene }\end{array}$ & o-xylene \\
\hline 1 & 5.2 & 0.129 & 0.062 & 0.000 & 0.000 & 0.000 \\
2 & 10.6 & 0.451 & 0.203 & 0.102 & 0.066 & 0.083 \\
3 & 19.0 & 0.685 & 0.341 & 0.190 & 0.098 & 0.153 \\
4 & 27.2 & 0.781 & 0.468 & 0.225 & 0.196 & 0.205 \\
5 & 37.9 & 0.864 & 0.571 & 0.275 & 0.208 & 0.228 \\
6 & 48.0 & 0.947 & 0.667 & 0.332 & 0.262 & 0.360 \\
7 & 59.7 & 0.954 & 0.749 & 0.434 & 0.391 & 0.433 \\
8 & 70.9 & 0.987 & 0.783 & 0.549 & 0.426 & 0.549 \\
9 & 82.4 & 0.987 & 0.820 & 0.567 & 0.498 & 0.620 \\
10 & 90.6 & 1.031 & 0.900 & 0.632 & 0.529 & 0.670 \\
11 & 101.5 & 1.047 & 0.855 & 0.631 & 0.614 & 0.724
\end{tabular}


Table C- 12. Data for BTEX removal from the $1^{\text {st }}$ regeneration cycle on column LST1

\begin{tabular}{|c|c|c|c|c|c|c|c|c|c|c|c|}
\hline \multirow[b]{2}{*}{ Sample } & \multirow[b]{2}{*}{$\begin{array}{c}\text { Pore } \\
\text { Volumes } \\
\end{array}$} & \multicolumn{5}{|c|}{ Concentration $(\mathrm{mg} / \mathrm{L})$} & \multicolumn{5}{|c|}{ Mass Removed (mg) } \\
\hline & & Benzene & Toluene & Ethylbenzene & $\begin{array}{l}\mathrm{p}-\& \mathrm{~m}- \\
\mathrm{xylene}\end{array}$ & o-xylene & Benzene & Toluene & Ethylbenzene & $\begin{array}{l}\mathrm{p}-\& \mathrm{~m}- \\
\mathrm{xylene}\end{array}$ & o-xylene \\
\hline 1 & 88.8 & 0.0337 & 0.4202 & 0.0314 & 0.1389 & 0.1019 & 0.088 & 1.090 & 0.082 & 0.360 & 0.264 \\
\hline 2 & 205.4 & 0.0752 & 0.2455 & 0.0215 & 0.0956 & 0.0791 & 0.273 & 2.224 & 0.172 & 0.760 & 0.573 \\
\hline 3 & 322.0 & 0.0598 & 0.1559 & 0.0170 & 0.0733 & 0.0670 & 0.503 & 2.907 & 0.237 & 1.047 & 0.821 \\
\hline 4 & 438.6 & 0.0227 & 0.1043 & 0.0128 & 0.0570 & 0.0533 & 0.643 & 3.350 & 0.288 & 1.269 & 1.026 \\
\hline 5 & 555.2 & 0.0145 & 0.0715 & 0.0102 & 0.0456 & 0.0440 & 0.707 & 3.649 & 0.327 & 1.444 & 1.192 \\
\hline 7 & 788.3 & 0.0064 & 0.0248 & 0.0052 & 0.0179 & 0.0196 & 0.785 & 4.006 & 0.384 & 1.683 & 1.433 \\
\hline 8 & 904.9 & 0.0050 & 0.0251 & 0.0062 & 0.0240 & 0.0270 & 0.804 & 4.091 & 0.403 & 1.755 & 1.513 \\
\hline 9 & 1021.5 & 0.0038 & 0.0202 & 0.0054 & 0.0200 & 0.0225 & 0.819 & 4.168 & 0.423 & 1.829 & 1.597 \\
\hline 10 & 1138.1 & 0.0031 & 0.0161 & 0.0048 & 0.0172 & 0.0202 & 0.830 & 4.230 & 0.440 & 1.893 & 1.670 \\
\hline 11 & 1254.7 & 0.0027 & 0.0125 & 0.0040 & 0.0149 & 0.0171 & 0.840 & 4.279 & 0.455 & 1.948 & 1.733 \\
\hline 12 & 1371.2 & 0.0022 & 0.0095 & 0.0037 & 0.0123 & 0.0157 & 0.849 & 4.316 & 0.468 & 1.994 & 1.789 \\
\hline 13 & 1487.8 & 0.0020 & 0.0084 & 0.0036 & 0.0109 & 0.0147 & 0.856 & 4.347 & 0.481 & 2.033 & 1.840 \\
\hline
\end{tabular}


Table C- 13. Data for BTEX removal from the $5^{\text {th }}$ regeneration cycle on column LST1

\begin{tabular}{|c|c|c|c|c|c|c|c|c|c|c|c|}
\hline \multirow[b]{2}{*}{ Sample } & \multirow[b]{2}{*}{$\begin{array}{c}\text { Pore } \\
\text { Volumes }\end{array}$} & \multicolumn{5}{|c|}{ Concentration (mg/L) } & \multicolumn{5}{|c|}{ Mass Removed (mg) } \\
\hline & & Benzene & Toluene & Ethylbenzene & $\begin{array}{l}\mathrm{p}-\& \mathrm{~m}- \\
\text { xylene }\end{array}$ & o-xylene & Benzene & Toluene & Ethylbenzene & $\begin{array}{l}\mathrm{p}-\& \mathrm{~m}- \\
\text { xylene }\end{array}$ & o-xylene \\
\hline 1 & 76.4 & 0.0590 & 0.3858 & 0.0368 & 0.1482 & 0.1213 & 0.132 & 0.861 & 0.082 & 0.331 & 0.271 \\
\hline 3 & 303.5 & 0.0598 & 0.1579 & 0.0162 & 0.0807 & 0.0754 & 0.540 & 2.519 & 0.247 & 1.057 & 0.888 \\
\hline 4 & 417.0 & 0.0236 & 0.1036 & 0.0124 & 0.0697 & 0.0618 & 0.679 & 2.952 & 0.294 & 1.307 & 1.115 \\
\hline 5 & 530.5 & 0.0166 & 0.0734 & 0.0103 & 0.0565 & 0.0506 & 0.746 & 3.246 & 0.332 & 1.516 & 1.302 \\
\hline 7 & 757.5 & 0.0064 & 0.0332 & 0.0076 & 0.0325 & 0.0355 & 0.823 & 3.596 & 0.391 & 1.809 & 1.591 \\
\hline 8 & 871.0 & 0.0044 & 0.0245 & 0.0060 & 0.0258 & 0.0302 & 0.841 & 3.692 & 0.413 & 1.906 & 1.700 \\
\hline 9 & 984.6 & 0.0034 & 0.0172 & 0.0052 & 0.0216 & 0.0248 & 0.854 & 3.761 & 0.432 & 1.984 & 1.791 \\
\hline 10 & 1098.1 & 0.0024 & 0.0136 & 0.0044 & 0.0183 & 0.0198 & 0.863 & 3.812 & 0.448 & 2.051 & 1.865 \\
\hline 11 & 1211.6 & 0.0020 & 0.0129 & 0.0039 & 0.0161 & 0.0163 & 0.870 & 3.856 & 0.461 & 2.108 & 1.925 \\
\hline 12 & 1325.1 & 0.0016 & 0.0083 & 0.0032 & 0.0114 & 0.0138 & 0.876 & 3.891 & 0.473 & 2.153 & 1.975 \\
\hline 13 & 1438.6 & 0.0015 & 0.0054 & 0.0030 & 0.0109 & 0.0126 & 0.882 & 3.914 & 0.483 & 2.190 & 2.019 \\
\hline
\end{tabular}


Table C- 14. Data for BTEX removal from the $10^{\text {th }}$ regeneration cycle on column LST1

\begin{tabular}{|c|c|c|c|c|c|c|c|c|c|c|c|}
\hline \multirow[b]{2}{*}{ Sample } & \multirow[b]{2}{*}{$\begin{array}{c}\text { Pore } \\
\text { Volumes }\end{array}$} & \multicolumn{5}{|c|}{ Concentration (mg/L) } & \multicolumn{5}{|c|}{ Mass Removed (mg) } \\
\hline & & Benzene & Toluene & Ethylbenzene & $\begin{array}{l}\text { p- \& m- } \\
\text { xylene }\end{array}$ & o-xylene & Benzene & Toluene & Ethylbenzene & $\begin{array}{l}\text { p- \& m- } \\
\text { xylene }\end{array}$ & o-xylene \\
\hline 1 & 73.4 & 0.0633 & 0.4208 & 0.0311 & 0.1419 & 0.0962 & 0.136 & 0.902 & 0.067 & 0.304 & 0.206 \\
\hline 2 & 181.2 & 0.0654 & 0.2325 & 0.0211 & 0.0891 & 0.0775 & 0.338 & 1.931 & 0.149 & 0.668 & 0.480 \\
\hline 3 & 297.8 & 0.0529 & 0.1383 & 0.0138 & 0.0751 & 0.0617 & 0.540 & 2.562 & 0.208 & 0.948 & 0.717 \\
\hline 4 & 414.4 & 0.0304 & 0.0889 & 0.0105 & 0.0556 & 0.0457 & 0.682 & 2.949 & 0.250 & 1.170 & 0.899 \\
\hline 5 & 531.0 & 0.0162 & 0.0662 & 0.0083 & 0.0461 & 0.0379 & 0.761 & 3.213 & 0.282 & 1.343 & 1.042 \\
\hline 6 & 647.5 & 0.0119 & 0.0551 & 0.0066 & 0.0348 & 0.0322 & 0.809 & 3.420 & 0.307 & 1.481 & 1.161 \\
\hline 7 & 764.1 & 0.0073 & 0.0371 & 0.0056 & 0.0291 & 0.0288 & 0.842 & 3.577 & 0.328 & 1.590 & 1.265 \\
\hline 8 & 880.7 & 0.0047 & 0.0241 & 0.0044 & 0.0223 & 0.0227 & 0.862 & 3.681 & 0.345 & 1.677 & 1.353 \\
\hline 9 & 997.3 & 0.0032 & 0.0182 & 0.0038 & 0.0203 & 0.0172 & 0.876 & 3.753 & 0.359 & 1.750 & 1.421 \\
\hline 10 & 1113.9 & 0.0029 & 0.0149 & 0.0033 & 0.0158 & 0.0155 & 0.886 & 3.809 & 0.370 & 1.812 & 1.476 \\
\hline 11 & 1230.5 & 0.0027 & 0.0120 & 0.0033 & 0.0127 & 0.0141 & 0.895 & 3.855 & 0.382 & 1.860 & 1.527 \\
\hline 12 & 1347.0 & 0.0023 & 0.0095 & 0.0026 & 0.0095 & 0.0120 & 0.904 & 3.892 & 0.392 & 1.898 & 1.571 \\
\hline 13 & 1463.6 & 0.0022 & 0.0077 & 0.0024 & 0.0086 & 0.0112 & 0.912 & 3.921 & 0.400 & 1.929 & 1.611 \\
\hline 14 & 1580.2 & 0.0022 & 0.0070 & 0.0025 & 0.0078 & 0.0106 & 0.919 & 3.946 & 0.409 & 1.957 & 1.648 \\
\hline
\end{tabular}


Table C- 15. Data for BTEX removal from the $15^{\text {th }}$ regeneration cycle on column LST1

\begin{tabular}{|c|c|c|c|c|c|c|c|c|c|c|c|}
\hline \multirow[b]{2}{*}{ Sample } & \multirow[b]{2}{*}{$\begin{array}{c}\text { Pore } \\
\text { Volumes }\end{array}$} & \multicolumn{5}{|c|}{ Concentration (mg/L) } & \multicolumn{5}{|c|}{ Mass Removed (mg) } \\
\hline & & Benzene & Toluene & Ethylbenzene & $\begin{array}{l}\mathrm{p}-\& \mathrm{~m}- \\
\text { xylene }\end{array}$ & o-xylene & Benzene & Toluene & Ethylbenzene & $\begin{array}{l}\text { p- \& m- } \\
\text { xylene }\end{array}$ & o-xylene \\
\hline 1 & 73.4 & 0.0537 & 0.4934 & 0.0400 & 0.1467 & 0.1101 & 0.115 & 1.057 & 0.086 & 0.314 & 0.236 \\
\hline 2 & 178.6 & 0.0647 & 0.2726 & 0.0271 & 0.0921 & 0.0887 & 0.297 & 2.234 & 0.189 & 0.681 & 0.541 \\
\hline 3 & 295.2 & 0.0604 & 0.1622 & 0.0178 & 0.0777 & 0.0706 & 0.510 & 2.975 & 0.265 & 0.970 & 0.813 \\
\hline 4 & 411.7 & 0.0357 & 0.1042 & 0.0134 & 0.0575 & 0.0523 & 0.674 & 3.428 & 0.318 & 1.200 & 1.022 \\
\hline 5 & 525.3 & 0.0176 & 0.0776 & 0.0106 & 0.0476 & 0.0434 & 0.762 & 3.730 & 0.358 & 1.375 & 1.181 \\
\hline 6 & 638.8 & 0.0105 & 0.0646 & 0.0085 & 0.0359 & 0.0369 & 0.809 & 3.965 & 0.390 & 1.513 & 1.314 \\
\hline 7 & 752.3 & 0.0065 & 0.0435 & 0.0072 & 0.0301 & 0.0330 & 0.837 & 4.145 & 0.416 & 1.623 & 1.430 \\
\hline 8 & 865.8 & 0.0054 & 0.0283 & 0.0056 & 0.0231 & 0.0260 & 0.856 & 4.264 & 0.437 & 1.711 & 1.528 \\
\hline 9 & 979.3 & 0.0050 & 0.0214 & 0.0048 & 0.0210 & 0.0197 & 0.874 & 4.346 & 0.455 & 1.784 & 1.603 \\
\hline 10 & 1092.8 & 0.0032 & 0.0174 & 0.0042 & 0.0163 & 0.0177 & 0.887 & 4.410 & 0.469 & 1.846 & 1.665 \\
\hline 11 & 1206.3 & 0.0023 & 0.0141 & 0.0042 & 0.0131 & 0.0162 & 0.896 & 4.462 & 0.483 & 1.895 & 1.722 \\
\hline 12 & 1319.9 & 0.0018 & 0.0112 & 0.0033 & 0.0098 & 0.0137 & 0.903 & 4.504 & 0.496 & 1.933 & 1.771 \\
\hline 13 & 1433.4 & 0.0011 & 0.0090 & 0.0031 & 0.0089 & 0.0128 & 0.908 & 4.538 & 0.507 & 1.964 & 1.815 \\
\hline 14 & 1546.9 & 0.0011 & 0.0082 & 0.0032 & 0.0080 & 0.0121 & 0.911 & 4.566 & 0.517 & 1.992 & 1.856 \\
\hline
\end{tabular}


Table C- 16. Data for BTEX removal from the $20^{\text {th }}$ regeneration cycle on column LST1

\begin{tabular}{|c|c|c|c|c|c|c|c|c|c|c|c|}
\hline \multirow[b]{2}{*}{ Sample } & \multirow[b]{2}{*}{$\begin{array}{c}\text { Pore } \\
\text { Volumes }\end{array}$} & \multicolumn{5}{|c|}{ Concentration $(\mathrm{mg} / \mathrm{L})$} & \multicolumn{5}{|c|}{ Mass Removed (mg) } \\
\hline & & Benzene & Toluene & Ethylbenzene & $\begin{array}{l}\text { p- \& m- } \\
\text { xylene }\end{array}$ & o-xylene & Benzene & Toluene & Ethylbenzene & $\begin{array}{l}\mathrm{p}-\& \mathrm{~m}- \\
\mathrm{xylene}\end{array}$ & o-xylene \\
\hline 1 & 88.0 & 0.0508 & 0.4036 & 0.0412 & 0.1604 & 0.1087 & 0.131 & 1.038 & 0.106 & 0.413 & 0.279 \\
\hline 2 & 186.1 & 0.0634 & 0.2230 & 0.0279 & 0.1007 & 0.0875 & 0.294 & 1.935 & 0.205 & 0.786 & 0.560 \\
\hline 3 & 296.7 & 0.0547 & 0.1327 & 0.0183 & 0.0849 & 0.0697 & 0.485 & 2.510 & 0.279 & 1.086 & 0.814 \\
\hline 4 & 410.2 & 0.0404 & 0.0852 & 0.0138 & 0.0629 & 0.0517 & 0.643 & 2.871 & 0.332 & 1.331 & 1.016 \\
\hline 5 & 526.8 & 0.0138 & 0.0635 & 0.0109 & 0.0521 & 0.0428 & 0.735 & 3.124 & 0.374 & 1.527 & 1.176 \\
\hline 7 & 759.9 & 0.0090 & 0.0356 & 0.0074 & 0.0329 & 0.0326 & 0.816 & 3.473 & 0.435 & 1.806 & 1.429 \\
\hline 8 & 876.5 & 0.0065 & 0.0232 & 0.0058 & 0.0253 & 0.0257 & 0.842 & 3.573 & 0.458 & 1.905 & 1.528 \\
\hline 9 & 993.1 & 0.0049 & 0.0175 & 0.0050 & 0.0230 & 0.0194 & 0.861 & 3.642 & 0.476 & 1.987 & 1.605 \\
\hline 10 & 1109.7 & 0.0033 & 0.0143 & 0.0043 & 0.0179 & 0.0175 & 0.875 & 3.696 & 0.492 & 2.057 & 1.668 \\
\hline 11 & 1226.3 & 0.0021 & 0.0115 & 0.0044 & 0.0144 & 0.0159 & 0.885 & 3.740 & 0.507 & 2.111 & 1.725 \\
\hline 12 & 1342.9 & 0.0019 & 0.0091 & 0.0034 & 0.0107 & 0.0135 & 0.891 & 3.775 & 0.520 & 2.154 & 1.775 \\
\hline 13 & 1459.4 & 0.0016 & 0.0074 & 0.0032 & 0.0098 & 0.0127 & 0.897 & 3.803 & 0.531 & 2.189 & 1.819 \\
\hline
\end{tabular}


Table C- 17. Data for BTEX removal from the $25^{\text {th }}$ regeneration cycle on column LST1

\begin{tabular}{|c|c|c|c|c|c|c|c|c|c|c|c|}
\hline \multirow[b]{2}{*}{ Sample } & \multirow[b]{2}{*}{$\begin{array}{c}\text { Pore } \\
\text { Volumes }\end{array}$} & \multicolumn{5}{|c|}{ Concentration (mg/L) } & \multicolumn{5}{|c|}{ Mass Removed (mg) } \\
\hline & & Benzene & Toluene & Ethylbenzene & $\begin{array}{l}\text { p- \& m- } \\
\text { xylene }\end{array}$ & o-xylene & Benzene & Toluene & Ethylbenzene & $\begin{array}{l}\text { p- \& m- } \\
\text { xylene }\end{array}$ & o-xylene \\
\hline 1 & 225.0 & 0.0817 & 0.2743 & 0.0217 & 0.1038 & 0.0718 & 0.537 & 1.802 & 0.142 & 0.682 & 0.472 \\
\hline 2 & 348.2 & 0.0426 & 0.1864 & 0.0172 & 0.0851 & 0.0627 & 0.761 & 2.632 & 0.212 & 1.022 & 0.714 \\
\hline 3 & 456.1 & 0.0227 & 0.1367 & 0.0132 & 0.0670 & 0.0514 & 0.864 & 3.140 & 0.260 & 1.262 & 0.894 \\
\hline 4 & 566.7 & 0.0135 & 0.0953 & 0.0111 & 0.0572 & 0.0458 & 0.922 & 3.515 & 0.300 & 1.462 & 1.050 \\
\hline 5 & 683.2 & 0.0081 & 0.0680 & 0.0094 & 0.0458 & 0.0379 & 0.959 & 3.793 & 0.335 & 1.638 & 1.193 \\
\hline 6 & 799.8 & 0.0049 & 0.0468 & 0.0075 & 0.0368 & 0.0306 & 0.981 & 3.989 & 0.363 & 1.778 & 1.309 \\
\hline 7 & 916.4 & 0.0034 & 0.0349 & 0.0060 & 0.0297 & 0.0261 & 0.995 & 4.128 & 0.386 & 1.892 & 1.406 \\
\hline 8 & 1033.0 & 0.0023 & 0.0252 & 0.0050 & 0.0247 & 0.0225 & 1.005 & 4.230 & 0.405 & 1.984 & 1.489 \\
\hline 9 & 1149.6 & 0.0017 & 0.0186 & 0.0043 & 0.0199 & 0.0189 & 1.011 & 4.305 & 0.421 & 2.060 & 1.559 \\
\hline 10 & 1266.2 & 0.0014 & 0.0143 & 0.0035 & 0.0172 & 0.0169 & 1.017 & 4.361 & 0.434 & 2.123 & 1.620 \\
\hline 11 & 1382.7 & 0.0011 & 0.0107 & 0.0031 & 0.0145 & 0.0142 & 1.021 & 4.403 & 0.445 & 2.177 & 1.673 \\
\hline 12 & 1499.3 & 0.0009 & 0.0084 & 0.0027 & 0.0125 & 0.0126 & 1.024 & 4.436 & 0.455 & 2.223 & 1.719 \\
\hline 13 & 1615.9 & 0.0009 & 0.0066 & 0.0025 & 0.0104 & 0.0114 & 1.028 & 4.461 & 0.464 & 2.262 & 1.760 \\
\hline 14 & 1732.5 & 0.0009 & 0.0025 & 0.0022 & 0.0096 & 0.0096 & 1.031 & 4.477 & 0.472 & 2.296 & 1.795 \\
\hline
\end{tabular}


Table C- 18. Data for BTEX removal from the $30^{\text {th }}$ regeneration cycle on column LST1

\begin{tabular}{|c|c|c|c|c|c|c|c|c|c|c|c|}
\hline \multirow[b]{2}{*}{ Sample } & \multirow[b]{2}{*}{$\begin{array}{c}\text { Pore } \\
\text { Volumes }\end{array}$} & \multicolumn{5}{|c|}{ Concentration (mg/L) } & \multicolumn{5}{|c|}{ Mass Removed (mg) } \\
\hline & & Benzene & Toluene & Ethylbenzene & $\begin{array}{l}\text { p- \& m- } \\
\text { xylene }\end{array}$ & o-xylene & Benzene & Toluene & Ethylbenzene & $\begin{array}{l}\mathrm{p}-\& \mathrm{~m}- \\
\text { xylene }\end{array}$ & o-xylene \\
\hline 1 & 75.1 & 0.0573 & 0.4165 & 0.0304 & 0.1507 & 0.1073 & 0.126 & 0.914 & 0.067 & 0.331 & 0.236 \\
\hline 2 & 183.0 & 0.0738 & 0.2817 & 0.0212 & 0.1151 & 0.0897 & 0.332 & 2.014 & 0.148 & 0.749 & 0.546 \\
\hline 3 & 293.6 & 0.0525 & 0.1987 & 0.0154 & 0.0914 & 0.0707 & 0.536 & 2.790 & 0.207 & 1.083 & 0.805 \\
\hline 4 & 407.1 & 0.0310 & 0.1273 & 0.0121 & 0.0709 & 0.0595 & 0.675 & 3.331 & 0.253 & 1.352 & 1.021 \\
\hline 5 & 520.6 & 0.0171 & 0.0844 & 0.0099 & 0.0543 & 0.0495 & 0.755 & 3.681 & 0.289 & 1.559 & 1.201 \\
\hline 6 & 634.1 & 0.0120 & 0.0576 & 0.0085 & 0.0436 & 0.0422 & 0.803 & 3.917 & 0.320 & 1.722 & 1.354 \\
\hline 7 & 747.7 & 0.0090 & 0.0450 & 0.0066 & 0.0348 & 0.0366 & 0.838 & 4.087 & 0.345 & 1.851 & 1.484 \\
\hline 8 & 861.2 & 0.0077 & 0.0357 & 0.0057 & 0.0294 & 0.0305 & 0.866 & 4.221 & 0.365 & 1.958 & 1.596 \\
\hline 9 & 974.7 & 0.0058 & 0.0247 & 0.0049 & 0.0260 & 0.0253 & 0.888 & 4.321 & 0.383 & 2.050 & 1.688 \\
\hline 10 & 1088.2 & 0.0042 & 0.0186 & 0.0037 & 0.0195 & 0.0227 & 0.905 & 4.393 & 0.397 & 2.125 & 1.768 \\
\hline 11 & 1201.7 & 0.0020 & 0.0109 & 0.0031 & 0.0181 & 0.0195 & 0.915 & 4.441 & 0.408 & 2.188 & 1.838 \\
\hline 12 & 1315.2 & 0.0009 & 0.0093 & 0.0030 & 0.0153 & 0.0162 & 0.920 & 4.475 & 0.418 & 2.243 & 1.897 \\
\hline 13 & 1428.7 & 0.0006 & 0.0061 & 0.0028 & 0.0132 & 0.0126 & 0.922 & 4.500 & 0.428 & 2.290 & 1.945 \\
\hline 14 & 1542.3 & 0.0005 & 0.0044 & 0.0025 & 0.0108 & 0.0093 & 0.924 & 4.518 & 0.437 & 2.330 & 1.981 \\
\hline
\end{tabular}


Table C- 19. Data for BTEX removal from the $35^{\text {th }}$ regeneration cycle on column LST1

\begin{tabular}{|c|c|c|c|c|c|c|c|c|c|c|c|}
\hline \multirow[b]{2}{*}{ Sample } & \multirow[b]{2}{*}{$\begin{array}{c}\text { Pore } \\
\text { Volumes }\end{array}$} & \multicolumn{5}{|c|}{ Concentration (mg/L) } & \multicolumn{5}{|c|}{ Mass Removed (mg) } \\
\hline & & Benzene & Toluene & Ethylbenzene & $\begin{array}{l}\text { p- \& m- } \\
\text { xylene }\end{array}$ & o-xylene & Benzene & Toluene & Ethylbenzene & $\begin{array}{l}\mathrm{p}-\& \mathrm{~m}- \\
\text { xylene }\end{array}$ & o-xylene \\
\hline 1 & 80.4 & 0.0527 & 0.4032 & 0.0380 & 0.1476 & 0.1130 & 0.124 & 0.947 & 0.089 & 0.347 & 0.265 \\
\hline 2 & 180.7 & 0.0712 & 0.2765 & 0.0283 & 0.0979 & 0.0798 & 0.305 & 1.942 & 0.186 & 0.706 & 0.548 \\
\hline 3 & 300.5 & 0.0461 & 0.1829 & 0.0179 & 0.0783 & 0.0675 & 0.510 & 2.746 & 0.267 & 1.015 & 0.805 \\
\hline 4 & 420.3 & 0.0184 & 0.1070 & 0.0144 & 0.0660 & 0.0530 & 0.623 & 3.253 & 0.324 & 1.267 & 1.016 \\
\hline 5 & 540.2 & 0.0119 & 0.0777 & 0.0118 & 0.0550 & 0.0426 & 0.676 & 3.577 & 0.370 & 1.479 & 1.184 \\
\hline 6 & 660.0 & 0.0094 & 0.0581 & 0.0103 & 0.0461 & 0.0388 & 0.714 & 3.814 & 0.408 & 1.656 & 1.326 \\
\hline 7 & 776.6 & 0.0077 & 0.0450 & 0.0080 & 0.0348 & 0.0318 & 0.743 & 3.990 & 0.439 & 1.794 & 1.446 \\
\hline 8 & 893.1 & 0.0069 & 0.0335 & 0.0070 & 0.0303 & 0.0245 & 0.768 & 4.123 & 0.465 & 1.905 & 1.542 \\
\hline 9 & 1009.7 & 0.0054 & 0.0204 & 0.0067 & 0.0256 & 0.0210 & 0.789 & 4.215 & 0.488 & 2.000 & 1.620 \\
\hline 10 & 1126.3 & 0.0034 & 0.0133 & 0.0058 & 0.0181 & 0.0182 & 0.804 & 4.273 & 0.510 & 2.074 & 1.686 \\
\hline 11 & 1242.9 & 0.0024 & 0.0072 & 0.0049 & 0.0148 & 0.0159 & 0.814 & 4.308 & 0.528 & 2.130 & 1.744 \\
\hline 12 & 1359.5 & 0.0011 & 0.0059 & 0.0045 & 0.0115 & 0.0122 & 0.820 & 4.330 & 0.544 & 2.175 & 1.792 \\
\hline 13 & 1476.1 & 0.0007 & 0.0044 & 0.0039 & 0.0110 & 0.0116 & 0.823 & 4.348 & 0.558 & 2.213 & 1.833 \\
\hline 14 & 1592.6 & 0.0006 & 0.0031 & 0.0035 & 0.0070 & 0.0106 & 0.825 & 4.360 & 0.571 & 2.244 & 1.871 \\
\hline
\end{tabular}


Table C- 20. Data for BTEX removal from the $40^{\text {th }}$ regeneration cycle on column LST1

\begin{tabular}{|c|c|c|c|c|c|c|c|c|c|c|c|}
\hline \multirow[b]{2}{*}{ Sample } & \multirow[b]{2}{*}{$\begin{array}{c}\text { Pore } \\
\text { Volumes }\end{array}$} & \multicolumn{5}{|c|}{ Concentration (mg/L) } & \multicolumn{5}{|c|}{ Mass Removed (mg) } \\
\hline & & Benzene & Toluene & Ethylbenzene & $\begin{array}{l}\text { p- \& m- } \\
\text { xylene }\end{array}$ & o-xylene & Benzene & Toluene & Ethylbenzene & $\begin{array}{l}\text { p- \& m- } \\
\text { xylene }\end{array}$ & o-xylene \\
\hline 1 & 94.8 & 0.0685 & 0.3121 & 0.0408 & 0.1302 & 0.1019 & 0.190 & 0.864 & 0.113 & 0.360 & 0.282 \\
\hline 2 & 208.3 & 0.0725 & 0.2488 & 0.0270 & 0.0874 & 0.0756 & 0.423 & 1.794 & 0.225 & 0.721 & 0.577 \\
\hline 3 & 321.8 & 0.0462 & 0.1691 & 0.0187 & 0.0736 & 0.0619 & 0.620 & 2.487 & 0.301 & 0.988 & 0.804 \\
\hline 4 & 435.4 & 0.0263 & 0.1150 & 0.0128 & 0.0588 & 0.0510 & 0.740 & 2.958 & 0.353 & 1.208 & 0.992 \\
\hline 5 & 548.9 & 0.0145 & 0.0696 & 0.0098 & 0.0529 & 0.0430 & 0.808 & 3.264 & 0.391 & 1.393 & 1.147 \\
\hline 6 & 662.4 & 0.0101 & 0.0490 & 0.0074 & 0.0374 & 0.0340 & 0.849 & 3.461 & 0.419 & 1.542 & 1.275 \\
\hline 7 & 775.9 & 0.0067 & 0.0389 & 0.0061 & 0.0348 & 0.0287 & 0.876 & 3.606 & 0.442 & 1.662 & 1.379 \\
\hline 8 & 889.4 & 0.0058 & 0.0299 & 0.0054 & 0.0267 & 0.0233 & 0.897 & 3.720 & 0.461 & 1.764 & 1.465 \\
\hline 9 & 1002.9 & 0.0050 & 0.0206 & 0.0045 & 0.0202 & 0.0189 & 0.915 & 3.804 & 0.477 & 1.841 & 1.535 \\
\hline 10 & 1116.4 & 0.0034 & 0.0158 & 0.0038 & 0.0174 & 0.0181 & 0.929 & 3.865 & 0.491 & 1.904 & 1.596 \\
\hline 11 & 1230.0 & 0.0015 & 0.0083 & 0.0036 & 0.0125 & 0.0153 & 0.937 & 3.905 & 0.503 & 1.953 & 1.652 \\
\hline 12 & 1343.5 & 0.0011 & 0.0072 & 0.0033 & 0.0097 & 0.0136 & 0.941 & 3.930 & 0.515 & 1.990 & 1.700 \\
\hline 13 & 1457.0 & 0.0008 & 0.0047 & 0.0031 & 0.0073 & 0.0115 & 0.944 & 3.950 & 0.526 & 2.019 & 1.741 \\
\hline 14 & 1570.5 & 0.0006 & 0.0031 & 0.0029 & 0.0069 & 0.0094 & 0.947 & 3.963 & 0.535 & 2.042 & 1.776 \\
\hline
\end{tabular}


Table C- 21. Data for BTEX removal from the $45^{\text {th }}$ regeneration cycle on column LST1

\begin{tabular}{|c|c|c|c|c|c|c|c|c|c|c|c|}
\hline \multirow[b]{2}{*}{ Sample } & \multirow[b]{2}{*}{$\begin{array}{c}\text { Pore } \\
\text { Volumes }\end{array}$} & \multicolumn{5}{|c|}{ Concentration (mg/L) } & \multicolumn{5}{|c|}{ Mass Removed (mg) } \\
\hline & & Benzene & Toluene & Ethylbenzene & $\begin{array}{l}\mathrm{p}-\& \mathrm{~m}- \\
\text { xylene }\end{array}$ & o-xylene & Benzene & Toluene & Ethylbenzene & $\begin{array}{l}\text { p- \& m- } \\
\text { xylene }\end{array}$ & o-xylene \\
\hline 1 & 92.4 & 0.0412 & 0.3522 & 0.0299 & 0.1323 & 0.0889 & 0.111 & 0.951 & 0.081 & 0.357 & 0.240 \\
\hline 2 & 219.3 & 0.0540 & 0.2383 & 0.0173 & 0.0964 & 0.0693 & 0.288 & 2.045 & 0.168 & 0.781 & 0.533 \\
\hline 3 & 342.5 & 0.0411 & 0.1462 & 0.0132 & 0.0736 & 0.0558 & 0.459 & 2.737 & 0.223 & 1.087 & 0.759 \\
\hline 4 & 459.1 & 0.0290 & 0.0983 & 0.0096 & 0.0573 & 0.0453 & 0.578 & 3.154 & 0.262 & 1.310 & 0.931 \\
\hline 5 & 572.6 & 0.0207 & 0.0610 & 0.0078 & 0.0497 & 0.0370 & 0.661 & 3.418 & 0.291 & 1.487 & 1.067 \\
\hline 6 & 689.2 & 0.0125 & 0.0523 & 0.0068 & 0.0397 & 0.0337 & 0.717 & 3.611 & 0.316 & 1.640 & 1.188 \\
\hline 7 & 805.8 & 0.0092 & 0.0346 & 0.0056 & 0.0313 & 0.0257 & 0.754 & 3.759 & 0.337 & 1.761 & 1.289 \\
\hline 8 & 922.4 & 0.0059 & 0.0251 & 0.0048 & 0.0257 & 0.0217 & 0.780 & 3.860 & 0.355 & 1.857 & 1.370 \\
\hline 9 & 1039.0 & 0.0040 & 0.0176 & 0.0044 & 0.0209 & 0.0185 & 0.797 & 3.933 & 0.370 & 1.937 & 1.438 \\
\hline 10 & 1155.6 & 0.0033 & 0.0114 & 0.0036 & 0.0177 & 0.0151 & 0.809 & 3.982 & 0.384 & 2.002 & 1.495 \\
\hline 11 & 1272.2 & 0.0022 & 0.0065 & 0.0030 & 0.0165 & 0.0146 & 0.819 & 4.013 & 0.395 & 2.060 & 1.546 \\
\hline 12 & 1388.7 & 0.0010 & 0.0058 & 0.0031 & 0.0148 & 0.0126 & 0.824 & 4.034 & 0.406 & 2.114 & 1.592 \\
\hline 13 & 1505.3 & 0.0009 & 0.0043 & 0.0026 & 0.0119 & 0.0096 & 0.828 & 4.051 & 0.415 & 2.159 & 1.630 \\
\hline 14 & 1621.9 & 0.0005 & 0.0025 & 0.0027 & 0.0080 & 0.0091 & 0.830 & 4.063 & 0.424 & 2.193 & 1.662 \\
\hline
\end{tabular}


Table C- 22. Data for BTEX removal from the $50^{\mathrm{h}}$ regeneration cycle on column LST1

\begin{tabular}{|c|c|c|c|c|c|c|c|c|c|c|c|}
\hline \multirow[b]{2}{*}{ Sample } & \multirow[b]{2}{*}{$\begin{array}{c}\text { Pore } \\
\text { Volumes }\end{array}$} & \multicolumn{5}{|c|}{ Concentration (mg/L) } & \multicolumn{5}{|c|}{ Mass Removed (mg) } \\
\hline & & Benzene & Toluene & Ethylbenzene & $\begin{array}{l}\text { p- \& m- } \\
\text { xylene }\end{array}$ & o-xylene & Benzene & Toluene & Ethylbenzene & $\begin{array}{l}\mathrm{p}-\& \mathrm{~m}- \\
\text { xylene }\end{array}$ & o-xylene \\
\hline 1 & 88.0 & 0.0543 & 0.4025 & 0.0351 & 0.1302 & 0.1095 & 0.140 & 1.035 & 0.090 & 0.335 & 0.282 \\
\hline 2 & 186.1 & 0.0624 & 0.2994 & 0.0206 & 0.0990 & 0.0844 & 0.307 & 2.040 & 0.170 & 0.663 & 0.559 \\
\hline 3 & 296.7 & 0.0562 & 0.1800 & 0.0163 & 0.0800 & 0.0705 & 0.498 & 2.814 & 0.230 & 0.952 & 0.809 \\
\hline 4 & 410.2 & 0.0350 & 0.1053 & 0.0131 & 0.0679 & 0.0600 & 0.649 & 3.287 & 0.278 & 1.197 & 1.026 \\
\hline 5 & 526.8 & 0.0228 & 0.0716 & 0.0087 & 0.0563 & 0.0506 & 0.748 & 3.588 & 0.316 & 1.409 & 1.214 \\
\hline 6 & 643.4 & 0.0124 & 0.0602 & 0.0081 & 0.0466 & 0.0408 & 0.808 & 3.813 & 0.344 & 1.584 & 1.370 \\
\hline 7 & 759.9 & 0.0084 & 0.0413 & 0.0077 & 0.0376 & 0.0333 & 0.843 & 3.985 & 0.371 & 1.727 & 1.496 \\
\hline 8 & 876.5 & 0.0038 & 0.0325 & 0.0062 & 0.0276 & 0.0289 & 0.864 & 4.111 & 0.395 & 1.838 & 1.602 \\
\hline 9 & 993.1 & 0.0032 & 0.0243 & 0.0053 & 0.0236 & 0.0240 & 0.876 & 4.208 & 0.414 & 1.925 & 1.692 \\
\hline 10 & 1109.7 & 0.0022 & 0.0147 & 0.0047 & 0.0174 & 0.0201 & 0.885 & 4.274 & 0.431 & 1.995 & 1.767 \\
\hline 11 & 1226.3 & 0.0018 & 0.0090 & 0.0042 & 0.0149 & 0.0183 & 0.892 & 4.315 & 0.447 & 2.050 & 1.832 \\
\hline 12 & 1342.9 & 0.0012 & 0.0078 & 0.0037 & 0.0138 & 0.0155 & 0.897 & 4.343 & 0.460 & 2.099 & 1.889 \\
\hline 13 & 1459.4 & 0.0008 & 0.0063 & 0.0035 & 0.0130 & 0.0142 & 0.901 & 4.367 & 0.472 & 2.145 & 1.940 \\
\hline 14 & 1576.0 & 0.0005 & 0.0031 & 0.0032 & 0.0084 & 0.0126 & 0.903 & 4.383 & 0.484 & 2.181 & 1.986 \\
\hline
\end{tabular}


Table C- 23. Data for BTEX BTCs from the $1^{\text {st }}$ sorption cycle on column LST2

\begin{tabular}{ccccccc} 
& & \multicolumn{5}{c}{ C/Co } \\
\cline { 3 - 7 } Sample & Pore Volumes & Benzene & Toluene & Ethylbenzene & $\begin{array}{c}\mathrm{p} \text { - \& m- } \\
\text { xylene }\end{array}$ & o-xylene \\
\hline 1 & 3.4 & 0.030 & 0.030 & 0.000 & 0.000 & 0.000 \\
2 & 8.5 & 0.079 & 0.083 & 0.114 & 0.000 & 0.000 \\
3 & 15.5 & 0.396 & 0.135 & 0.149 & 0.063 & 0.079 \\
4 & 24.3 & 0.657 & 0.218 & 0.186 & 0.084 & 0.113 \\
5 & 31.6 & 0.730 & 0.354 & 0.256 & 0.153 & 0.156 \\
6 & 40.8 & 0.821 & 0.483 & 0.336 & 0.202 & 0.231 \\
7 & 51.0 & 0.888 & 0.592 & 0.395 & 0.282 & 0.315 \\
8 & 69.1 & 0.985 & 0.739 & 0.506 & 0.423 & 0.423 \\
9 & 79.6 & 0.999 & 0.795 & 0.498 & 0.484 & 0.460 \\
10 & 96.7 & 0.996 & 0.810 & 0.590 & 0.528 & 0.543
\end{tabular}

Table C- 24. Data for BTEX BTCs from the $5^{\text {th }}$ sorption cycle on column LST2

\begin{tabular}{ccccccc} 
& & \multicolumn{5}{c}{ C/Co } \\
\cline { 3 - 7 } Sample & Pore Volumes & Benzene & Toluene & Ethylbenzene & $\begin{array}{c}p \text { - \& } \mathrm{m} \text { - } \\
\text { xylene }\end{array}$ & o-xylene \\
\hline 1 & 8.2 & 0.116 & 0.017 & 0.000 & 0.000 & 0.000 \\
2 & 8.1 & 0.421 & 0.072 & 0.000 & 0.023 & 0.000 \\
3 & 8.0 & 0.577 & 0.222 & 0.124 & 0.063 & 0.116 \\
4 & 7.9 & 0.722 & 0.315 & 0.212 & 0.092 & 0.196 \\
5 & 7.9 & 0.787 & 0.435 & 0.233 & 0.143 & 0.268 \\
6 & 7.9 & 0.839 & 0.564 & 0.276 & 0.196 & 0.288 \\
7 & 8.0 & 0.919 & 0.624 & 0.353 & 0.288 & 0.386 \\
8 & 7.7 & 0.873 & 0.679 & 0.440 & 0.335 & 0.426 \\
9 & 7.8 & 0.961 & 0.736 & 0.489 & 0.441 & 0.487 \\
10 & 7.6 & 0.931 & 0.772 & 0.556 & 0.503 & 0.577 \\
11 & 7.6 & 0.973 & 0.825 & 0.546 & 0.564 & 0.569
\end{tabular}


Table C- 25. Data for BTEX BTCs from the $10^{\text {th }}$ sorption cycle on column LST2

\begin{tabular}{ccccccc} 
& & \multicolumn{5}{c}{ C/Co } \\
\cline { 3 - 7 } Sample & Pore Volumes & Benzene & Toluene & Ethylbenzene & $\begin{array}{c}\mathrm{p} \text { - \& } \mathrm{m} \text { - } \\
\text { xylene }\end{array}$ & o-xylene \\
\hline 1 & 5.3 & 0.054 & 0.000 & 0.000 & 0.000 & 0.000 \\
2 & 10.9 & 0.306 & 0.092 & 0.073 & 0.023 & 0.072 \\
3 & 18.3 & 0.556 & 0.265 & 0.109 & 0.043 & 0.088 \\
4 & 25.5 & 0.628 & 0.284 & 0.164 & 0.067 & 0.160 \\
5 & 32.9 & 0.832 & 0.409 & 0.199 & 0.128 & 0.198 \\
6 & 41.4 & 0.879 & 0.524 & 0.246 & 0.168 & 0.262 \\
7 & 49.2 & 0.925 & 0.626 & 0.275 & 0.230 & 0.308 \\
8 & 58.2 & 0.976 & 0.702 & 0.362 & 0.297 & 0.394 \\
9 & 67.1 & 0.975 & 0.746 & 0.424 & 0.385 & 0.443 \\
10 & 77.7 & 0.955 & 0.834 & 0.481 & 0.455 & 0.479 \\
11 & 91.1 & 1.003 & 0.812 & 0.581 & 0.482 & 0.511 \\
12 & 101.8 & 0.988 & 0.843 & 0.648 & 0.544 & 0.560
\end{tabular}

Table C- 26. Data for BTEX BTCs from the $15^{\text {th }}$ sorption cycle on column LST2

\begin{tabular}{ccccccc} 
& & \multicolumn{5}{c}{ C/Co } \\
\cline { 3 - 7 } Sample & Pore Volumes & Benzene & Toluene & Ethylbenzene & $\begin{array}{c}\text { p- \& } \mathrm{m} \text { - } \\
\text { xylene }\end{array}$ & o-xylene \\
\hline 1 & 5.9 & 0.104 & 0.036 & 0.000 & 0.000 & 0.000 \\
2 & 11.4 & 0.366 & 0.119 & 0.000 & 0.026 & 0.000 \\
3 & 19.0 & 0.559 & 0.245 & 0.163 & 0.029 & 0.159 \\
4 & 28.6 & 0.689 & 0.370 & 0.186 & 0.087 & 0.225 \\
5 & 36.6 & 0.776 & 0.536 & 0.229 & 0.167 & 0.265 \\
6 & 45.2 & 0.821 & 0.622 & 0.287 & 0.229 & 0.324 \\
7 & 53.0 & 0.855 & 0.652 & 0.355 & 0.271 & 0.410 \\
8 & 64.2 & 0.958 & 0.771 & 0.392 & 0.409 & 0.427 \\
9 & 70.9 & 0.942 & 0.814 & 0.514 & 0.424 & 0.521 \\
10 & 80.2 & 0.998 & 0.832 & 0.537 & 0.502 & 0.522 \\
11 & 91.2 & 0.943 & 0.911 & 0.615 & 0.540 & 0.641 \\
12 & 101.7 & 0.979 & 0.972 & 0.615 & 0.611 & 0.585
\end{tabular}


Table C- 27. Data for BTEX BTCs from the $20^{\text {th }}$ sorption cycle on column LST2

\begin{tabular}{ccccccc} 
& & \multicolumn{5}{c}{ C/Co } \\
\cline { 3 - 7 } Sample & Pore Volumes & Benzene & Toluene & Ethylbenzene & $\begin{array}{c}\text { p- \& } \mathrm{m} \text { - } \\
\text { xylene }\end{array}$ & o-xylene \\
\hline 1 & 5.4 & 0.162 & 0.049 & 0.000 & 0.000 & 0.000 \\
2 & 10.6 & 0.287 & 0.139 & 0.107 & 0.026 & 0.068 \\
3 & 17.4 & 0.476 & 0.253 & 0.130 & 0.059 & 0.150 \\
4 & 22.7 & 0.670 & 0.368 & 0.147 & 0.072 & 0.161 \\
5 & 30.9 & 0.777 & 0.395 & 0.185 & 0.145 & 0.235 \\
6 & 40.2 & 0.813 & 0.612 & 0.224 & 0.234 & 0.319 \\
7 & 49.0 & 0.856 & 0.705 & 0.230 & 0.329 & 0.386 \\
8 & 57.5 & 0.921 & 0.702 & 0.273 & 0.367 & 0.428 \\
9 & 65.8 & 0.944 & 0.782 & 0.364 & 0.448 & 0.531 \\
10 & 77.9 & 0.980 & 0.883 & 0.442 & 0.523 & 0.559 \\
11 & 89.7 & 1.032 & 0.966 & 0.510 & 0.565 & 0.584 \\
12 & 100.8 & 1.028 & 0.924 & 0.582 & 0.594 & 0.666
\end{tabular}

Table C- 28. Data for BTEX BTCs from the $25^{\text {th }}$ sorption cycle on column LST2

\begin{tabular}{ccccccc} 
& & \multicolumn{5}{c}{ C/Co } \\
\cline { 3 - 7 } Sample & Pore Volumes & Benzene & Toluene & Ethylbenzene & $\begin{array}{c}\mathrm{p} \text { - \& } \mathrm{m} \text { - } \\
\text { xylene }\end{array}$ & o-xylene \\
\hline 1 & 5.5 & 0.082 & 0.000 & 0.000 & 0.000 & 0.000 \\
2 & 11.8 & 0.241 & 0.145 & 0.100 & 0.047 & 0.000 \\
3 & 22.3 & 0.557 & 0.284 & 0.146 & 0.103 & 0.110 \\
4 & 29.5 & 0.709 & 0.471 & 0.197 & 0.147 & 0.163 \\
5 & 36.3 & 0.855 & 0.582 & 0.265 & 0.256 & 0.239 \\
6 & 46.2 & 0.880 & 0.623 & 0.308 & 0.256 & 0.309 \\
7 & 56.1 & 0.840 & 0.658 & 0.358 & 0.346 & 0.346 \\
8 & 65.1 & 0.921 & 0.784 & 0.397 & 0.453 & 0.404 \\
9 & 73.8 & 0.960 & 0.782 & 0.455 & 0.471 & 0.468 \\
10 & 81.2 & 1.017 & 0.829 & 0.555 & 0.576 & 0.534 \\
11 & 91.4 & 1.062 & 0.887 & 0.516 & 0.626 & 0.570 \\
12 & 102.1 & 1.012 & 0.948 & 0.568 & 0.633 & 0.591
\end{tabular}


Table C- 29. Data for BTEX BTCs from the $30^{\text {th }}$ sorption cycle on column LST2

\begin{tabular}{ccccccc} 
& & \multicolumn{5}{c}{ C/Co } \\
\cline { 3 - 7 } Sample & Pore Volumes & Benzene & Toluene & Ethylbenzene & $\begin{array}{c}\mathrm{p} \text { - \& } \mathrm{m} \text { - } \\
\text { xylene }\end{array}$ & o-xylene \\
\hline 1 & 5.0 & 0.073 & 0.000 & 0.000 & 0.000 & 0.000 \\
2 & 10.4 & 0.273 & 0.063 & 0.072 & 0.023 & 0.079 \\
3 & 17.7 & 0.425 & 0.196 & 0.112 & 0.041 & 0.119 \\
4 & 22.8 & 0.619 & 0.351 & 0.163 & 0.061 & 0.138 \\
5 & 30.8 & 0.664 & 0.488 & 0.260 & 0.113 & 0.181 \\
6 & 39.6 & 0.755 & 0.589 & 0.299 & 0.139 & 0.247 \\
7 & 49.0 & 0.880 & 0.681 & 0.314 & 0.233 & 0.355 \\
8 & 60.2 & 0.856 & 0.824 & 0.346 & 0.325 & 0.451 \\
9 & 69.7 & 0.898 & 0.784 & 0.460 & 0.424 & 0.573 \\
10 & 82.0 & 0.938 & 0.912 & 0.449 & 0.467 & 0.554 \\
11 & 91.6 & 0.959 & 0.891 & 0.580 & 0.501 & 0.616 \\
12 & 102.6 & 1.018 & 0.947 & 0.665 & 0.576 & 0.616
\end{tabular}

Table C- 30. Data for BTEX BTCs from the $35^{\text {th }}$ sorption cycle on column LST2

\begin{tabular}{ccccccc} 
& & \multicolumn{5}{c}{ C/Co } \\
\cline { 3 - 7 } Sample & Pore Volumes & Benzene & Toluene & Ethylbenzene & $\begin{array}{c}\text { p- \& m- } \\
\text { xylene }\end{array}$ & o-xylene \\
\hline 1 & 6.0 & 0.044 & 0.024 & 0.000 & 0.000 & 0.000 \\
2 & 11.9 & 0.280 & 0.094 & 0.086 & 0.026 & 0.000 \\
3 & 18.6 & 0.368 & 0.247 & 0.183 & 0.053 & 0.115 \\
4 & 26.7 & 0.696 & 0.377 & 0.194 & 0.124 & 0.141 \\
5 & 34.6 & 0.743 & 0.465 & 0.248 & 0.176 & 0.286 \\
6 & 42.7 & 0.777 & 0.566 & 0.308 & 0.221 & 0.318 \\
7 & 51.2 & 0.881 & 0.634 & 0.305 & 0.314 & 0.418 \\
8 & 60.2 & 0.925 & 0.728 & 0.423 & 0.413 & 0.427 \\
9 & 73.0 & 1.002 & 0.817 & 0.510 & 0.486 & 0.554 \\
10 & 79.6 & 1.025 & 0.913 & 0.609 & 0.568 & 0.522 \\
11 & 89.2 & 0.997 & 0.873 & 0.616 & 0.578 & 0.563 \\
12 & 102.2 & 0.964 & 0.949 & 0.674 & 0.614 & 0.617
\end{tabular}


Table C- 31. Data for BTEX BTCs from the $40^{\text {th }}$ sorption cycle on column LST2

\begin{tabular}{ccccccc} 
& & \multicolumn{5}{c}{ C/Co } \\
\cline { 3 - 7 } Sample & Pore Volumes & Benzene & Toluene & Ethylbenzene & $\begin{array}{c}\text { p- \& m- } \\
\text { xylene }\end{array}$ & o-xylene \\
\hline 1 & 5.3 & 0.064 & 0.000 & 0.000 & 0.000 & 0.000 \\
2 & 10.3 & 0.341 & 0.109 & 0.111 & 0.065 & 0.000 \\
3 & 17.2 & 0.559 & 0.159 & 0.198 & 0.096 & 0.139 \\
4 & 24.9 & 0.704 & 0.284 & 0.245 & 0.117 & 0.183 \\
5 & 32.9 & 0.796 & 0.474 & 0.308 & 0.186 & 0.213 \\
6 & 41.0 & 0.885 & 0.604 & 0.353 & 0.289 & 0.285 \\
7 & 49.0 & 0.893 & 0.727 & 0.398 & 0.349 & 0.333 \\
8 & 57.1 & 0.920 & 0.766 & 0.434 & 0.396 & 0.417 \\
9 & 69.1 & 0.986 & 0.800 & 0.506 & 0.482 & 0.469 \\
10 & 78.6 & 0.942 & 0.824 & 0.523 & 0.594 & 0.524 \\
11 & 89.9 & 0.975 & 0.874 & 0.644 & 0.630 & 0.571 \\
12 & 100.2 & 1.022 & 0.898 & 0.701 & 0.650 & 0.609
\end{tabular}

Table C- 32. Data for BTEX BTCs from the $45^{\text {th }}$ sorption cycle on column LST2

\begin{tabular}{ccccccc} 
& & \multicolumn{3}{c}{ C/Co } \\
\cline { 3 - 7 } Sample & Pore Volumes & Benzene & Toluene & Ethylbenzene & $\begin{array}{l}\text { p- \& m- } \\
\text { xylene }\end{array}$ & o-xylene \\
\hline 1 & 5.9 & 0.146 & 0.061 & 0.000 & 0.000 & 0.000 \\
2 & 12.0 & 0.393 & 0.169 & 0.103 & 0.037 & 0.091 \\
3 & 17.6 & 0.604 & 0.284 & 0.145 & 0.078 & 0.102 \\
4 & 23.2 & 0.720 & 0.370 & 0.189 & 0.090 & 0.126 \\
5 & 30.0 & 0.763 & 0.437 & 0.192 & 0.118 & 0.197 \\
6 & 38.1 & 0.809 & 0.612 & 0.257 & 0.177 & 0.254 \\
7 & 46.1 & 0.904 & 0.663 & 0.324 & 0.232 & 0.355 \\
8 & 54.4 & 1.005 & 0.786 & 0.366 & 0.414 & 0.393 \\
9 & 63.6 & 0.947 & 0.826 & 0.440 & 0.415 & 0.431 \\
10 & 74.9 & 0.985 & 0.872 & 0.527 & 0.501 & 0.498 \\
11 & 87.2 & 1.087 & 0.908 & 0.538 & 0.586 & 0.558 \\
12 & 101.5 & 1.055 & 0.937 & 0.608 & 0.606 & 0.622
\end{tabular}


Table C- 33. Data for BTEX BTCs from the $50^{\text {th }}$ sorption cycle on column LST2

\begin{tabular}{ccccccc} 
& & \multicolumn{5}{c}{ C/Co } \\
\cline { 3 - 7 } Sample & Pore Volumes & Benzene & Toluene & Ethylbenzene & $\begin{array}{c}\text { p- \& } \mathrm{m} \text { - } \\
\text { xylene }\end{array}$ & o-xylene \\
\hline 1 & 5.5 & 0.213 & 0.000 & 0.000 & 0.000 & 0.000 \\
2 & 11.1 & 0.340 & 0.163 & 0.080 & 0.022 & 0.124 \\
3 & 18.9 & 0.510 & 0.259 & 0.171 & 0.068 & 0.144 \\
4 & 26.6 & 0.694 & 0.394 & 0.205 & 0.150 & 0.204 \\
5 & 33.3 & 0.794 & 0.523 & 0.236 & 0.178 & 0.234 \\
6 & 44.1 & 0.881 & 0.704 & 0.291 & 0.227 & 0.322 \\
7 & 52.9 & 0.928 & 0.686 & 0.320 & 0.315 & 0.390 \\
8 & 61.4 & 0.993 & 0.798 & 0.384 & 0.410 & 0.454 \\
9 & 71.3 & 0.990 & 0.872 & 0.451 & 0.449 & 0.499 \\
10 & 79.6 & 0.985 & 0.904 & 0.563 & 0.489 & 0.598 \\
11 & 89.1 & 1.038 & 0.865 & 0.628 & 0.578 & 0.597 \\
12 & 100.7 & 1.029 & 0.966 & 0.657 & 0.644 & 0.668
\end{tabular}


Table C- 34. Data for BTEX removal from the $1^{\text {st }}$ regeneration cycle on column LST2

\begin{tabular}{|c|c|c|c|c|c|c|c|c|c|c|c|}
\hline \multirow[b]{2}{*}{ Sample } & \multirow[b]{2}{*}{$\begin{array}{c}\text { Pore } \\
\text { Volumes }\end{array}$} & \multicolumn{5}{|c|}{ Concentration (mg/L) } & \multicolumn{5}{|c|}{ Mass Removed (mg) } \\
\hline & & Benzene & Toluene & Ethylbenzene & $\begin{array}{l}\mathrm{p}-\& \mathrm{~m}- \\
\text { xylene }\end{array}$ & o-xylene & Benzene & Toluene & Ethylbenzene & p- \& m-xylene & o-xylene \\
\hline 1 & 72.5 & 0.1012 & 0.5819 & 0.0346 & 0.1304 & 0.1359 & 0.217 & 1.247 & 0.074 & 0.279 & 0.291 \\
\hline 2 & 167.3 & 0.1115 & 0.3250 & 0.0231 & 0.0995 & 0.1068 & 0.529 & 2.157 & 0.139 & 0.558 & 0.590 \\
\hline 3 & 274.0 & 0.0805 & 0.2166 & 0.0178 & 0.0750 & 0.0911 & 0.782 & 2.839 & 0.195 & 0.794 & 0.877 \\
\hline 4 & 383.3 & 0.0530 & 0.1506 & 0.0136 & 0.0613 & 0.0782 & 0.954 & 3.326 & 0.239 & 0.992 & 1.130 \\
\hline 5 & 495.6 & 0.0366 & 0.1200 & 0.0101 & 0.0499 & 0.0642 & 1.075 & 3.723 & 0.273 & 1.158 & 1.343 \\
\hline 6 & 607.8 & 0.0227 & 0.0869 & 0.0082 & 0.0412 & 0.0546 & 1.150 & 4.012 & 0.300 & 1.294 & 1.524 \\
\hline 7 & 720.1 & 0.0159 & 0.0659 & 0.0068 & 0.0342 & 0.0473 & 1.203 & 4.230 & 0.322 & 1.408 & 1.681 \\
\hline 8 & 832.3 & 0.0116 & 0.0510 & 0.0061 & 0.0278 & 0.0395 & 1.242 & 4.399 & 0.342 & 1.500 & 1.812 \\
\hline 9 & 944.6 & 0.0093 & 0.0408 & 0.0049 & 0.0220 & 0.0335 & 1.273 & 4.535 & 0.359 & 1.573 & 1.923 \\
\hline 10 & 1056.8 & 0.0076 & 0.0332 & 0.0041 & 0.0177 & 0.0284 & 1.298 & 4.645 & 0.372 & 1.631 & 2.017 \\
\hline 11 & 1169.1 & 0.0060 & 0.0246 & 0.0037 & 0.0156 & 0.0242 & 1.318 & 4.726 & 0.385 & 1.683 & 2.097 \\
\hline 12 & 1281.3 & 0.0036 & 0.0193 & 0.0031 & 0.0137 & 0.0209 & 1.329 & 4.790 & 0.395 & 1.728 & 2.167 \\
\hline 13 & 1393.6 & 0.0020 & 0.0115 & 0.0025 & 0.0113 & 0.0180 & 1.336 & 4.828 & 0.403 & 1.766 & 2.226 \\
\hline 14 & 1505.8 & 0.0011 & 0.0069 & 0.0021 & 0.0090 & 0.0160 & 1.340 & 4.851 & 0.410 & 1.796 & 2.279 \\
\hline
\end{tabular}


Table C- 35. Data for BTEX removal from the $5^{\text {th }}$ regeneration cycle on column LST2

\begin{tabular}{|c|c|c|c|c|c|c|c|c|c|c|c|}
\hline \multirow[b]{2}{*}{ Sample } & \multirow[b]{2}{*}{$\begin{array}{c}\text { Pore } \\
\text { Volumes }\end{array}$} & \multicolumn{5}{|c|}{ Concentration (mg/L) } & \multicolumn{5}{|c|}{ Mass Removed (mg) } \\
\hline & & Benzene & Toluene & Ethylbenzene & $\begin{array}{l}\mathrm{p}-\& \mathrm{~m}- \\
\text { xylene }\end{array}$ & o-xylene & Benzene & Toluene & Ethylbenzene & $\begin{array}{l}\mathrm{p}-\& \mathrm{~m}- \\
\text { xylene }\end{array}$ & o-xylene \\
\hline 1 & 79.5 & 0.1149 & 0.6869 & 0.0412 & 0.1537 & 0.0992 & 0.270 & 1.613 & 0.097 & 0.361 & 0.233 \\
\hline 3 & 316.4 & 0.0712 & 0.2203 & 0.0208 & 0.0770 & 0.0641 & 0.990 & 3.646 & 0.268 & 0.996 & 0.732 \\
\hline 4 & 431.7 & 0.0478 & 0.1401 & 0.0159 & 0.0629 & 0.0541 & 1.152 & 4.123 & 0.322 & 1.210 & 0.916 \\
\hline 5 & 544.0 & 0.0354 & 0.1123 & 0.0125 & 0.0498 & 0.0446 & 1.270 & 4.495 & 0.364 & 1.375 & 1.064 \\
\hline 7 & 768.5 & 0.0197 & 0.0667 & 0.0084 & 0.0342 & 0.0340 & 1.417 & 4.975 & 0.425 & 1.625 & 1.306 \\
\hline 8 & 880.7 & 0.0147 & 0.0520 & 0.0070 & 0.0293 & 0.0287 & 1.466 & 5.147 & 0.448 & 1.722 & 1.401 \\
\hline 9 & 993.0 & 0.0111 & 0.0363 & 0.0063 & 0.0231 & 0.0240 & 1.502 & 5.268 & 0.469 & 1.799 & 1.481 \\
\hline 10 & 1105.2 & 0.0094 & 0.0265 & 0.0054 & 0.0201 & 0.0205 & 1.534 & 5.356 & 0.487 & 1.866 & 1.549 \\
\hline 11 & 1217.5 & 0.0066 & 0.0193 & 0.0050 & 0.0173 & 0.0178 & 1.556 & 5.420 & 0.504 & 1.923 & 1.608 \\
\hline 12 & 1329.7 & 0.0040 & 0.0136 & 0.0047 & 0.0156 & 0.0158 & 1.569 & 5.465 & 0.519 & 1.975 & 1.660 \\
\hline 13 & 1442.0 & 0.0018 & 0.0077 & 0.0039 & 0.0137 & 0.0140 & 1.575 & 5.491 & 0.532 & 2.020 & 1.706 \\
\hline
\end{tabular}


Table C- 36. Data for BTEX removal from the $10^{\text {th }}$ regeneration cycle on column LST2

\begin{tabular}{|c|c|c|c|c|c|c|c|c|c|c|c|}
\hline \multirow[b]{2}{*}{ Sample } & \multirow[b]{2}{*}{$\begin{array}{c}\text { Pore } \\
\text { Volumes }\end{array}$} & \multicolumn{5}{|c|}{ Concentration (mg/L) } & \multicolumn{5}{|c|}{ Mass Removed (mg) } \\
\hline & & Benzene & Toluene & Ethylbenzene & $\begin{array}{l}\text { p- \& m- } \\
\text { xylene }\end{array}$ & o-xylene & Benzene & Toluene & Ethylbenzene & $\begin{array}{l}\mathrm{p}-\& \mathrm{~m}- \\
\text { xylene }\end{array}$ & o-xylene \\
\hline 1 & 86.3 & 0.0896 & 0.4318 & 0.0516 & 0.1547 & 0.1253 & 0.229 & 1.101 & 0.132 & 0.395 & 0.320 \\
\hline 2 & 185.5 & 0.1178 & 0.2087 & 0.0385 & 0.1126 & 0.1059 & 0.574 & 1.713 & 0.244 & 0.724 & 0.630 \\
\hline 3 & 294.9 & 0.0925 & 0.1622 & 0.0289 & 0.0910 & 0.0855 & 0.873 & 2.237 & 0.338 & 1.018 & 0.906 \\
\hline 4 & 410.2 & 0.0589 & 0.1271 & 0.0217 & 0.0728 & 0.0719 & 1.073 & 2.670 & 0.412 & 1.266 & 1.151 \\
\hline 5 & 522.4 & 0.0357 & 0.0985 & 0.0175 & 0.0598 & 0.0601 & 1.192 & 2.996 & 0.470 & 1.465 & 1.350 \\
\hline 7 & 746.9 & 0.0169 & 0.0608 & 0.0113 & 0.0405 & 0.0418 & 1.331 & 3.441 & 0.554 & 1.758 & 1.652 \\
\hline 8 & 859.2 & 0.0126 & 0.0518 & 0.0099 & 0.0334 & 0.0351 & 1.373 & 3.613 & 0.587 & 1.868 & 1.768 \\
\hline 9 & 971.4 & 0.0087 & 0.0379 & 0.0087 & 0.0254 & 0.0293 & 1.402 & 3.738 & 0.616 & 1.953 & 1.866 \\
\hline 10 & 1083.7 & 0.0059 & 0.0306 & 0.0074 & 0.0233 & 0.0245 & 1.421 & 3.840 & 0.640 & 2.030 & 1.947 \\
\hline 11 & 1195.9 & 0.0037 & 0.0240 & 0.0063 & 0.0206 & 0.0200 & 1.434 & 3.919 & 0.661 & 2.098 & 2.013 \\
\hline 12 & 1308.1 & 0.0033 & 0.0166 & 0.0054 & 0.0187 & 0.0177 & 1.444 & 3.974 & 0.679 & 2.160 & 2.072 \\
\hline 13 & 1420.4 & 0.0019 & 0.0149 & 0.0046 & 0.0162 & 0.0144 & 1.451 & 4.024 & 0.694 & 2.214 & 2.120 \\
\hline
\end{tabular}


Table C- 37. Data for BTEX removal from the $15^{\text {th }}$ regeneration cycle on column LST2

\begin{tabular}{|c|c|c|c|c|c|c|c|c|c|c|c|}
\hline \multirow[b]{2}{*}{ Sample } & \multirow[b]{2}{*}{$\begin{array}{c}\text { Pore } \\
\text { Volumes }\end{array}$} & \multicolumn{5}{|c|}{ Concentration $(\mathrm{mg} / \mathrm{L})$} & \multicolumn{5}{|c|}{ Mass Removed (mg) } \\
\hline & & Benzene & Toluene & Ethylbenzene & $\begin{array}{l}\mathrm{p}-\& \mathrm{~m}- \\
\text { xylene }\end{array}$ & o-xylene & Benzene & Toluene & Ethylbenzene & $\begin{array}{l}\text { p- \& m- } \\
\text { xylene }\end{array}$ & o-xylene \\
\hline 1 & 84.6 & 0.0939 & 0.5073 & 0.0333 & 0.1598 & 0.0903 & 0.235 & 1.268 & 0.083 & 0.399 & 0.226 \\
\hline 3 & 292.8 & 0.0689 & 0.1387 & 0.0163 & 0.0878 & 0.0605 & 0.757 & 2.524 & 0.205 & 1.017 & 0.631 \\
\hline 4 & 402.2 & 0.0434 & 0.1034 & 0.0131 & 0.0703 & 0.0512 & 0.897 & 2.858 & 0.247 & 1.245 & 0.797 \\
\hline 5 & 517.5 & 0.0339 & 0.0815 & 0.0107 & 0.0582 & 0.0416 & 1.012 & 3.136 & 0.283 & 1.443 & 0.939 \\
\hline 7 & 748.0 & 0.0159 & 0.0438 & 0.0070 & 0.0392 & 0.0275 & 1.139 & 3.500 & 0.337 & 1.735 & 1.146 \\
\hline 8 & 863.3 & 0.0107 & 0.0378 & 0.0059 & 0.0323 & 0.0233 & 1.176 & 3.629 & 0.357 & 1.845 & 1.226 \\
\hline 9 & 978.6 & 0.0067 & 0.0265 & 0.0054 & 0.0255 & 0.0180 & 1.199 & 3.719 & 0.375 & 1.932 & 1.287 \\
\hline 10 & 1093.9 & 0.0061 & 0.0166 & 0.0045 & 0.0200 & 0.0143 & 1.219 & 3.775 & 0.390 & 2.000 & 1.336 \\
\hline 11 & 1209.2 & 0.0037 & 0.0128 & 0.0036 & 0.0166 & 0.0127 & 1.232 & 3.819 & 0.403 & 2.057 & 1.379 \\
\hline 12 & 1324.4 & 0.0024 & 0.0090 & 0.0035 & 0.0152 & 0.0117 & 1.240 & 3.850 & 0.414 & 2.108 & 1.419 \\
\hline 13 & 1439.7 & 0.0015 & 0.0064 & 0.0031 & 0.0124 & 0.0107 & 1.245 & 3.872 & 0.425 & 2.151 & 1.455 \\
\hline
\end{tabular}


Table C- 38. Data for BTEX removal from the $\mathbf{2 0}^{\text {th }}$ regeneration cycle on column LST2

\begin{tabular}{|c|c|c|c|c|c|c|c|c|c|c|c|}
\hline \multirow[b]{2}{*}{ Sample } & \multirow[b]{2}{*}{$\begin{array}{c}\text { Pore } \\
\text { Volumes }\end{array}$} & \multicolumn{5}{|c|}{ Concentration $(\mathrm{mg} / \mathrm{L})$} & \multicolumn{5}{|c|}{ Mass Removed (mg) } \\
\hline & & Benzene & Toluene & Ethylbenzene & $\begin{array}{l}\text { p- \& m- } \\
\text { xylene }\end{array}$ & o-xylene & Benzene & Toluene & Ethylbenzene & $\begin{array}{l}\mathrm{p}-\text { \& m- } \\
\text { xylene }\end{array}$ & o-xylene \\
\hline 1 & 72.9 & 0.0675 & 0.4460 & 0.0411 & 0.1636 & 0.0965 & 0.145 & 0.961 & 0.089 & 0.352 & 0.208 \\
\hline 2 & 185.2 & 0.0729 & 0.2637 & 0.0279 & 0.1065 & 0.0763 & 0.387 & 1.835 & 0.181 & 0.706 & 0.461 \\
\hline 3 & 297.4 & 0.0566 & 0.1709 & 0.0205 & 0.0828 & 0.0619 & 0.575 & 2.401 & 0.249 & 0.980 & 0.666 \\
\hline 4 & 409.7 & 0.0318 & 0.0976 & 0.0164 & 0.0653 & 0.0547 & 0.680 & 2.725 & 0.303 & 1.197 & 0.847 \\
\hline 5 & 521.9 & 0.0233 & 0.0834 & 0.0128 & 0.0553 & 0.0467 & 0.757 & 3.002 & 0.346 & 1.380 & 1.002 \\
\hline 7 & 746.4 & 0.0090 & 0.0456 & 0.0088 & 0.0403 & 0.0327 & 0.836 & 3.339 & 0.409 & 1.671 & 1.238 \\
\hline 8 & 858.6 & 0.0078 & 0.0359 & 0.0078 & 0.0341 & 0.0289 & 0.862 & 3.458 & 0.434 & 1.784 & 1.334 \\
\hline 9 & 970.9 & 0.0059 & 0.0282 & 0.0067 & 0.0283 & 0.0245 & 0.882 & 3.552 & 0.457 & 1.878 & 1.415 \\
\hline 10 & 1083.1 & 0.0044 & 0.0195 & 0.0061 & 0.0248 & 0.0207 & 0.896 & 3.616 & 0.477 & 1.960 & 1.484 \\
\hline 11 & 1195.4 & 0.0029 & 0.0138 & 0.0053 & 0.0205 & 0.0160 & 0.906 & 3.662 & 0.495 & 2.028 & 1.537 \\
\hline 12 & 1307.6 & 0.0022 & 0.0114 & 0.0047 & 0.0165 & 0.0137 & 0.913 & 3.700 & 0.510 & 2.083 & 1.582 \\
\hline 13 & 1419.9 & 0.0012 & 0.0077 & 0.0037 & 0.0158 & 0.0119 & 0.917 & 3.725 & 0.522 & 2.135 & 1.622 \\
\hline
\end{tabular}


Table C- 39. Data for BTEX removal from the $25^{\text {th }}$ regeneration cycle on column LST2

\begin{tabular}{|c|c|c|c|c|c|c|c|c|c|c|c|}
\hline \multirow[b]{2}{*}{ Sample } & \multirow[b]{2}{*}{$\begin{array}{c}\text { Pore } \\
\text { Volumes }\end{array}$} & \multicolumn{5}{|c|}{ Concentration (mg/L) } & \multicolumn{5}{|c|}{ Mass Removed (mg) } \\
\hline & & Benzene & Toluene & Ethylbenzene & $\begin{array}{l}\text { p- \& m- } \\
\text { xylene }\end{array}$ & o-xylene & Benzene & Toluene & Ethylbenzene & $\begin{array}{l}\text { p- \& m- } \\
\text { xylene }\end{array}$ & o-xylene \\
\hline 1 & 63.5 & 0.0769 & 0.3582 & 0.0378 & 0.1471 & 0.0940 & 0.144 & 0.672 & 0.071 & 0.276 & 0.176 \\
\hline 2 & 165.0 & 0.0878 & 0.2556 & 0.0289 & 0.1082 & 0.0768 & 0.408 & 1.439 & 0.158 & 0.600 & 0.407 \\
\hline 3 & 277.3 & 0.0741 & 0.1801 & 0.0215 & 0.0847 & 0.0637 & 0.653 & 2.036 & 0.229 & 0.881 & 0.618 \\
\hline 4 & 389.5 & 0.0448 & 0.1138 & 0.0172 & 0.0658 & 0.0539 & 0.802 & 2.413 & 0.286 & 1.099 & 0.797 \\
\hline 5 & 504.8 & 0.0339 & 0.0892 & 0.0137 & 0.0526 & 0.0439 & 0.918 & 2.717 & 0.333 & 1.279 & 0.946 \\
\hline 6 & 620.1 & 0.0250 & 0.0678 & 0.0104 & 0.0407 & 0.0365 & 1.003 & 2.948 & 0.368 & 1.417 & 1.071 \\
\hline 7 & 735.4 & 0.0168 & 0.0513 & 0.0085 & 0.0338 & 0.0303 & 1.060 & 3.123 & 0.397 & 1.533 & 1.174 \\
\hline 8 & 850.6 & 0.0132 & 0.0405 & 0.0075 & 0.0279 & 0.0241 & 1.105 & 3.261 & 0.423 & 1.627 & 1.256 \\
\hline 9 & 965.9 & 0.0096 & 0.0354 & 0.0065 & 0.0238 & 0.0195 & 1.138 & 3.381 & 0.445 & 1.709 & 1.322 \\
\hline 10 & 1081.2 & 0.0065 & 0.0267 & 0.0055 & 0.0221 & 0.0163 & 1.160 & 3.472 & 0.463 & 1.784 & 1.378 \\
\hline 11 & 1196.5 & 0.0053 & 0.0218 & 0.0045 & 0.0195 & 0.0144 & 1.178 & 3.546 & 0.479 & 1.850 & 1.427 \\
\hline 12 & 1311.8 & 0.0032 & 0.0160 & 0.0038 & 0.0179 & 0.0122 & 1.189 & 3.601 & 0.492 & 1.911 & 1.469 \\
\hline 13 & 1427.1 & 0.0020 & 0.0087 & 0.0037 & 0.0158 & 0.0105 & 1.196 & 3.630 & 0.504 & 1.965 & 1.505 \\
\hline 14 & 1542.3 & 0.0011 & 0.0056 & 0.0033 & 0.0136 & 0.0087 & 1.200 & 3.649 & 0.516 & 2.011 & 1.534 \\
\hline
\end{tabular}


Table C- 40. Data for BTEX removal from the $30^{\text {th }}$ regeneration cycle on column LST2

\begin{tabular}{|c|c|c|c|c|c|c|c|c|c|c|c|}
\hline \multirow[b]{2}{*}{ Sample } & \multirow[b]{2}{*}{$\begin{array}{c}\text { Pore } \\
\text { Volumes }\end{array}$} & \multicolumn{5}{|c|}{ Concentration (mg/L) } & \multicolumn{5}{|c|}{ Mass Removed (mg) } \\
\hline & & Benzene & Toluene & Ethylbenzene & $\begin{array}{l}\text { p- \& m- } \\
\text { xylene }\end{array}$ & o-xylene & Benzene & Toluene & Ethylbenzene & $\begin{array}{l}\mathrm{p}-\& \mathrm{~m}- \\
\text { xylene }\end{array}$ & o-xylene \\
\hline 1 & 77.4 & 0.1313 & 0.4544 & 0.0451 & 0.1758 & 0.1125 & 0.300 & 1.039 & 0.103 & 0.402 & 0.257 \\
\hline 2 & 184.0 & 0.1672 & 0.2765 & 0.0327 & 0.1321 & 0.0929 & 0.827 & 1.910 & 0.206 & 0.818 & 0.550 \\
\hline 3 & 290.6 & 0.1097 & 0.1966 & 0.0253 & 0.1015 & 0.0757 & 1.172 & 2.529 & 0.286 & 1.138 & 0.788 \\
\hline 4 & 400.0 & 0.0754 & 0.1204 & 0.0194 & 0.0830 & 0.0667 & 1.416 & 2.918 & 0.349 & 1.406 & 1.004 \\
\hline 5 & 512.3 & 0.0419 & 0.0852 & 0.0157 & 0.0707 & 0.0543 & 1.555 & 3.200 & 0.400 & 1.640 & 1.184 \\
\hline 6 & 624.5 & 0.0267 & 0.0751 & 0.0128 & 0.0600 & 0.0456 & 1.643 & 3.449 & 0.443 & 1.839 & 1.335 \\
\hline 7 & 736.8 & 0.0212 & 0.0523 & 0.0108 & 0.0512 & 0.0377 & 1.713 & 3.623 & 0.479 & 2.009 & 1.460 \\
\hline 8 & 849.0 & 0.0159 & 0.0443 & 0.0085 & 0.0414 & 0.0321 & 1.766 & 3.770 & 0.507 & 2.146 & 1.567 \\
\hline 9 & 961.3 & 0.0118 & 0.0342 & 0.0073 & 0.0340 & 0.0264 & 1.805 & 3.883 & 0.531 & 2.259 & 1.654 \\
\hline 10 & 1073.5 & 0.0074 & 0.0282 & 0.0061 & 0.0302 & 0.0216 & 1.830 & 3.977 & 0.551 & 2.359 & 1.726 \\
\hline 11 & 1185.7 & 0.0063 & 0.0175 & 0.0058 & 0.0251 & 0.0170 & 1.851 & 4.034 & 0.570 & 2.442 & 1.782 \\
\hline 12 & 1298.0 & 0.0031 & 0.0110 & 0.0054 & 0.0217 & 0.0155 & 1.861 & 4.071 & 0.588 & 2.514 & 1.834 \\
\hline 13 & 1410.2 & 0.0021 & 0.0091 & 0.0047 & 0.0187 & 0.0127 & 1.868 & 4.101 & 0.604 & 2.576 & 1.876 \\
\hline 14 & 1522.5 & 0.0015 & 0.0070 & 0.0044 & 0.0179 & 0.0098 & 1.873 & 4.124 & 0.619 & 2.636 & 1.908 \\
\hline
\end{tabular}


Table C- 41. Data for BTEX removal from the $35^{\text {th }}$ regeneration cycle on column LST2

\begin{tabular}{|c|c|c|c|c|c|c|c|c|c|c|c|}
\hline \multirow[b]{2}{*}{ Sample } & \multirow[b]{2}{*}{$\begin{array}{c}\text { Pore } \\
\text { Volumes }\end{array}$} & \multicolumn{5}{|c|}{ Concentration $(\mathrm{mg} / \mathrm{L})$} & \multicolumn{5}{|c|}{ Mass Removed (mg) } \\
\hline & & Benzene & Toluene & Ethylbenzene & $\begin{array}{l}\mathrm{p}-\& \mathrm{~m}- \\
\text { xylene }\end{array}$ & o-xylene & Benzene & Toluene & Ethylbenzene & $\begin{array}{l}p-\& m- \\
\text { xylene }\end{array}$ & o-xylene \\
\hline 1 & 91.9 & 0.0729 & 0.4224 & 0.0451 & 0.1727 & 0.1014 & 0.198 & 1.146 & 0.122 & 0.469 & 0.275 \\
\hline 3 & 328.9 & 0.0659 & 0.1684 & 0.0249 & 0.0930 & 0.0658 & 0.746 & 2.561 & 0.325 & 1.209 & 0.792 \\
\hline 4 & 444.1 & 0.0428 & 0.1079 & 0.0204 & 0.0743 & 0.0574 & 0.892 & 2.929 & 0.395 & 1.462 & 0.988 \\
\hline 5 & 559.4 & 0.0282 & 0.0801 & 0.0160 & 0.0557 & 0.0485 & 0.988 & 3.201 & 0.449 & 1.652 & 1.153 \\
\hline 7 & 790.0 & 0.0130 & 0.0473 & 0.0102 & 0.0362 & 0.0362 & 1.103 & 3.576 & 0.528 & 1.925 & 1.421 \\
\hline 8 & 905.3 & 0.0080 & 0.0355 & 0.0082 & 0.0292 & 0.0311 & 1.130 & 3.697 & 0.556 & 2.025 & 1.527 \\
\hline 9 & 1020.5 & 0.0043 & 0.0261 & 0.0069 & 0.0256 & 0.0257 & 1.145 & 3.785 & 0.579 & 2.112 & 1.615 \\
\hline 10 & 1135.8 & 0.0037 & 0.0208 & 0.0060 & 0.0229 & 0.0209 & 1.158 & 3.856 & 0.600 & 2.190 & 1.686 \\
\hline 11 & 1251.1 & 0.0025 & 0.0182 & 0.0056 & 0.0194 & 0.0173 & 1.166 & 3.918 & 0.619 & 2.256 & 1.745 \\
\hline 12 & 1366.4 & 0.0022 & 0.0123 & 0.0052 & 0.0153 & 0.0148 & 1.174 & 3.960 & 0.636 & 2.308 & 1.795 \\
\hline 13 & 1481.7 & 0.0015 & 0.0096 & 0.0048 & 0.0129 & 0.0130 & 1.179 & 3.993 & 0.653 & 2.352 & 1.840 \\
\hline
\end{tabular}


Table C- 42. Data for BTEX removal from the $40^{\text {th }}$ regeneration cycle on column LST2

\begin{tabular}{|c|c|c|c|c|c|c|c|c|c|c|c|}
\hline \multirow[b]{2}{*}{ Sample } & \multirow[b]{2}{*}{$\begin{array}{c}\text { Pore } \\
\text { Volumes }\end{array}$} & \multicolumn{5}{|c|}{ Concentration (mg/L) } & \multicolumn{5}{|c|}{ Mass Removed (mg) } \\
\hline & & Benzene & Toluene & Ethylbenzene & $\begin{array}{l}\text { p- \& m- } \\
\text { xylene }\end{array}$ & o-xylene & Benzene & Toluene & Ethylbenzene & $\begin{array}{l}\mathrm{p}-\& \mathrm{~m}- \\
\text { xylene }\end{array}$ & o-xylene \\
\hline 1 & 77.4 & 0.0667 & 0.4503 & 0.0438 & 0.1114 & 0.1131 & 0.153 & 1.029 & 0.100 & 0.255 & 0.258 \\
\hline 2 & 178.9 & 0.0763 & 0.2285 & 0.0304 & 0.0836 & 0.0971 & 0.381 & 1.715 & 0.191 & 0.506 & 0.550 \\
\hline 3 & 288.3 & 0.0704 & 0.1628 & 0.0219 & 0.0659 & 0.0805 & 0.609 & 2.241 & 0.262 & 0.719 & 0.810 \\
\hline 4 & 400.6 & 0.0466 & 0.1155 & 0.0154 & 0.0521 & 0.0678 & 0.764 & 2.624 & 0.313 & 0.891 & 1.035 \\
\hline 5 & 512.8 & 0.0346 & 0.0920 & 0.0118 & 0.0425 & 0.0572 & 0.879 & 2.929 & 0.353 & 1.032 & 1.224 \\
\hline 6 & 625.0 & 0.0263 & 0.0768 & 0.0092 & 0.0338 & 0.0489 & 0.966 & 3.183 & 0.383 & 1.144 & 1.387 \\
\hline 7 & 737.3 & 0.0169 & 0.0592 & 0.0070 & 0.0296 & 0.0401 & 1.022 & 3.380 & 0.406 & 1.242 & 1.520 \\
\hline 8 & 849.5 & 0.0140 & 0.0484 & 0.0062 & 0.0237 & 0.0343 & 1.068 & 3.540 & 0.427 & 1.321 & 1.633 \\
\hline 9 & 961.8 & 0.0101 & 0.0276 & 0.0051 & 0.0188 & 0.0281 & 1.102 & 3.632 & 0.444 & 1.383 & 1.726 \\
\hline 10 & 1074.0 & 0.0084 & 0.0250 & 0.0042 & 0.0158 & 0.0218 & 1.130 & 3.714 & 0.458 & 1.436 & 1.799 \\
\hline 11 & 1186.3 & 0.0058 & 0.0185 & 0.0042 & 0.0124 & 0.0179 & 1.149 & 3.776 & 0.471 & 1.476 & 1.858 \\
\hline 12 & 1298.5 & 0.0046 & 0.0146 & 0.0037 & 0.0115 & 0.0156 & 1.164 & 3.824 & 0.484 & 1.515 & 1.910 \\
\hline 13 & 1410.8 & 0.0026 & 0.0104 & 0.0036 & 0.0097 & 0.0119 & 1.173 & 3.859 & 0.496 & 1.547 & 1.949 \\
\hline 14 & 1523.0 & 0.0012 & 0.0092 & 0.0035 & 0.0075 & 0.0118 & 1.177 & 3.889 & 0.507 & 1.572 & 1.988 \\
\hline
\end{tabular}


Table C- 43. Data for BTEX removal from the $45^{\text {th }}$ regeneration cycle on column LST2

\begin{tabular}{|c|c|c|c|c|c|c|c|c|c|c|c|}
\hline \multirow[b]{2}{*}{ Sample } & \multirow[b]{2}{*}{$\begin{array}{c}\text { Pore } \\
\text { Volumes }\end{array}$} & \multicolumn{5}{|c|}{ Concentration (mg/L) } & \multicolumn{5}{|c|}{ Mass Removed (mg) } \\
\hline & & Benzene & Toluene & Ethylbenzene & $\begin{array}{l}\mathrm{p}-\& \mathrm{~m}- \\
\text { xylene }\end{array}$ & o-xylene & Benzene & Toluene & Ethylbenzene & $\begin{array}{l}\mathrm{p}-\& \mathrm{~m}- \\
\text { xylene }\end{array}$ & o-xylene \\
\hline 1 & 98.7 & 0.0696 & 0.3926 & 0.0375 & 0.1675 & 0.1187 & 0.203 & 1.144 & 0.109 & 0.488 & 0.346 \\
\hline 3 & 314.7 & 0.0607 & 0.1525 & 0.0225 & 0.0984 & 0.0793 & 0.657 & 2.290 & 0.271 & 1.195 & 0.906 \\
\hline 4 & 424.0 & 0.0294 & 0.1101 & 0.0183 & 0.0748 & 0.0675 & 0.752 & 2.645 & 0.330 & 1.437 & 1.124 \\
\hline 5 & 536.3 & 0.0205 & 0.0833 & 0.0144 & 0.0613 & 0.0589 & 0.820 & 2.922 & 0.378 & 1.640 & 1.319 \\
\hline 7 & 760.8 & 0.0116 & 0.0505 & 0.0101 & 0.0414 & 0.0439 & 0.909 & 3.298 & 0.452 & 1.947 & 1.632 \\
\hline 8 & 873.0 & 0.0089 & 0.0429 & 0.0088 & 0.0331 & 0.0363 & 0.938 & 3.440 & 0.481 & 2.057 & 1.752 \\
\hline 9 & 985.3 & 0.0067 & 0.0354 & 0.0075 & 0.0252 & 0.0292 & 0.961 & 3.557 & 0.506 & 2.141 & 1.849 \\
\hline 10 & 1097.5 & 0.0049 & 0.0298 & 0.0060 & 0.0213 & 0.0247 & 0.977 & 3.656 & 0.526 & 2.211 & 1.930 \\
\hline 11 & 1209.8 & 0.0026 & 0.0212 & 0.0054 & 0.0188 & 0.0198 & 0.985 & 3.727 & 0.544 & 2.274 & 1.996 \\
\hline 12 & 1322.0 & 0.0024 & 0.0156 & 0.0045 & 0.0169 & 0.0167 & 0.993 & 3.778 & 0.559 & 2.330 & 2.052 \\
\hline 13 & 1434.3 & 0.0015 & 0.0088 & 0.0043 & 0.0119 & 0.0145 & 0.998 & 3.808 & 0.573 & 2.369 & 2.100 \\
\hline
\end{tabular}


Table C- 44. Data for BTEX removal from the $50^{\text {h }}$ regeneration cycle on column LS

\begin{tabular}{|c|c|c|c|c|c|c|c|c|c|c|c|}
\hline \multirow[b]{2}{*}{ Sample } & \multirow[b]{2}{*}{$\begin{array}{c}\text { Pore } \\
\text { Volumes }\end{array}$} & \multicolumn{5}{|c|}{ Concentration (mg/L) } & \multicolumn{5}{|c|}{ Mass Removed (mg) } \\
\hline & & Benzene & Toluene & Ethylbenzene & $\begin{array}{l}\text { p- \& m- } \\
\text { xylene }\end{array}$ & o-xylene & Benzene & Toluene & Ethylbenzene & $\begin{array}{l}\text { p- \& m- } \\
\text { xylene }\end{array}$ & o-xylene \\
\hline 1 & 69.2 & 0.0911 & 0.3984 & 0.0510 & 0.1662 & 0.1228 & 0.186 & 0.815 & 0.104 & 0.340 & 0.251 \\
\hline 2 & 173.3 & 0.1170 & 0.2373 & 0.0374 & 0.1274 & 0.0991 & 0.546 & 1.544 & 0.219 & 0.732 & 0.556 \\
\hline 3 & 291.8 & 0.0748 & 0.1595 & 0.0285 & 0.0963 & 0.0794 & 0.808 & 2.103 & 0.319 & 1.069 & 0.833 \\
\hline 4 & 407.0 & 0.0380 & 0.1060 & 0.0197 & 0.0746 & 0.0676 & 0.937 & 2.464 & 0.386 & 1.323 & 1.064 \\
\hline 5 & 519.3 & 0.0224 & 0.0821 & 0.0160 & 0.0589 & 0.0580 & 1.011 & 2.736 & 0.439 & 1.518 & 1.256 \\
\hline 6 & 631.5 & 0.0166 & 0.0638 & 0.0129 & 0.0473 & 0.0492 & 1.066 & 2.948 & 0.482 & 1.675 & 1.419 \\
\hline 7 & 743.8 & 0.0127 & 0.0480 & 0.0106 & 0.0348 & 0.0433 & 1.108 & 3.107 & 0.517 & 1.790 & 1.563 \\
\hline 8 & 856.0 & 0.0087 & 0.0368 & 0.0090 & 0.0287 & 0.0366 & 1.137 & 3.229 & 0.547 & 1.885 & 1.684 \\
\hline 9 & 968.3 & 0.0047 & 0.0259 & 0.0073 & 0.0244 & 0.0312 & 1.153 & 3.314 & 0.571 & 1.966 & 1.788 \\
\hline 10 & 1080.5 & 0.0036 & 0.0192 & 0.0058 & 0.0220 & 0.0249 & 1.165 & 3.378 & 0.590 & 2.039 & 1.870 \\
\hline 11 & 1192.8 & 0.0028 & 0.0152 & 0.0053 & 0.0187 & 0.0199 & 1.174 & 3.429 & 0.608 & 2.101 & 1.936 \\
\hline 12 & 1305.0 & 0.0021 & 0.0110 & 0.0047 & 0.0163 & 0.0169 & 1.181 & 3.465 & 0.623 & 2.155 & 1.992 \\
\hline 13 & 1417.3 & 0.0014 & 0.0081 & 0.0039 & 0.0118 & 0.0147 & 1.186 & 3.492 & 0.636 & 2.194 & 2.041 \\
\hline 14 & 1529.5 & 0.0009 & 0.0040 & 0.0036 & 0.0108 & 0.0136 & 1.189 & 3.505 & 0.648 & 2.230 & 2.086 \\
\hline
\end{tabular}


Table C- 45. Cumulative BTEX mass sorbed and removed from column LST1.

\begin{tabular}{|c|c|c|c|c|c|c|c|}
\hline \multirow[b]{2}{*}{ Cycle } & & \multicolumn{5}{|c|}{ Concentration $(\mathrm{mg} / \mathrm{L})$} & \multirow{2}{*}{$\begin{array}{c}\text { Mean \% recovery } \\
\text { (std. dev.) }\end{array}$} \\
\hline & & Benzene & Toluene & Ethylbenzene & p- \& m-xylene & o-xylene & \\
\hline \multirow{3}{*}{1} & sorption & 0.864 & 4.301 & 0.487 & 2.131 & 2.068 & \\
\hline & regeneration & 0.862 & 4.374 & 0.493 & 2.069 & 1.888 & \\
\hline & $\%$ recovery & 99.8 & 101.7 & 101.2 & 97.1 & 91.3 & $98.2(4.2)$ \\
\hline \multirow{3}{*}{5} & sorption & 0.863 & 4.232 & 0.462 & 2.292 & 2.264 & \\
\hline & regeneration & 0.886 & 3.930 & 0.493 & 2.224 & 2.059 & \\
\hline & $\%$ recovery & 102.7 & 92.9 & 106.8 & 97.1 & 90.9 & $98.1(6.7)$ \\
\hline \multirow{3}{*}{10} & sorption & 0.944 & 3.854 & 0.434 & 2.026 & 1.639 & \\
\hline & regeneration & 0.919 & 3.946 & 0.409 & 1.957 & 1.648 & \\
\hline & $\%$ recovery & 97.3 & 102.4 & 94.1 & 96.6 & 100.5 & $98.2(3.3)$ \\
\hline \multirow{3}{*}{15} & sorption & 0.886 & 4.607 & 0.538 & 2.043 & 1.842 & \\
\hline & regeneration & 0.911 & 4.566 & 0.517 & 1.992 & 1.856 & \\
\hline & $\%$ recovery & 102.8 & 99.1 & 96.1 & 97.5 & 100.8 & $99.3(2.6)$ \\
\hline \multirow{3}{*}{20} & sorption & 0.982 & 4.229 & 0.561 & 2.237 & 1.918 & \\
\hline & regeneration & 0.902 & 3.827 & 0.542 & 2.221 & 1.861 & \\
\hline & $\%$ recovery & 91.9 & 90.5 & 96.7 & 99.2 & 97.0 & $95.1(3.7)$ \\
\hline \multirow{3}{*}{25} & sorption & 1.103 & 4.569 & 0.477 & 2.308 & 1.778 & \\
\hline & regeneration & 1.031 & 4.477 & 0.472 & 2.296 & 1.795 & \\
\hline & $\%$ recovery & 93.5 & 98.0 & 99.0 & 99.5 & 100.9 & $98.2(2.8)$ \\
\hline \multirow{3}{*}{30} & sorption & 0.867 & 4.175 & 0.431 & 2.179 & 1.786 & \\
\hline & regeneration & 0.924 & 4.518 & 0.437 & 2.330 & 1.981 & \\
\hline & $\%$ recovery & 106.6 & 108.2 & 101.4 & 106.9 & 110.9 & $106.8(3.4)$ \\
\hline \multirow{3}{*}{35} & sorption & 0.763 & 4.268 & 0.582 & 2.076 & 1.753 & \\
\hline & regeneration & 0.825 & 4.360 & 0.571 & 2.244 & 1.871 & \\
\hline & $\%$ recovery & 108.1 & 102.2 & 98.2 & 108.1 & 106.7 & $104.6(4.3)$ \\
\hline \multirow{3}{*}{40} & sorption & 0.996 & 4.158 & 0.546 & 2.108 & 1.834 & \\
\hline & regeneration & 0.947 & 3.963 & 0.535 & 2.042 & 1.776 & \\
\hline & $\%$ recovery & 95.0 & 95.3 & 98.1 & 96.9 & 96.9 & $96.4(1.3)$ \\
\hline \multirow{3}{*}{45} & sorption & 0.798 & 3.993 & 0.431 & 2.173 & 1.657 & \\
\hline & regeneration & 0.830 & 4.063 & 0.424 & 2.193 & 1.662 & \\
\hline & $\%$ recovery & 104.0 & 101.7 & 98.5 & 100.9 & 100.3 & $101.1(2.0)$ \\
\hline \multirow{3}{*}{50} & sorption & 0.823 & 4.234 & 0.460 & 2.182 & 1.966 & \\
\hline & regeneration & 0.903 & 4.383 & 0.484 & 2.181 & 1.986 & \\
\hline & $\%$ recovery & 109.6 & 103.5 & 105.1 & 100.0 & 101.0 & $103.9(3.8)$ \\
\hline & $\begin{array}{l}\text { Mean \% recovery } \\
\text { (std. dev.) }\end{array}$ & $101.1(6.0)$ & $99.5(5.1)$ & 99.5 (3.8) & $100.0(4.0)$ & $99.8(5.9)$ & \\
\hline
\end{tabular}


Table C- 46. Cumulative BTEX mass sorbed and removed from column LST2.

\begin{tabular}{|c|c|c|c|c|c|c|c|}
\hline \multirow[b]{2}{*}{ Cycle } & & \multicolumn{5}{|c|}{ Concentration (mg/L) } & \multirow{2}{*}{$\begin{array}{l}\text { Mean \% recovery } \\
\text { (std. dev.) }\end{array}$} \\
\hline & & Benzene & Toluene & Ethylbenzene & p- \& m-xylene & o-xylene & \\
\hline \multirow{3}{*}{1} & sorption & 1.23 & 4.77 & 0.40 & 1.73 & 2.23 & \\
\hline & regeneration & 1.34 & 4.85 & 0.41 & 1.80 & 2.28 & \\
\hline & $\%$ recovery & 109.2 & 101.6 & 102.0 & 103.8 & 102.4 & $103.8(3.1)$ \\
\hline \multirow{3}{*}{5} & sorption & 1.46 & 5.32 & 0.53 & 1.98 & 1.74 & \\
\hline & regeneration & 1.58 & 5.51 & 0.54 & 2.06 & 1.75 & \\
\hline & $\%$ recovery & 108.3 & 103.6 & 103.2 & 104.0 & 100.8 & $104.0(2.7)$ \\
\hline \multirow{3}{*}{10} & sorption & 1.50 & 4.30 & 0.75 & 2.29 & 2.30 & \\
\hline & regeneration & 1.45 & 4.04 & 0.71 & 2.26 & 2.15 & \\
\hline & $\%$ recovery & 96.8 & 94.0 & 94.6 & 98.7 & 93.7 & $95.6(2.2)$ \\
\hline \multirow{3}{*}{15} & sorption & 1.29 & 3.83 & 0.42 & 2.33 & 1.60 & \\
\hline & regeneration & 1.25 & 3.89 & 0.44 & 2.19 & 1.49 & \\
\hline & $\%$ recovery & 96.6 & 101.6 & 103.3 & 94.0 & 93.0 & $97.7(4.6)$ \\
\hline \multirow{3}{*}{20} & sorption & 0.96 & 4.02 & 0.56 & 2.29 & 1.75 & \\
\hline & regeneration & 0.92 & 3.74 & 0.53 & 2.18 & 1.66 & \\
\hline & \% recovery & 95.9 & 93.2 & 95.9 & 95.2 & 94.5 & $95.0(1.2)$ \\
\hline \multirow{3}{*}{25} & sorption & 1.14 & 3.44 & 0.48 & 1.96 & 1.44 & \\
\hline & regeneration & 1.20 & 3.65 & 0.52 & 2.01 & 1.53 & \\
\hline & $\%$ recovery & 105.3 & 106.2 & 106.8 & 102.7 & 106.4 & $105.5(1.6)$ \\
\hline \multirow{3}{*}{30} & sorption & 1.80 & 3.97 & 0.64 & 2.52 & 1.86 & \\
\hline & regeneration & 1.87 & 4.12 & 0.62 & 2.64 & 1.91 & \\
\hline & $\%$ recovery & 104.0 & 103.9 & 96.3 & 104.5 & 102.6 & $102.3(3.4)$ \\
\hline \multirow{3}{*}{35} & sorption & 1.20 & 4.13 & 0.64 & 2.34 & 1.84 & \\
\hline & regeneration & 1.18 & 4.01 & 0.67 & 2.39 & 1.88 & \\
\hline & \% recovery & 98.3 & 97.3 & 104.0 & 102.0 & 102.3 & $100.8(2.8)$ \\
\hline \multirow{3}{*}{40} & sorption & 1.25 & 4.13 & 0.52 & 1.68 & 2.03 & \\
\hline & regeneration & 1.18 & 3.89 & 0.51 & 1.57 & 1.99 & \\
\hline & $\%$ recovery & 94.2 & 94.2 & 98.3 & 93.4 & 97.9 & $95.6(2.3)$ \\
\hline \multirow{3}{*}{45} & sorption & 0.98 & 3.88 & 0.58 & 2.34 & 2.05 & \\
\hline & regeneration & 1.00 & 3.83 & 0.59 & 2.40 & 2.14 & \\
\hline & $\%$ recovery & 101.7 & 98.8 & 100.8 & 102.8 & 104.5 & $101.7(2.1)$ \\
\hline \multirow{3}{*}{50} & sorption & 1.09 & 3.23 & 0.58 & 2.07 & 1.98 & \\
\hline & regeneration & 1.19 & 3.51 & 0.65 & 2.23 & 2.09 & \\
\hline & $\%$ recovery & 108.6 & 108.6 & 111.7 & 107.5 & 105.2 & $108.3(2.4)$ \\
\hline & $\begin{array}{l}\text { Mean \% recovery } \\
\text { (std. dev.) }\end{array}$ & $101.7(5.6)$ & $100.3(5.2)$ & $101.5(5.1)$ & $100.8(4.7)$ & $100.3(4.8)$ & \\
\hline
\end{tabular}


Table C- 47. Calculated $K_{d}$ values for BTEX from columns LST1 and LST2

\begin{tabular}{ccccccc}
\multirow{2}{*}{ Column } & Cycle & Benzene & Toluene & Ethylbenzene & $\mathrm{p}$ - \& m-xylene & o-xylene \\
\cline { 2 - 7 } & 1 & 12.6 & 35.2 & 70.4 & 77.0 & 75.5 \\
& 5 & 12.1 & 30.5 & 80.9 & 67.0 & 65.5 \\
& 10 & 15.9 & 29.5 & 66.1 & 60.1 & 62.2 \\
& 15 & 13.1 & 33.5 & 67.9 & 68.9 & 69.9 \\
& 20 & 13.9 & 31.2 & 65.1 & 69.8 & 66.8 \\
& 25 & 18.6 & 35.4 & 82.2 & 73.1 & 78.9 \\
& 30 & 13.2 & 33.3 & 57.8 & 60.5 & 73.3 \\
& 35 & 10.9 & 26.2 & 65.3 & 71.8 & 52.8 \\
& 40 & 11.9 & 27.4 & 66.8 & 66.0 & 60.5 \\
& 45 & 11.0 & 39.3 & 61.7 & 62.7 & 53.0 \\
& 50 & 11.3 & 28.6 & 59.1 & 67.6 & 52.6 \\
& & & & & & \\
& 1 & 15.8 & 34.0 & 62.5 & 67.1 & 68.4 \\
& 5 & 14.1 & 34.4 & 67.0 & 64.4 & 65.3 \\
& 10 & 13.7 & 32.2 & 61.6 & 71.6 & 68.3 \\
& 15 & 15.9 & 28.4 & 60.7 & 64.8 & 62.9 \\
& 20 & 14.1 & 26.6 & 70.2 & 66.4 & 56.0 \\
& 25 & 15.3 & 29.3 & 68.3 & 57.6 & 66.4 \\
& 30 & 17.5 & 27.1 & 64.7 & 66.7 & 56.3 \\
& 35 & 16.5 & 28.9 & 56.2 & 59.2 & 69.0 \\
& 40 & 13.6 & 31.6 & 56.5 & 54.3 & 62.8 \\
& 45 & 10.8 & 24.9 & 63.1 & 58.4 & 60.3 \\
& 50 & 13.3 & 25.6 & 59.1 & 60.1 & 55.9
\end{tabular}




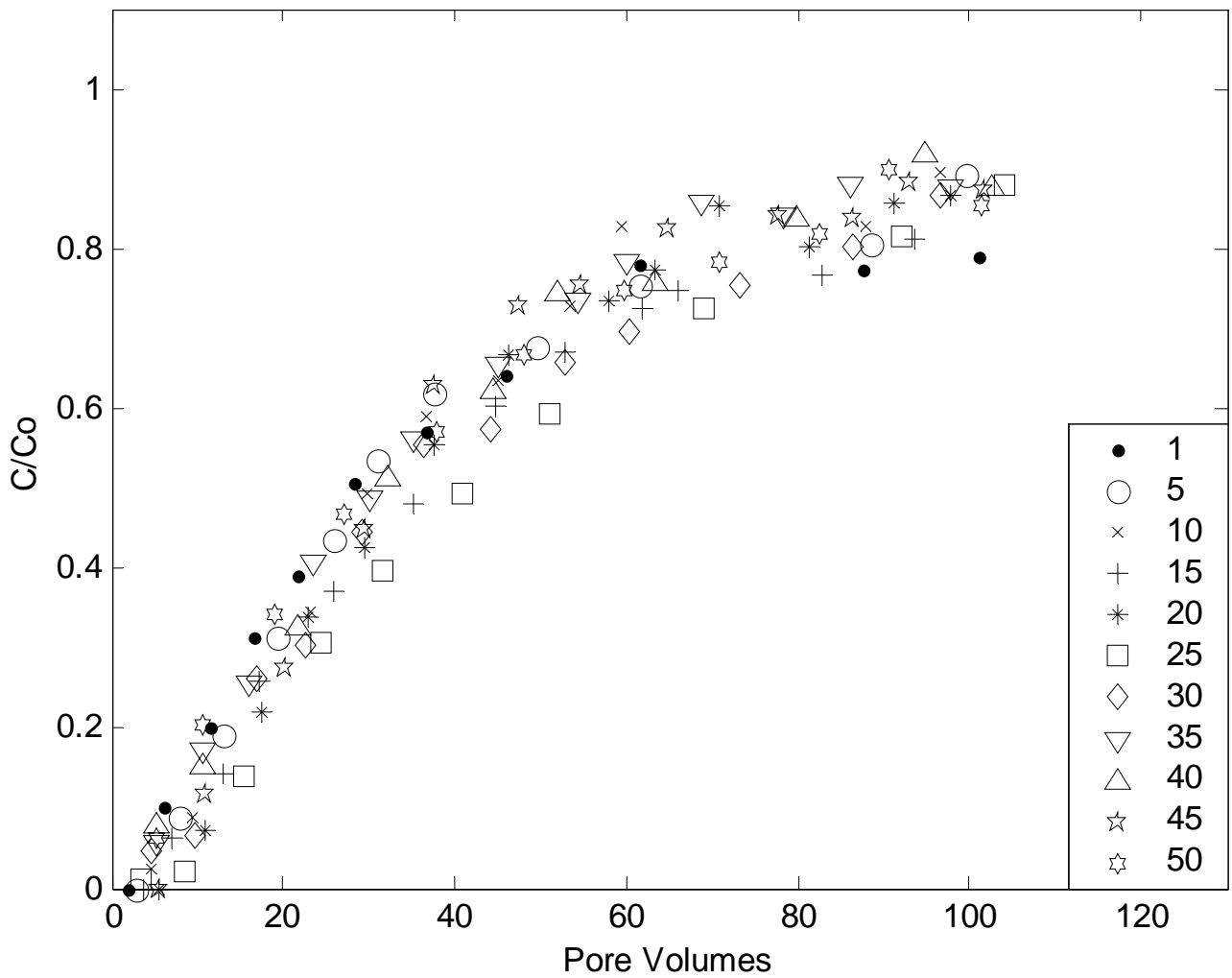

Figure C- 1. BTCs of toluene for every fifth sorption cycle on column LST1. 


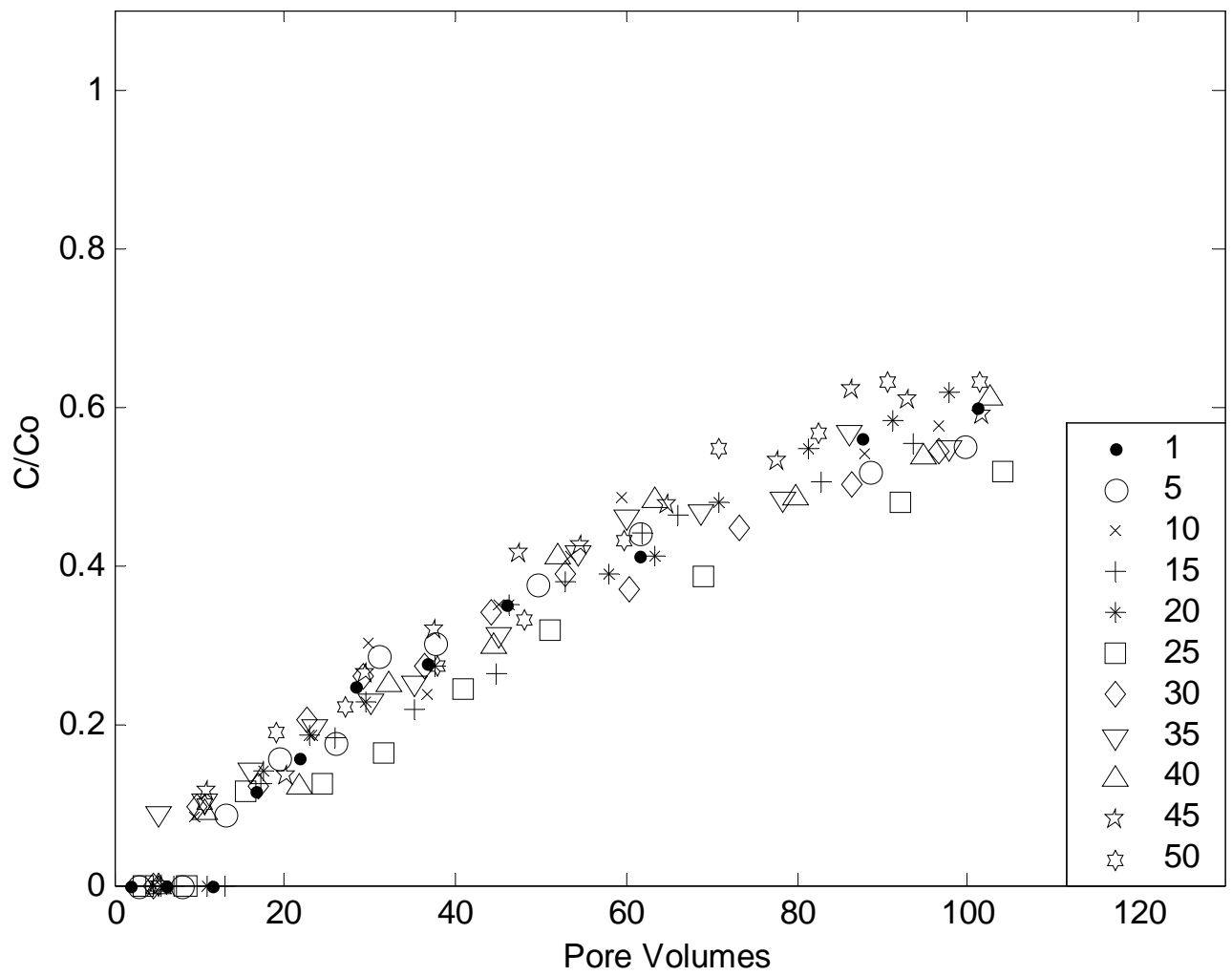

Figure C- 2. BTCs of ethylbenzene for every fifth sorption cycle on column LST1. 


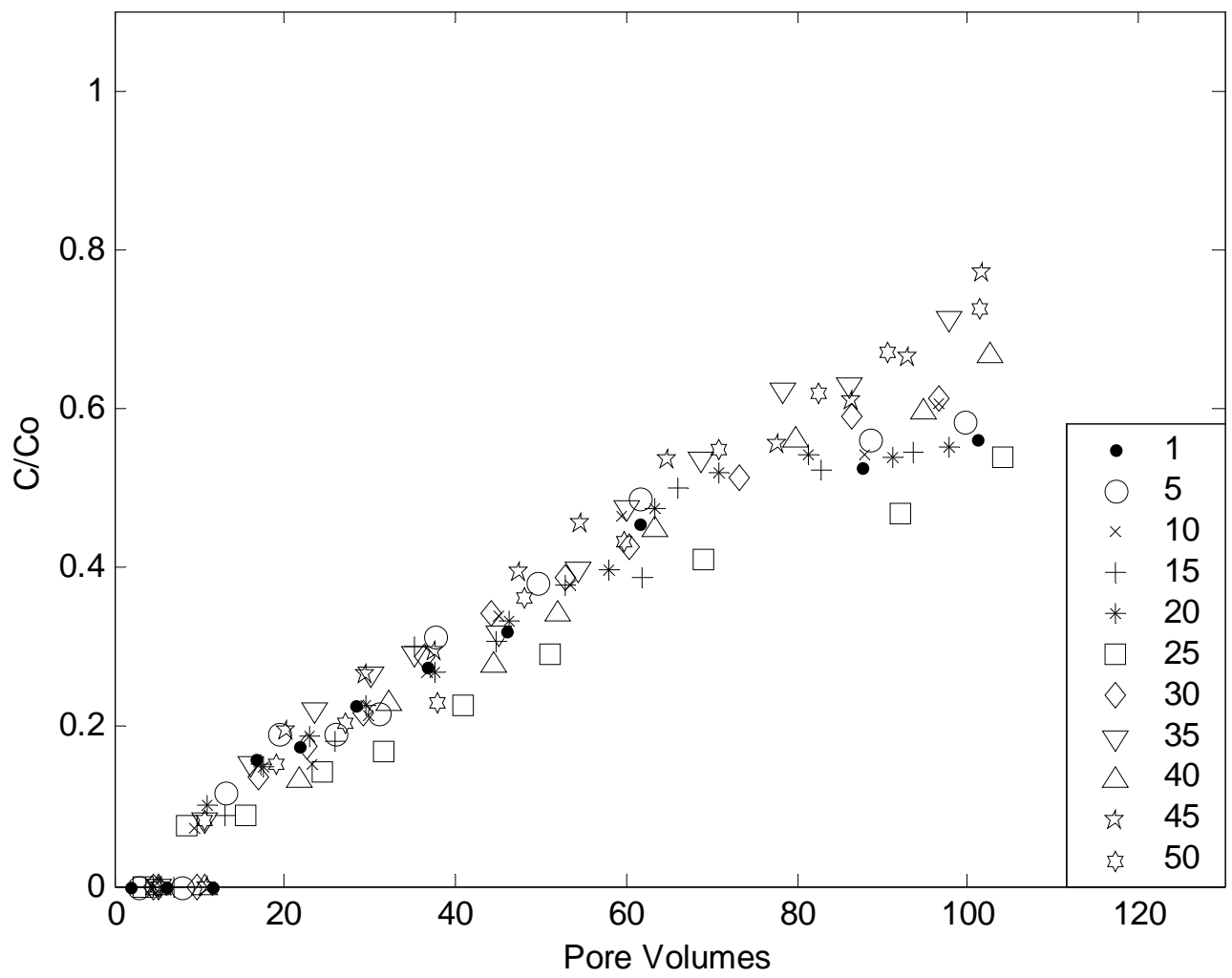

Figure C- 3. BTCs of o-xylene for every fifth sorption cycle on column LST1. 


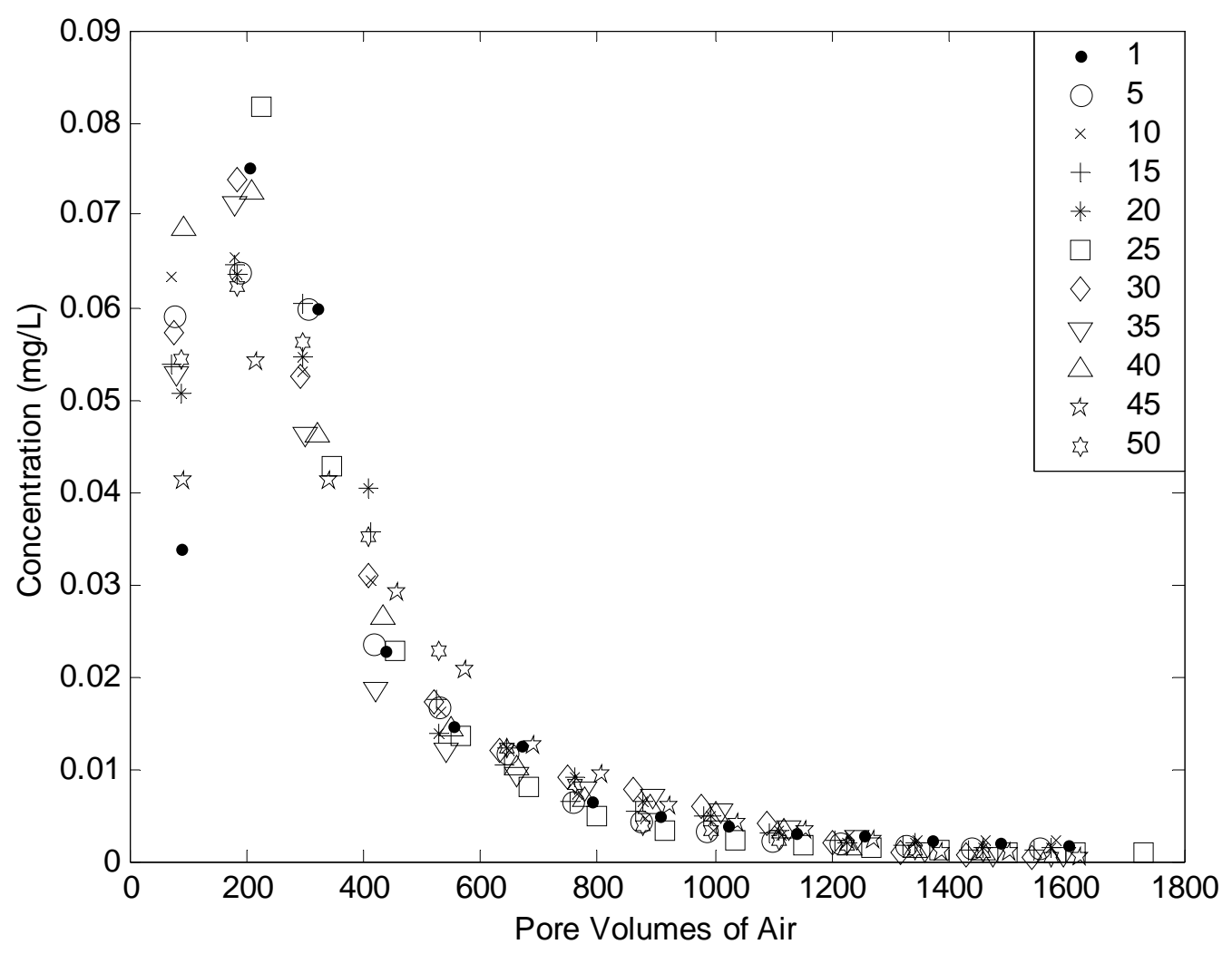

Figure C- 4. Benzene removal for every fifth regeneration cycle on column LST1. 


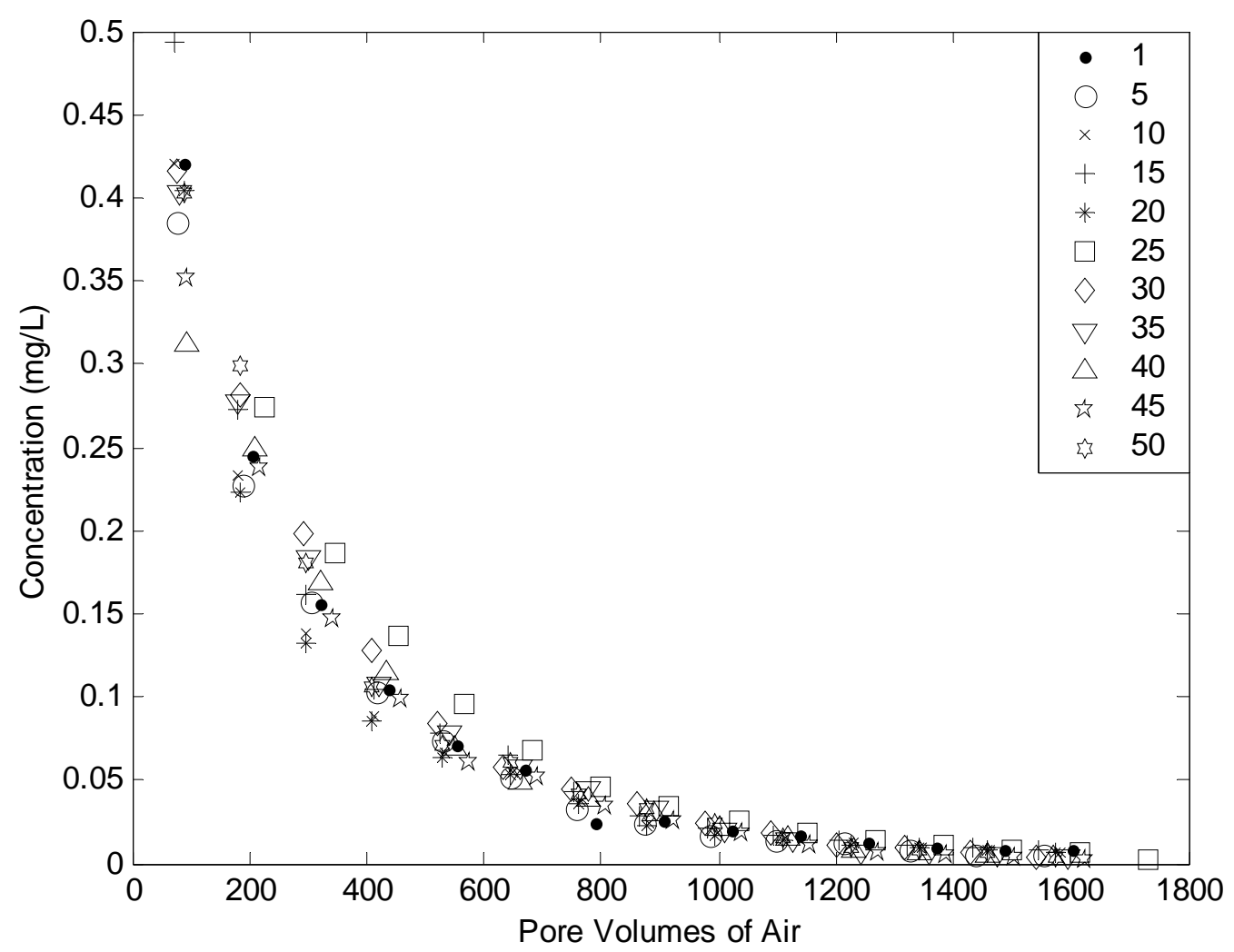

Figure C- 5. Toluene removal for every fifth regeneration cycle on column LST1. 


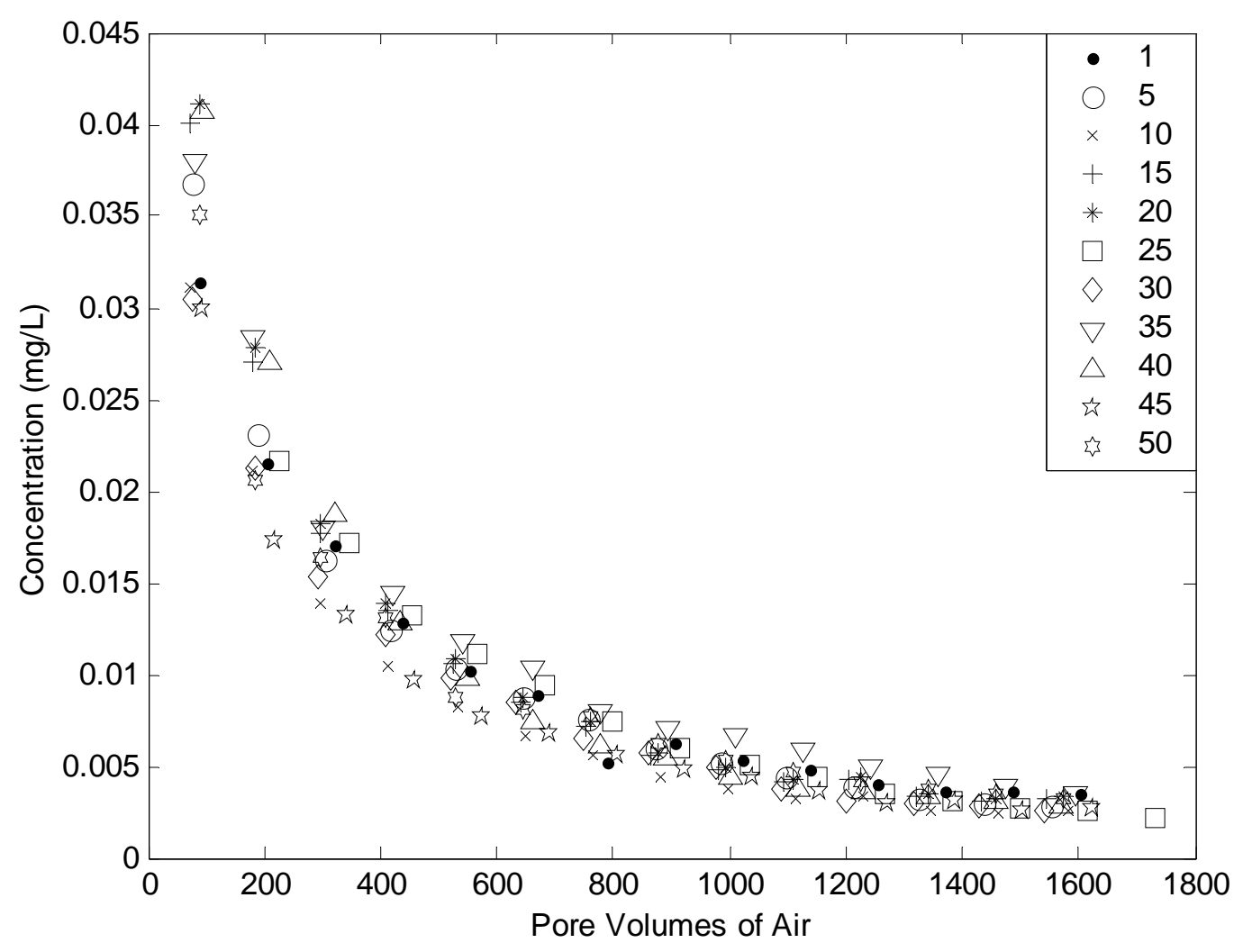

Figure C- 6. Ethylbenzene removal for every fifth regeneration cycle on column LST1. 


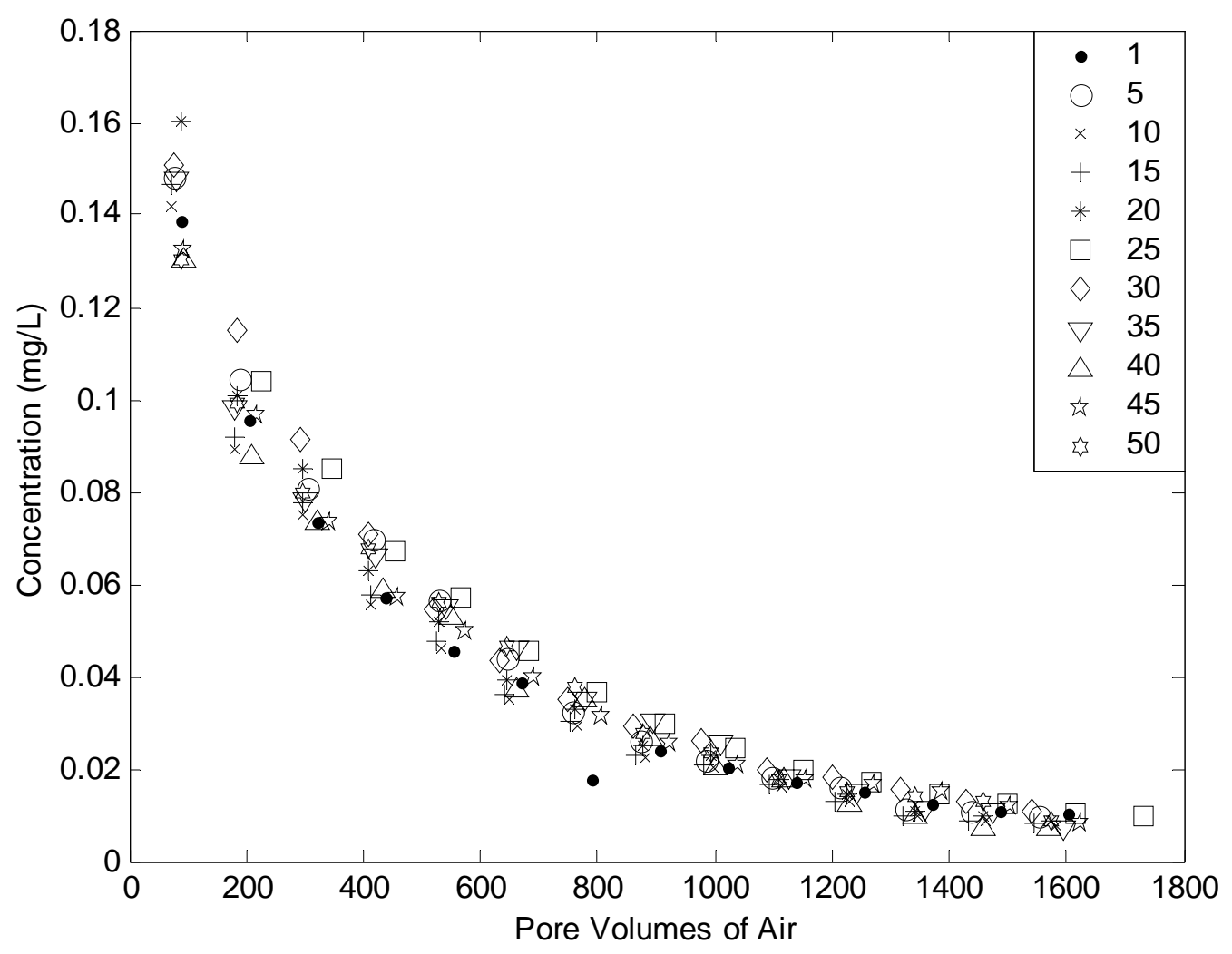

Figure C- 7. p- \& m-xylene removal for every fifth regeneration cycle on column LST1. 


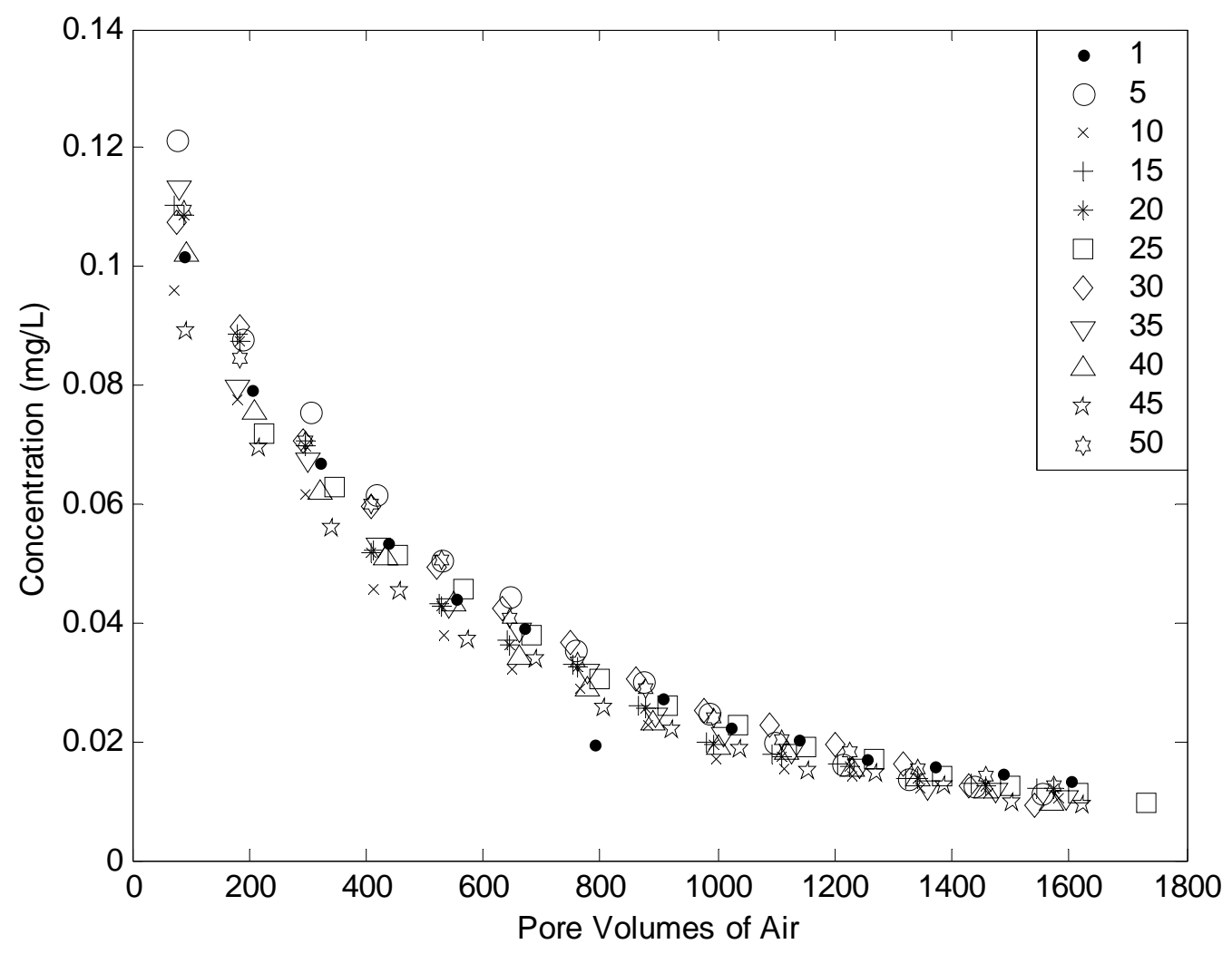

Figure C- 8. o-xylene removal for every fifth regeneration cycle on column LST1. 


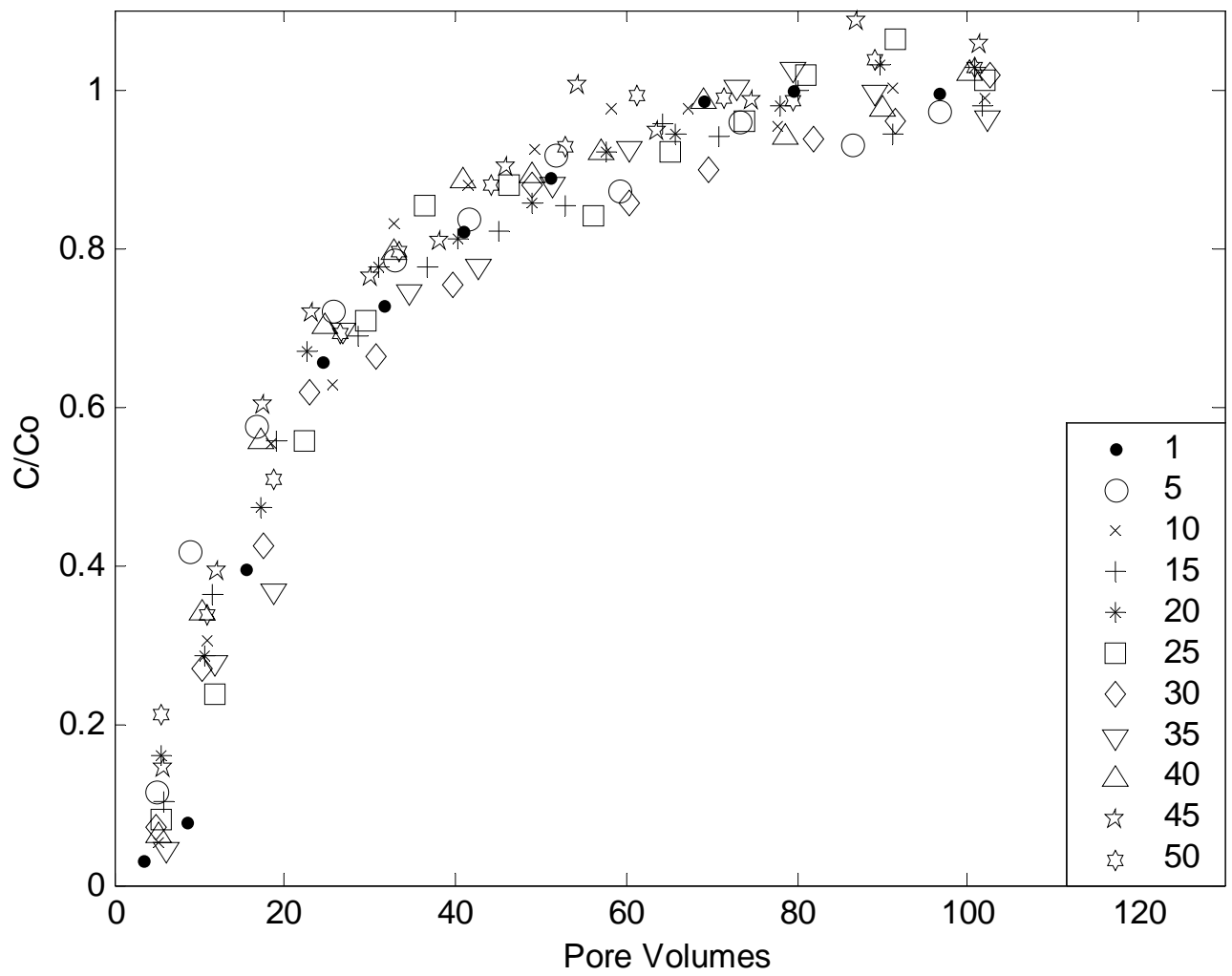

Figure C- 9. BTCs of benzene for every fifth sorption cycle on column LST2. 


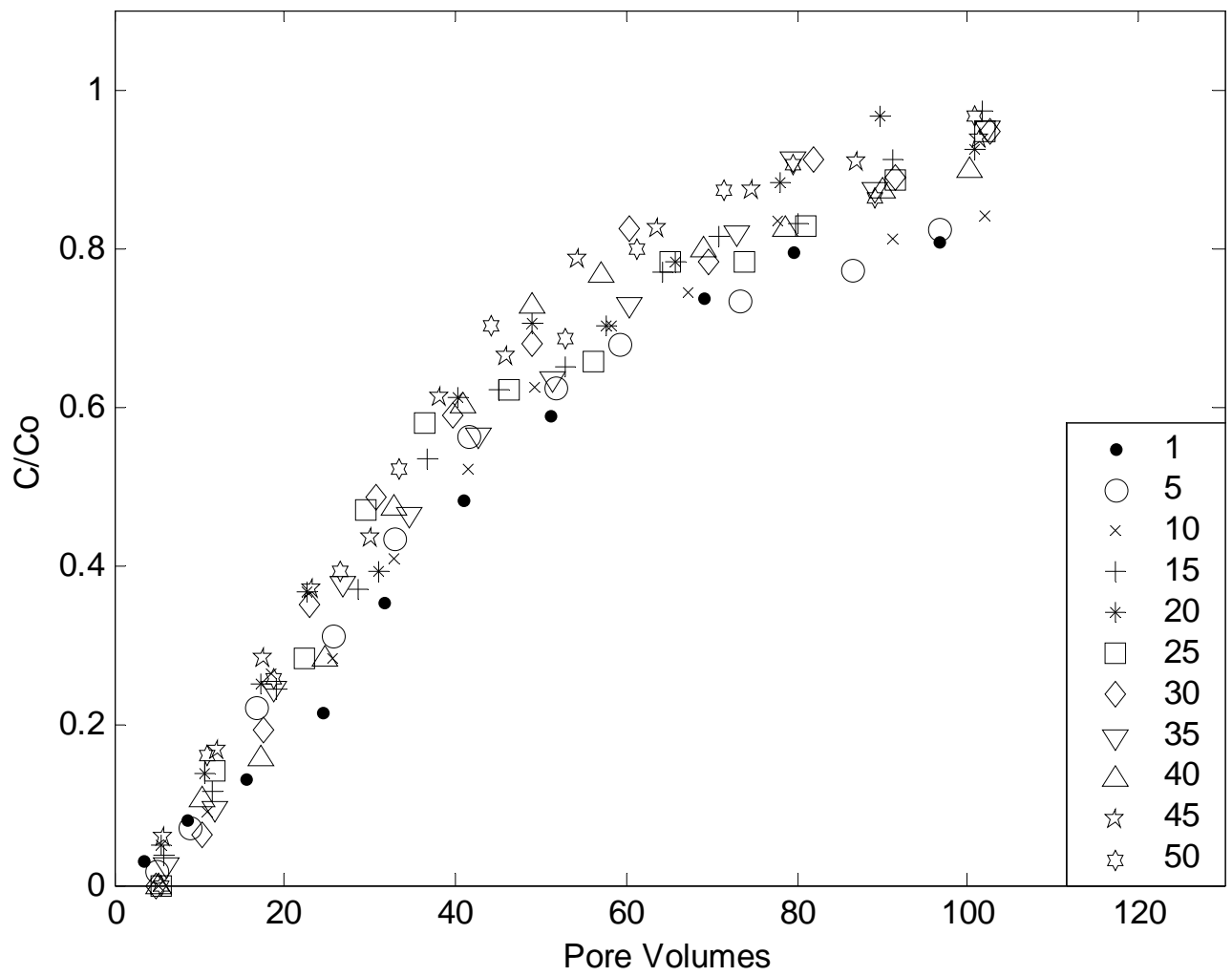

Figure C- 10. BTCs of toluene for every fifth sorption cycle on column LST2. 


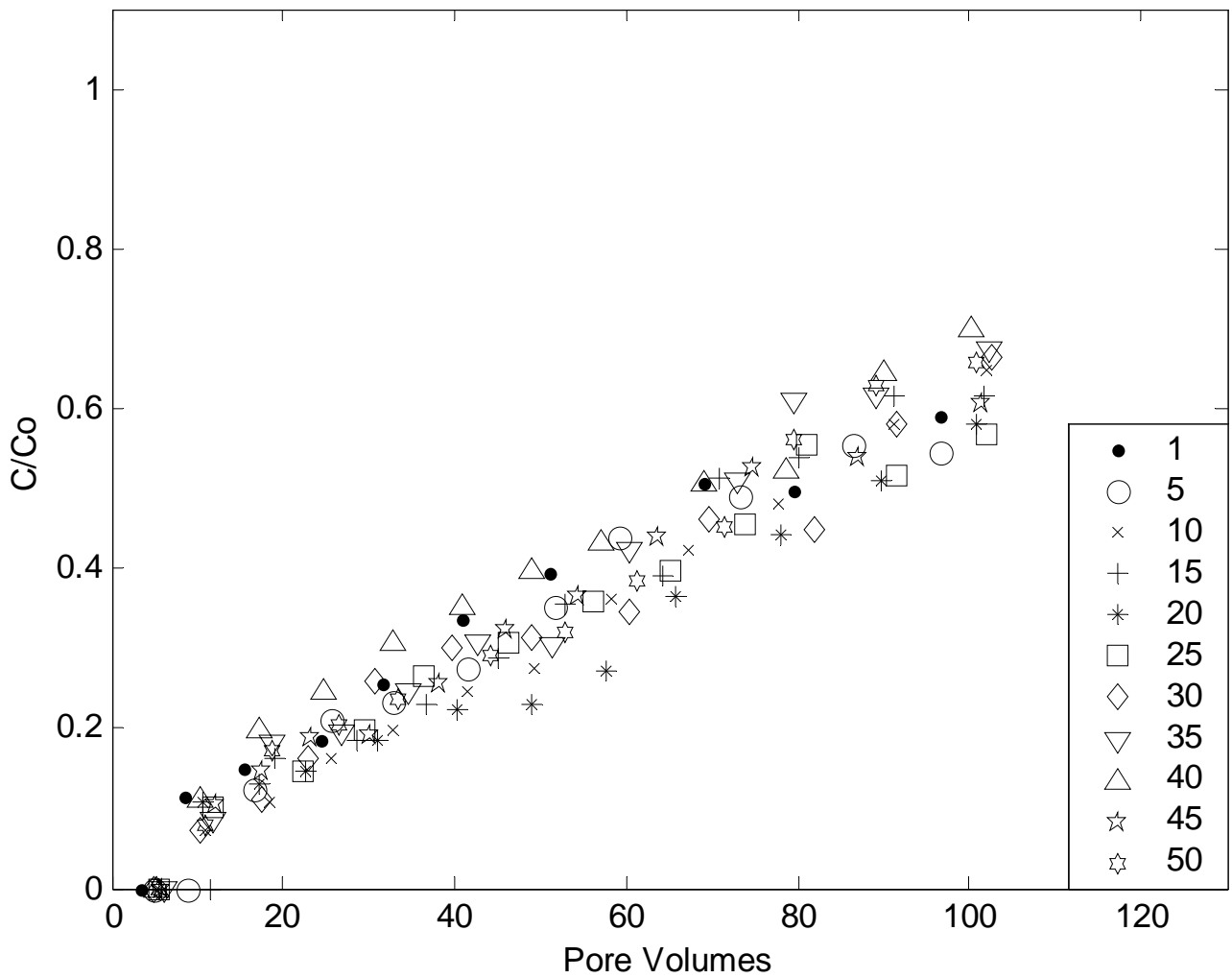

Figure C- 11. BTCs of ethylbenzene for every fifth sorption cycle on column LST2. 


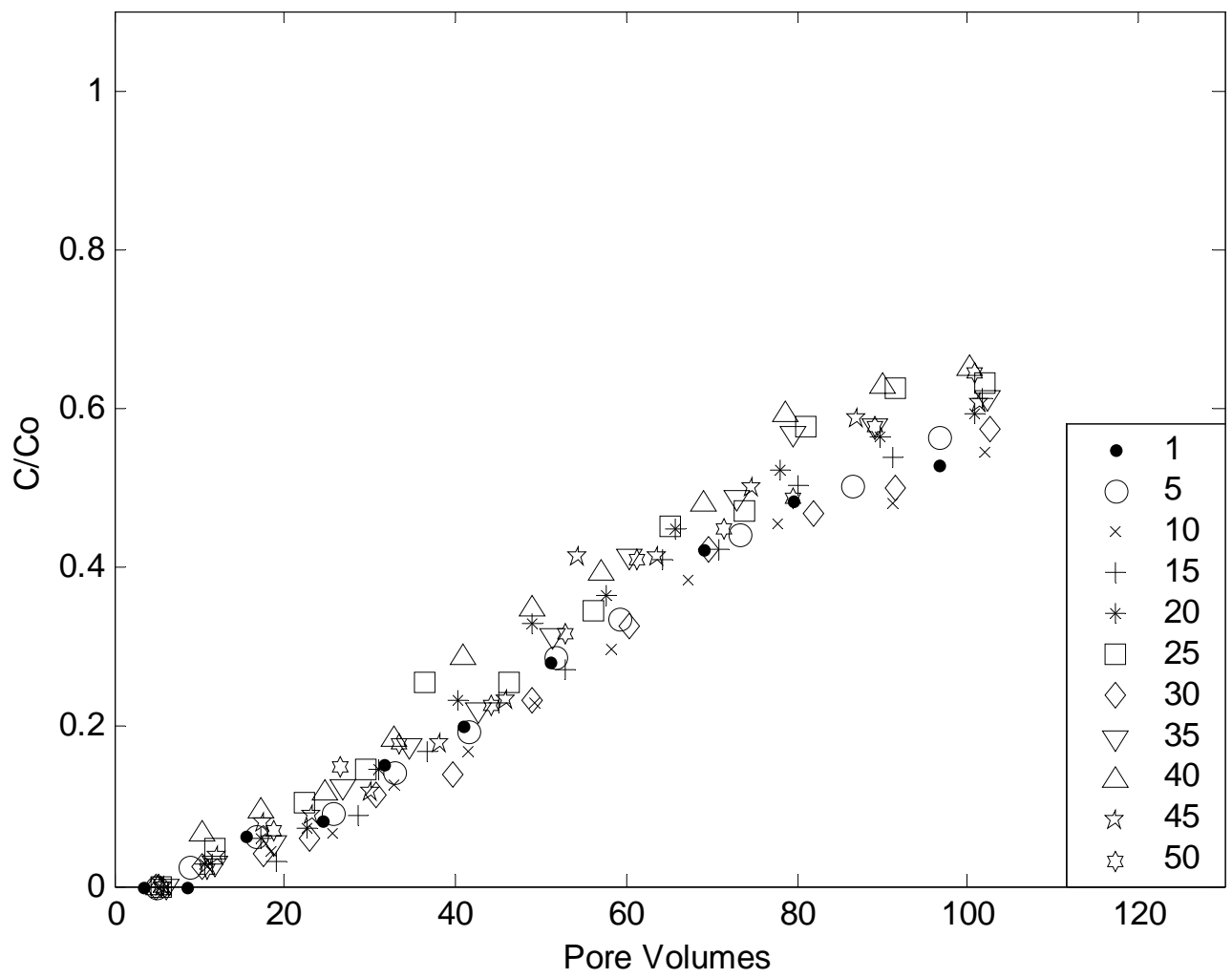

Figure C- 12. BTCs of p- \& m-xylene for every fifth sorption cycle on column LST2. 


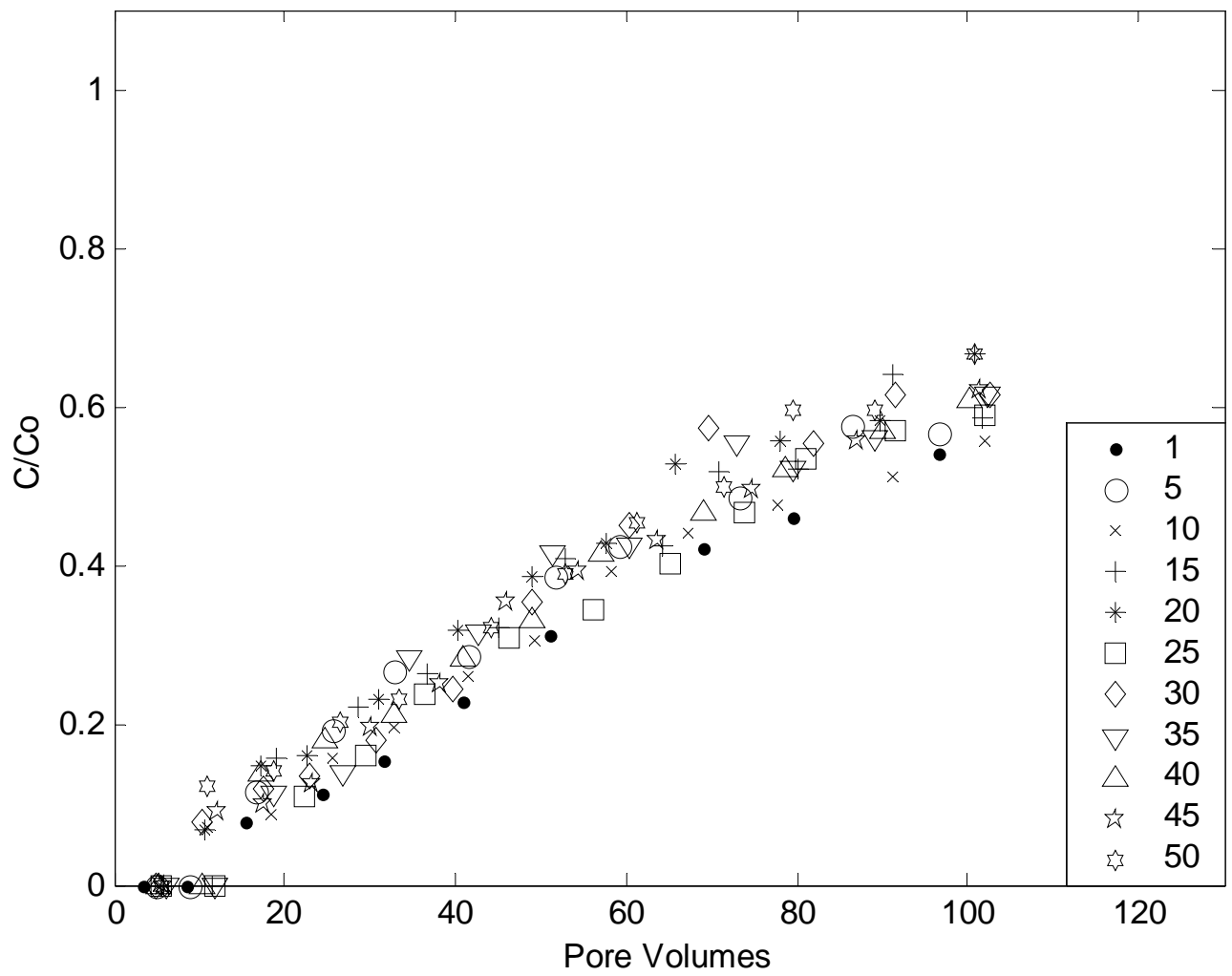

Figure C- 13. BTCs o-xylene for every fifth sorption cycle on column LST2. 


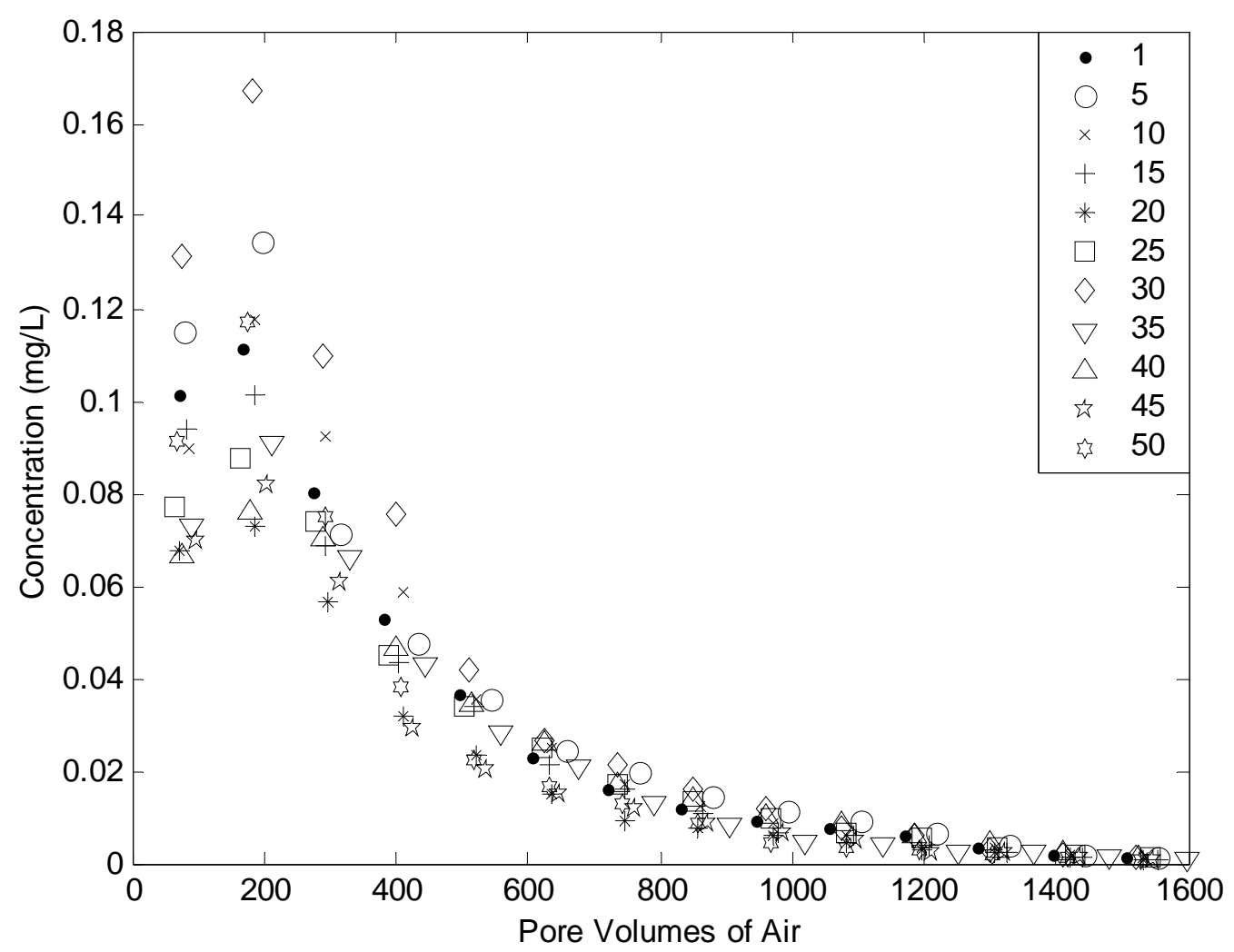

Figure C- 14. Benzene removal for every fifth regeneration cycle on column LST2 


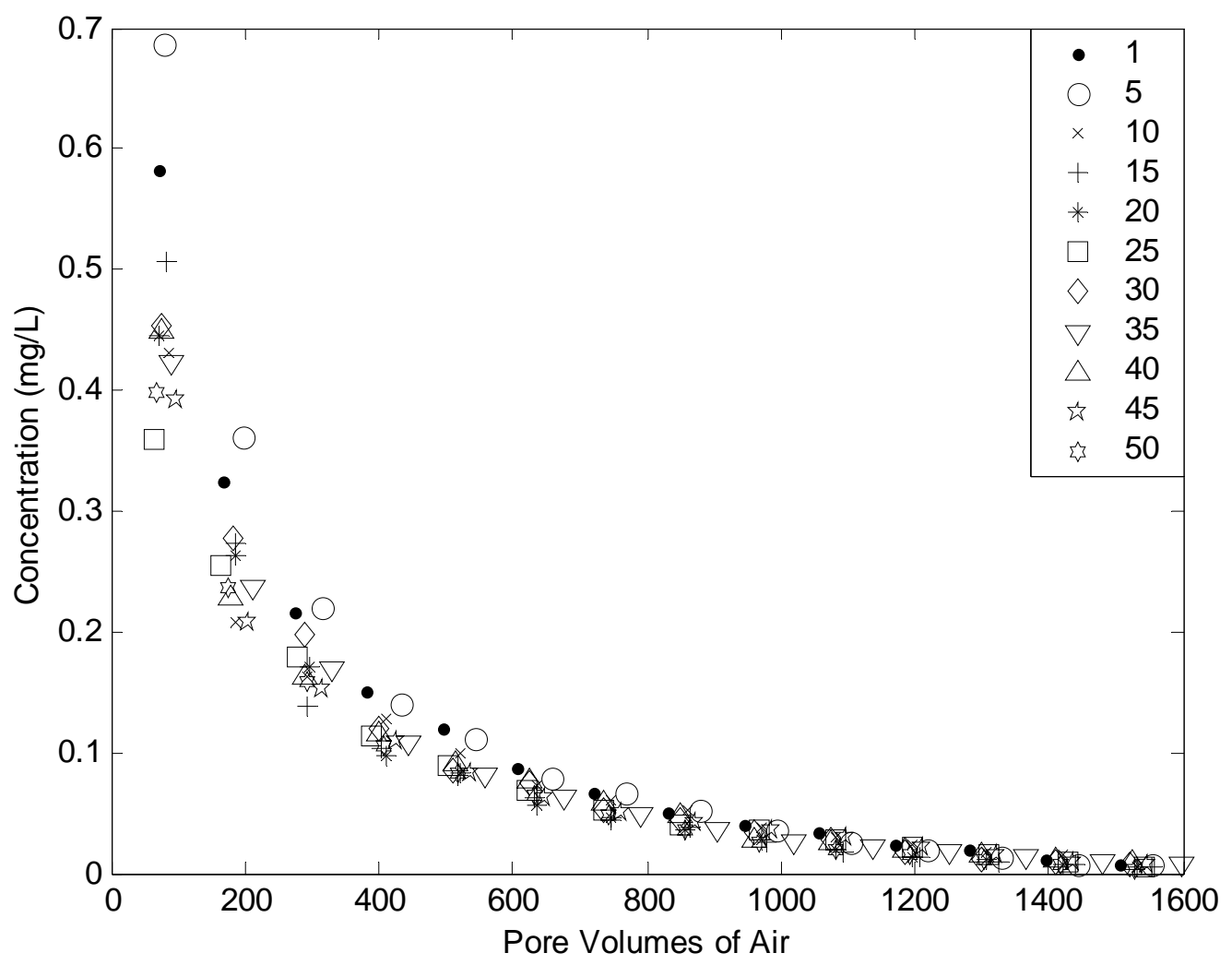

Figure C- 15. Toluene removal for every fifth regeneration cycle on column LST2 


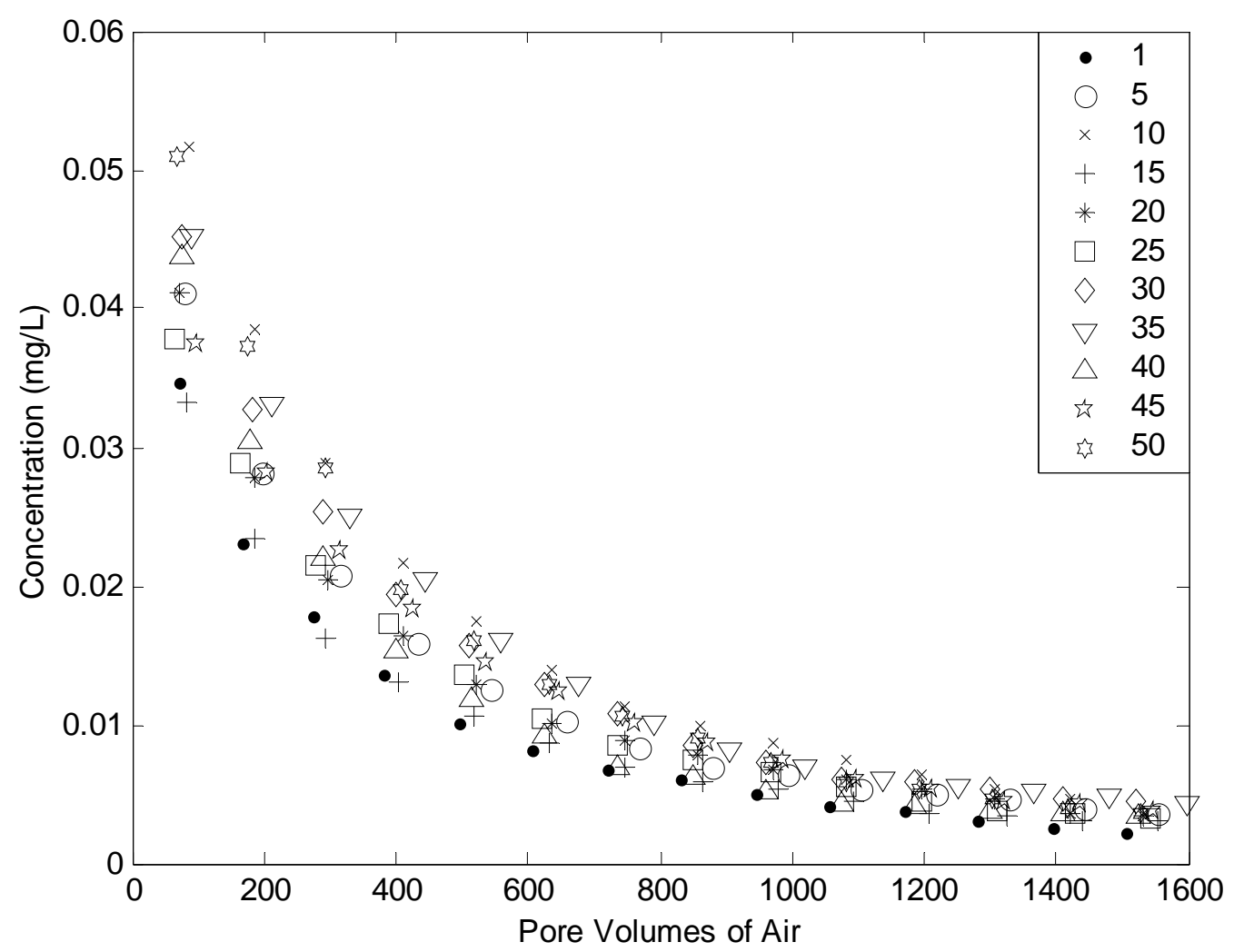

Figure C- 16. Ethylbenzene removal for every fifth regeneration cycle on column LST2 


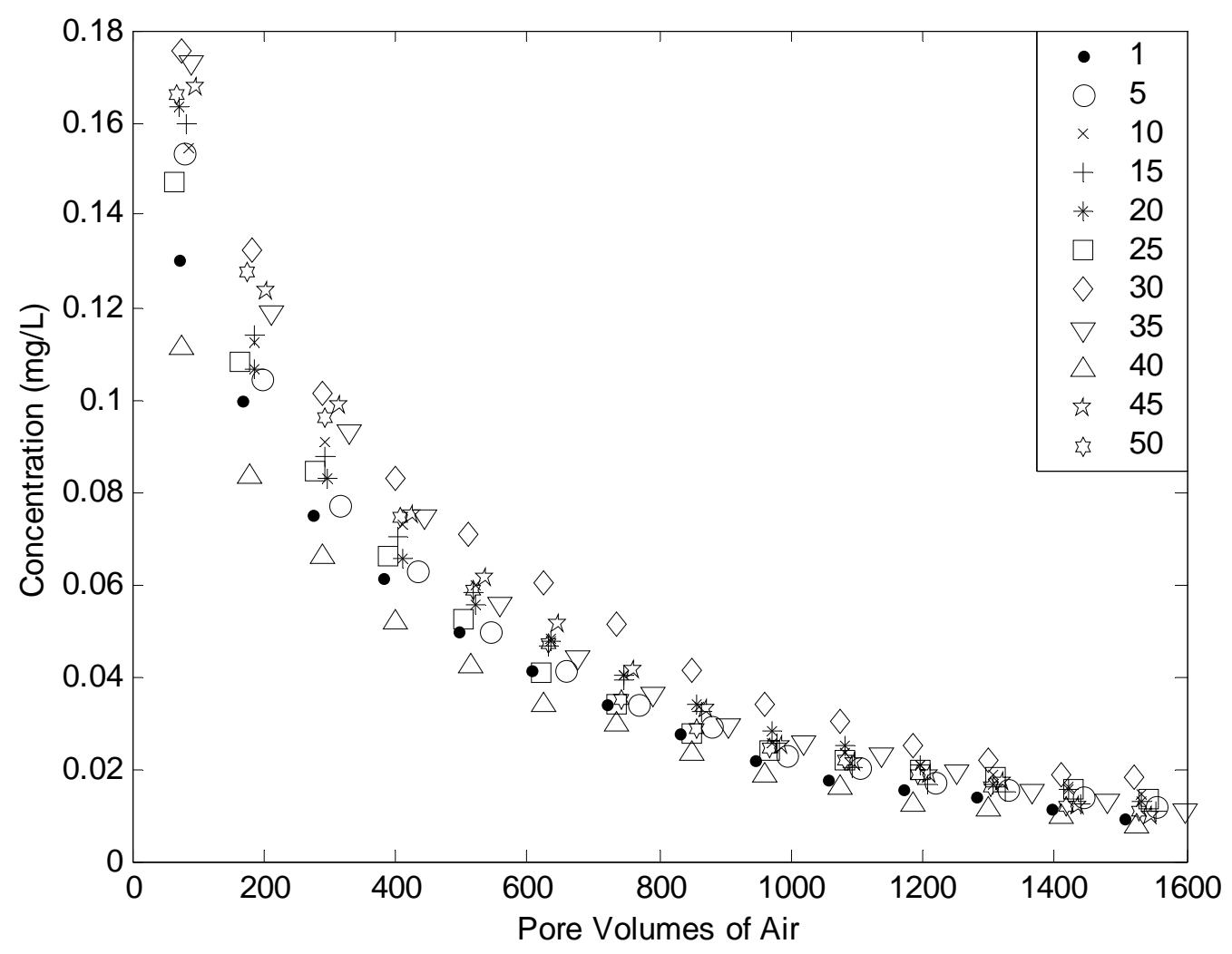

Figure C- 17. p- \& m-xylene removal for every fifth regeneration cycle on column LST2 


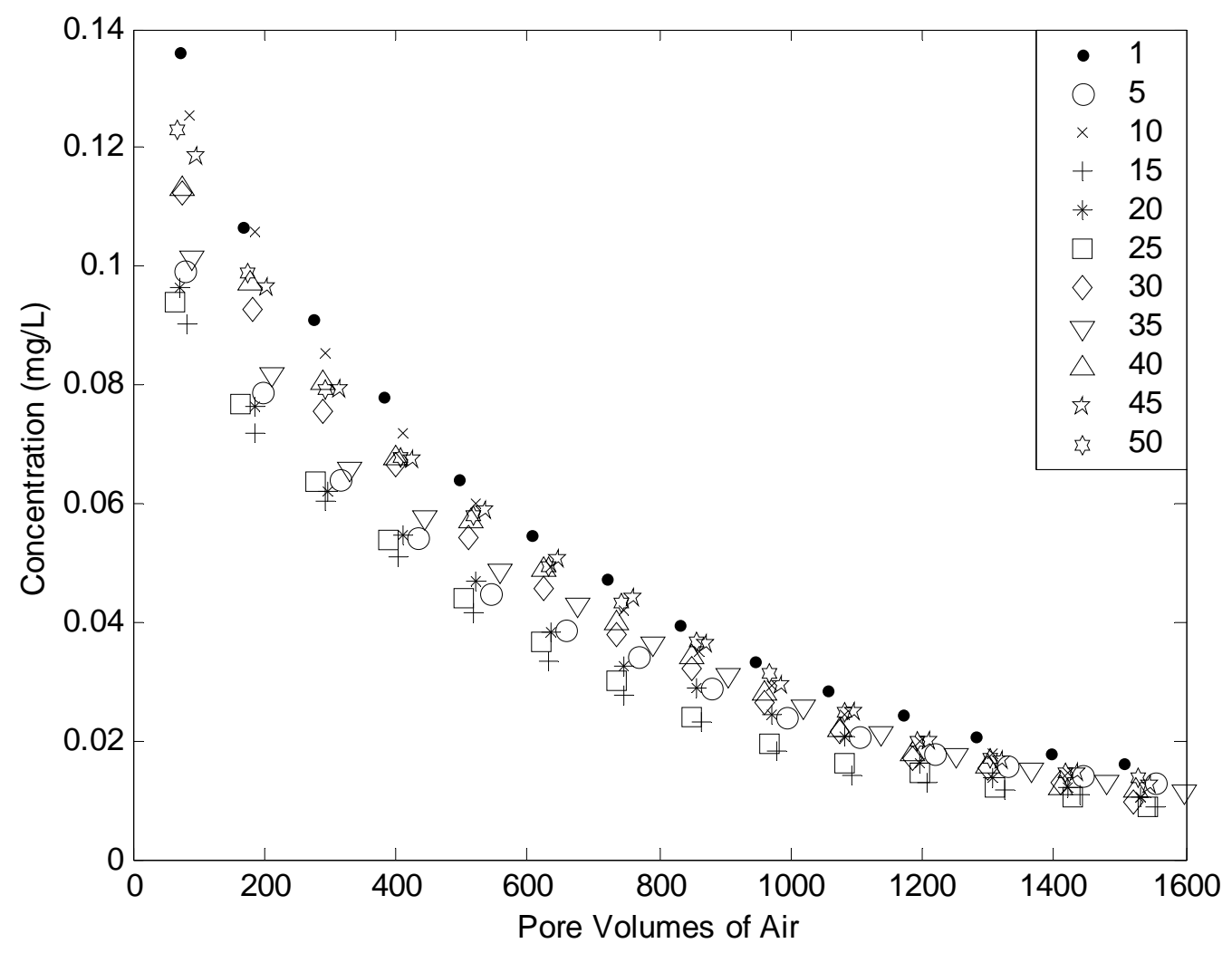

Figure C- 18. o-xylene removal for every fifth regeneration cycle on column LST2 


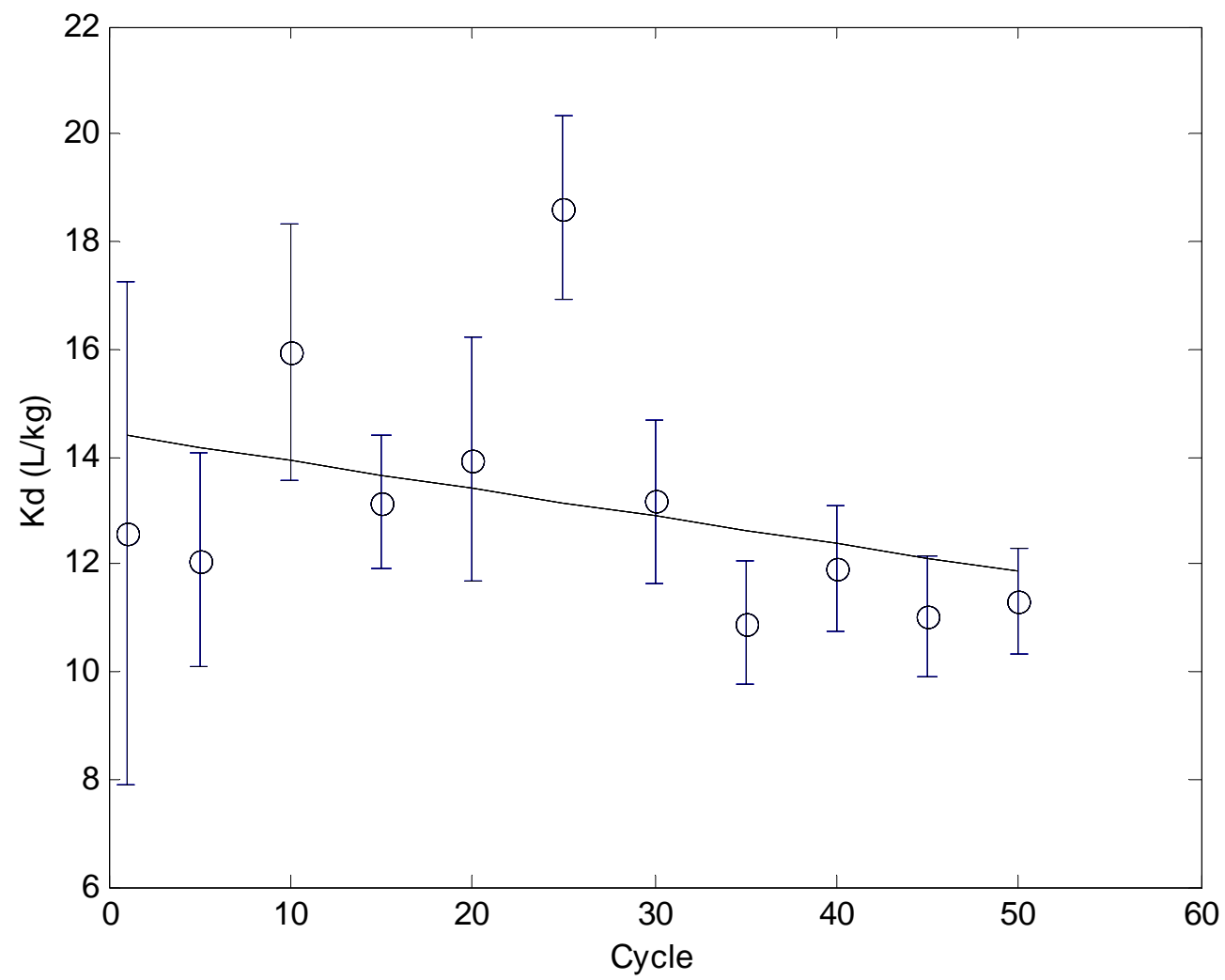

Figure C- 19. $K_{d}$ 's and linear regression fit to the $K_{d}$ values for benzene from column LST1. Error bars represent the $95 \%$ confidence interval from the curve-fit process using CXTFIT. 


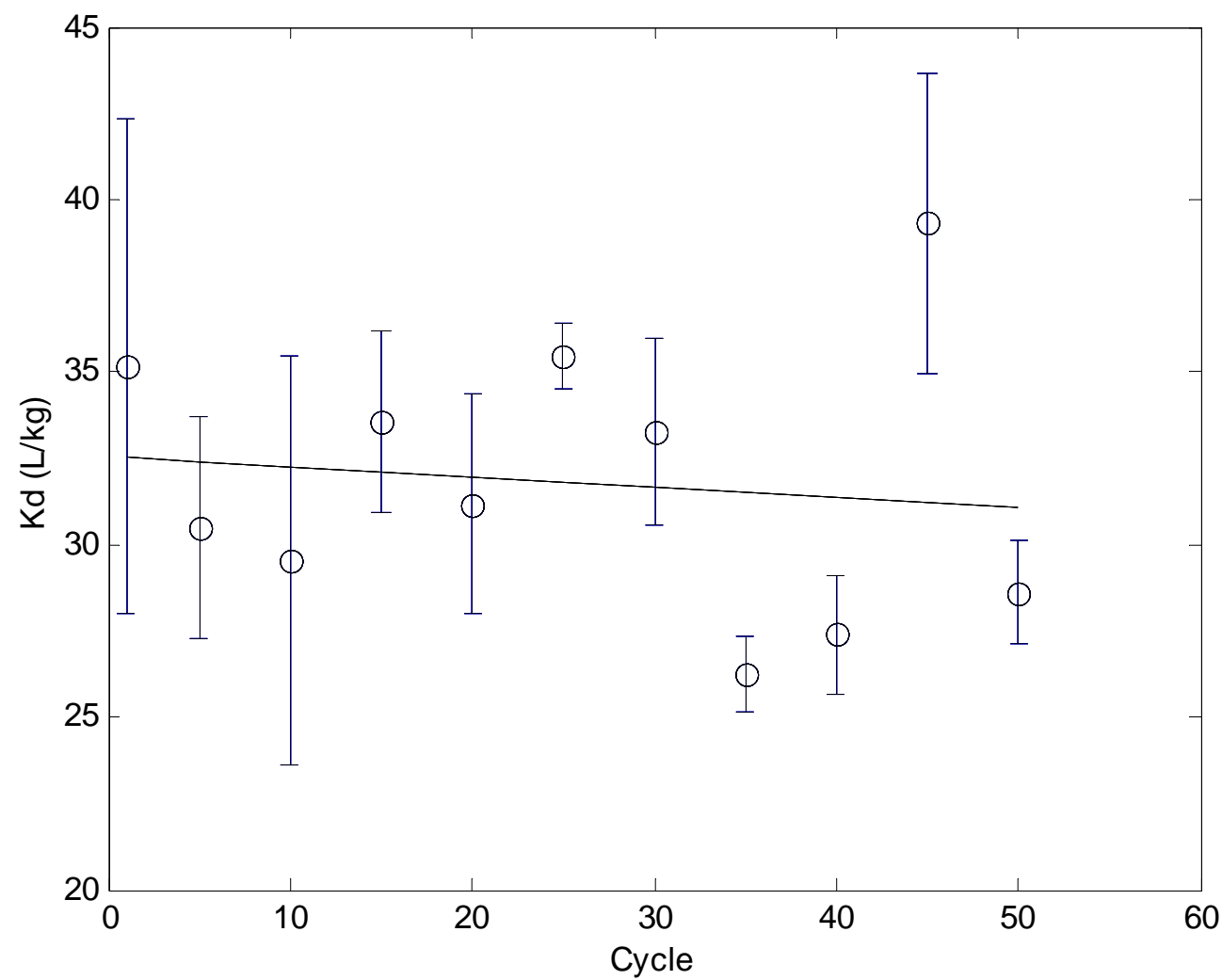

Figure C- 20. $K_{d}$ 's and linear regression fit to the $K_{d}$ values for toluene from column LST1. Error bars represent the $95 \%$ confidence interval from the curve-fit process using CXTFIT. 


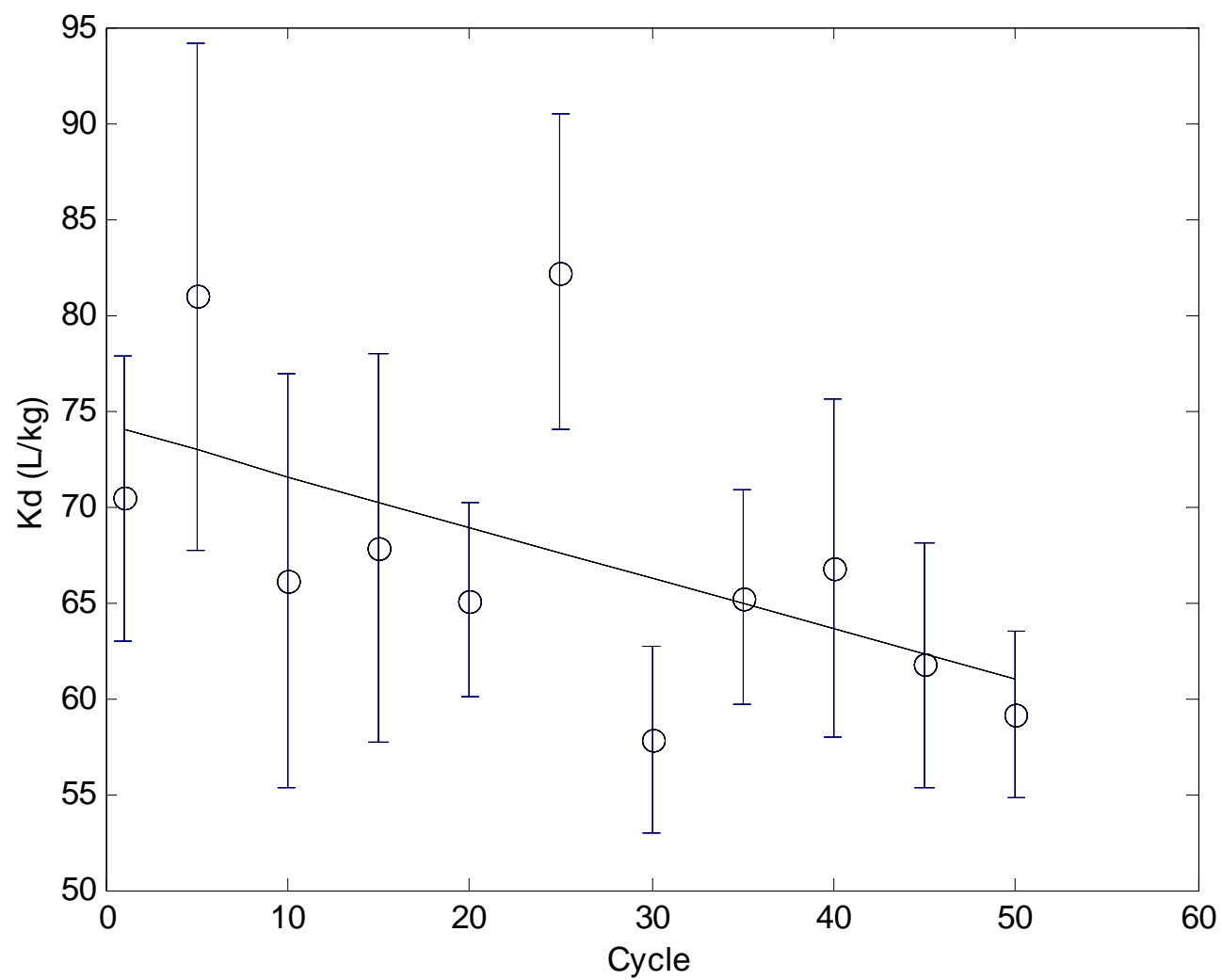

Figure C- 21. $K_{d}$ 's and linear regression fit to the $K_{d}$ values for ethylbenzene from column LST1. Error bars represent the $95 \%$ confidence interval from the curve-fit process using CXTFIT. 


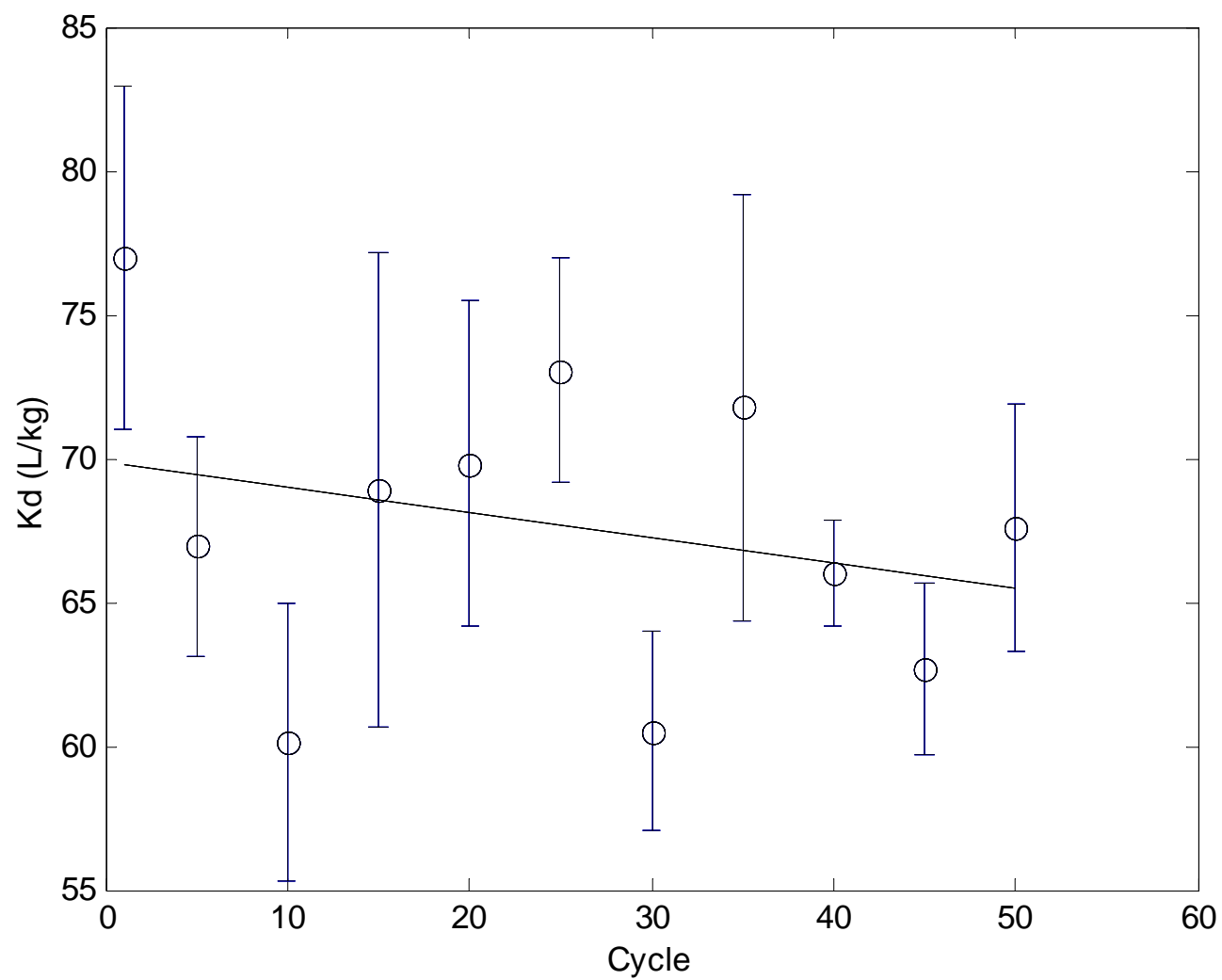

Figure C- 22. $K_{d}$ 's and linear regression fit to the $K_{d}$ values for $p$ - \& $m$-xylene from column LST1. Error bars represent the $95 \%$ confidence interval from the curve-fit process using CXTFIT. 


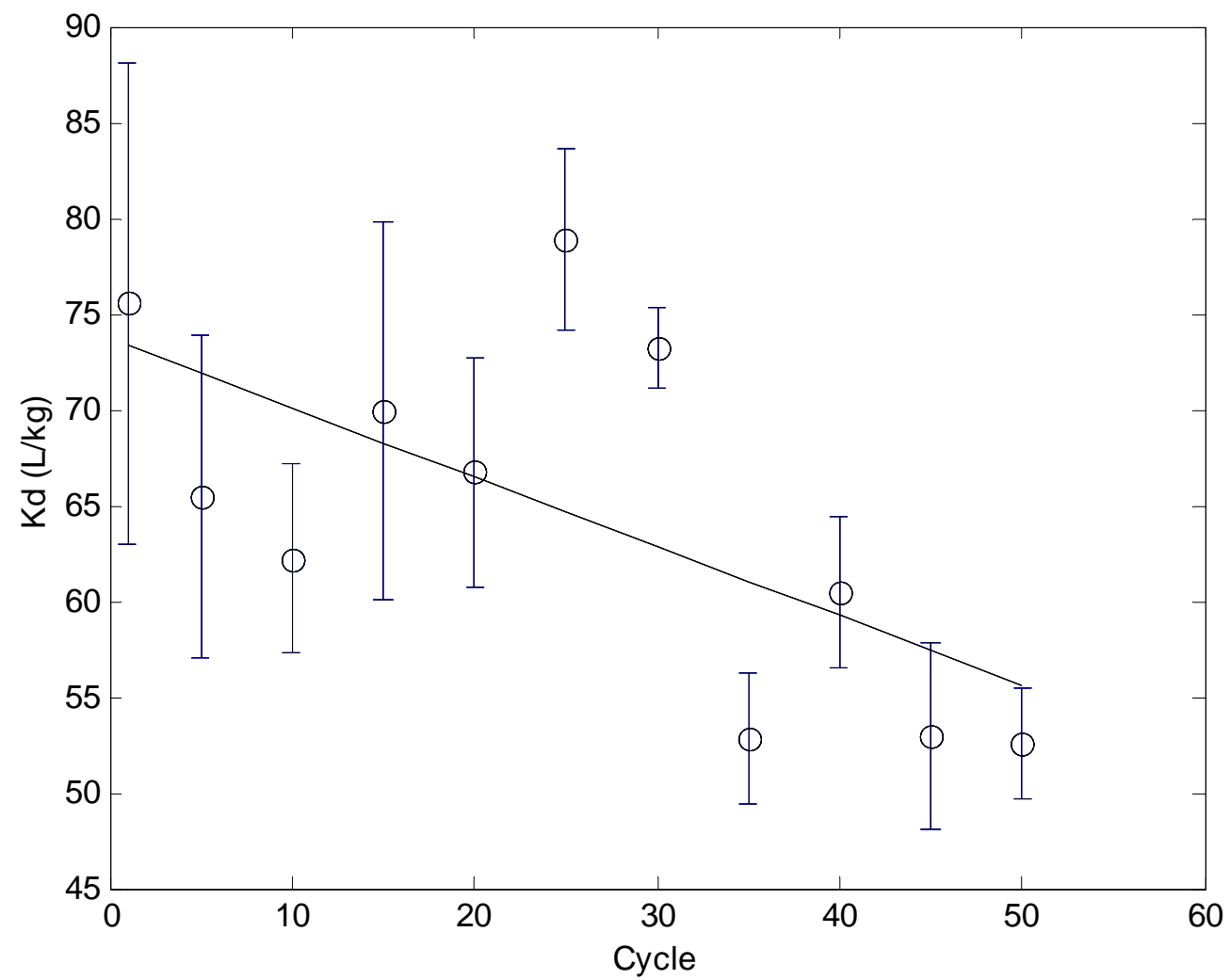

Figure C- 23. $K_{d}$ 's and linear regression fit to the $K_{d}$ values for $o$-xylene from column LST1. Error bars represent the $95 \%$ confidence interval from the curve-fit process using CXTFIT. 


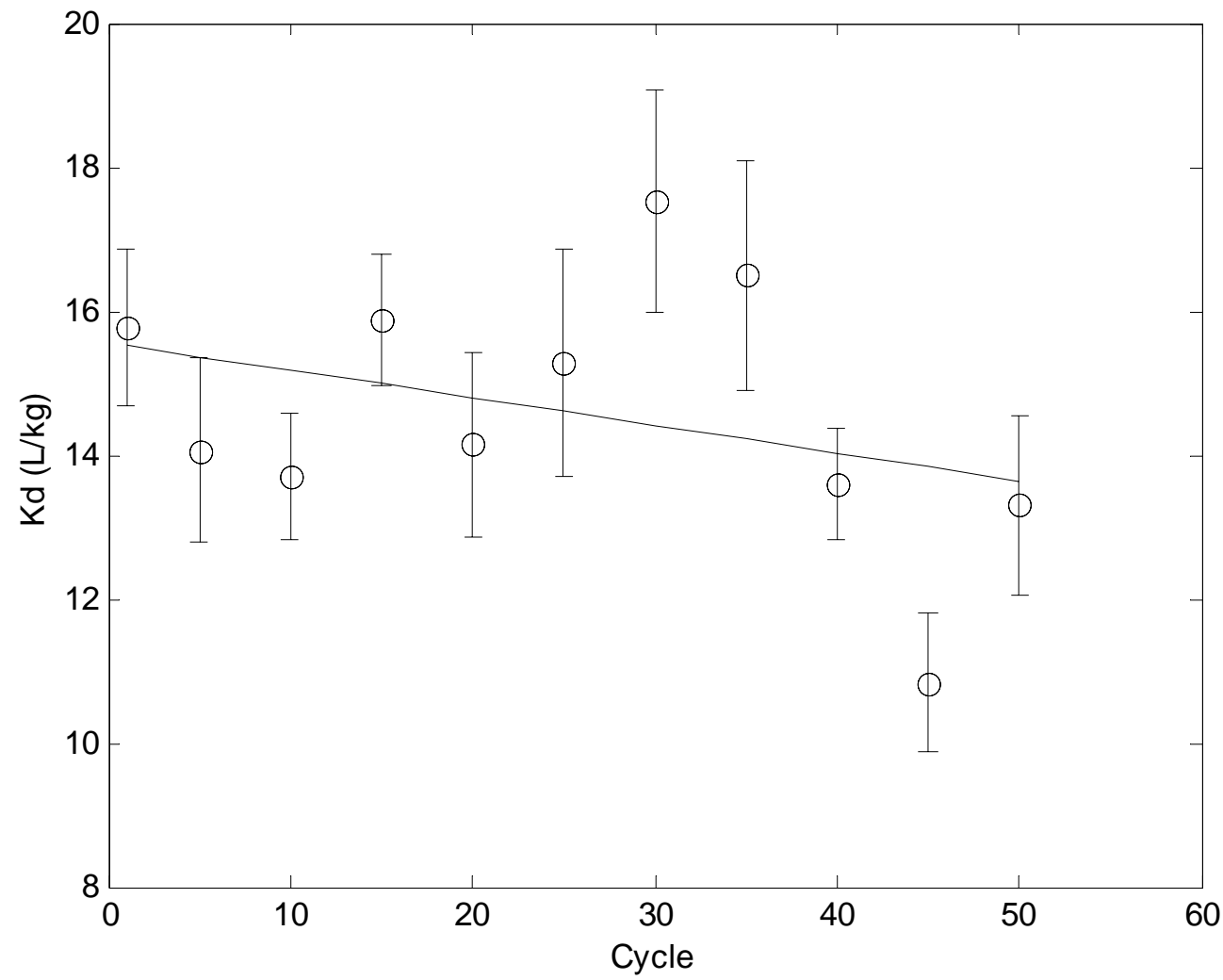

Figure C- 24. $K_{d}$ 's and linear regression fit to the $K_{d}$ values for benzene from column LST2. Error bars represent the $95 \%$ confidence interval from the curve-fit process using CXTFIT. 


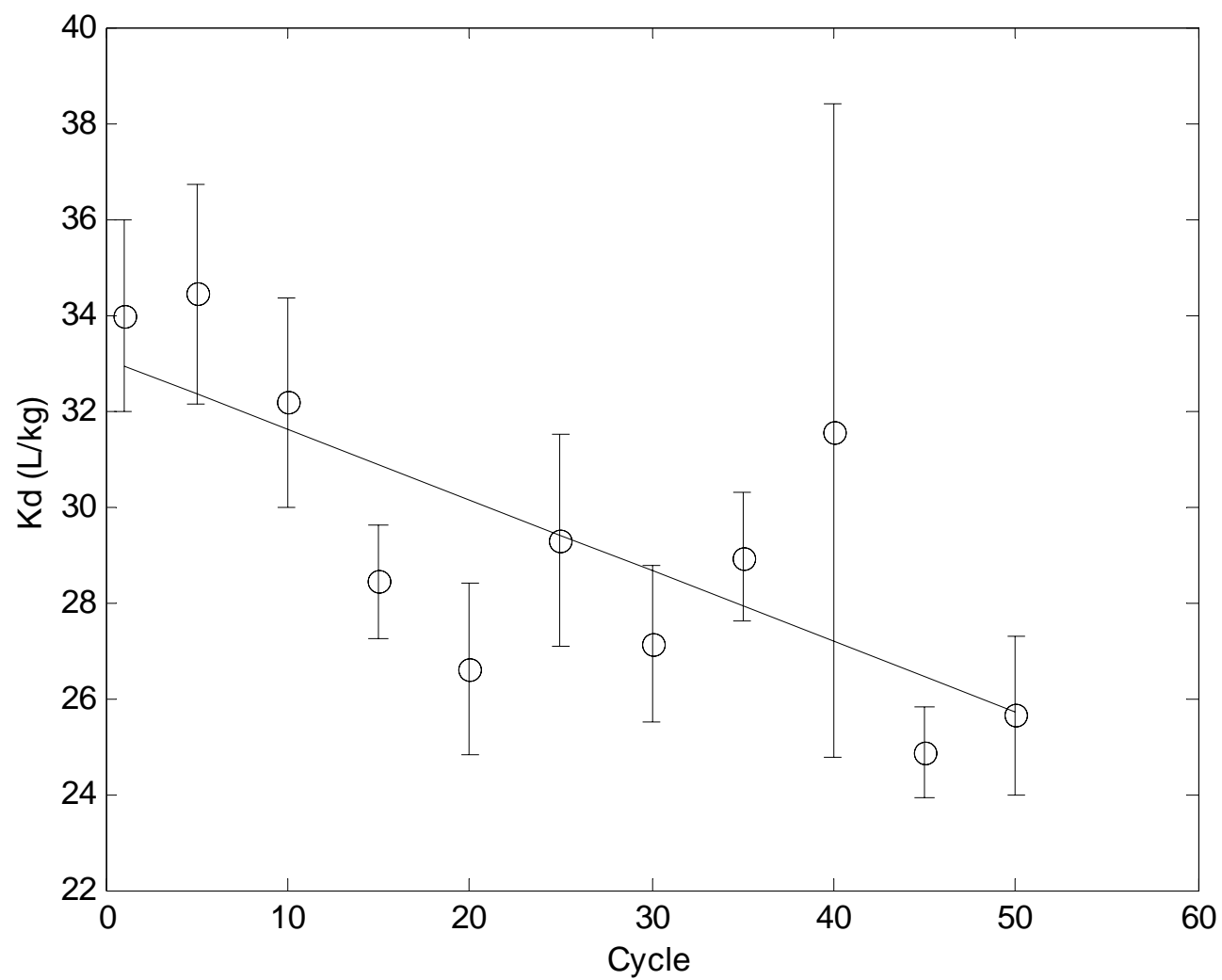

Figure C- 25. $K_{d}$ 's and linear regression fit to the $K_{d}$ values for toluene from column LST2. Error bars represent the $95 \%$ confidence interval from the curve-fit process using CXTFIT. 


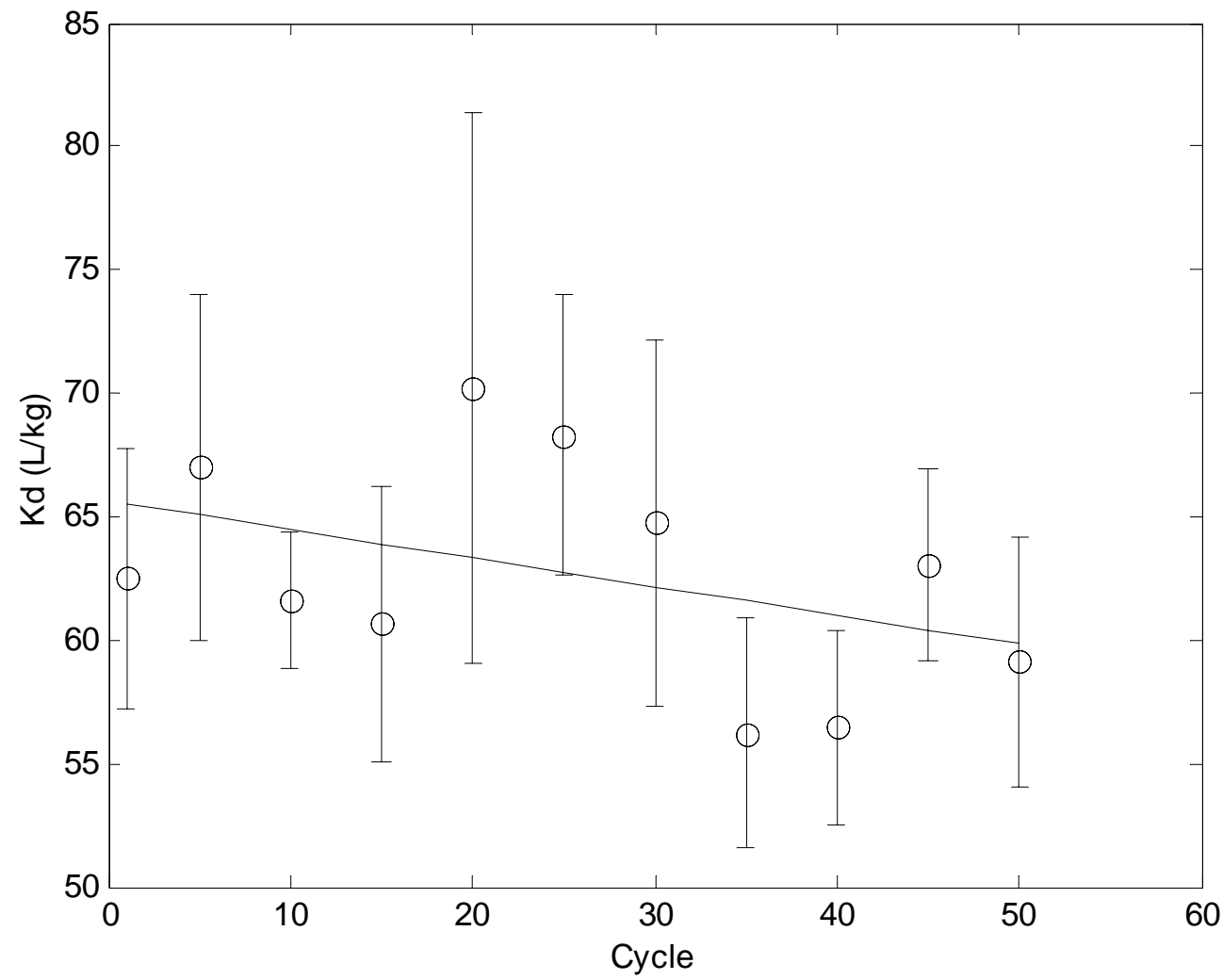

Figure C- 26. $K_{d}$ 's and linear regression fit to the $K_{d}$ values for ethylbenzene from column LST2. Error bars represent the $95 \%$ confidence interval from the curve-fit process using CXTFIT. 


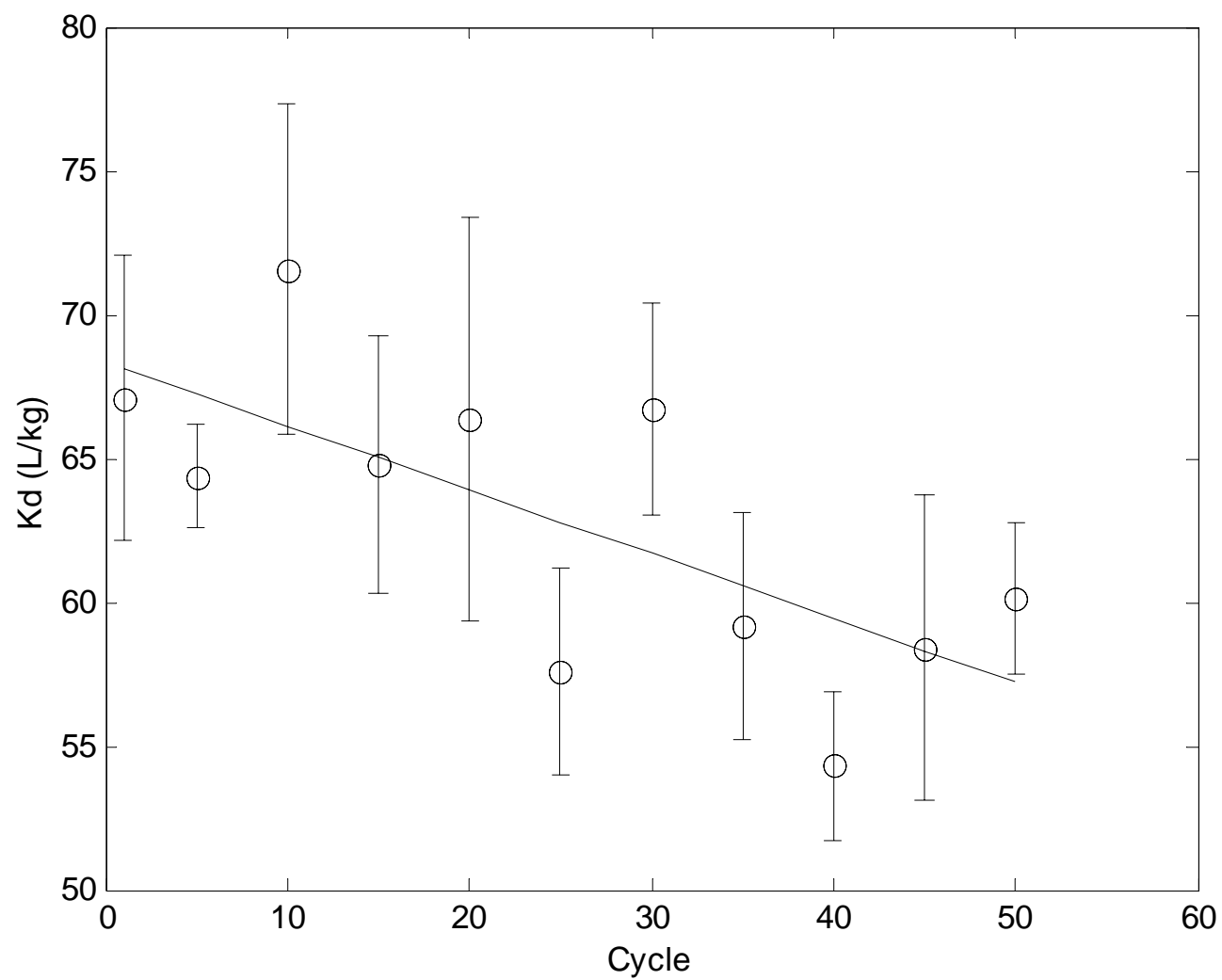

Figure C- 27. $K_{d}$ 's and linear regression fit to the $K_{d}$ values for $p$ - \& $m$-xylene from column LST2. Error bars represent the $95 \%$ confidence interval from the curve-fit process using CXTFIT. 


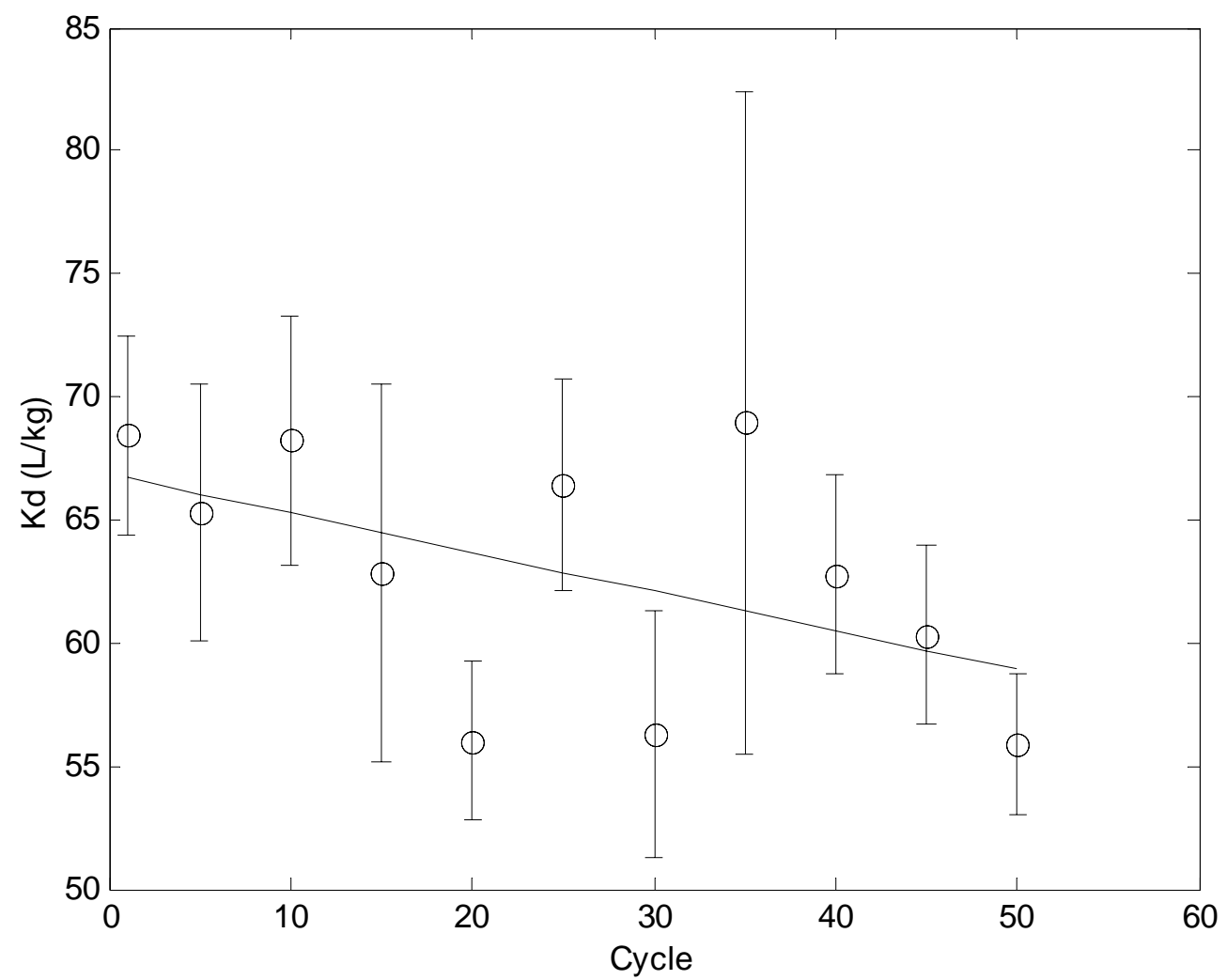

Figure C- 28. $K_{d}$ 's and linear regression fit to the $K_{d}$ values for $o$-xylene from column LST2. Error bars represent the $95 \%$ confidence interval from the curve-fit process using CXTFIT. 


\section{APPENDIX D. HYDRAULIC CONDUCTIVITY AND GRAIN SIZE MEASUREMENTS FOR THE LONG-TERM STABILITY EXPERIMENTS}

Appendix D contains the results of hydraulic conductivity and grain size measurements for columns LST1 and LST2. Table D-1 contains all conductivity values recorded for the LST experiments as well as the conductivity of the used column with new frits in the end fittings. Discoloration of the used frits was noted during replacement, particularly for the influent frit. This indicates that some material either passed through the $0.45 \mu \mathrm{m}$ syringe-tip filter or precipitated out of solution and accumulated on the frits. While clogging of the frits remains a concern for future laboratory experiments, the pilotscale field tests mentioned in the manuscript did not use a similar type of frit.

Figures D-1 through D-3 show grain size distribution curves for virgin 14 - 40 mesh SMZ and used 14 - 40 mesh SMZ from columns LST1, LST2, respectively. As noted in the manuscript, the percentage of material finer than $0.075 \mathrm{~mm}$ increased from $1.83 \%$ for virgin SMZ to $13.68 \%$ for column LST1 and $17.84 \%$ for column LST2. This increase in fine material most likely led to the observed loss in hydraulic conductivity. Biofouling was eliminated as a possibility for the observed conductivity loss, as discussed in the results section of the manuscript. 
Table D- 1. Hydraulic conductivity measurements made after every fifth cycle on columns LST1 and LT2

\begin{tabular}{ccc}
\multirow{2}{*}{ Cycles } & \multicolumn{2}{c}{$\mathrm{K}(\mathrm{cm} / \mathrm{min})$} \\
\cline { 2 - 3 } & LST1 & LST2 \\
\hline virgin & 2.49 & 2.19 \\
5 & 2.36 & 1.91 \\
10 & 2.27 & 2.11 \\
15 & 1.97 & 2.03 \\
20 & 0.62 & 1.52 \\
25 & 0.06 & 0.67 \\
30 & 0.06 & 0.09 \\
35 & 0.06 & 0.05 \\
40 & 0.05 & 0.04 \\
45 & 0.05 & 0.05 \\
50 & 0.03 & 0.04 \\
$50+$ new frits & 1.67 & 1.46
\end{tabular}




\section{Particle Size Distribution}

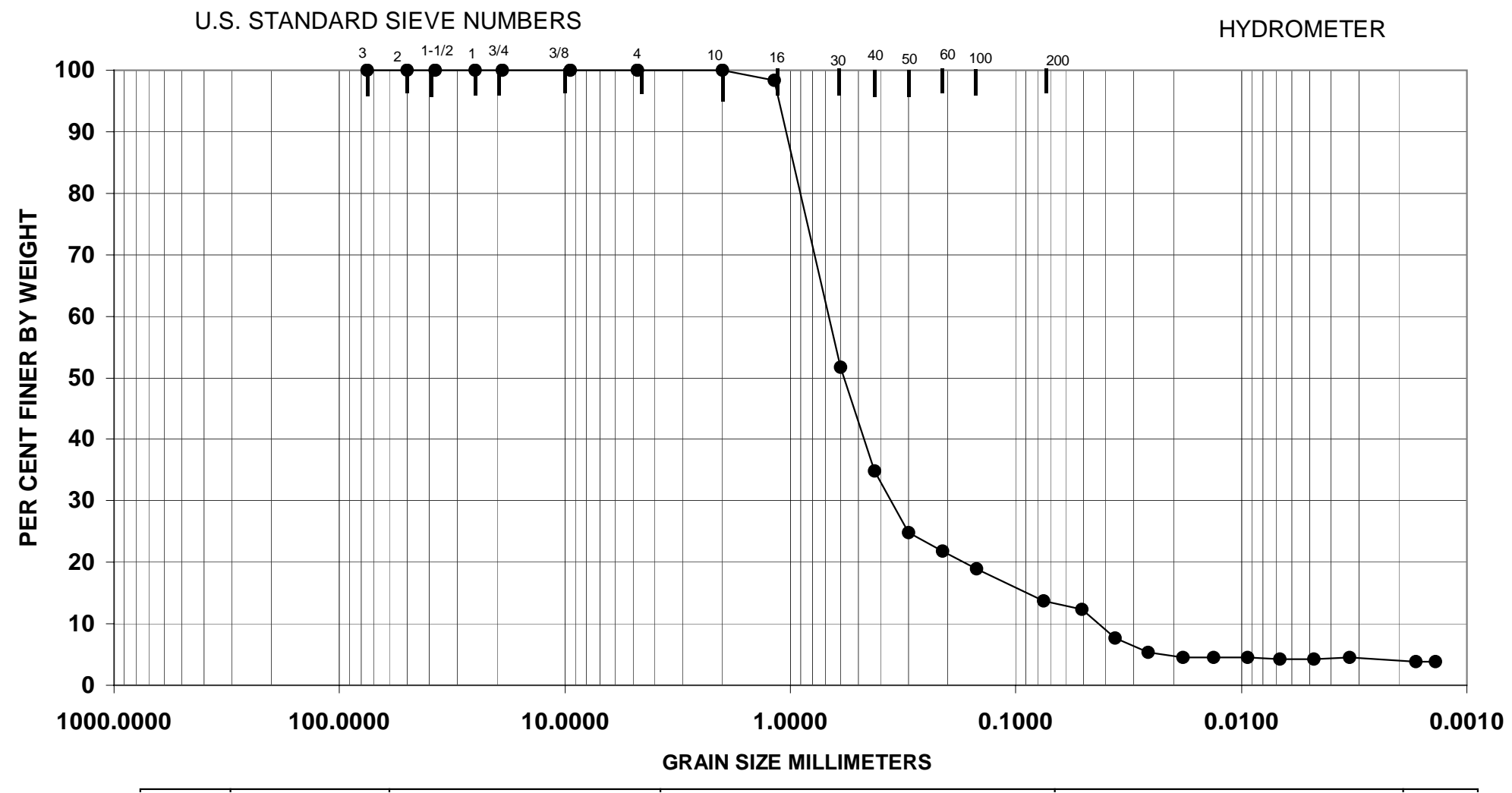

Figure D- 1. Grain size distribution for used 14 - 40 mesh SMZ from column LST1 


\section{Particle Size Distribution}

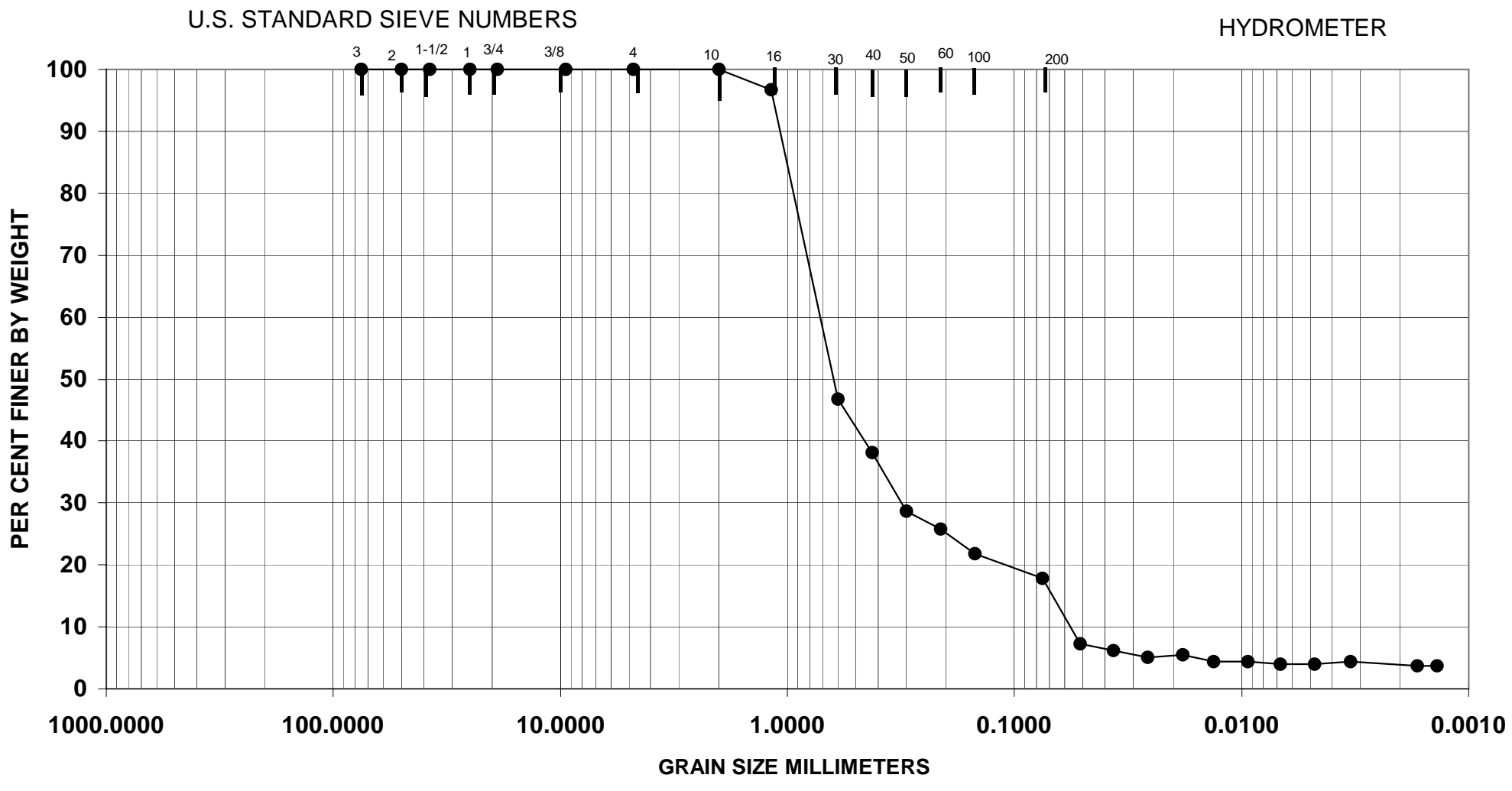

Figure D- 2. Grain size distribution for used 14 - 40 mesh SMZ from column LST2 
Particle Size Distribution

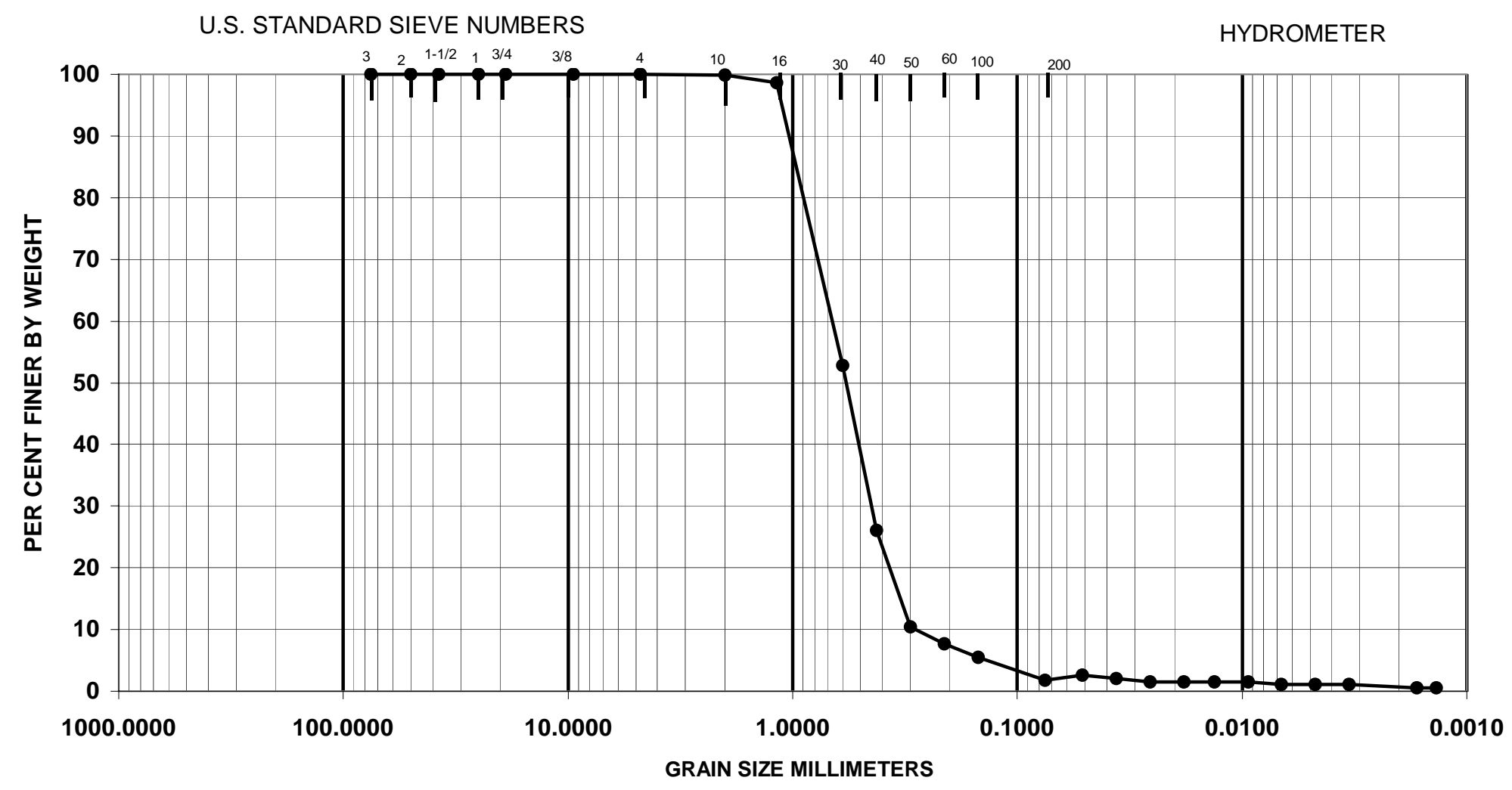

Figure D- 3. Grain size distribution for virgin 14 - 40 mesh SMZ 


\section{APPENDIX E. SEM IMAGES, CHEMICAL ANALYSIS, AND CHEMICAL DISTRIBUTION MAPS OF SMZ FROM LONG-TERM STABILITY EXPERIMENTS}

Appendix E contains images taken from the scanning electron microscope (SEM) and x-ray maps for chemical distribution of used SMZ from the LST experiments. We thank Dr. Nelia Dunbar, of the New Mexico Bureau of Geology, for her help in preparing and interpreting these images.

Figures E-1 through E-3 show backscattered electron SEM images for virgin SMZ and used SMZ from columns LST1 and LST2, respectively. Additional SEM images are presented and discussed in the manuscript.

Table E-1 presents the results of a chemical analysis for iron and manganese on used and virgin SMZ.

Figures E-4 through E-9 show the results of microprobe analysis of SMZ particles. Part (a) of each figure is a backscattered image of the SMZ surface while part (b) is an iron distribution map, where lighter colors represent higher amounts of iron. The images were prepared by mounting the particles with epoxy and polishing the mount to a smooth surface for analysis. The polishing step removed the outer surfaces of the SMZ and chemical distribution maps were made for the inside of each particle. This process inherently prevented analysis of surface coatings on the SMZ grains. Iron is present around the interior void spaces on both used and virgin SMZ. No distinct trends were noted from these images with regards to increased iron presence on used SMZ. 
Additional chemical distribution maps (not shown here) showed that essentially no mangansese was present on used or virgin SMZ. 
Table E- 1. Total iron and manganese for used SMZ from columns LST1 and LST2 and for virgin SMZ. Units are mg of analyte per $\mathrm{kg}$ of SMZ

\begin{tabular}{ccc} 
& $\mathrm{Fe}(\mathrm{mg} / \mathrm{kg})$ & $\mathrm{Mn}(\mathrm{mg} / \mathrm{kg})$ \\
\hline LST1 & 9090 & 6816 \\
LST2 & 9867 & 6828 \\
virgin SMZ & 7981 & 7758 \\
virgin SMZ (duplicate) & 9278 & 7841
\end{tabular}




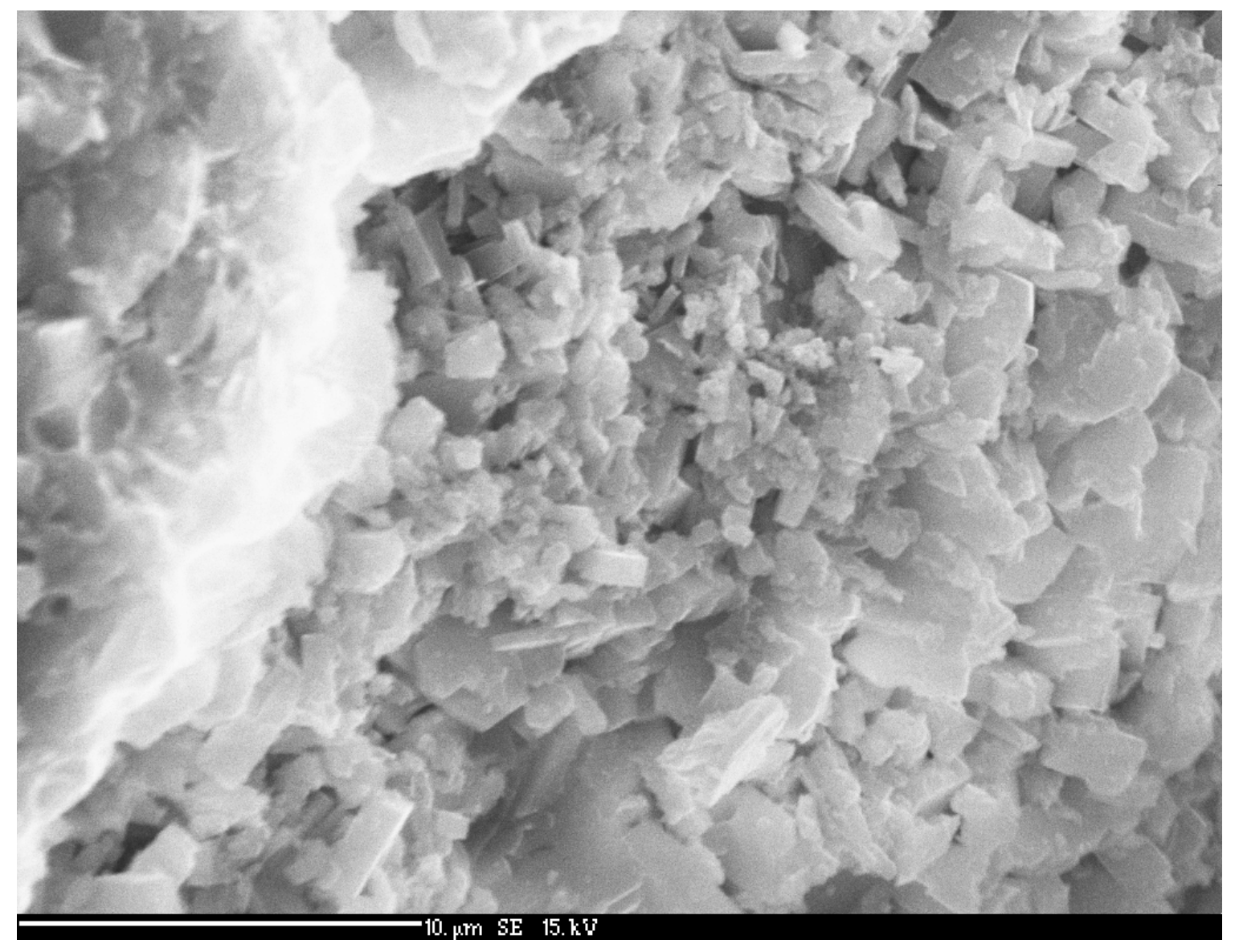

Figure E- 1. Backscattered SEM image of a virgin SMZ grain. 


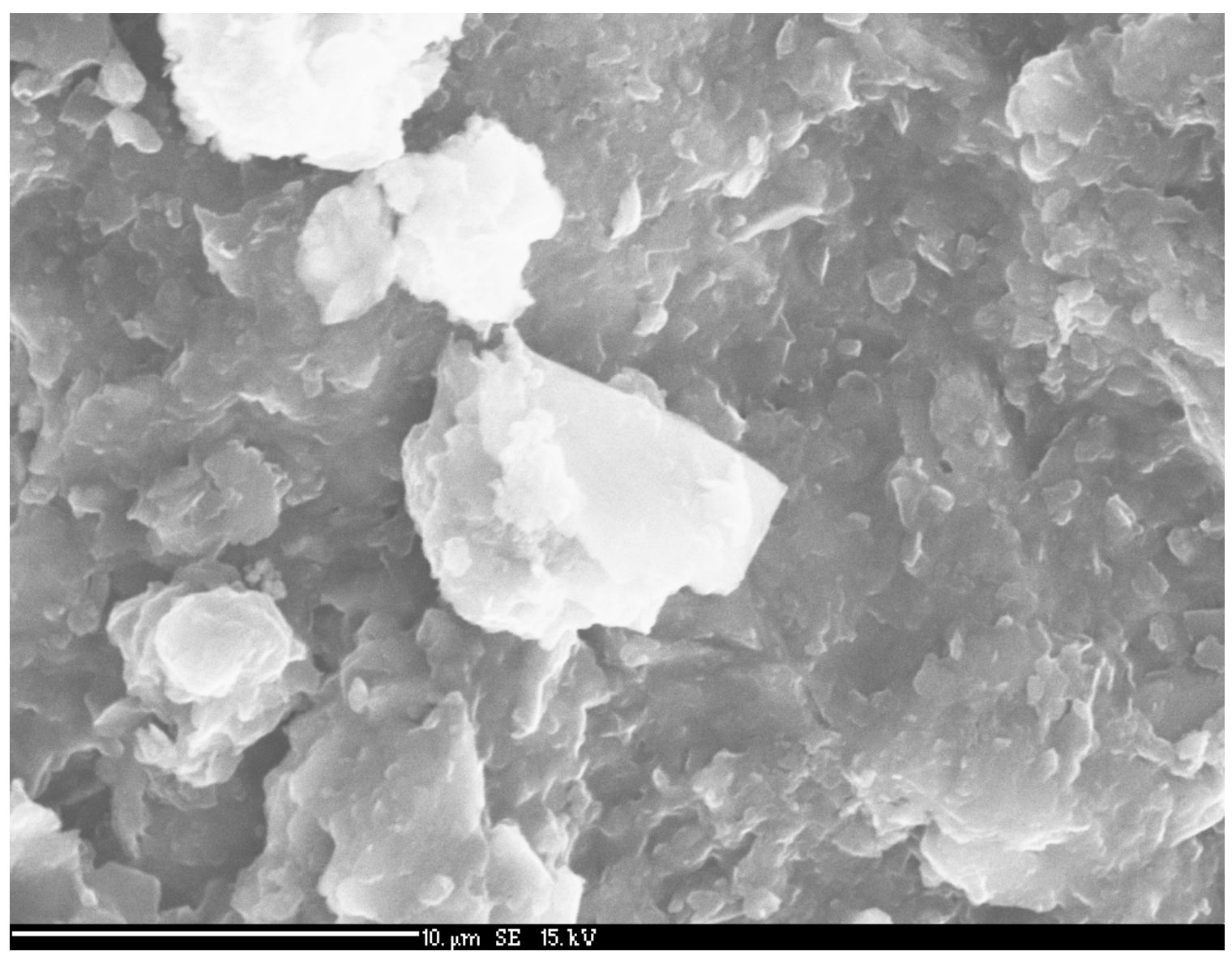

Figure E- 2. Backscattered SEM image of a used SMZ grain from column LST1. 


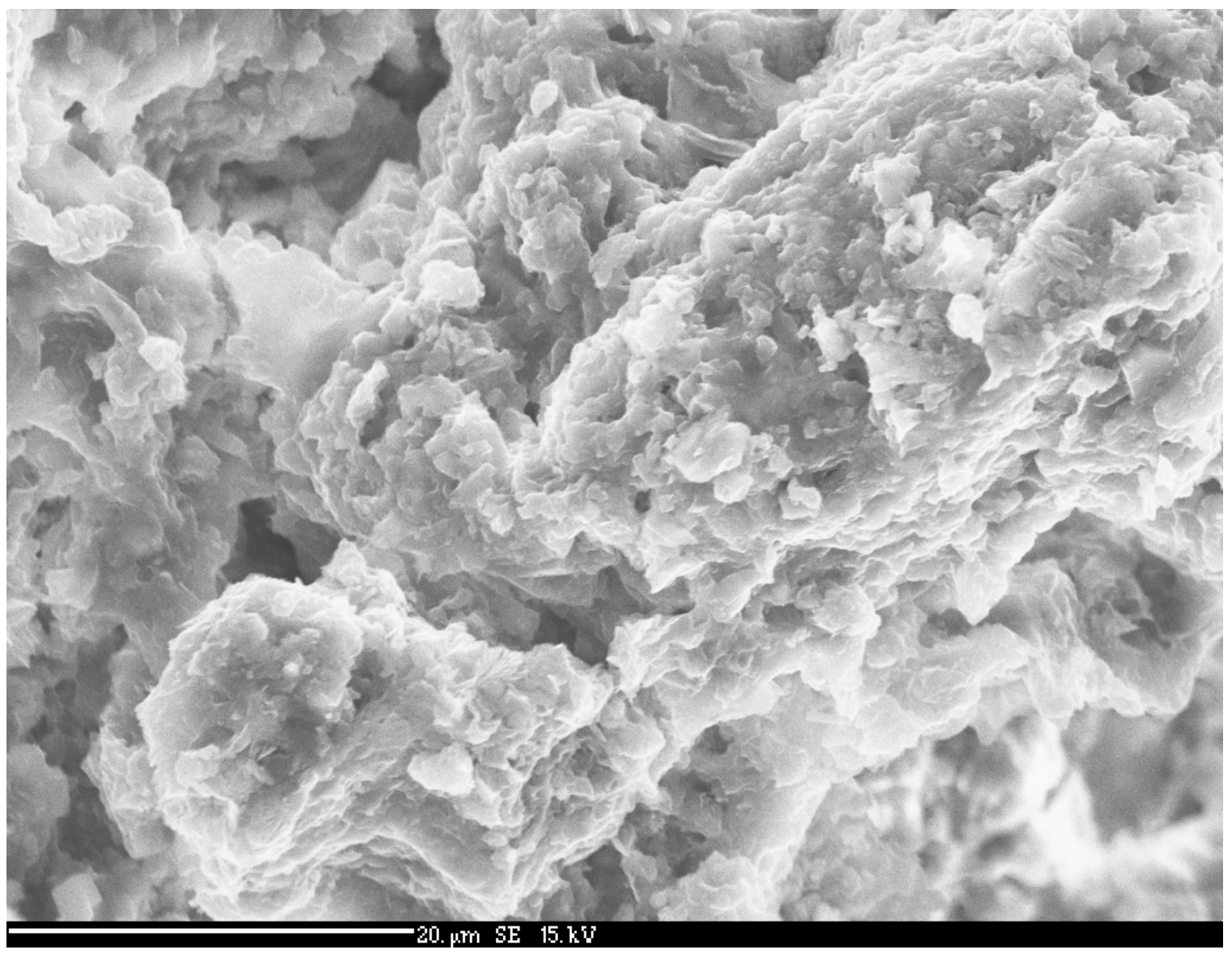

Figure E- 3. Backscattered SEM image of a used SMZ grain from column LST2. 
(a)

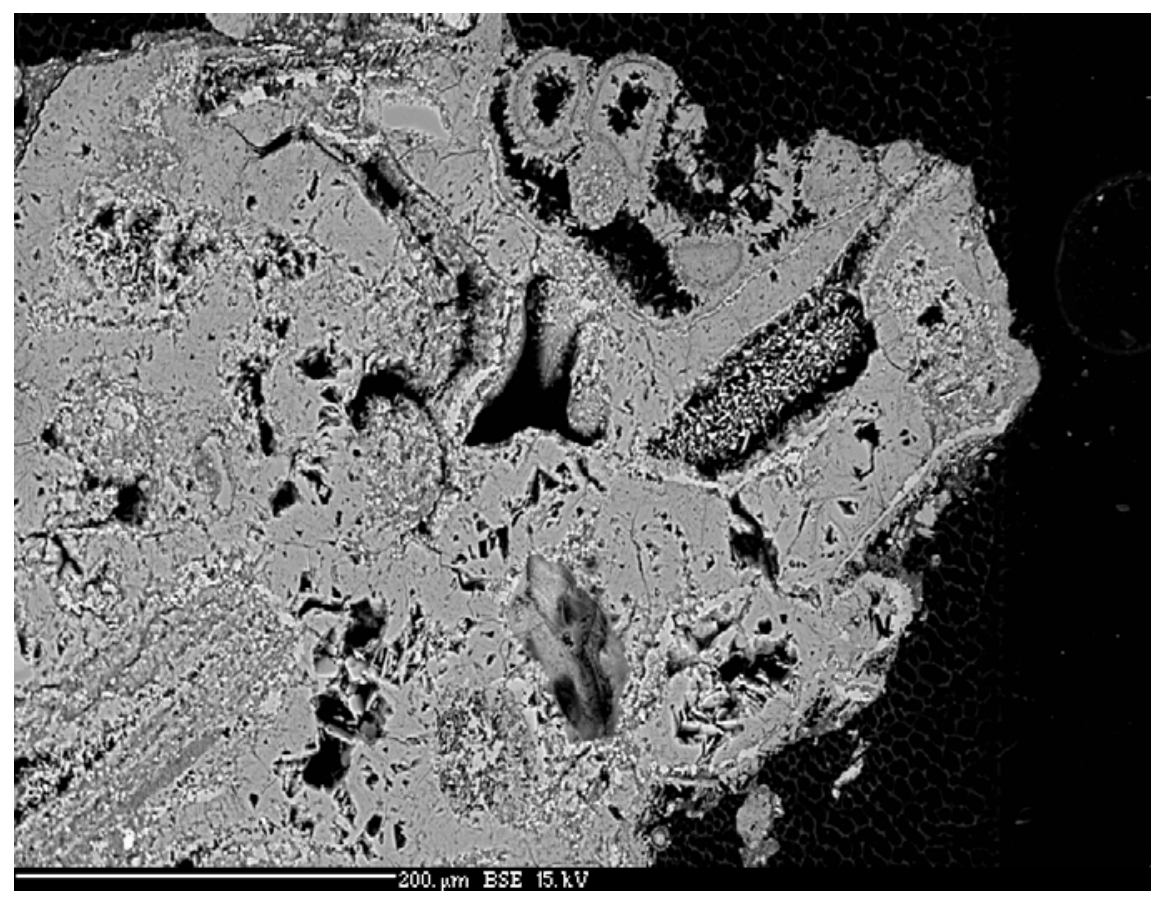

(b)

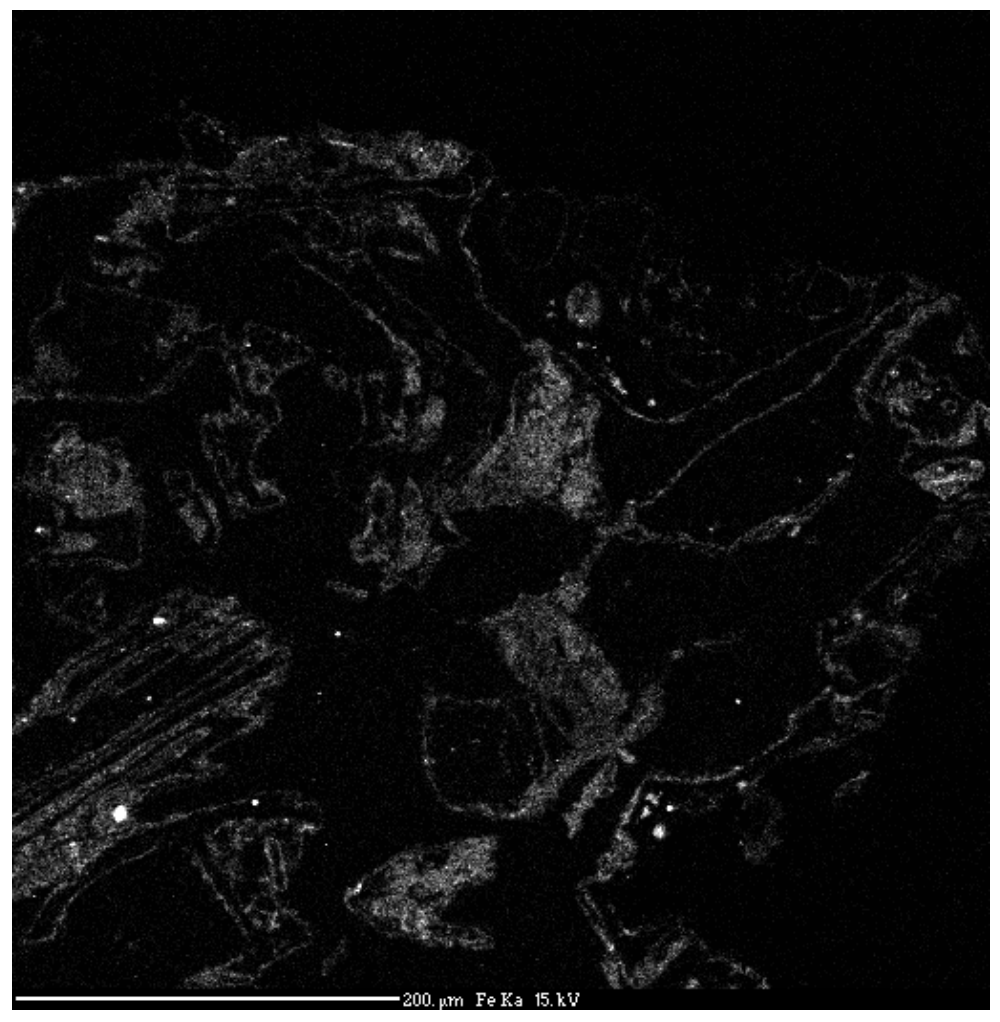

Figure E- 4. (a) Backscattered electron image and (b) iron distribution map of a virgin SMZ grain. 
(a)

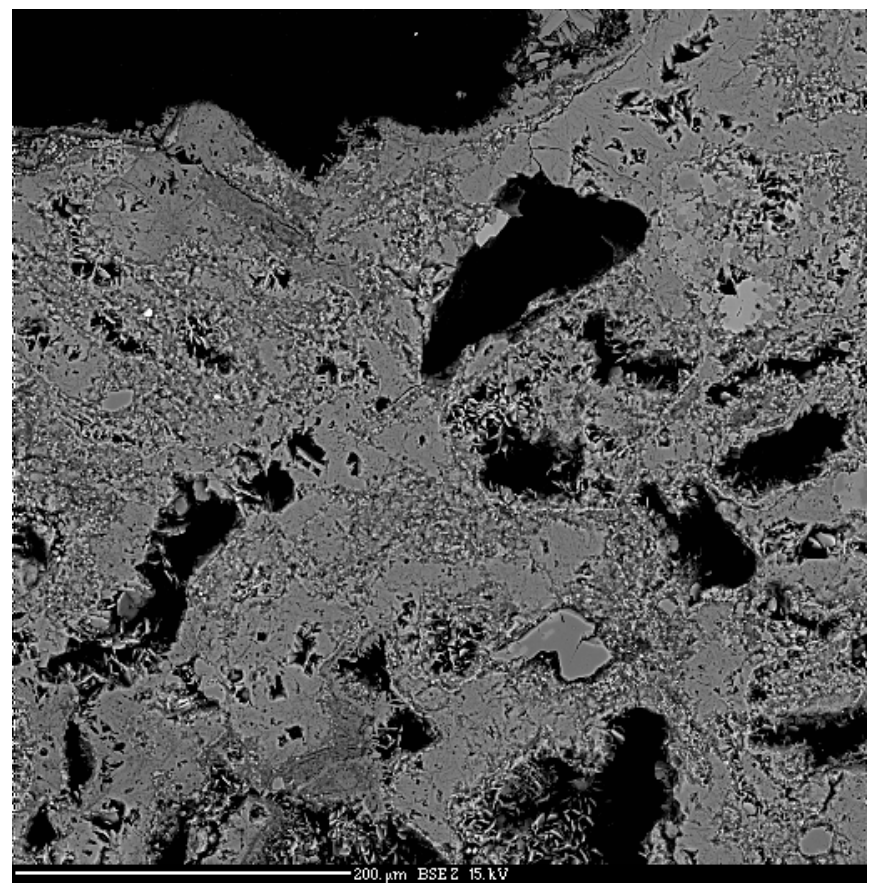

(b)

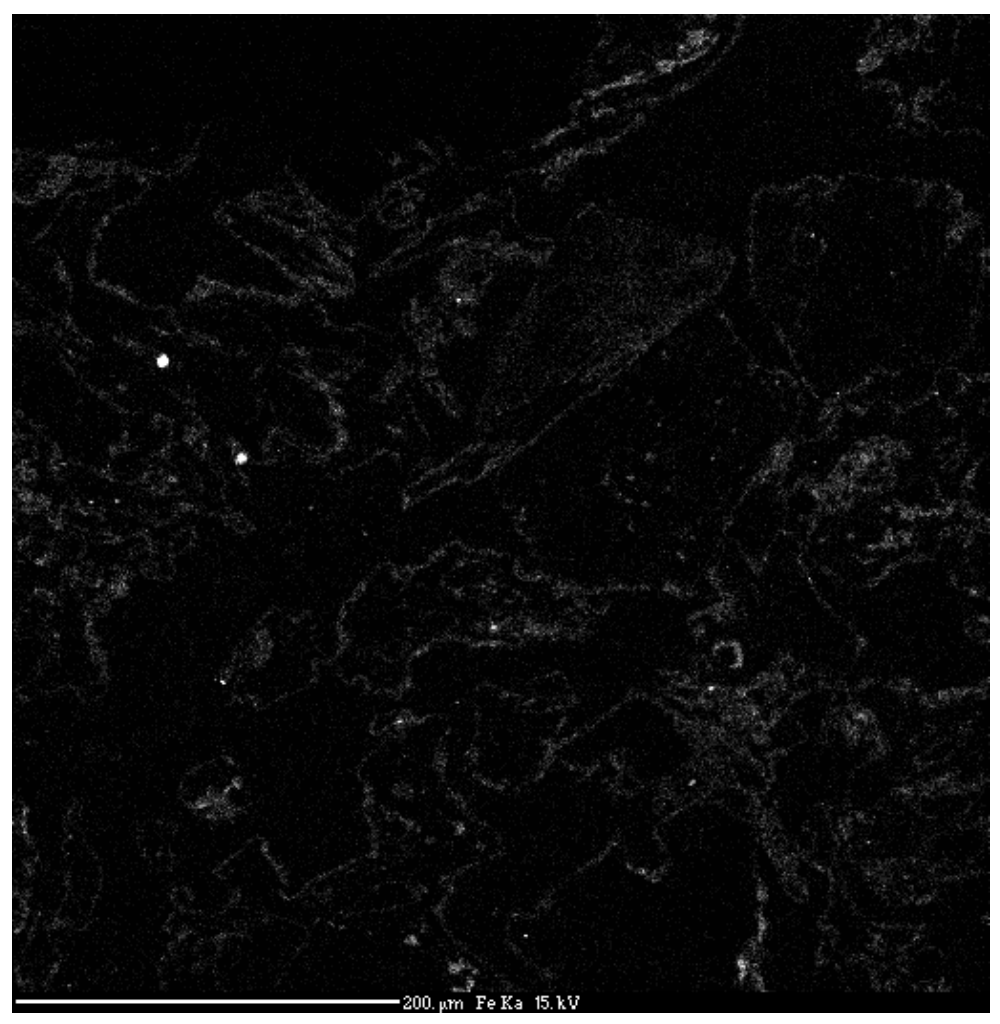

Figure E- 5. (a) Backscattered electron image and (b) iron distribution map of a virgin SMZ grain 
(a)

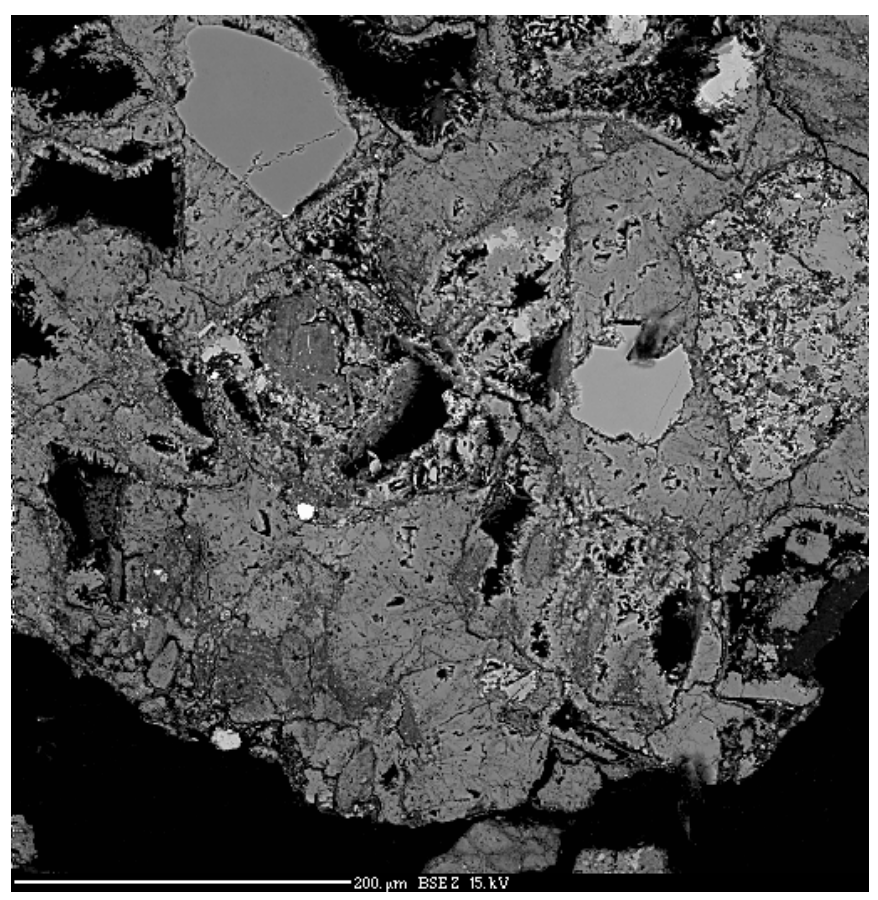

(b)

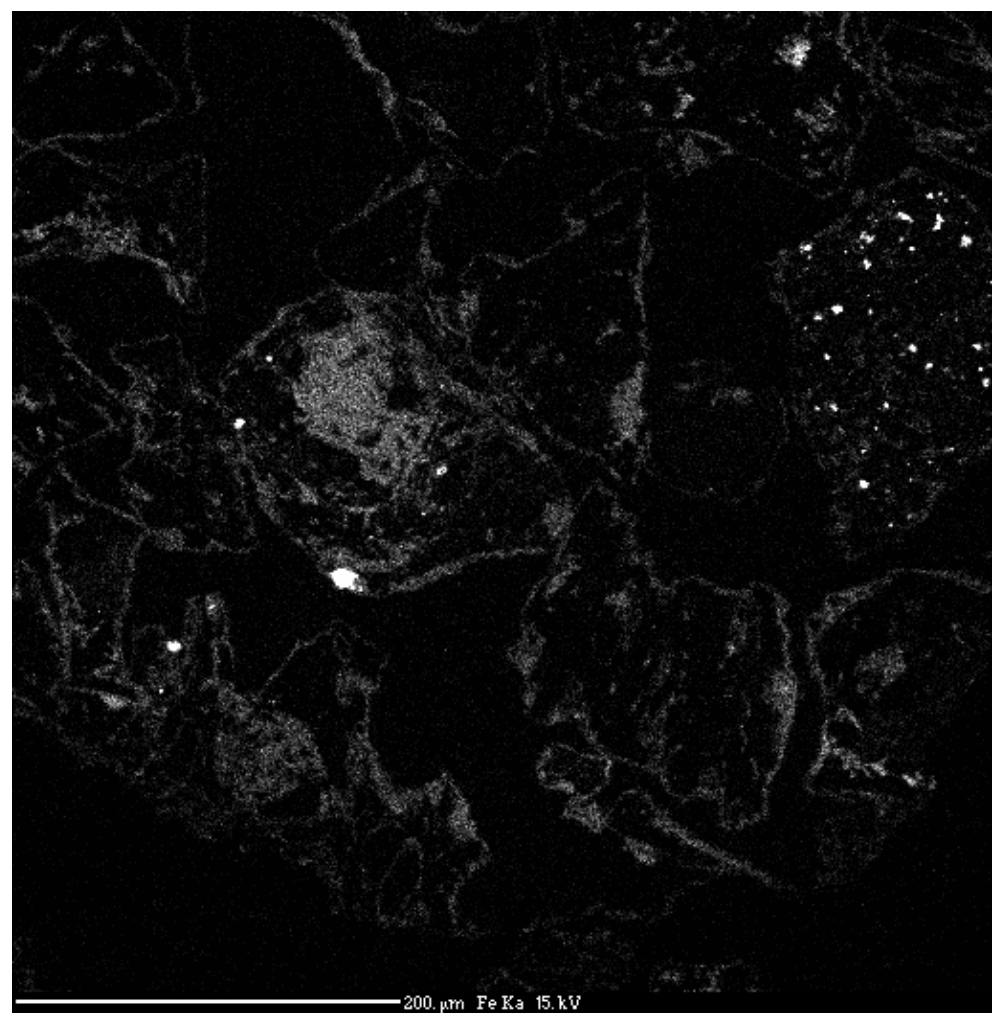

Figure E- 6. (a) Backscattered electron image and (b) iron distribution map of a used SMZ grain from column LST1 
(a)

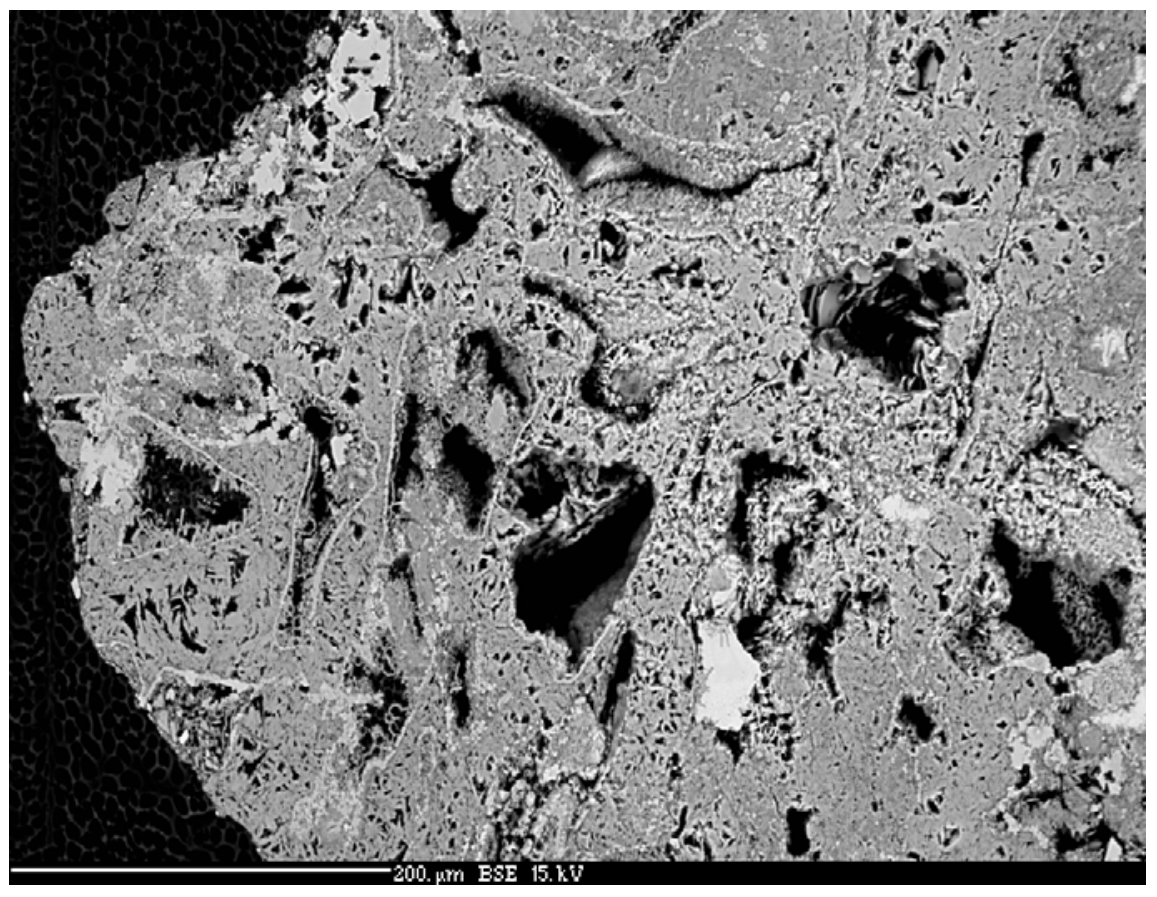

(b)

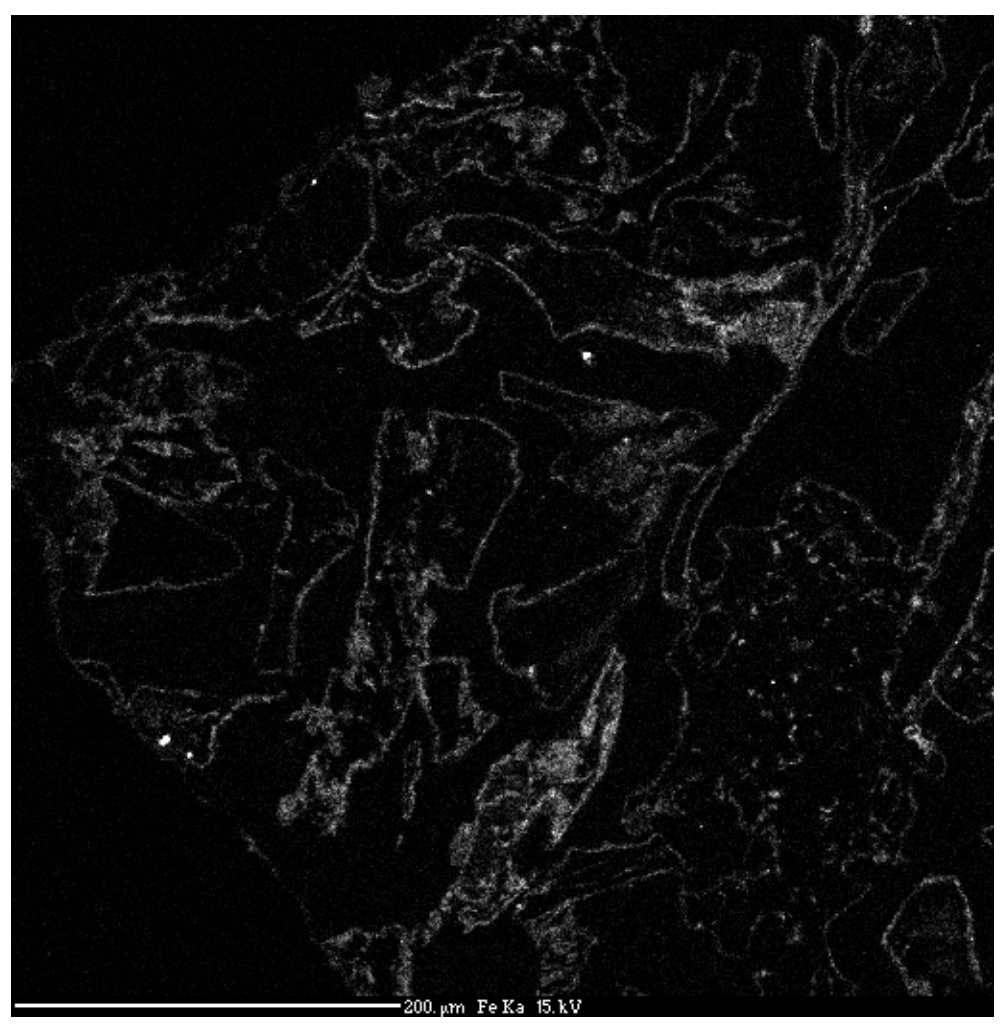

Figure E- 7. (a) Backscattered electron image and (b) iron distribution map of a used SMZ grain from column LST1 
(a)

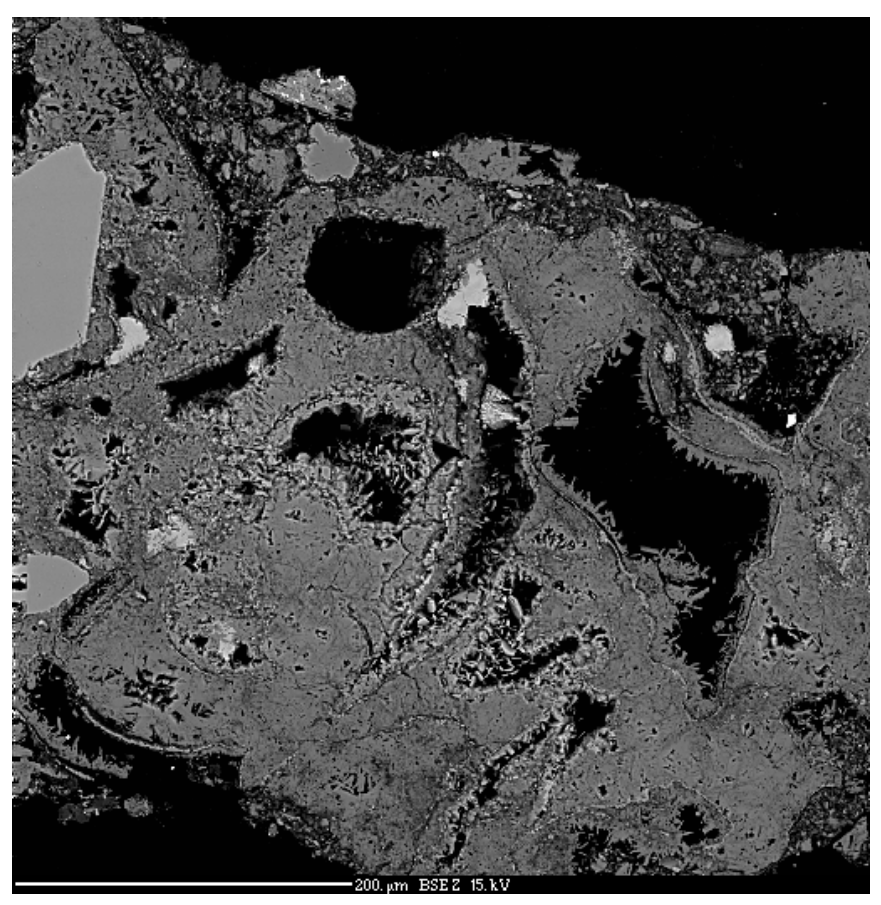

(b)

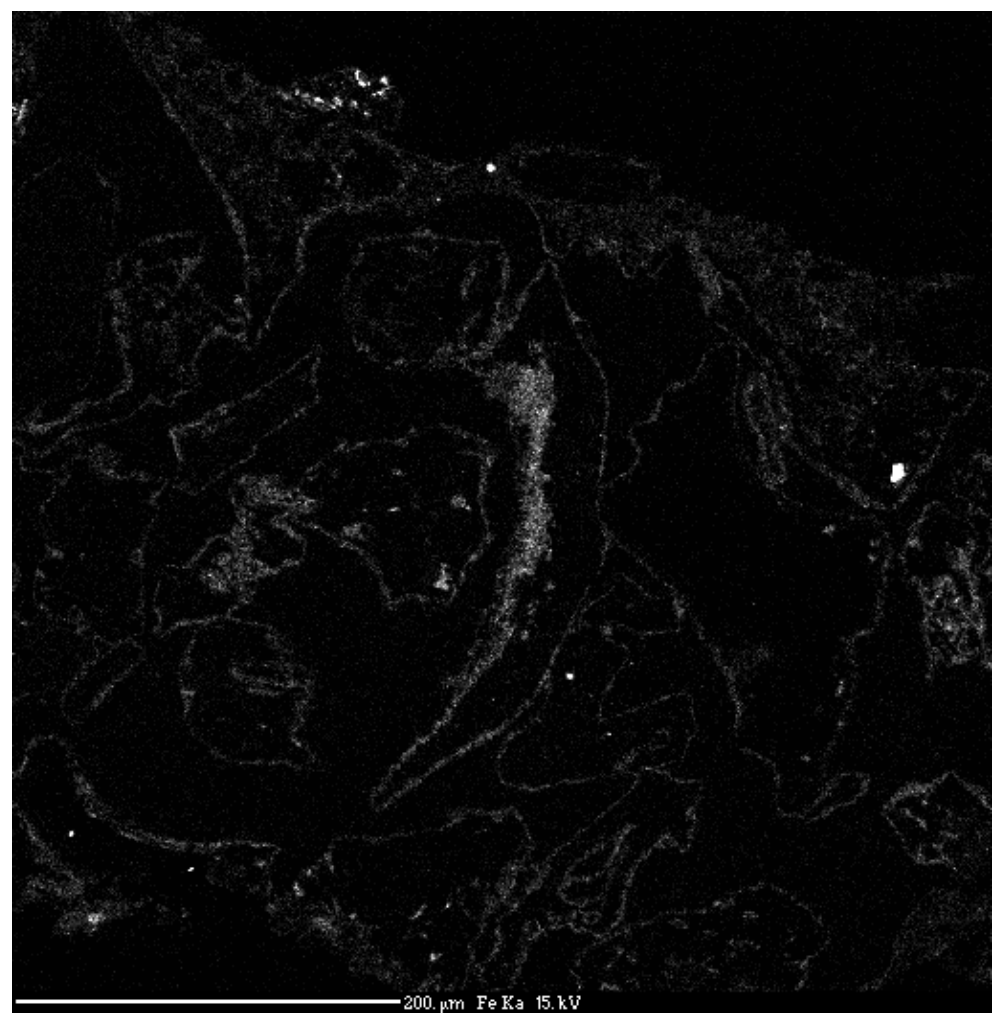

Figure E- 8. (a) Backscattered electron image and (b) iron distribution map of a used SMZ grain from column LST2 
(a)

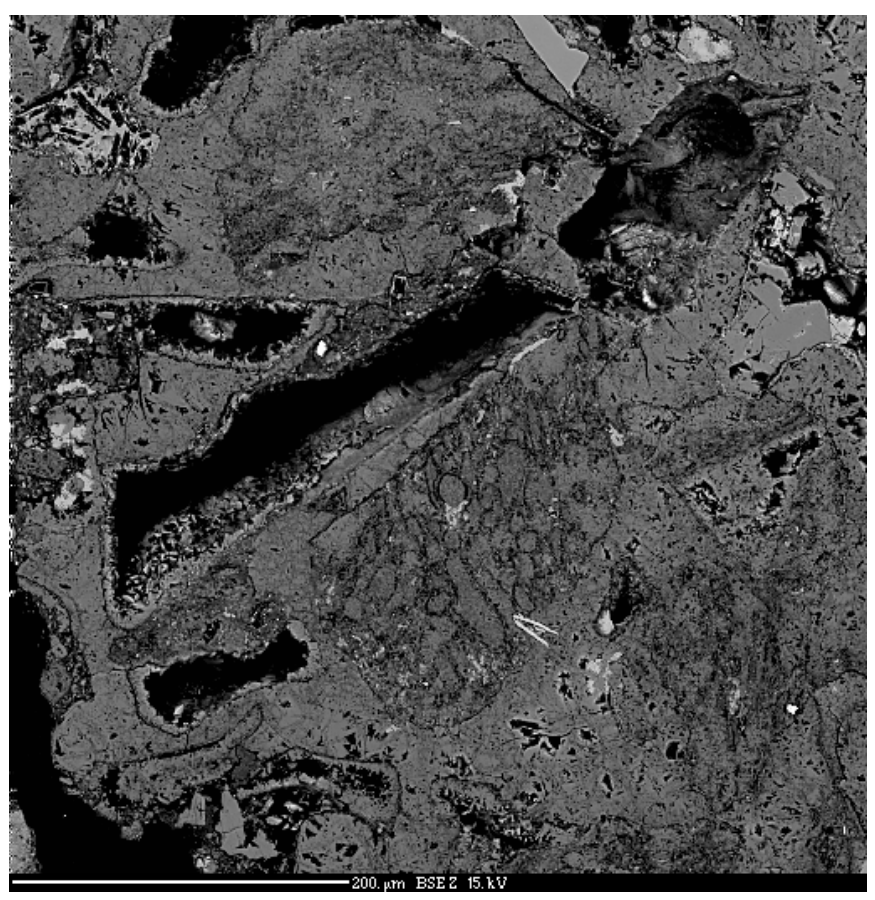

(b)

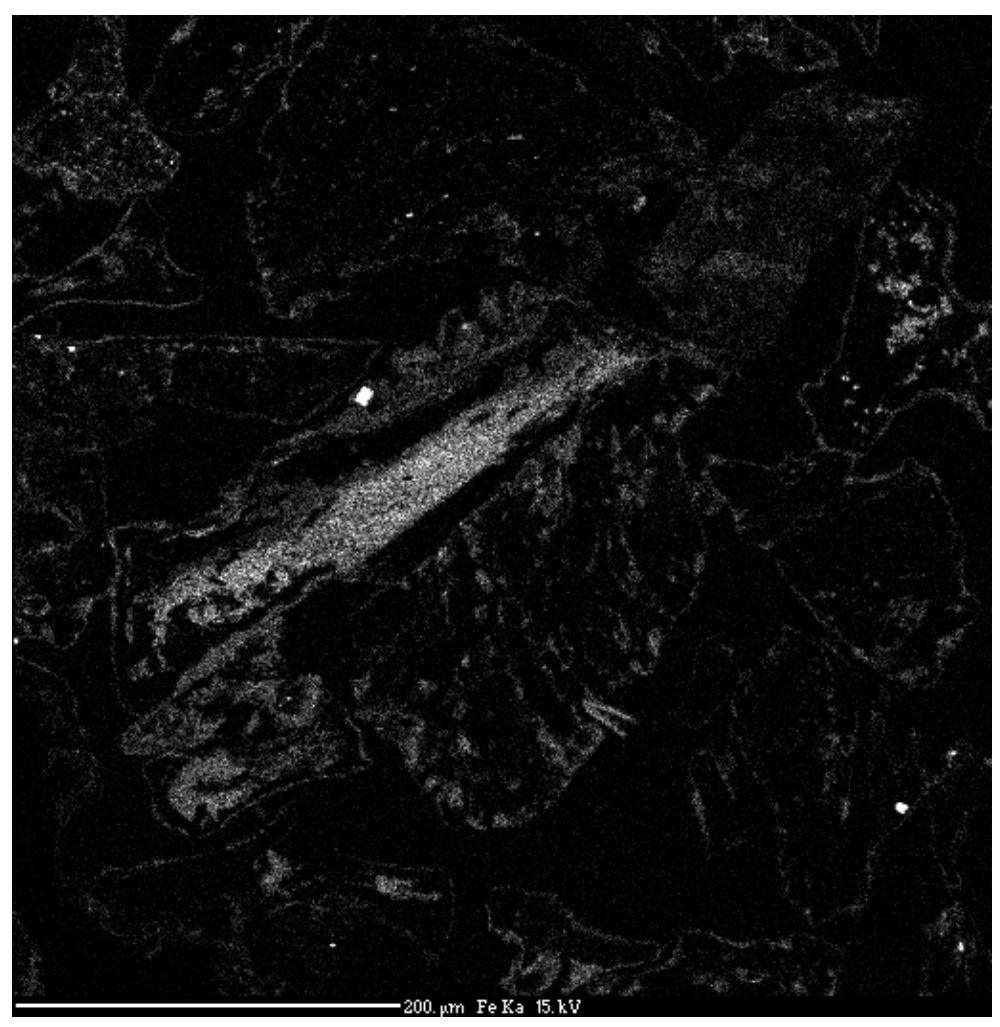

Figure E- 9. (a) Backscattered electron image and (b) iron distribution map of a used SMZ grain from column LST2 